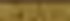

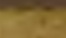

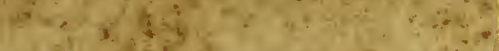

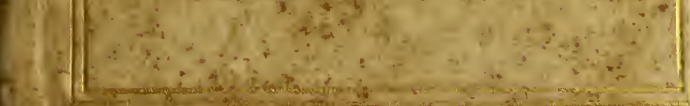

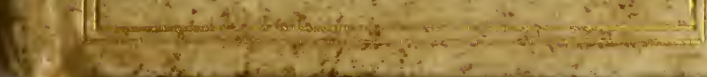




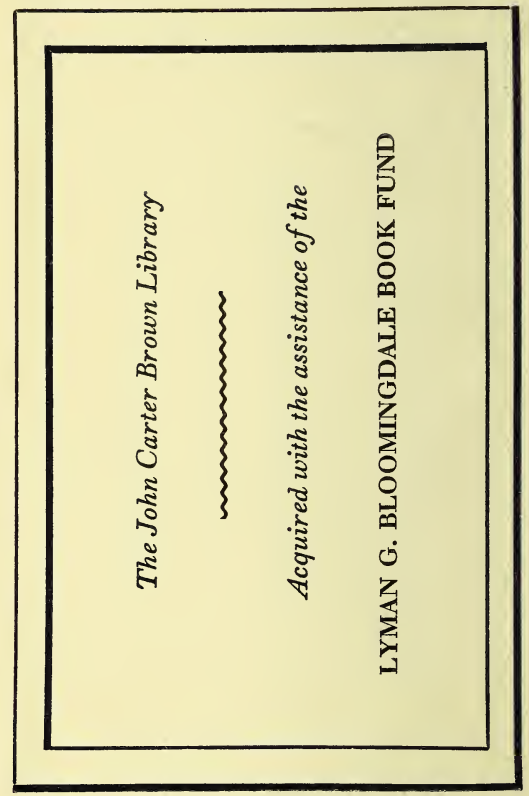





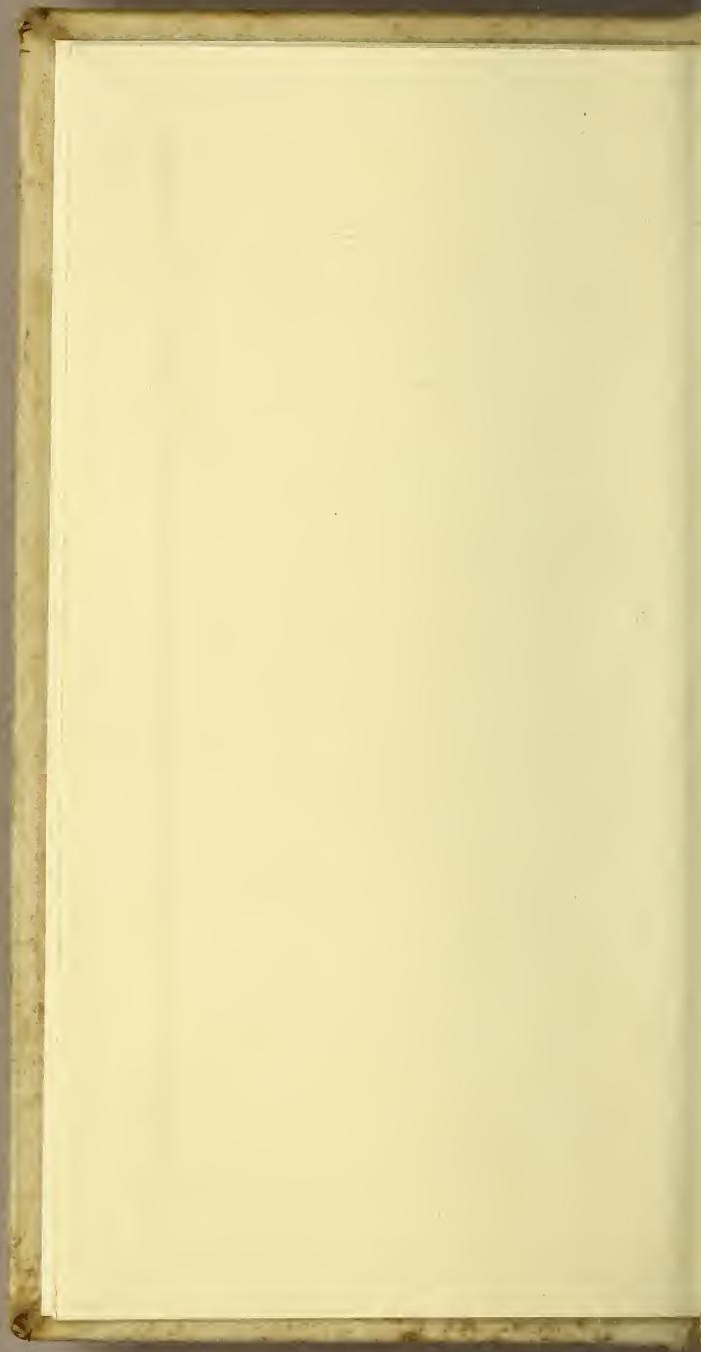





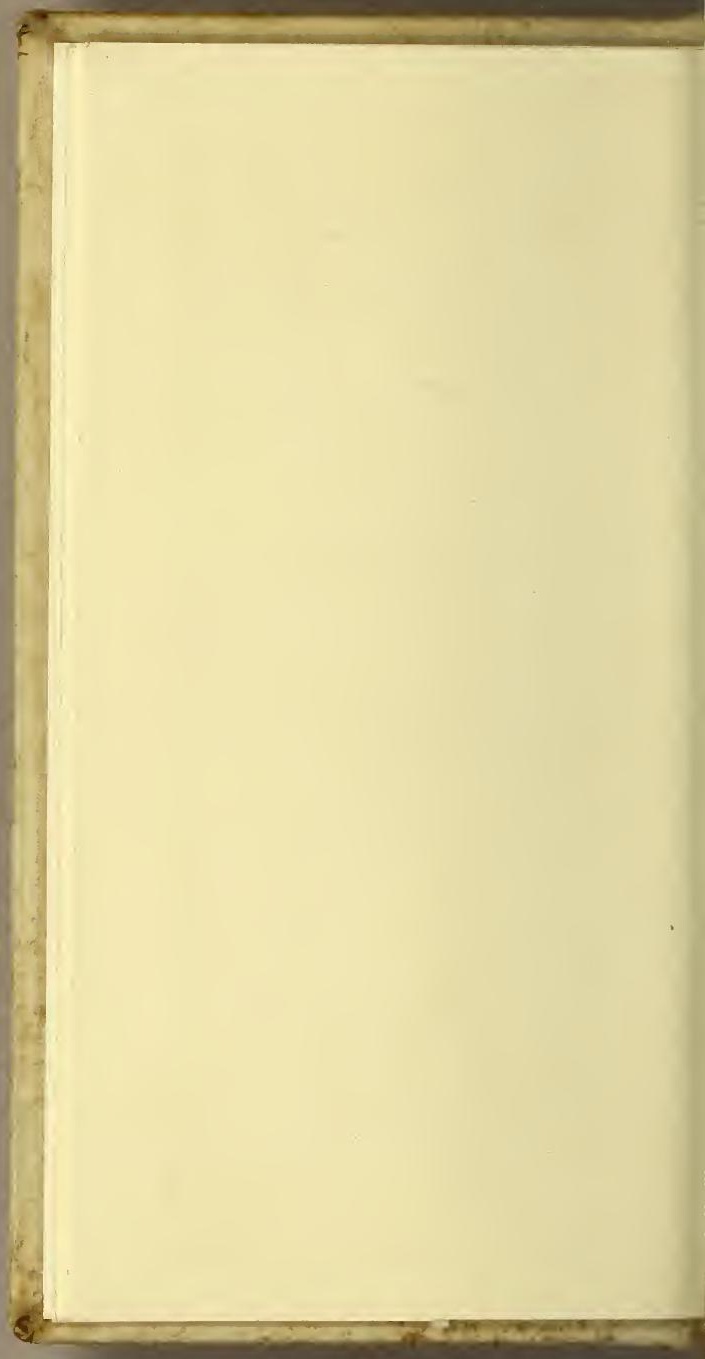


TROISIESME IIVRE

\section{DES SEREES}

DE GVILLAVME

- BOVCHET, SIEVR

DE BROCOVRT.

Renen of corrizé de nouneau parl'Autbeur.

ET NVGA SERIA DVCVNT.

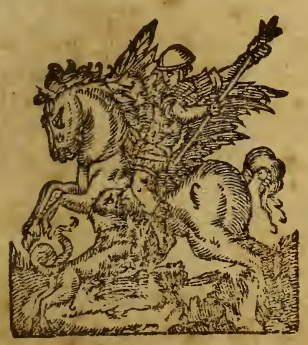

Se vendene

A PARIS,

HEZ IEREM IE PER IER, tenant $f$ a boutique fur la petite montee du Palais.

$$
\text { M. DCVIII. }
$$

Auec privilege de fa Majesté. 


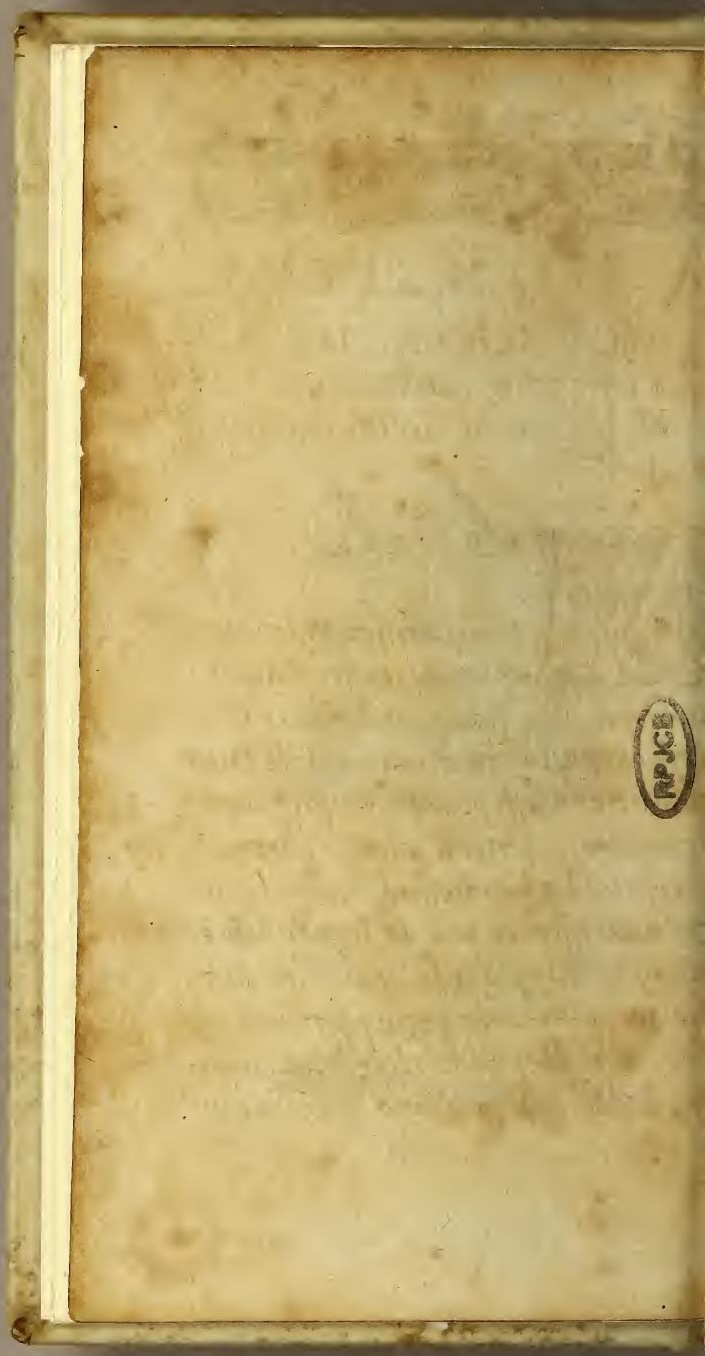


A MONSIEVR, MONSIEVR DE LA CLYELLE, CONSEILLER \& Maiftre d'Hoftel ordinaire du Roy.

D IEVR, eux qui vous font part de leurs Oeures, que vous en eftes commele Dien itelaire. C'eft pouranoy appes awoir emué coutes fortes d' aduis à part moy, a) prins la hardieffe de vous dreffer addrefer ce peu de lignes, ois ie employeray point les traitts de Rherique pour vous perfuader aux efcts dont elles vous recerchent. Ie diay feulement, qui ayant recogneul in$A 2$ 


\section{E P I S T R E.}

tention du Sieur Bouchet, de vous d dier les derniers fruicts de Jes labeur o Dieul layant retiré a $\int o y, i e \int u i s ~ d i$ meuré executeur de cefte fienne des nieve volonté. Il m'eft impoßible de ri diger par efcrit les dignes conception quil auoit furce fuiet; mais en Jui. de fon intention, ie diray franchemer of Sans lsypocrifie, qu'il n'a peu fai clection d'ven perfonnage plus prop; à gever of adminiftrer la tutelle de

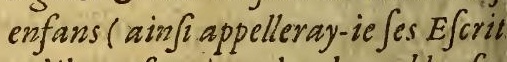
quil a enfanté par les plus nobles fun. ctions de fon entendement. Ils for maintenant de fnuez par le decez a leur progeniteur de tout Jecours ba main,pour fe guarantir des poinctur. acerees de la mal-veillance; vor auez en main tous les moyens necefJa - res á lcs maintenir enuers \& cont tous par wostre bien-veillance. $L$ garde-noble vous en eft iustersĕt deu Elle ne vous Jera point debatue ni cor tester 


\section{E P I S T R E.}

istee, nul außine la peut accepterque vous, à qui clle eft commife, of telle foit l'eperance du mourant. Voicy tone fon troifiefme qui s'offre of preente pour estre mis fous vostre tutelle or protection. Il ejpere de la bonté d'eforitnee en vous, le me fme traidzement qu' auez faict au fecond, qui vous fut dedié par le pere. Plies on garde les fleurs des becuux ofprits, plus elles font reconmanabules. Te ne vous recommanderay point celles cy,puif que wout cognoiffez déslorig temps celtiy quiles a produictes, lequel fe recommandoit a fez de Soy-mefme, comme ayant esté le moins imparfaict (que ie ne die le plus parfaict) des bonzmes de fa qualité o de fon aage. Toutesfois, ven que toutes chofes fornt fubiectes au controlle, iofe vous prier prendre leur defenfe en main, contre leurs controlleurs, ou pluAtof calomniatenrs. La momoiredusefunct vous y conuic; fescendresmeritët A 3 


\section{E P I S T R E.}

cet bonneur, vostre bon naturel vous porte à luy rendre office, voire n'en eftäs pas requis"; fes merites do fes vertus mobligent à vious en requerir. Ayans tous deux demeuré quelques anzees comme en feuelis, ils reviensët au iour, accöpagnez de leur aifné, qui requiert pareillement voftre faueur luy eftre cosamuniquee. Et iagoit que le pere luy ait laiffe d'autres parrains ( qui femblent eftre quafi perpetuels) fi eft-ce que la cōfideration des deux pofteriessrs vous refoudra d'antät plus à la mainsensië du premier,quills ne peurüt marcberl'rn Sans l'autre,ni mefme s'affeurergu'à l'abry de voftre gloire, or fous le fanal de voftre generale a sista¿e, quine peut engendrer aucune enuie ni ialoufie. Or pour venir à mon particulier,i aduovë ingenuémët que fi cefte Epistrefuft Sortie des mains du Sieur Bouchet, elle feroit d'vn fyle plus releué, \&o d'une poliffeure plus nette, ois 


\section{E P IS T R E.}

us la trouncrez mal-ageancee ofo polie : mais voftre douccur couira ma rudefe; mon denoir rendu of vous or à la volonté de l'Autbeur cufera mes defectuofitez, le lustre $\delta$ plendeur de vos vertus conioinctes uftreront \& embelliront la terniffure - laideur de mor difcours. Que $\int i$ ay moindre fentiment queles premices e mes vaux vous ayent pleu, vous me rez vn autre soleil qui efchauffera es epprits à vous confacrer toute ma ie le fernice que vous a woüé,

MONSIEVR,

Voltre plus humble \& $\mathrm{p}$ plus fidele feruiteur,

IEREMIE PERIER.

De Paris ce premier iour de

Nouembre, 1607.

$A+4$ 


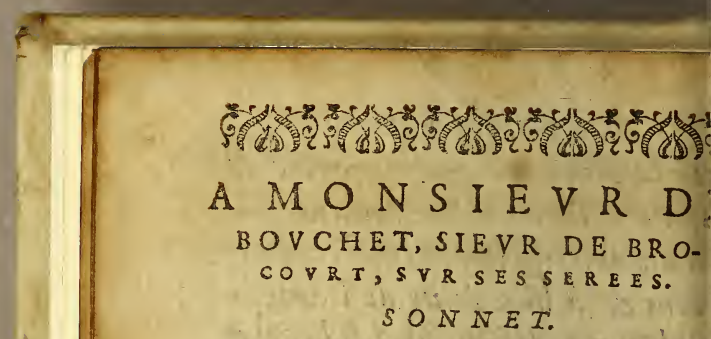

On BO $\checkmark$ C H E T tes difcours, font aut an C.X.

- Qit wi ceptiuent nos coeurs d'vn rauiffement dous Ils font tous pleins de laid, ois Mercure ialoux Trempe fon caducé pour charmer nos oreilles. De differentesfertios comme font les abeilles.

Tu fuģonres tor mist. dont le goufs plaift aे tous,

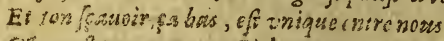

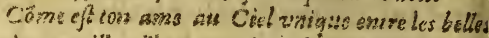

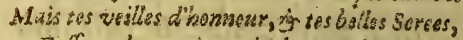

Fuffent des Emativex és das ans denorees

Sans le fupport beureux d'vn Sóleil de ce remps. D'vn doste la C I Y E I I E anx vertus fauorable 2ui rendint ton trausil contre les ans durable, Te rend simé des bons, ér crainct des medifans. LA ROCHE, DOSSEA Y:

\section{A $Y$ M E SME.}

Bo $\mathrm{V}$ C II 5 a iele dy fansmenior, Vous faictes $\sqrt{2}$ baut retentir Voftre rom par vojicrebuen dire, Que iufterient on vous athinte:

Car rien ne fe vsit de pliss doux, Plus docte ny plus agreable: Ha !combien c'eff ibofeloürable Defaire bien au gré de tous.

$$
\text { Y.B. S.D.L.C: }
$$




\section{$=\begin{aligned} 2 \\ =\end{aligned}$}

\section{O M B E A V D E}

MONSIEVR BOVCHET, Sieur de Brocourt.

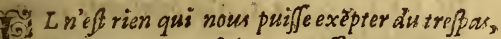
B. BO v C H E T repole icy, toy pajfant ne croy pas Q2ue pourtant il foit mort, il a durant $\int a$ vie Dompté par fa verta, do la mort ó l'enuie. uid fois dix ans complets, en ce monde inesnftant, Sans peine, of Sans douleur, il a vefcu contant, Puis iufte il a payé le tribut à nature, Son ame eft daras le Ciel, fon corps en fepulture. octe, aux dostes efcrits, fon efprit exerça Iu ques au iour fatal, que le corps illaiffa, son temps fut compajfé fes courures rae furees,

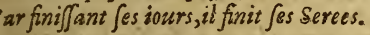

PASSANT ARRESTE-TOX, PRIE DIEV QV'A SES OS

LA TERRE SOIT IEGERE, ETERNEL LE REPOS.

Y.B.S.D. L.C.

\section{A V T R E.}

Bien que Lon ait compris en fi pet ite efpace, 3 o С H E T qui se la mort fin le triste butin, Veantmoins fes vertus. (a valeur do fa grace, V'ont pour but limité que des fiecles la fin.

M.R.D. RAGVENEA V. $A$ \& 


\section{6" SVR LA MORT D] MONSIEVR BOVCHET, Sieur de Brocourt.}

De BROCO V k T n'eft point mert comme. snonde perfe,

Jamisis be vertutux ne dort entre les morts: Mais forz effirit laffé di feiour de fon corps, Efla allé vijuzier le licu de fa naijfance.

\section{IA ROCHE DOSSEAV}

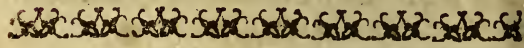

\section{A V T R E.}

Tu as refcu au monde, ò̀ ta foy fut confante, Tu mefprifas le vice, \&o l'bonneur fut ta loy, Tis fis chery de tous, maintenant fans efmoy Iit es as bens feiour oì effoit ton attente. 
م2

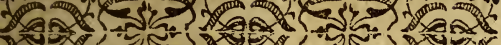

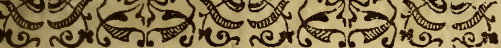

\section{ES SEREES QVI} font contenuës cn ce troiffefme Liure.

$X X V$. Desgens de guerre. fueil. $x$ $X X V I$. Des perfornes groffes of grajjes.

30

$X X V I 1:$ Des Barbiers, or du mal des dents.

XVIII. Des Peintres \& peintures. 82

$X X I X$. Des Mores, des Negres, \& des Noirs. 105 $X X X$. Des Paures of des Mandians.

$X X X I$. Des Riches, \& des awaricieux. $14 I$ $X X X I T$. De la musique, of des ioüeurs d'instrumens. 567 A 6 
XXXIIT. Desgensd'Eglife. 172 XXXIIIT. Desfols, plaifans, idiots co badins.

Igs

$X X X V$. De la diuerfité des langaves or du langage. 226

IXXVT. Des Ladris or des MefSeaux.

244

\section{TROI}

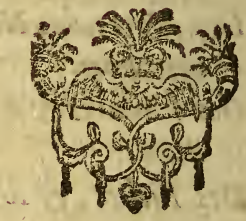


VINGTCINQVIESM E de nom, \& qu'ils ont auffi vne mefme definition:parce aufli que par efchange de l'vn,aifémét fe faict l'autre: \& qu'Ariftote appelle les Grecs barbare, desce qu'ils alloient armez : encores qu'il n'y ait chofe plus neceffaire à l'entretien de noftre vie que la guerre: toute chofe vemant à fe defreigler fans fon aide, parce qu'il fe trouue toufiours des hömes qui ne veulent obeir aux Loix que par force: $\&$ les ftatuts ne pouuans rien faire contre telles gens, il fut necelfaire que les armes accompagnaffent les Loix. Car quelle force \& authorjté auroient les Loix, Statuts \& Ordonmances, fil'on ne trouuoit qui les fift obferuer ? Et quile peut mieux faire que les hommes vaillans duits à manier les armes?Certainement fans eux les citoyés ne feroient pas affeurez en leurs propres maifons, on ne pourroit defendre les.confins des feigneuries, on ne repoufferoit les iniures, l'on ne mettroit pas fin aux feditions, les vertus ne feroient pas maintenuës, la paix \& le repos public conferué, les voifins ne craindroient de nous faire tort, de nous

occu 
occuper nos biens, \& faire violence à l'honnefteté. Et m'eft aduis, veu toutes ces raifons, que les Loix font faictes pour maintenir les vertus, \& les armes pour la deffenfe d'icelles: car autrement elles s'en iroient en ruine, voire, comme difoit Xenophon, la Iuftice, les Loix \& les fubjets font fous la tutelle \& protection des armes. Et comme les Republiques, les Rois, \& les villes, doiwent mettre toute diligence à conferuer les gens de bien \& pacifiques, elle deuoit eftre redoublee en la militie, tel eftant l'eftat d'vn chacun, qu'elle eft l'intention de celuy qui l'exerce : car en quel hóme doit eftre plus la crainte de Dieu, qu'en celuy qui fe foubmet tous les iours à perils infinis? En quel homme doit rechercher la patrie plus grande foy, qu'é celuy qui luy promet de mourir pour elle.En quel homme doit eftre l'amour de la paix, qu'en celuy qui peut eftre feulement offenf'e de la guerre? Et ay toufiours trouué bonne la loy de Solon, qui vouloit que les enfans de celuy qui meurt en bataille, fursét nourris du public : \& la couftume d'vn païs, là où les 
VING TCI NQVIESME

les femmes, qui perdent leurs maris en la guerre fe peuuét remarier, les autres non. Mais il eft aduenu que la medecine eft plus à craindre que la maladie, $\&$ comme dit quelqu'vn, Noftre mal s'empoifonne du fecours qu'on luy donne:les gens de guerre s'eftans fi mal goumernez on la difcipline militaire, qu'on a mieux aimé laiffer les Republiques en leurs maladies, que tafcher à les guerir par les armes:Si bien que ceux qui maintenoient la paix, \& la iuftice,repouffoient Ia violence \& la tyrannie, \& qui pour cela eftoient honnorez \& refpectez de tout le peuple, font fi reculez de toute modefie \& bonté, que tout le monde a mieux aimé laiffer leurs maifons, leur païs, \& tout leur bien, que les y attëdre \& rencótrer : qui eft caufe que le foldat en eft mal traicté, \& ne trouuant rien que manger en vn lieu, eft cótrainct de s'efcarter au loing pour troutuer des viures, \& pour foy loger: \& e efãs ainfi feparé les vns des autres, font fubiects à efre chargez par l'ennemy,ou par ceux du pais s'ils les trouuét demeurez apres leurs compagnons, \& à plufieurs autres incon 
$S$ E R E E.

nconueniens: comme il arriua à vin foltat, qui eftant logé à l'efcart, trouua vn on lict, garny de coutuerture, \& de draps, fe met deffus le lict, dedans les draps, \& deffous la counerture. Et là eftant bien à fon aife, \& fans bruit, dort depuis le foir iufques au lendemain apres midy: foit qu'il euft efté de garde la nuict precedente, foit qu'il fuft grand dormard, pour auoir les veines fort petites:foit que la froideur du cerueau luy caufatt vn fi profond dormir : foit qu'il cuft la teite gráfe, contenant bencoup de vapeurs: Soit qu'il euft mangé d'vn licure, qui prouoque le dormir, felon Catô:foit qu'il cuft trauaillé, les efprits ayans befoin d'eftre recrecz. Or eftāt ce foldat ainfi endormy, il arriue en cefte maifon vn Sergent, qui execute le liat où il eftoit, \& enueloppant dans la couverture les draps, le foldat, \& le lict, les garrote \& charge dans wne charrette, conduifant le tout iufques au plus prochain marché, fans que le foldat en fentift iamais rien, \& fans que le Sergent fceuft que le foldat y fuft. Eftant le Sergèt arriué où fe tenoit le marché,il faict 
VING T C IN QVIESME fes proclamations, reçoit les encheres, criè aे pleine tefte, le lict à cent fols, qui dit, qui dit, \& ce pour la derniere fois. Soit que le cry du Sergét, ou le bruit de la foire interrompirt le fommeil du foldat, ayant l'air, qui eft renfermé en fon oreille, efté meu \& pouffé par vn autre air venant du dehors:foit que l'heure de fon refueil fuft venuë,les vapeurs montees au cerueau, procedantes de la viăde digeree en l'eftomach, eftans cuites, attenues, \& confumees par la chaleur, qui fe retire audedans durant le dormir:foit que les femmes qui mettoient à l'enchere, en maniant le lict, fillent tourner le foldat d'vn cofté fur l'autre, il fe va refueiller fur les quatre heures du foir, \& fe defueloppant du lict, des draps, \& de la counerture, fort hors tout nud,fe iettant au beau milieu de $l_{a}$ foire comme vne mouche fans tefte:\& ayant fon piftolet bandé, commence à crier, goujat, apporte ma chemife. Les fermmes qui vouloient achepter ce lict, \& le remuoient, eurent fi grand peur, que depuis ne furent en leur bon'tens: le Sergent n'a point faict fon profit dés 
temps-là,eftimant eftre $\nabla n$ efprit qui vouloit punir d'auoir executé de aures gens qui awoient tant de maux: $s$ hommes n'eltans pas plus affeurez ue les femmes, à caufe qu'ils ne pouoient arrefter ces femmes, qui fuyoiét ai çà, qui là, voyant ce foldat tout nud lec fon piftolet bandé \&z efmorché, en ayans iamais veu de tel qualibre. ref comme fic ceuft efté vne tremeur anique, tous ceux de la foire s'enfui:nt,\& arriuerent bien tard à leur logis, caufe de la peur qui leur auoit entraéles pieds, \& auffi qu'ils ne penfoient as qu'il fut fi tard, ayant veu l'aiguille ir le midy. Ce pauure foldat fe troutăt infi tout nud, fans fçauoir qui l'auoit 1 apporté, \& que tous ceux de la foire fuyoient comme s'il euft efté gabeoux, penfoit eftre en vn autre monde, $z$ eftre enchanté, que quelque forciere e Bodin, l'ayăt graifé, \& luy ayant mis $n$ bafton entre les iambes, l'euft enleé en l'air, \& laiffé là : eftant fi eftonné u'il ne faifoit femblant de couurir ce u'on ne pouuoit dire fa pauureté. Que in ne veut croire cefte hiftoire, qu'on ne 
VINGTCINQVIESME ne laifle à lire tout ce que iay peu re cueillir de ce qui fut dit en cefte Sere des gés-darmes, \&z on verra bié de pli grands \& eftranges cas. Et pour le vou donner à cognoiftre, dés l'entree de ce fte Seree, il fe leua vin Franc-à-tripe, q nous va conter le deportement d'v Capitaine bien efueillé, lequel n'efto point endormy comme noftre foldat Et commença ainfi: Il y auoit ces iour paffez en vne de mes meftairies vn $\mathrm{Ca}$ pitaine, \& des foldats, qui vinoient difcretion, ou pluftot, pour mienx par let, fans difcretion, encores quie le $\mathrm{Ca}_{2}$ pitaine fit toufiours mettre fon hoft aupres de lay à la table, l'inuitant à boi re, \& beuuant à luy plus foutent qu'i ne vouloit. Ce bon-homme, au lieu de luy faire bonne chere, demandoit at Capitaine, \&rà â fes foldats:Qu’au droį auez vous de manger ainfi noftre ben: Le Capitaine luy va refpondre, $P_{21}$ droict de guerre,comme fit Bremus aux Romains, qui luy demandoient, Q2 й inre hac facitis??quand il leur refpondit, Iurebelli Ce Capitaine prenant plaifir à la liberté de parler de fon hofte, luy va di- 


\section{$S E R E E$.}

, Mon pere, ie vous prie de boire à oy. Le bon homme eftant preft à boi, le Capitaine luy va dire:mon hofte, onnez vous garde de mettre ce bon in en vin mefchant vailfeau. Et quoy? yy repliqua ce villageois, penfez vous ue ie le vueille verfer au voftre? Ce Japitaine ne s'en faifant que rire, ne aiffoit pourtant à mettre vine main au ol de ce bon homme, \& l'autre en fa ourfe. En fin ils ne laifferent encores e boire l'vn à l'autre, \& en beuuant \& aifant bonne chere, le Capitaine difoit fon hofte, dites, Maudite foit chicheé, lequel pour luy complaire, difoit, naudit foit le dechiqueté. Vous ne dies pas bien, repliquoit le Capitaine, il aut dire, à tous les Diables chicheté. A ous les Diables le dechiqueté, difoit oufrours le bon homme. Le Capitaine 1e s'en faifoit que rire, mais fon hofte a'en auoir nulle enuie : auffi que ce feroit vne grande folie de rire, \& voir manger fon bien deuant foy. Celuy qui faifoit le conte, fut interrompu par vn de la Seree, lequel fouftenoit que dechiqueté eftoit venu d'vn nommé Chiquart, 


\section{VINGTCINQVIESME}

quart, ear on dit, Braue comme $C h$ quart, ou bien de chic à chic, c'elt à d re, de petit à petit, \& dont eft venu ch canoux, qu'on prononçoit ancienn ment chiche-à-nous : car iamais ils n veulent debourcer. Mais, adioufta-i foit venu le mot dechiqueté d'où voudra,fi eft-ce vne mauuaife chofe d decouper le drap, \& les foyes, de tell. forte qu'elles ne peuuent durer beal. coup, ny feruir qu'à vn maiftre : ce que les Turcs nous reprochét à bon droict, nous appellans enragez \& forcenez, de gafter, cóme en defpit de Dicu, les biếs qu'il nous donne:\& encores qu'ils ayét de la foye plus que nous, il eft deffendu fur la vie de la decouper. Celuy qui auoit cómencé le conte, reprenant la parole, va dire que ce Capitaine trouua só hofte fi à fon gré, quil parla ainfi à luy: Mon bon homme, ie vous veux bailler quelque chofe, à fin qu’ayez böne fouuenance de moy. Le villageois luy refpond, Möfieur, ne me laiffez rien, car il m'en fouuiendra bien toute ma vie, \& à mes enfans auec. Lors le Capitaine va dire à fes foldats, il veut que nous $\mathrm{cm}$ -

portions 


\section{SE R $\hat{\mathbf{E}}$ E.}

ortions tout, \& que nous ne luy laifions rien. Le bon homme repliqua, ie $y$, rien du voftre. Lors vn de la Seree a deplorer le piteux eftat de la guerre le maintenant, \& va dire que Bartheleny Giurgenitus, qui a demeuré ferfen Curquie treze ans, dit qu'eftãt à la guere du Turc, contre les Perfes, il vid deoler vin hóme d'armes, \& fon feruiteur i fon cheual, pource que le cheual s'etant deflié auoit entré dans le chãp de uelqu'vn. Pour n'entrer plus auant en es dif cours tragiques, on commença onter comme s'eftoit porté à la guere vn homme de village eltant deuenu oldat. Pour faire le recit de ceft archer le Bagnolet, il fut dit, que du temps de Charles feptiefme, les Francs-archers Francs-taupins eftoient efleus \& hoifis par les parroiffes, pour feruir de oldats à la guerre, comme on faict auourd'huy les pionniers. Ce que les Frăois faifoient à l'imitation des Ronains, qui eltimoiêt le ruftic plus prorè à la guerre que le citadin : le villazeois eftant plus accouftumé à dormir ur la dure, au trauail,à endurer froid \& chaut, 
VINGICINQVIESME chaut, faim \& foif, que les nobles, \& ceux des villes: eftans les Romains curieux à eflire \& choifr leurs gens d guerre, que le Iurifconfulte eftime mot Miles, eftre dict comme qui diroi millefime:pour autăt que de mille l'o en eflifoit vn:comme Centefimus, fignifi l'vin de cent. Or pour acheuer com $\mathrm{m}$ noftre Franc-taupin s'eftoit porté à li guerre, ilfut adioufté, qu'eftant bier habillé, \& bien armé ( car en ce temp là l'homme de pied auoit la falade, \& corcelet) les fabriqueurs de la parroilt luy demandant fi fon habillemét eftoi bien faict, \& s'il ne le bleffoit point il refpondit, Ie m'en rapporte à la par: roiffe : fi les fouliers ne le preffüien point, il s'en rapportoit auffi à la parroiffe : fi fa falade \& fon corcelet ne le ferroient point par trop, il s'en remettoit toufiours à la parroiffe, tant il éftoit doux \& paifible. Toutesfois il ne trouuoit pas bon dequoy on le chargeoit de tant de harnois, difant qu'il eftoit affez hardy, \& 'qu'il ne craignoit rien que les dangers. La parroifle luy replique, nous ne t'auons pas armé commeifi

tu auois 


$$
\text { S E R E E. }
$$

auois peur, mais nous t'auons ainequippé affin que tu n'eulfes point peur. Parquioy les parroiffiens le yant armé iufques au collet, \& bien baftonné, luy vont dire: $V$ a hardimét guerre, n'ayes point de peur,il n'y a rfonne qui te fçeuft bleffer, battie, ne er. Le Franc-archer leur refpond, ils oient bien mefchans de me faire mal, ainfi que ie fuis, ie ne me fçaurois fendre ny aider en façon du monde. it aduanturier ne laiffa pourtant à ee receu à la monftre, \&r enuoyé auec autres de là les Monts. Là où il ne fut slong temps, qu'il ne fe defrobalt de regiment, ne demeurant en Italie te l'Efté. Eftant de retour, on luy deinde pourquoy il s'en e?toit reuenu oft: Il dit, qu'il ne s'en eltoit pas fuy peur des coups, ne fuy d'vne bataille efcarmouche, la crainte luy clouant entrauant fi bien les pieds quand il it ioner des cónteaux, qu'il luy eft poffible de bouger d'vn lieu, \& cuuff il auait foument ouy dire d'où il veit, qu'aux batailles \& rencontres d'ars, plus d'hommes mouroient en Liubiij. 


\section{VING I-C I NQV I ES M E}

fuyant qu'en combatant. Mais ce qu m'a fait tolt reuenir, difoit ce Franc archer de Bagnolet, c'ett que Meffieut les Italiens ne mont faict manger tou l'Efté, que i'ay efté en ltalie, finon de herbes, que fi i'y fuffe demeuré celte hy uer ils m'eufent fait máger foing : ay heu donc bonne raifon de m'en veni leur difoit-il. On n'auoit pas acheuéd rire, qu'on va dire que ce n'eltoit pas d maintenant que. l'Italien mange forc herbes, fi nous en croyons le Comic qu dit, Apponunt prata patinis. Puis l'vn deu va demander, \&xc. dont eftoit ven cemot de Franc-taupin. Celuy qui a woit fait le conte refpond, qu'a fon ad uis, ce mot de taupin venoit du mo Grec Tapinos, qui vaut autát à dire (com me on luy auoit dit que hrmilis en Lati parce,difoit-il, que ces Francs-taupin eftoient leuez du peuple le plus bas, $\mathrm{c}^{\prime}$ affauoir des ruftiques \& gés des champs là ou auiourd'huy on leue les gens di pied de toutes conditions \& eftats, qu'oi appelloit n'a pas long temps Aduantu riers, quafi parati ad omnem euentupn, \& Soldats maintenant, à la mode des Ro. 
nains \& Italiens, quafifolo dati, ou felon ucuns. quod folidumjtipendium eis daretur. es gens de pied, que nous appellons uiourd'huy Soldats, va dire vn autre iont faict fouuenir des Pionniers, que n leue des champs, qui furent leuez our affieger vne ville, lefquels furent rins pour foldats, tant poufteltre bien eftus des couleurs de leur eflection, ue pour faire autant de mal qu'eux; iuint comme eux, \& comme s'ils euffent té gentil-hommes, appelloient les ens des champs, où ils palfoient \& geoyent, vilains, pitaux, rultiques, ed-gris, \& paifans : mefmes les foldats u camp ne les pouuoyent difcernei de $x$, tant ils eftoient desbordez en pillees \& blafphemes. Parquoy eftans mar$s$ les foldats dequoy l'vn eftoit prins ourl'autre, \& que les Pióniers iuroyent Iffi bien qu' eux, leur vont dire, $\mathrm{Ne}$ iuz plus mort-Dieu, fang-Dieu, il n'apartiét pas à vn vilain de iurer Dieu : iu$z$ tant feulement, fi vous voulez qu'on ous croye, ie ne puiffe iamais partir d'i,ce qui aduint. Vous m’aués mis en me oire.va direquelqu'vn', la refpóle que 


\section{VINGT-CINQVIESME}

fit en ceft affregemét vn Capitaine à ceux qui fe plaignoiét à luy que fes foldats les auoient deftrouflez : car ce Collonnel voyant que ceux qui fe difoient auoir efté volez par ceux de fon regiment, auoiét encores leurs pourpoints \& leurs chauffes, par le corpsDieu, leur difoit-il, ce ne sōt point mes gés,ie m'affeure que fi c'eftoient eux, ils ne vous euffent laiffé ny pourpoint ny chauffes. Mais elcoutez,adiouita il,qu'il arriua à ce capitaine lequel s'acommodant auffibien que fes foldats, fe laiffa pourtant tromper en partageant vn butin d'vne ville prinfe d'affaut : ne prenant pour fa part qu'vn prifonnier tout habillé de velours, auec force palfemens d'or, \& de boutcns? car ce Capitaine penfant en retirer quelque bonne rançon, le traictoit magnifiquement, luy baillant toufiours le premier lieu de la table. Mais quand ce fut a fe mettre à rançon, on trouua que ce n'eftoit qu'vn coufturser \& tailleur, qui nauoit pas vaillant fix blancs, oftez les habillemens qu'il auoit fur luy, defquels, pour fe fauuer d'eftre tué auec la populace, il s'eftoit accoufté, prenans les meil 
meilleurs veftemens qui fuffent en fa boutique.Le Capitaine, apres l'auoir lóg temps nourry, defpouille ce tailleur, \& l'entroye, \& ne s'en falut gueres qu'il ne fuft mal accouftré, tant pour la moquerie des autres Capitaines fes compagnons, que pour n'auoir rien gagné en cefte prinfe. Vnde la Seree prenant la parolle leur va dire, Puis quauez ris du Capitaine, ie vous feray rire d'vn foldat. Dură les gueres ciuiles, commença-ilà conter il y auoit vn Seigneur,qui faifoit fauter du haut de fon chafteau en bas ceux qu'il prenoit de faction contraire, sils nauoyent moyen de paier leur rançon. Il arriua qu'vn foldat ia cogneu tomba entre fes mains, lequel n'auoit aucun moien de fe rachepter. Parquoy ce Seigneur le mene à la cime de fa tour luy difant, il faut que fautiez du haut en bas. Ce foldat comme affeuré, luy demande, Monfieur, faut-il que ie faute tout d'vin coup: le Seigneur luy refpond qu'ouy : tout d'vn faut, repliqua le foldat Par-dieu,mon Capitaine, ie vous le donne en trois. L'affeurăce du foldat, adioufta-il, \& la rencontre en tel danger, \& 


\section{VINGT-CINQVIESME}

anfli que Dieu tient le cœur des hommes, ploya fi bien l'affection de ce tirar qu'ill luy fauua la vie. Que fr ie ne l'auois veu, difoit-il, ie ne fçay fi ie pourrois croire qu'en vin tel danger vn homme, tant affeuré foit-il, peut auoir dit cela: la peur en fes affaires glaçant le fang, lequel glacé eftoupe fi bien les conduits par où nous refpirons, qu'en telle crainte nous demeurós muets, \& infenfibles, ix fans mouuements, voire mefme les plus refolus. Du depuis i'ay oui dire que il eftoit miferablement : car en la guerre $\&$ en holtitité melmes, ily a quelque borne que la nature a prefcrite \& limitee pourles vainqueurs:outre \& pardeffus laquelle ce qui fe faict \& commet, ne fe peut deformais couurir du nom de guerre, qui a de só colté, comme la paix, fes droits \& couftumes. Parquoy és chofes, où l'on procede par violence, il doit encore y auoir lieu de quelque douceur, pitié, \& humanité. Si nos gens de guerre, repliqua quelque autre-eftoient auffi affeurez que ce foldat, vous ne verriez point tant de vanteries que font ces iarnignois, qui font trébler le falé iufques 
lans les celiers:puis quand ce viét à bailer le pain benift de la cófrairie, font les remiers, non pas a fuir, ce difent-ils, nais à fe retirer. Et ne faut point que eux cy craignent, que leur trop grande udace leur face tirer le fang de la vene, omme il fe faifoit entre les Romains: yans bien plus de befoin d'vfer \& $x$ maner du Pautot comme font les Turcs, qui nt vne certaine opinion qu'ils en font lus furieux, vaillans $\& z$ defefperez à la yuerre, quands ils en ont pris: ce quiles aict expofer temerairement aux perils, ce dit Belon.Si eft ce, repliqua vn autre, gue iay leu que ancienement on puniffoit les foldats qui awoient failly en leur cirant du fang des venes : dequoy on ne peut rendre raifon, finon que ceux qui commettét des fautes ne font pas fains, car des mauuaifes humeurs viennent les mauuaifes maurs. Et feroit debefoing que nos gés de pieds fuffent armez comme les Romains armoient leurs foldats, le plus pefanment qu'ils poumoyent, pour les rendre plus fernes contreles ennemis, \& que fentans leurs perfonnes ainfichargees, ils ne s'attendiffent point

B 4 


\section{VINGT-CINQVIESME}

de fe fauuer. Que pleuft à Dieu, difoit-j que la loy Trefantas des Lacedemoniens c'elt à dire de ceux qui auoient peur, eut lieu pour le jourd'huy, vous en verrie beaucoup fans dignitez, fans femmes ayans des robbes de couleur rapiecees, la barbe feulement d'vin cofté, \& a auc tou cela fuiets à eftre frappez \& outragez fanss'ofer defendre ne reuanger, l'ayme. rois mieux, repliqua vn Drolle, que la loy $\mathrm{d}$ C Charódas fuft practiquee, par laquel le les fuyards n'eftoyent que contraints de s'habiller en fémes:aufí qu'il fe trouue par efcrit de vaillans gens. d'armes auoir fuy:comme fit Catulus Luctatius, capitaine Romain, lequel voyat fuir fes foldats deuát les Cymbres, fans les pouuoir arrefter, fe mit entre les fuiards, \& fit le couard, afin qu'ils femblaffent plus colt fui ure leur chef, que fuir l'ennemy, pour les fauuer de reproche : combien qu'il n'y ait pas beaucoup de perfonnes qui donnent leur honneur à autruy. Et fi eftime, adiouftoit noftre Drolle, plus le Conful Varron, qui s'enfuit, que Paul fon collegue, qui y mourut : \& nô autrement en iugea le Senat, \& le peuple Ro-

main, 
nain, qui luy fendirent graces publiuement de ce qu'il n'auoit point defereré de la Republique. Vn homme d'arnes, qui eftoit en celte Serce, voyant u'on purloit de ceux qui fuient, va feuement dire, queles hommes d'armes rançois, qui fe doiluent tenir fermes, $\mathbb{Z}$ omme en vn fort, ne deuoient s'accouumer aux courfes \& eficarmonches, là ù il faut le plus foutient fuir : car ils s'y ont fi bien accouftumez, que là où il aut tenir bon", ils monfrent les talons. es peuples noumellement def couuerts, ue nous appellons Barbares \& Sauuaes, nous accufent de peur \& de couarife, combien que nous nous difons les lus vaillans du monde : eitant chofe efaerueill able que de la fermeté de leurs ombats, qui ne finiffent ja mais que par peurtre \& effufion de fang:car de crainde mourir, de routes \& d'esfroy, ils ne. çauent que c'êt Et comme dit de Móaigne, Ie ne fuis pas marri fi nous renarquons l'horreur barbarefque, mais uy bien dequoy iugeons bien de leurs autes, nous foyós fi aueuglez és noftres. Ces Barbares, que nous n'eltimons rien, B 5 


\section{VING T.CINQVIESME}

ne demandent à leurs prifonniers, autr rançon que la confeffion \& recognoif fance d'eftre vaincus: mais tant ils fon hardis \& vertueux qu'il ne s'en trouu pas vn, qui n'aime mieux la mort, qu de retafcher, n'y par contenance n'y pas parolle, vn feul point de courage inuin cible, D'auantage , difoit-il, ce qui faic que les vieux portent plus aifément le jeufne que les ieunes:c'eit qu' ils ont grá amas d'excremens pituiteux, où la cha leur naturelle agift, qui eft caufe qu'ell ne diffipe pas tant d'humeur radicale ne de la malfe du corps. Par ces raifon nous trouuons qués villes affiegees où il y a famine, les ieunes meurent le: premiers de faim. Combien de iour: peut on viure fans manger? demand quelqu'vn. A qui il fut refpondu, qu'i eftoit impoffible par nature que I'homme fain peut viure plus de fix iours fan rien manger, tant ait il les pores eftroit $\&$ tant foit-il abondant en groffes hu meurs \& gluantes, quelque chofe qu'or en trouue par efrit. Car notrs trouuon qu'vn eftant condamné à mourir de faim, ne vefquit que fix iours, \& que le fepriefme 
ptiefme on le trouua mort, ayant tangé de la chair d'vn de fes bras. Que if y a quelqu'vn qui ait vefcutrente ours, ou d'auantage, fans manger, comaffeurent Albert \& Auicenne, cela ient du flegme ou de la melancholie, ui leur feruoient d'alimés \& nourritu- Et fi fut adioufté que nous'enduriós lus tont la faim que la foif:parce que la if nous contrifte plus que la faim, preans plus de plaifir a boire, quand nous tons grand foif, qu’a manger quand ous auons grand faim, l'humeur nous electant plus, d'autant que la vie en eft lus entretenue que de toute autre quaté : or ce qui nous contrifte le plus, eft ce qui contrarie le plus à ce qui ous plaift. Soit la faim ou la foif, va ire vn de la Seree, qui face plus tolt endre les villes, fur toutes nations il en y a pas vne qui les fupporte moins ue le François, \& fe fafche plus de oire de l'eau \& máger des rats que luy: e fe contétant pas de lard, de bifcuit, \& evin-aigre, comme les anciens Ronains. Encores trouuons nous dans les Cómentaires de Cefar, que de fon temps 


\section{$\checkmark I N G T-C I N Q V I E S M E$}

les foldats Romains n'auoiét pour tout munition que du bled fans eftre moulu \& vn peu de vini-aigre, pour mefler auec leur eau: \& les Atheniens ne portoyen à la guerre que des viures aufquels n falloit point de feu : les autres ne por toyent que de l'ail : dont elt venu le pro uerbe Latin, à fabis of allits abjtinendum c'eft à dire des magiftrats, \& de la guerre n'y ayát pire nouuelle, que de predire\& annoncer la guerre:les Grecs eftant coufumiers de dire à ceux qui apportoyen quelque mauuaife nouuelle, Eft-ce guerre que vous denoncez? Parquoy, ad jouftoit-il, ne fuut mettre le François ou il eft befoin de combatre de monftre de faim, n'y ayant au monde chofe plus mi ferable, ce dit Cicero ad Atticum, comme l'ont bien montré les doctes Egyptiens en leurs facrees lettres, qui peignoyent vin aigle ayant le bec ciochu, pourfignifer vn homme qui meurt de la plus miferable mort du monde, qui eft la faim. Que fi voulez renfermer vn François, baillez luy,pour le moins, vn pot de vin par iour, \& deux liures de pain, ou ailleurs gu'd la guerre, trois le nourriffent. 
Que fi voulez renfermer des femmes arec des hómes, baillez leur plus à boire y'aux hommes, \& moins à manger : car on tient que les femmes font ordinairenent plus alterees que les hómes, mais qu'elles mangent moins. Expource, diCoit-il, que cela femblera eftrange à plufieurs, ie vous diray leurs raifons. C'eft que rien, n'altere tant que le beaucoup, fouuent, \& vehement parier, que nous diforis babiller, dont les femmes fe fçauent fort bien efcrimer: Et fi ne laiffent les femmes fans parlaméter de s'alterer, mais c'elt par trop filer: car en fillant \& mouillant foument le fil, elles efpuifent l'humidité aqueufe, dontles glandules de la langue font arroufees, \&r de ce defechement vient la foif, \& n'elt fans propos le commun dire, ma comnere, quád ie file, ie boy tant. Er auffi que la complexió cholerique foumét atteinte de foif êt que fi la femme ne l'eft d'humeurs, elle le fera de moeurs, \& par accident,ayant toufrours quelque chofe a de menler, \& à fe farcher. Plus, nous auons dit que les femmes mangent moins que les hommes:or eft il,que tant moins qu'on man- 
VING T-CIN QVIESME ge, plus on boit : tefmoins les femmes qui difent, Quand ie ieufne, ma commere, ie boy tant. Que fi nous voulons renfermer, adiouftoit-il, le foldat François, il faut renouueller la compofition de Alima \& $A d \nu p \int a$, qui oftoit la faim, \&z la foif: ou bien luy bailler vne herbe que les Ameriquains ( qui eft vne partie du monde, nouuellement defcouuerte, contenant plus de deux mille lieuës) nomment Petum : de laquelle ils prennent quatre ou cinq feuilles, qu'ils font deffecher, puis les enuelopent dans vne autre grande feuille d'arbre, en façon de cornet à efpice : cela fait, ils mettent le feu par le petitbout, \& l'aprochent ainfi allumé dans leur bouche, \& en tirent la fumee, qui les nourrit cing ou fix iours fans manger aucune chofe: faifant cela principalement quandils vont à la guerre, \& que la neceffitéles preffe. Que fi vous prenez de la Nico. tiane, ou herbe à la Royne (qu'aucuns maintenant appellent Petum ) \& on n'y trouue cefte vertu, foyez affeuré que ces deux plantes n'ont rien de commur ny en fortune, ny en proprieté, auec

le 
vray Petum des Ameriquains, non plus ue l'Augoumoife, qu'on vante eftre le ray Petũ.Pline auffi dit, adiouftoit il enores, que les Scythes, pautre peuple, renoyent en la bouche vne herbe nonnee Hippicen, que les Latins nomment uffi Spartania, autres Scitbyca, portant le rom des Scythes qui l'inuenterent prenieremét, qui faifoit qu'ils ne fentoient oint la faim douze iours tous entiers. upres qu'ils l'auoyent prinfe : \& que nefmes leurs cheuaux ayans mangé de zefte herbe, enduroyent long temps la: faim \& la foif. Les Scythes auffi, dit Áule-Gelle, par le rapport d'Enafiftrate, pour endurer la faim, fe ferroyent le ventre \& l'eftomach auec de grandes bandes : parce que ne laiffant gueres: de vuide, Ia faim tourmente moins: laquelle vient, felon Eriftratus, des fibres du ventricule \& des inteltins, quand ils demeurent vuides. Parquoy nous voyons couftumieremét que ceux qui ont de grandes obftructions és parties vifcerales $\&$ inteltines, n'ont pas grand appetit. Mais ie craindrois, repliqua incontinent vne feffe-tonduë, 


\section{VING T-CIN QVIESM E}

que ceite ligature me prouoqualt lafciuité: car on tiét que ceux qui fe fer rent fort; font plus incitez \&z enclins: luxure : dót il en y a qui defendé aux fil les \& femmes de fe ferrer fi fort, pour ni fentir les aiguillons de la chair, \& auf pour euiter d'eftre bofrues \& cótrefaites mais ie vous diray, adiou?ta-il, Venus ef mal aggreable à ceux qui endurent grác faim. Que fi ceux du iourd'huy, qui ne fe ferrent point, \& ne contraignent point leur panfe, le font pour celte occafion, i'approune leur maniere de fe habiller auec leur cotton. Aucuns ont dit, difoit il encores, comme Turnebus, que le fromage de iument pounoit nourrir dix ou douze iours, fars manger autre chofe: mais ils ne difentrien de noulueau, car les Scy thes la plus partdu temps ne viuent d'autre chofe. Les autres affeurent que pout fe paffer lông temps fans manger, qu' il n'y a rien meilleur que de boire oleum violaceum, meflé auec vn peu de greffe, ou de l'hulle d'amandres, oubien manger du beurre. Autres afferment que le papier mafchée efáche la foif, auffi bien que de tenir des boules de fer en 
bouche, come il fe trouue en l'hitoire Portugais. Et fi ie n'en puis trouuer fer, repliqua vn des noftes, prenez en e merde, luy refpond Franc-à-tripe.Cei qui auoit elté affiné, ne laiffa en riant dire qu'il auoit experimenté, eftant à guerre que ce que dit Pline du Pouliot toit vray, \& qu'il engardoit d'auoir foif iff bié que les graines de Halinus fauage, tenues foubs la lágue : \& qu’ayant aduré la faim, il s'eftoit bien trouué uis apres de ne máger gueres, \& d'vfer boutillons de vieiles poulaillesbien onfumees, \& laict de cheures, \&cautres hofes propres pour eflargir les boyaux. traicts. Vn de la Seree, encores qu'il x cerçait le meftier de la guerre, ne laiffa faire vn conte d'vn de fes companons d'armes, lequel eltoit forty d'vne ille affiegee. Et le commença ainfr. Vn iommes d'armes de notre compagnie, uant efté renfermé en vne ville afegee, \& pour cela lay femblant que out le monde luy eftoir tenu,en paffant ar vne ville fit quelque exces, penfant ncores eftre à la guerre, dont il fut reherché iufques à fon holtellerie : où ne 
VI NG T-C I NQVIES ME

letrouuant point, ou print fon cheu fans s'amufer à prendre la felle. Mo compagnon, de gend'arme : fafché a poffible de fon cheual, menace toute ville, iure qu'ils s'en repentiront, \& qu' fçautoit bien qu'il ferout. Par l'aduis de ville, fon cheual luy eft rendu:les plus a uifez de la ville difans qu'il venoit d'vis ville quirauoit enduré le frege lon temp où il auoit enduréla faim, \& qu'il ne fa. loit iamais irriter telles gés, la faim aya augmenté la cholere. En rendant le che ual à mon compagnon d'armes, ceux d la ville lüy demandent, Et bien Mor fieur, que eufliez vous faict, fi on ne vou euft rendu voltre cheual? Que i'eulfe fai mort-Dieu ? Va-il refpondre, íeuf vendu la felle. Lors ceux de la ville co gneurent bien qu'il n'eftoit pasfigran diable qu'il efoit noir. Auff l'holte, ad ioulta celuy qui faifoit le conte, $\mathrm{m}^{\text {'a }}$ uoit conté que ce fendant eftant log en fon logis, wn iour fe voulantcou cher auoit denandé vn courure-chef \& voyant que les chambrieres fai foient les longues, il s'eftoit fi bier prins à iurer \& maugreer, que tou 2 ?

ceux 
ux du logis ne s'ofoient trouuer dent luy. A vne fois ildifoit qu'il metoit le feu au logis, qu'il eftoit gentilmme de bonne part, \& bien appanté, que ce n'eltoit pas à luy à qui on deuoit iouër : que fi on le voyoit mal ordre, qu'il venoit d'vn fiege, \& 'il auroit bien cinq \& fix paires d'hallemens s'il vouloit, \& qu'il ne teit qu'à l'argent qu'il ne les euft. En courroux, perfonne n'ofoit prendre hardiefle de luy prefenter vn cou-chef, fçachant que de l'homme uurroucé fe faut efcarter pour vn téps, de l'ennemy pour toufiours. A la fin, in hofteffe print la hardieffe, apres luy loir baillé vn couure-chef, de luy mander, Et bien, monfieur, qu'eufez vous fait, fi on ne vous euf apporvn courure-chef ? Que i'eulfe faict, ng-Dieu ! va-il refpondre àl'heure: me fulfe coeffé de ma chemife. Lors, on hofteffe, quile cognoiffoit, en s'exufant, luy va dire, Et viayement, moneur, ie ne me fuis pas auancee de vous orter vn cousure-chef, car i'ay veu que e portiez rien en volte tefte. Ie n'y aauffi 


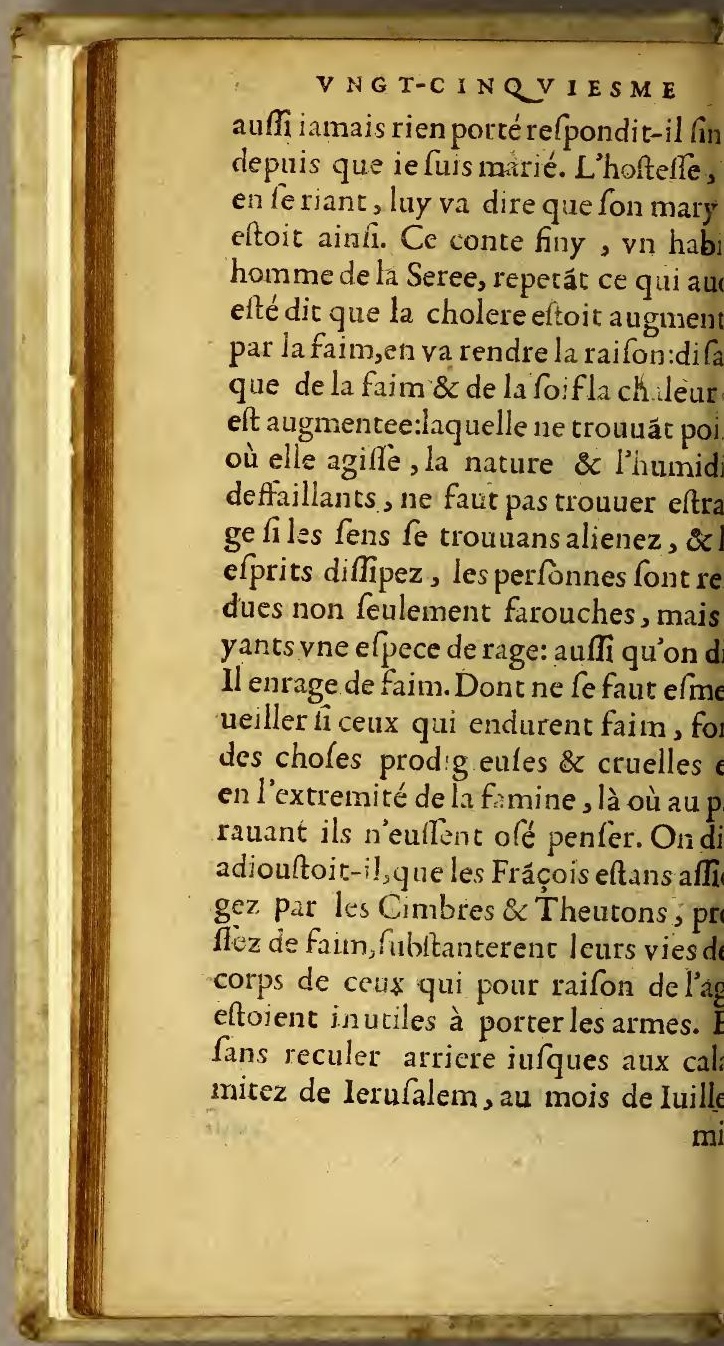


cinq cents feptante \& trois if adì. Snnxerte, que les affiegez, rets a l'extremité, \& cótraints de mancuirs, parchemins \& autres immones, que vne petite fille de l'aage d'enon trois ans, eftant morte de faim à pauture habitant de la ville, vne vieilqui feruoit luy \& fa femme, leur feilla de s'aider de leur infortune: \& fait en mangerent lesentrailles, la m contraignant la mere de remettre fon ventre l'enfant qui n'en faifoit eres que de fortir. Mais ayans mis la te à c'uire dans le pot, cela eltant deftuert par les foldats, ils furent brunez. s. Allemans eftans affiegez par les ircs, \& $z$ ayans faute de viures, \& 2 prinalement d'eau, ils tuerent des cheux \& auec leur fang meflé auec vn u. de farine, ils remedioient à la if \& à la faim. Ceux de Crotte fiegez par Mettellus, fe troutuerent telle neceffité de breuuage, quio'ils, feruirent de l'vrine de leurs cheux. Mefme le cheual preffé de im mangera fon maiftre : comme ous troutions qu'vn cheual renfermé auec 


\section{I G T-CI NQV IESME}

auec.Limone, par la fentence de fon $\mathrm{p}$ re Hyppomene de grande faim mang. fa fille. A uenzrat dit que la famine fut grande en fon païs, qu'on des enterro les corps morts, afin de fuccer la moël des os defgarnis de mufcles \& de chai $\&$ de fe paiftre de leurscharougnes: forte qu'on fut contraint de metred gardes aux repulchres. Apres qu'one conté les effects de la faim, quel qu'vn $\mathrm{r}_{1}$ prenant ce qu'auoit dit le gentil-homm lequel eftant defpourueu de biens de n ture, \& de fortune, les recherchoite: fes anciens \& predeceffeurs, s'en mc quoit, allegant ces vers:

Quigenus laudat funm:aliena laudat. Et fi difoit que Homere, quand il vet recommander vn bon gendarme, il me toit l'átiquité de la nobleffe toute la der niere, \& apres toutes les autres loiiange de celuy qu'il vent louer :la vraye no bleffe s'acquerant en viuant, \& non pa ennaiffant? \& comme dict Erupide.

D'eftre de noble fang, c'eft un tiltre hon. norable:

Et la nobleffe en croift en ceux qui ont fem blable. 


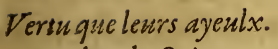

apres luy le Seigneur de Pybrac: Cie n'eft paspen naijfant d'vn tige illuftre, Efire efclairé par fes anteceffeurs:

Mais c'eft bien plusluire à fes fucceffeurs, Q 2 e des ayeulx feulement prendre luftre.

ys que vous moquez, repliqua vn aue, de ceux que ne font nobles que de ce, que direz vous de ceux qui fe font noblir ? Il luy fut refpondu, ce que leu il,n'y a pas long temps:

Iu dis que tu es gentil-bomme

Par la faueur du parchemin:

Si vn rat le trosue en chemin,

Que feras tu? comme vn autre homme.

lais, demáda quelqu'vn, puis que nous yons ceux qui ne font que babiller $\&$ ufer de leur nobleffe, \& ceux qui fe. antent \& menaffent, eftre plus poltrons couards, que ceux qui ne difent mot; sbabillards defendans leur caufe par la ngue, ne pouuans faire autre chofe, les arates eftás vaines où l'effect auec l'wure fe manifeltent:qui eft caufe de la harieffe d'aucuns, \& de la timidité des au-. es?ithy fut refpondu, que les animaux ui ons le cour grand, lafche \& $\mathrm{rmol}$; font 


\section{VING T-CIN Q VIES ME}

font fort craintifs, poureux, timides $\varepsilon$ couards:\& le prouma par les cerf, lieure $\&$ afnes, \& autres beftes timides, qL ont le cour fort grand, ayant efgard aे । proportion des autres membres $d u d t$ dans : or eft-il que la chaleur n'eft pas grande en vne grande efpace qu'en vn petite, vn mefme feu ef hauffant plu vne petite chambre qu'vne grande: $c$ n'eft donc pas de merueille fi ces befte timides, nayans pas grande chaleur a cour, ont le fang froid: la hardieffe ve nant de la chaleur du fang. Au contraj re, des animaux qui ont le coeur petit époix, dur \& ferré, comme lelion, \& 1 chien, lefquels font courageux, d cau fe que la chaleur fe garde mieux \& n'el pas fídebile en vn petit lieu qu'en vn au tre grand : l'homme tant plus qu'ilel chauld, tant plus ayant de hardieffe toutesfois contre la commine, qui di d'vin hóme hardy \& courageux, Il a gran cours:car c'eft tout le contraire. Aint voit on ceux qui ne craignent rien, \& font affeurez,auoir la voix haute $\&$ gref le, à caufe de l'extreme chaleur qui ef en eux. Mais d'oùvient, repliqua quel 


\section{S E R E E.}

ivn, fila chaleur caufe la hardieffe, ie iay veu de braues foldats \& harqui trembloient quand ce venoit à ier des coutéaux, la chaleur fe retirant dedans, \& delaiffant les membres exieurs froids, femblans le Franc-arer de Bagnolet, qui trembloit de harffe ? Il fut refpondu, que combien que Loy Trefentas ait efté ainfi dicte, comeltant faicte contre ceux qui tremnt, qu'il ne s'enfuiuoit pas qu'on ne uuaft des perfonnes vaillantes $\&$ hars, qui tremblét \& muent de couleur, cores qu'elles n'ayent nulle peur, \& ent des pltts courageufes. Cela fe faiit, difoient-ils, de ce que leur corps It pas efchauffé d'vne miefme chaleur and ce vient aux difributions maelles, \& que par l'mpetuofité de la leur bouillante, qui les furprend, il ait vn mounement inegal en toutes parties de leur corps, qui caufe ce mblemét tumultuecix par trop granabondance d'efprits \& de fang : dont tient que ceux ci,en yn bon affaire, fe ppét deteurs mains, à fin qu'ilils forent hauffez en tous leurs membres d'vne Liu. iij. 
VI N G T-C I N QVIES M E

mefme chaleur, qui fera celfer ce trer blement à l'unitation du Lyon, qui bat de fa queuë, pour s'efchauffer \& e trer en cholere. le croy, va dire vn mi Atre és Arts, \& en toute archipedenter: qui eftoit en celte Seree, que ie n'aurc pas fi grand peur, \& ne tremblerois $F$ tant, $f$ ie me battois moy-mefine, qui d'autres me frappoient : mais ie me do te bien, difoit-il que tous mes batt mens ne m’empercheroiét d'auoir pel $\&$ de trembler s'il me falloit deffenc ou affaillir:veu que toutes les fentinel. corps de garde patroiiitles, rōdes, qu' m'a faict faire durant les troubles, mont fceu rendre plus hardy, \& fi n'o peu m'engarder de trembler, feuleme quand il falloit demander à vn fall ou à vne lanterne, Qui va là? Magrar mere aufin mia foument dict, que quád vins au monde, il fe fit vn trembleme de terre, mefime qu'à l'heure que ie $n$ : qui il tonna bien fort, \& qu elle aut ouy dire autresfois à mon grand $p^{e}$ fon mary, qui eftoit maiftre és Arts col me moy, que ceux qui naiffent l'ann que la terre tremble, on le iour qu 
ane, font naturellement craintifs \& nides. Et auffi que ce grand pere,regar.. nt mes bras cours, me difoit que ie feis fort coü ard \& poureux : I longueur grandeur des bras eftant figne de chair,cóme les courts de froideur, \& que la chaleur procede la hardieffe, \& de froideur la crainte. Et ay bien cognetr puis, que mon grand pere difoit vray ceux qui faifoient la fentinelle auec y, fentirent bien vne nuict, qu'on us bailla vn faux alarme, que $i$ 'eftois plus timides : comme auffi fit la ronvine autresfois, laquelle monta en e tour, où i'eftois en fentinelle, qui me uloit tuer, parce qu'en paffant, \& pellant fentinelle, ie n'auois rien refndu, \& difoit que ie dotmois. Ie dy, que ie ne luy auois veritablement in dit, pource que ie n'auois pas nom, atinelle : mais qu'on mappelloit maie Iean. Et n'euffe iamais penfé, fans cedifoit nottre maiftre és Arts, que la ur feruit d'apothicaire, \& de clyftere, ne voulois pas croire la recepteque actiquoit Meffire Pantolfe de la Cafe,Sienois, quand il eftoit contipé, ne 
VING T-C I N QVIESM E que les armoiries de Fran mifes és p uez des Anglois leur feruifient de que que chofe. Mais maintenant ie fçay $p$ experience, que les fymptomes $\&$ acc dans de la peur feruent de faire ouurir guichet du ferrail, auquel à temps matiere fecale elt retenuë: à caufe $q$ la chaleur naturelle qui eft en nous, quafi comme notre vie, fuyant ce $q$ luy elt contraire, \& qu'elle craint, $v$ nant du dehors, fe retirant au dedar vient à efmouuoir \& fondre notre ve tre \&z la veffie: $\$ z$ auffi que la peur faifa retourner le fang \& la chaleur au ca \&r au dedás, fai ct que la vertu retenti du ventre perd fa force. Que fi le fie de la ville où i'êtois renfermé, adio ftoit noftre maifre Iean, euft duré pl long temps, i’auois deliberé de port des chauffes à la martingalle, ou à pöt uis. Quand noftre maiftre aux Artss a perceut qu'on fe mocquoir deluy, il dire.Encores que cela ne foit aduenu, que ie ne foys des plus hardis, ie ne m' eftime pas moins ayant leu en mon $A r$ ftote, que la prudence confite en fro deur, \& le courage \& vaillance en ch: 
ar,pourquoy i'ayme mieux, difoit-il, re pridés miles, que Gallicus miles, qui eft lire temerarins: \& ces deux qualitez ás contraires \& repugnantes, il eft imffible qu'vin homme foit courageux \& udent.

Quelqu'vn de la Seree, eftant bon ançois, demanda à noftre maiftre és ts : appellez-vous temerité fe mettre bien combatant és perils de la guerauec vn cœur inuincible? Penfez-vous shonnorer les François, quád vous les imez, Gallicus miles? veu qu'on dit que gaillard \& gaillardife viennêt à Galliandacia, \& que ceux font appellez gailrds, qui courageufemét entreprennét relque chofe, tant auentureufe foit elPourtant, repliqua maiftre Iean, Cer dit qu'il ne defiroit moins en thome de guerre la fageffe, la modeftie, \& beïfance, que la prouëffe \& grandeur courage:\& Polybe le cöfrrmant efrrit nfi. Les Romains ne defirét pas tant la ardieffe, ne le conténement de la mort leurs Capitaines, comme la conduite, unfance, \& bon confeil. Et Valere dit, diouftoit-il, que Clearque, Capitaine 
VINGT-CINQVIESME

Lacedemonien, fouloit à tous propos $r$ menteuoir à fes foldats, qu'il fait qu Phóme de guerre craignilt plus fon $C$ pitaine que l'ennemy, \& que le Cleand du Sieur de Preflac dit aufli que n’auo pas apprehéfion du danger, n'eft pas eftr vaillant, dautant qu'eftre vaillát eft pro pre à l'homme, \& le non aucir d'appre henfion rient de la belte. Dauantage, $d$. foit-il encores, la vaillance n'eftant autr chofe que le melpris des dangers, celu ne les mefprife qui ne les conçoit pas.E de faict, ce ix qui courent au danger, fan fe l'eftre reprefenté, dés auffi tolt qu'il fe trouluent , tant foit peu,engagez, del couturent clairement le peud'alfeuranci qu'ils y apportét, en ce qu'ils en retour nent pluftoft qu'ils n'y font allez. Là oi pour bien faire, au commencement $i$ faut iuger du peril, puis refoudre d'a cheuer l'entreprinfe ou la vie: Thucy. dide difant que l'ignorance faict les har. dis, \& la confideration les craintifs : la hardieffe eftant entre la crainte $\&$ la temerité : car ceux qui craignent tout, font coüards, \& ceux qui ne craignent rien, font temeraires. Vn Franc-a-tripe 
dire à noftre maiftre és Arts, que fans oir efgard à tout cela, ill'empefcheit d'auoir peur, \& file garentiroit de us dangers belliques, qui peuuent furnir au corps : ou luy baillant la chemideneceffité, quion a accouftumé ver quand on va à la guerre, laquelle eft icte de lin filé la nuict de Noel par des les chaftes, au nom du diable : ou bien y donneroit vn breuet tout plein de ttres fignees \& efcrites par les Preftres -Turquie, qu'on nomme Talafmans, ui appellent ces lettres Haymachy:ce reuet preferuant celuy quile porte à la uerre, d'eftre bleffé, ne par couteau, ne ar flefche, ne par harquebuze, ne par utre bouche a feu : ou bien luy feroit refent d'vne priere qui s'appelle Aletoria, qui fe trouue au ventre du coq: aquelle portee fur foy, faict que celuy ui la porte fera toufiours victorieux :à efte caufe le coq eft l'oifeau de Mars, \& ar lettres hierogliphy ques le coq figniie la vaillance: parquoy les Sybarites :ffeminez defendoiét de tenir le coq en eur ville : ou bien l'armeroit d'vn corclet \& morion qui feroient à l'efpreuue C 4 
VING T-CINQVIESME de toutes armes offenfiues: car il eny quiconfacrent des armes vfans de for ce croix, force noms de Dieu prins de Hebrieux, auec force prieres \& exorcil mes. Et de faict, difoit-il, pour vou monfrer que ce n'elt pas du iourd'hu que telle magie s'exerce, nous trou uons qu'au temps de nos peres Fran 6̧,is, toutes telles forges \& trempe d'armes faictes par confecration, eitoié seputees inuentions du diable, \& eftoié defenduës à ceux qui entroient en camp clos, \& mefmes ils iuroient au preala. ble, auant que combatre, que les armes qu'ils portoient n'eftoient forgees par les arts de l'ennemy, ne par inuocations d'efprits malins: celuy qui demandoit le combat requerant le Conneftable que fur ce il fit jurer le defendeur : ou bien pour n'anoir point de $\mathrm{mal}$, illuy apprendroit à dire vn mot, lequel eftant dict tout haut, fi vous combatez contre les Sauromates, il ne vous feront nul mal, ce mot eft Zirin: ou bien pour n'auoir point de peur, \& pour eltre refolu, il faut faire ce que fi. rent les Numantins : lefquels.voulans

faire 
ire vne faillie pour combatre, fe remirent de viandes, comme ayans faict le tin de leurs funerailles \& fi fe faoulent de chair deny crü̈, \& d'vn certain euuage faict de froment : que ceux du is appellent Calia. Puis noftre Francripe, s'addrelfant encores à noftre aiftre lean, luy va dire, nonobitant que peurdu faux alarme, \& de celuy qui ifoit la ronde, vous ayent mis bien es de la mort, fi s'en trouue-il de plus aintifs que vous, car pour moins i'en veu mourir : à caufe qu'en ces peurs, efprits nous voulans aider, s'affement tous au cour comme a la forterefde noltre vie, à fin que le cour ne defille en ce grand peril: \& pource que sefprits y vont fans ordre, \& tumulairement, \& auec grande foulle, ils us peuuent fuffoquer par celte trop ande haftiueté, dont s'enfuit la mort. - maiftre és Arts lors luy refpond, qu'il fbahylfoit fi on meurt de peur, coment il eftoit en vie, veu qu'il ne fçait homme au moude plus poltron \& mide que luy: que s'il s'en trouuoit vn us coiiard, il fe pendroit. Il luy fut 


\section{VING T-CINQVIES M E}

repliqué parle mefmé Franc-à-tripe, va donc te pendre,car tu.es plus hardy que moy, qui n'aurois pas le courage de me tuer \& pendre. Ce mailtre és Arts vi encores demander, comme luy eftoit ve nu ce flux de ventre: veu qu'vn moi auát celte alarme il n'auoit gueres man gé, \& î ne pounoit manger à caufe de peur:que li tous euffent efté de ma com plexion, difoit-il, la ville n'eult pas eft de long temps affamee. On luy repliqua que les poltrons \& coỉards gardiens d places imprenables, les font prenables 32 que pour garder bien qu'il y faudro metrre de plus vaillans gens \& honne ites que iny : \& qu'il eftoit fi vilain qu'o le receuroit bien en l'adminiftration d quelques Republiques, où il faut eftr vilain, pour le moins, de trois lignees, 8 qu'on trouruit eitrange dequoy il efto encores fi poltron, \& qu'il deuoit eftr venu vaillant, ayant elté en ce fiege aue des pius courageux de toute la France fe faifant beaucoup de chofes ef meruei lables par vne certaine fimilitude \& fre quétation:à caufé que celuy qui hanter te hardy, le fera, s'il hante lé coiiard, ill 
ra. Lors noftre maiftre lean va tresen repliquer, que les vices quifont naurels ou en l'efprit, ou au corps, ne fe auent du tout effacer par aucune inutrie, ce qui eft né aurec nous pouuant en eftre adoucy \& corrigé par art, ais non du tout furmonté \& arraché. arquicy ie penfe, difoit noftre maifte Arts, que pour lafcheté de cour yn Idat ne doit eltre puny de mort : ayant ac grande difference entre les fautes ai viennent de noftre nature, \& celles ai procedent de notre malice : de maiere que plufieurs ont penfé qu'on ne pounoit prendre à nous, que de ce que ous faifons contre noftre conficience. fur cefte reigle aucuns ont fondé, ce te Montagne, leur opinion de ne unir parmort les heretiques. Et quand euffe eftéle plus hardy du móde, difoit , ie n'euffe iamais fuiuy les armes, $l_{2}$ ondition de la guerre eftát tres-defraiinnable, là où vn chacun veut auoir honneur de ce qui eft bien faict, \& vn eul eft chargé des fautes. Vn de la Seree ui eftoit dians la ville affiegee anec nore maifte és Arts, nous va conter vn

C 6 


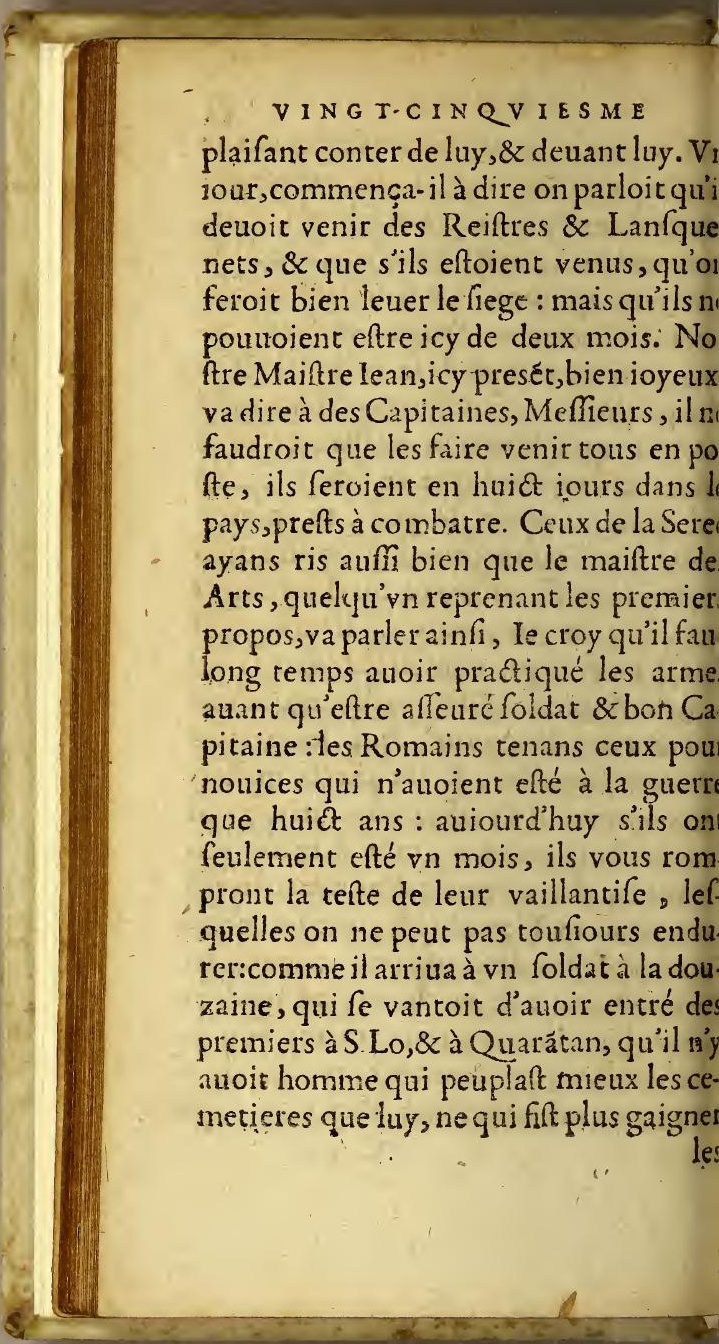




$$
S \text { E R E E. }
$$

s Chirurgiens. Vn foldat accort eftant f́ché de fon babil, \& de fes vanteries, ly va dire : Puis que tu es fi bon foldat, omme tu dis, mets le nez à mon cul, $8 z$ cie ville gaignee. Ce babillard faifant emblát d'entrer en cholere, va dire à ceyy qui fe mocquoit de fa vaillátife: Si tu ne fafche, ie t'accoultreray fi bien qu'il e te faudra Medecin ne Barbier. le le roy bien, luy replique ce foldat: cartu e me feras point de mal, tu es trop on. Ce Trafonefque luy vadire qu'il feroit auffi aifément qu'il aualeroit $n$ verre de vin, mais qu'il craignoit u'il ne fuft pas confeflé: $\& z$ par là on ogneuft bien, difoit celuy qui auoit ommencé le conte, que les paroles ftoient femelles, \& les effects mafles, $x$ pourtant fi l'euffiez vous prins pour n vaillant homme, tant il iuroit enrant en cholere: mais ie ne m'arrefteray amais à ces Picorcholes, qui fe choleent pour peu de chole : car, comme dit ieneque, l'ire \& la cholere ne rendent oint l'homme de guerre, ni autre, plus ardy : la vertu fe contentant d'elle mefne, fans atooir befoing d'vn vice, qui 


\section{ING T-CIN QVIES M E}

eft la cholere. Et me fouuient, adiouftoit il encores, auoir entendu d'vn vieil fol dat, qu'vn fien compagnon de guerre arriuant au logis, caffoit les bouteilles vin-aigre \& faifort mille infolences : du rapport defquelles fon Capitaine affauanté, le gardoit pour combler le foffe à quelque raifonnable brefche. L'heure qu'il attendoit venuë, voulàt faire marcher fon homme a la premiere poincte d'vn affaut, qui fe donnoit à Vezelay, il le trouna tout autre qu'il n'eftoit mangeant le cul des poulles fur le bon homme : car tremblant de hardieffe, pria fon Capitaine auoir pitié de luy, difant pour toute raifon quill eftoit fi chaud \& temeraire, qu'il le feroit ruer incontinent, fi on l'enuoyoit en lieu fi dangereux. Vn autre pour foulager ceftuy-cy qui en auoir affez conté, luy va dire, le vous prie metrez mon foldat auec le voftre: lequel faifant bien le quant à moy en vne querelle, \& voyant que fa partie aduerfes sen venoit à luy, fe renferma en vn logis, fon ennemy luy criant, forts poltron, forts fi tu es homme de bien:le foldat renfermé mettant le nez à la fenettre, luy demåde, 
fi i'y allois que me ferois tu: Que ie ferois, repliqua celuy qui vouloit róe la porte, ie taffeure que ie te coupeis la gorge, Le foldat renfermé lors luy dire, Pardieu ie n'y vois donc pas. Et uand il luy difoit, Tu n'as donc point zuie de te battre;ll refpondoit que non, qu'il s'aimoit trop. Que fi ces deux Idats, adioufta-il encores, euffent efté atre les pauures Scythes, on les euft ien empefché de communiquer à leurs eremonies : eftant deffendu à celuy qui auoit tué perfonne en guerre, d'entrer n leurs temples, \& moins leur eut elté ermis de faire vn facrifice, que les irecs appeloient Hecatomphonia, lequel 'eftoit permis qu'a ceux qui auoient ué cent hommes en guerre. Et ne femloient pas ces deux foldats, le Lacedenonien, qui auoit fon honneur en $f_{1}$ rande recommandation, que eftant ombé en terre, il pria fon ennemy de le uer par le deuant, honteux de mourir êtant bleffé par le derriere, à fin que les. lens n'euffent point de deshonneur le royant mort : l'homme genereux eftimant plus l'honneur vniuerfel des fiens, 
VING T.CI N VIES M E fiens, \& de fa race,que fa vie particulie re. Le Seigneur de Montagne à ce pro. pos a laiflé par efcrit, que le Capitaine Bayard eftant bleffé d'vne harquebufade $\&$ contrainct de fe retirer de la menlee commanda à vn fien gentil-homme de le coucher au pied d'vn arbre, mais que ce fuft en façon qu'il mouruft le vifage tourné vers l'ennemy:à fin qu'on ne pen. falt qu'il eult tourné le dos à l'ennemy. Que fi ces gens là auoient foucy de l'eftime qu's auroit d'eux apres leur mort, quel foucy penfez vous qu'ils euffent deleur honneur eltans en vie? Ce qui leur oftoit toute exaction \& pillerie allans à la guerre, car tát plus qu'ils eftoient gens de bien, tant plus on les eftmoit vaillas \& hardis, l'homme de guerre-mauuais \& mefchant, \& auec cela vaillant \& courageux, eftant à comparer à vn mauuais chien,qui faict bien la guerre aux loups, \& toutesfois eltrangle les brebis:ceux qui font profefió des armes doiuent eftre femblables aux bons chiens de garde, qui font mauuais contre ceux qui viennent du dehors pour mal faire, \& au contraire, doux à ceux qui 
at au dedans. Vous voudriez donc, luy -il repliqué que les gés de guerre fufat cóme le gentil-homme, lequel eftát a guerre ne frappoit l'ennemy que du it de fon efpee, dont eftant reprins, il oit qu'il auoit peur de le tuer, le vouat prendre tout vif: comme faifoiét les adiateurs, que les Romains nömoient tiarios. Et voicy le nom \& l'epitaphe de bon homme de guerre:Cy gift Froifin, dat, homme de bien, qui ne tira iamais ee, \& ne bleffa perfonme, n'entrant nais en cholere, \& fi ne pilloit point fubiects. Son efpee donc, repliqua e feffe-tondue, deuoit auoirbien du ct, n'eltant pas fouuent tiree : $\&$ ie y qu'il ne pilloit point fes fubiects, n ayant point. Que s'il euft efté Lacemonien, il n'euft point eu d'epitaphe, d'infoription fur fon tombeau : eltant fendu par la Loy de Lycure de n'efrefur vn tombeau, fi celuy là n'eitoit ort en guerre. Les Cariens ayans efté premiers iuuenteurs de faire mettre moiries \& fignes en leur efcus \& pais, efquels quelques vns ef criuoient ir nom : à fin qu'on peuft recognoiftre ceux 
VINGT-CINQVIESME

ceux qui auoient bien fáict err guerr les Atheniens auffi ayans vne place Athenes, où eftoient enterrez ceux q eftoient morts en guerre, dicte Piquil pour la varieté des hiltoires y depincte Eftant reçeu de tout temps non feul ment d'ef́tédre le foing que nous auor de nous au delà celte vie, mais encor de croire que bien foument les faueu celeftes nous accompagnent au ton beau, \& continuent à nos reliques. I fi anciennement il n'y auoit que les vai lans qui peufient porter leurs bouclies peints : carceux qui n'eftoient point es perimentez à la guerre, \& n'auoiét fai quelque acte vertuenx , portoient leu rondaches toutes blanches fans peints re: vnde eft, Porrináque inglorins alba, ides non picta. Et ainfi les armoiries fe do uent feulement attribuer à ceux qui or faict quelques beaux faicts d'arme feulement. Le Decameron dit: Nor fommes nais tous efgaux, \& auec e gale vertu : mais ceux qui furent plt vertueux, furent appellez nobles, le rt fte demeurant non noble : Et Diode re dit que beaucoup de nations, 
tre autres les doctes Egyptiens, n'eient point plus nobles les vns que les tres: \& n'eltoit permis à leurs funeilles de louër leurs parents \& predefleurs. Ie n'eftime pas moins, adiou-il, ceft homme deguerre, pourn'aoir tué perfonne : car peut eftre qu'il a iamais combatu que contre des gens di ne fe deffendoient point : eftant file de poltronife quand on ne s'adeffe qu'aux foibles \& timides, imitans s vilaines mouches, qui ne piquent iaais que les boufs maigres, chetifs, \& fcharnez, \& non le Lyon, qui affaut uftot les hommes que les femmes, \& mais les petits enfans que par famine: ine ayant eferit qu'il auoit ouy dire à ne femme de Getulie, qu'clle auoit aptifé la fureur de plufieurs Lyons, fe fant femme fugitiue $\&$ debile : en fupiant le maiftre, \& le plus noble des imaux, d'auoir pitié d'elle, \& qu'elle toit vne proie indigne de la nobleffe ceft animal :ce Lyon mignardant les etis chiens \& fe iouant auec eux, \& deorant les grands. Età ce propos, difoit , ie vous conteray vn braue acte d'vn gentil- 


\section{VING T-C I N V I ES ME}

gentil. homme, lequel fe monffra gen reux en vne querelle qu'il eut contrev fien cópagnon d'armes : car fon aduert partie eftant tombee en combatant, ne voulut offenfer,mais au contraire, luy $v$ dire, leue toy:ie taffeure que ie ne te $\mathrm{ft}_{\mathrm{f}}$ ray aucun mal tant que tu feras à teirr Celuy qui eftoit tombé , fe fiant en 1 promeffe, ne voulut iamais bougerd couché, tắt que fon ennemy fut là, que que affeurance qu'on luy peit faire de in l'offenfer couché ne debout. Il me fem ble, commença à dire vn des plus adui $\mathrm{fez}$ de noftre Seree, que les Romains exemplaires de tout bien, n'euffent pa fait ce que firent les Hennuiers à vn pautre femme, comme recite Froiffard qui efcrit quele fils du Cóte deHaynauı s'en alla à grand force pour conquerir l: Frife : mais quand fes gens vouluren prendre terre, l'armee de ceux du pay: vint à l'encontre, fortant vne femme ve. ftue de bleu, qui s'aduança feule pous empefcher la defcente de l'armee du Conte de Haynaut, \& eftant à vn iect de flefche pres de Hennuiers, leur tourna le dos, \& leuant fes draps, fa robbe, 
bbe, \& fa chemife, leur montra fon triere, en criant, prenez là voftre bienenuë,Meffieurs. Et dit Froiffard que les ennuiers, qui eftoient aux nauires, tirent apres elle flefches \& viretons, qui enferrerent par fon dèrriere de plus de nq cens flefches, iufques à la mort. Ce inte acheué, ceux de la Seree entrerent debat lequel eftoit plus eftimé à la terre, ou bien affailir,ou bien fe deffene, fe trouuant vne grande contrarieté cela entre les Romains \& les Grecs: Romains eltimans plus le bras droict le gauche, l'efpee que le bouclier, ffaillir que le deffendre : au contraire s Grecs, qui auoient plus d'efperance la main gauche qu'à la droicte,faifans us d'eltime de leurs boucliers que de urs efpees : eftant deffendu parleurs oix à ceux qui auoient perdu leurs oucliers à la guerre, de fe trouter en urs temples \& facrifices. Parquoy Ariilor fut banny de Lacedemone, pour oir efcrit quil valoit mieux laiffer n bouclier quela vie. Il fut dit qu'vfemme de Lacedemone difoit à fon $s$, en l'armant: ton pere t'a toufiours conferué 


\section{VINGI-CINQVIESME}

conferué ce bouclier, aduife de le garde auffi, ou de mourir : \& les Latins ont di qu'elle difoit à fon fils, aut cum bo aut in boc redi: les Grecs voulans dir que lon doit penfer premier à fe deffer dre que d'affaillir. Et celt pourquoy $\mathrm{Hc}$ mere defcrit toufiours les plus vaillar. \& hardis, les mieux armez. Auffi qu'I paminondas, a demy mort, demanda l'ennemy luy auoit point ofté fon bot clier en tombant, \& quand on le luy etil apporté, le va baifer en mourant, corr me compagnon de fes labeurs \& de! gloire : par cela voulant rendre tefmoi gnage, ce dit meffire Franfcifque Lotir que les braues \& genereux actes parlu faicts aux affaires des guerres Thebai nes, auoient efté par luy entreprins, pou fouftenir la paix, \& conferuer la Theba ne liberté, \& non pour faire aucune of fenfe : demonftrans les Grecs, que l'hon neur deu aux vaillans hommes, deuoi eftre plus toît dóné aux deffendás qu'aun. affaillans, encores que celuy qui affaut face demonftration d'eftre plus hardj que celuy qui deffend: $\&$ auffi pour don ner à cógnoiltre qu'il faut viure en paix 
quand ores on feroit forcé de comtre, il faut que ce foit pour deffendre, in pour offendre. A cefte caufe les Roains, encores qu'ils eftimaffent plus le as droict que le gauche, atioient de uftume toutesfois de metrre l'anneau ilitaire à la main gauche, \& noǹ à la oite, qui auoit maniél'efpee: pource e la main gauche eftoit celle qui ait porté le bouclier auec lequell'home fe deffend, fans en faire offenfe à pernne, les gens de guerre ne deuans pas nt s'ayder de l'efpee, qu'ils ne fe ferint auffidu bouclier, principalement c'elt vn chef de guerre, ou capitaine, i doit mourir vieil, combien qu'en vn foin il ne fe doiue efpargner : mais lec la vertu \& hardieffe, qui eft fort commandee à vn Capitaine \& gendare, n'aura pas tant d'e fgard à l'honneur, 'il ne fe foucie de fauuer fa vie, con!e fit le foldat, qui eftant bleffé \& tout ein de playes \& de fang, pour auoir en combatu, \& qu'on luy crioit qu'il allaft, ainfi fanglant comme il eftoit, onftrer au chef d'armee, leur refpond, ais plus tolt au chirurgien, ayant fa fanté 
: VINGT-CINQVIESME fantéen auffi grande recommandatio que l'honneur de la cheualerie qu'il eu peu auoir. Et qu'il eftoit meilleur defa re les cheualiers apres quelque acte ve tueux que les faire auant la bataille. $L_{1}$ autres difoient gue les cheualiers fe $d_{\text {. }}$ uoient pluftoft faire auant la bataill pour l'opinion qu'on a qu'ils en feror meilleur deuoir, comme fut paffé chen: lier par Baiard le grand Roy Françoi: auant qu'entrer en bataille en la iourne de Marignan:qui eft contre ce qu'on ds mande, Le Roy eft il Cheualier. Qu'o doiue donner l'ordre de Cheualeri auant le combat, cela eft confirmé pa l'ancienne practique: car les François \& Anglois eftans vn iour rangez en batail le, paffa deuant le camp François vi Lieure, dont fe fit grande huee parl derriere de l'armee, penfant que ce full commencement de la bataille, dont au cuns lors demanderent cheualerie: mai les deux armees ne faifans rien, furen appellez Cheualiers du Lieure. Mais de manda vn de la Seree à celluy qui auoì acheué ce conte, N'aduint il rien du depuis de finiftre \& mauuais aux François. 
u que le Lieure eft toufiours prins ur vn mauuais prefage, comme il adat à Amurat par vn Lieure qui vint urir à fes pieds, cependant qu'il preit plaifir de voir fauter en l'eau(eftant lieu haut)des Grecs atachez l'vn auec utre deux à deux.Que le lieure foit de umais prefage, c'elt parce qu'il eft rmaphrodite, felon aucuns, \& qu'il $i \ddot{d e}$ fexe tous les ans : \& s'il eft cefte nee manle, l'autre il fera femelle. rfonne ne refpondant à cefte deman, vn de la Seree va dire, le vours prie ne tons plus de la guerre, à fin qu'on ne us reproche en parler comme clercs rmes, \& que ne foyós mócquez com: fut vn Philolophe, lequel en Ephefe f choit le deuoir d'vn grand Capitai, \& commela guerre le deuoit faire: t Hammbal l'ayant efcouté, dit auoir ubeaucoup dhommes vieux qui refient, \& ne fçauoient qu'il difoient, is que ceftuy les paffoit en toute folie rlant fi affeurément, \& en maifre, in mettier duquel il n'auoit l'expence ny l'vfage, \& oùil n'entendoit n. Toute la Serce eftoit muette, de Liuriij. 


\section{VINGT-CINQVIESME}

peur de tomber en la moquerie du $\mathrm{Pl}$ lofophe Ephefien, quand quelqu'vn demender pourquoy les anciens defe doient qüon n'eunt à femer ne cultiv la menthe durant la vuerre. Il luy refpondu que la menthe rend les p fonnes molles \& lafches, \& fi diffoult femence: parquoy on defendoit a gens de guerre, \& à ceux qui vouloic viure chattement, de flairer ny manç de la menthe : encores quil me feml qu'on deuoit pluftoft defendre les fes mes en temps de guerre, lefquelles re dent bien plus les hommes vains $\& r$ i: beciles,quela menthe. On lity repliqi qu’il fe trouue de bons \& vaillans ger darmes, qui n'ont laiffè à eftre fuiets a femmes, \& qui en ont menéà la guer. Mefmesles Romains ménoient par $f_{t}$ les leurs aux lieux où ils alloient faire guerre, principalement quand il eft queftion d'y faire vn long fejour, la ck leur qui rend les hommes hardis, les 1 dans auff luxurieux , l'vin \& l'autre pr cedant de chaleur: car nous voyons I nations les plus belliqueufes eftre $e$ clines aux femmes, \& les aimer. Ceq 
SR R E E. : 32 Poctes ont baillé à entencire, quand sont marié Mars anec Venus. Et eft que dit Arifote, rendant la raifon ourquoy les Lacedemoniens, fe laifient gouuerner à leurs femmes : parce ae les hommes guerriers \& hardis font tenus volontiers fous le joug d'amour. uffi troute l'on qu'vn Capitaine Atheen, nommé Iphicrates, difoit que le on foldat deuoit eftre amoureux, auarieux \&r voluptueux tout enfemble, à 7, dit-il, quil ne ciraigne point de fe izarder aux perils, pour atoir dequoy urnir à fes cupiditez. Que fi le Franis eftoit auff auaricieux quil eft noureux \& voluptueux, ce feroit le eilleur foldat du monde, \& s'il faut gerle bon gendarme parces qualitez, fpagnol lera en danger de l'emporr, eftant fans comparaifon plus auacieux que le François. Noús trouns, adiouftoit-il, que les Carthagiis fe feruans des habitans des ifles Beares, qui font auiourd'huy nom mees aiorca \& Minorca, ne leur bailloient ur leur folde \& falaire, que des fernes \& du vin. Et pour montrer que 


\section{VING T-CI N Q V IES M E}

les foldats font addonnez aux femme cela eft fignifié des Lacedemoniens, ay: mis en leur ville. Venus armee, l'vn n' ftant fans l'autre. Il fut repliqué, que lı Lacedenononiés n'anoient pourtrait $V_{1}$ nus armee, pour möftrer les foldats eft fubjects aux femmes, mas que les Lac demoniens en laguerre contre les $\mathrm{Me}$ feiens, pour n'ofter leur cuiraffe de de fus leur dos, auoyent eu à faire à leu femmes tous armez,dont furent enget drez les Partheniés. Et 鼠 adioufté, qu pour monfter les femmes nauoir ric de commun auec la vaillantife, qu'c troutoit que les hommes facrifians Venus, fe veftoient en femmes, \& $\mathrm{l}$ femmes en hommes, comme voulas demontter que quiconque s'adon par trop au feruice de Venus, s'effemin Que fi les femmes ont ferui à la guerr ce n'eft pas par leur frequentation, ma pluftolt par leur perfuafion : comme fe trouue en Tacite, qui raconte qu quelques batailles defia bien efbranlee \& prentes à tourner le dos, ont efté r mifes fus par les femmes, moyennar leurs prieres, lors que reprefentans 
urs maris le fein tout nud, leur monoient au doigt la feruitude, laquelle ur l'amour d'elles leur deuoit eftre acore plus intolerable. Vous direz ce ue voudrez, repliqua vn de la Seree, du lariage de Mars \& Venus, fi eft ce que i’auois à leuer des gens de guerre, ie ne rendrois pas des effeminez \& fillerets: ais ie choifirois bien pluftoft des gens ades \& ruftiques, des Nomades \& $\mathrm{Pa}$ res, des Bundoliers \& Montagnarts, ue i eftime fur tout les plus puiffans \& ardis, \& qui endurent mieux la peine. Ceux qui habitent l'A rabie, difoit-il, l'ót ié monftré, lefquels n'ont peu encores Ate vaincus par les Turcs leurs yoifins, ombien qu'ils ayent fismonté vne gráe partie du monde enoignee d'eux. Et eit pourquoy Tite Liue louë plus la terilité d'vne contree, que la fertilité, our y auoir de bons foldats : difant que es hómes d'vn paìs gras \& tertile, font ordinairement poltrós \& coüards : mais qu'au contraire la ferilité \& pauureté d'va pais, rend les hommes fobres par neceffité, \& confequemment foigneux: vaillans, vigilans, \& induftrieux :com- 


\section{VING T-CINQVIESM E}

me eftoient les Atheniens, htuez en lie fort infertile; \& comme font auiour d'huy les Suylles, principalement ceu. qui habitent és hautes montagnes d futa, dictes de fainct Claude, de fainct Brigide, \& fainet Godar : qui font plu vaillans que leurs voifins, qu'on appell Valefiés, à caure qu'uils habitét és vąlees n'etans fi hardis que les autres Suyfle qui demenrent aux montagnes, car de regions molles viennent hommes mols parce que ce n'eft le propre, de inefin terre porter fruicts delectables, \& hom mes vaillans à la guerre. Euripide apoel le la Thrace le domicile de Mars, qui ef vn pais fort afpre \& $x$ fterile, \& dit qu'il font fivaillans que quand il tonne, il tirentleurs flefches contre le Ciel, \& menacent lupiter, ne cognoiffans autre Dieu que Mars. Ie ne prendrois pas auff pour bons foldats, adiountoit-il, ceux qui habitent les parties d'Orient, eltans pref que tous timides \& la lches, \& enclins de telle forte aux plaifirs charnels, que peu efchappent qui n'en foient infeAtez, mais ouy bien ceux des parties Seprentrionales lefquels naiffans en pais froid, 
id, font plus forts, \& mefprifans les ngers \&x plaifirs, combien que pluurs tiennét qu'ils ont faict leurs coneftes plus par multitude que par ver\& hardielle. Qu'il ne faille admettre a guerre, difoit-il; les gens coïards \& nideś, Homere l'enfeigne, quád il dit, ce le Roy Agamemnon difpenfa vn rie coiiard d'aller en guerre pour vne onne iument qu' il luy donna. En quoy eut bonne raifon, pource que l'home timide nuit beaucoup, \& fert de peu on feulement en guerre, mais en toute one \& vertueufe action. Langeay nous oprend, va repliquer vn autre, les fignes our cognoiftre les pi jdoines à la guer,celt çu'ils ayét les yeux vifs \& efueil, la tefte droiate, l'eftomach efleué, les paules larges, les bras longs, les doigts orts, le ventre petit, les cuyffes groffes, es iăbes grefles, \& les pieds fecs, pource ule l'hóme ainfi taillé ne peut faillir d'etre agile \& fort, qui font deux qualitez randemét requiles en tout bon foldat. Aufi Caton le vieux difoit, les bóns \& vaillans foldats eftre ceux qui en marchant ne bianflent point les bras. On de-

D 4 
VNGT-C I N V I ES M E

manda puis apres deux queftions: Ia pri miere, pourquoy il ne fe troumoit pli vne infinité de peuple laifrant leur pai $\&$ cherchant nouuelle habitation, con me au temps piffe. Il n'y fut point re. pondu au moins auec bonnes raifon La feconde eftoit, dont venoit ce? grande abondance d'hommes, qui vier des pais froids, pluttoit que des region chaudes. Il fut refpondi, que c'eltoi à caufe que "air n'elt gueres corromp au pairs froid, la corruption de l'air fre quente és paîs chauds, caufant diminu tion de la chaleur naturelle, \& ainf ac celetantia mort. Et î fut adioufté qui ceux qui habitent la partie Septentrio nale n'eltoient gens hardis, mais do gros \& lourd entendement : ce qui le faict hardis, elt l'abondance de fang \& d'efprits, defquels vient la hardief fe: mais la grande humidité qui fait les grands corps, hebete l'efprit. Il elt au contraire de ceux qui habitent le Midy, pource qu'ils ont peu de lang, à caufe de la chaleur du Soleil, qui affeicheles veines, \& confomme les efprits, tellement qu'ils font couards, \& bien peu hardis:

mais 
is ils ont bon entendement, par in chaleur naturelle, laquelle bouillát t'entendement aigu \& leger. le vous e, va dire vn dela Seree, que ie vous ate ce que i'ay leu en Oforius de la erre des Occidentaux contre les $\mathrm{Me}$ ionaux, \& fi cela feroit peur au peuSeptentrional. Il dit quivn peuple terres neufues fir leuer le fiege aux rtugais, pour auoir mis des ruches à el fur les inurailles, \& puis y auoir mis eu. Taciteauff raconte qu'il y a vne cion qui le fait craindre par art \& fain, en portant des efcus noirs, \& ayant corps teints de mefme, \& pour les tailles choififfent les plus noires nuits, portant vin eitonnement par la façon crainte d'vo telle ar mee morttaire: maniere quili ne fe tronue aucun qui wiffe endurer la veuë d'vn fi nouueau infernal appareil, eftant certain que $s$ yeux font les premiers vaincus en us combats. Ie vous laifle à penfer, diit-il , fi ces Montagnards \& Septenionaux, \& 8 mefmes la plus-part des gés e guerre de noftre Europe, ne vouroient pas fçauoir fi ces Farfadets, D 5 


\section{VING T-C I NQVIESM E}

Leuures, Larues, Genies, Manes, Lutiv. font aufi diables quils fe montre. noirs, \& s'ils auroient auffi grand pe dubanquet de Domitian,comme eure ceux qui y furent cóuiez, ainfi que no 'rroumons en Dion hiltorien. Vn mefl Panthilon voyant quil y auoit los temips qu'on n'auoit ris, contre la co ftume cies Serees, fe nuet à parler ain Vous Çauez bien, Mefieurs, que dura: lestroubles, il n'y auoit rien qui fut pl recommandé aux gens de guerre, qr $s^{2}$ accommoder, fibient quion ne le pe oublier durant la paix, tant la couftuin eft vin cruel tyran, \& auli que les ge: de guerre font toufours fouffreteu leurs deniers \& richeffes venăs comn il plait à Dieu, \& s'en allans comme plaift au diable. Tout ira au diable ta! que vous voudrez, va repliquer fon $Z$ ny, mais fien payerons-nous toufrou. la voiture. Panthalon reprenant ou auoit finy, qu'il eltoit mal-ailé de laiff vne couftume, nous va conter qu'en vi de nos paix, il fe trouua vn gouuernel deville, lequel voyant entrer vngenti houme d'allez bonne façon en la ville, 0 
ómandoit, fort bien monté, il le voufaire prifonnier, à fin de s'accomder de fon cheual : luy difant qu'il oit de la religion pretéduë. Ce gentilmme bien efbahy, vademander à ce uterneur, Comment, Monfieur, auósus pas la paix ? Le goumerneur luy pond, ie croy qu'ouy, \& les calices fir. Ceftúy fçachát que vouloit dire cepique fon cheual, \& s'ofte de là. Lors gouuerneur enuoye de fes foldats res luy, leur cómandant expreflément luy amener le cheual, fans offenfer n maiftre. Ils fe mettent hors en deuoir luy ofter fon cheual de force \& iurent ils l'auront. Le maintre du cheual augree en cores plus qu'eux, qu'ils aut pluftolt fa vie que fon cheual, les arolets reiurent qu'ils aurót fa vie \& fon beual.Mais le maiftre du cheual en iutant fe defend fibien d'eux, qu'ils n'euent ne l'vn ne l'autre. Parquoy les folats de ce gouuerneur font commandenent à ce gentil-homme Huguenot de enir parler a leur Capitaine, \& que luy, e les foldats, ne vouloient point de nakaux Huguenots, \& qu'ils ne you- 


\section{I NG T-C I N Q I E S M E}

loient que leur bien. Ce gentil-hour me n'en voulant rien faire, ils retou nent comme ils eftoyent allez : voyant ce gouuerneur que fes gen n'amenoient point le cheual, il le tance bien fort, les appellans chelme \& poltrons. Ec lors vin foldat va dire à c gouuerneur:mort-dicu, mon Capitain qu'eufions-nous fait? Pourquoy luy eu fions-nous ofté fon chenal: Il n'eft poin Hugnenot, iliure \& maugree cucore plus fort que nous? Vae Feffe tondue pour fermer cefte Seree, \& n'entrer plu auant en ces contes trigiques, va dir qu'il ne s'efmerueilloit fi les gens di guerre eftoient mautuais \& fubiects à $l$ : pince, veul qu'il auoit remarqué qu’au iourd'huy les foldats nappelloient ce Ly qui leur commande, mon Capitaine mais mon Cayntene : \& que cela le fai foit penfer qu'ils veulent dire que nom eft venu de Cann, qui fut le premie Capitáne qui fuiuit la guerre, felon que tromuons en lofephe. Auffi, adiouftoit-il ceux qui fuiuent la guerre font $f \mathrm{def}$ bordez, tenant cela de leur premier $\mathrm{Ca}$. fitaine, que les femmes \& filles ne.font point 
int plus affeurees que les autres, pour noins celles qui ont le bruit de fe faieruir à couuert. Et fi me voulez eftter, ie vous en feray vn plaifant conVous fçauez tous, difoit-il, que pluurs ont elté contraints, pour fe fau;, de fe mettre auec les trouppes, fans oir iamais penfé à frapper perfonne, à eftre frappé, perfonne ne pouuant chapper de leurs mains: car au Gibelin us ferez Guelphe, au Guelphe Gibe1. Or vn matin, fuiuant nottre enfeie, nous arriuafmes en vne bourgade, de loing nous entendifmes vn ieune rçon qui crioit à pleine telte: $\mathrm{Ma}$ me, ma mere, fuyez-vous en, voicy les ins- darmes qui prenent \& emmeinent utes les putains:\& fa mere luy refponoit, Va vilain, fuis-ie putain ? Le fils ui aimoit fa mere, lui repliquoit:A tou es aduentures, ma mere, fuyez-vous en. efte femme pourtant, qui en auoit bien eu diautres, tirant vn peu fur l'aage, ne ougea de fa maifon, difant par apres u'ils n'eltoient pas fi mefchans qu'on es faifoit, \& pour le moins qu'ils auoiét ela de bon, qu'ilne mefprifoient \& ne D 7 


\section{NGT-CINQVIES ME}

reiettoient point la vieillefle. Maisc foldats ayant de mal-heur trouué la fi de cefte femme cachee, penfant qu'e fuft du meltier de fa mere, la prefloie fort de fon honneur. Ce que voiant mere, fe mettant à genoux, les prie qu' luy facent tant qu'ils voudront, \& qu' laiffent fa fille. Celuy qui auoit faict conte, ayăt-laiffé rire ceux qui en auoi enuie, pourfuiuant va dire. Le can eftant rompu, quatre ou cinq foldats 6 fe retirant trounerent vn homme qi auoit deux au trois cheuaux (on dit qu c'eftoit vn Medecin ) à quiils demar derent la paffade, \& affeurerent ce Mor fieur qu'ils en auoient bien affaire. L Medecin leurva dire, qu'il falloit prie Dieu \& que Dieu leur aidegoit : Or bie donc, dirent les foldats, mettez pie à terre, \& prions Dieu tous enfem ble :à fin qu'sl nous aide à tous. Eftan defcendus, ils prient tous Dieu de leu aider. La priere achenee, vn des foldat và dire: Or regardons à qui Dieu a li plusaidé, Et ne trouuant en la bourf des feruiteurs de ce Medecin guere. d’argent, le leur laiffe, comme il feit à fe

compa 
mpagnons, difant que Dieu ne leur loit gueres aidé : mais apres auoir vifice Medecin, \& trouuans queDieu luy toit plus aidé qu'à tous les autres, va epartir ceft argent à tous également, fant que puis qu'ils auoient prié tous femble, qu'il falloit que Dieu aidaft itát à l'vn qu'à l'autre. Ie ne veux oulier, adioufta-il encores, de ce que me if ce PhificienMedecin, que ie renconcay vin iour ou deux apres cefte practiue de communité, pource qu'il n'eft as hors du propos de la Seree, lequel alfeura que fi on frotte le bout de l'aruebufe d'vn oignó, \& la corde de l'are, del'arbalefte, à l'endroit où fe pofe la leche, auec du lard, que iamais le plomb y la fleche n'irót droit. Et combien que e fçache, difoit-il, que tout cela ferue utant qu'vn miroir à vn aueugle, fi ne aifferay-ie à l'effayer à la premiere commodité. Le recit du Medecin \& des Soldats donna quelque apprehenfion à ceux de la Seree, (à qui Dieu n'auoit aidé ny efgalement garny les bourfés à l'vin comme à l'autre) de trouner en leur chemin de tels practiqueurs \& de communite: 


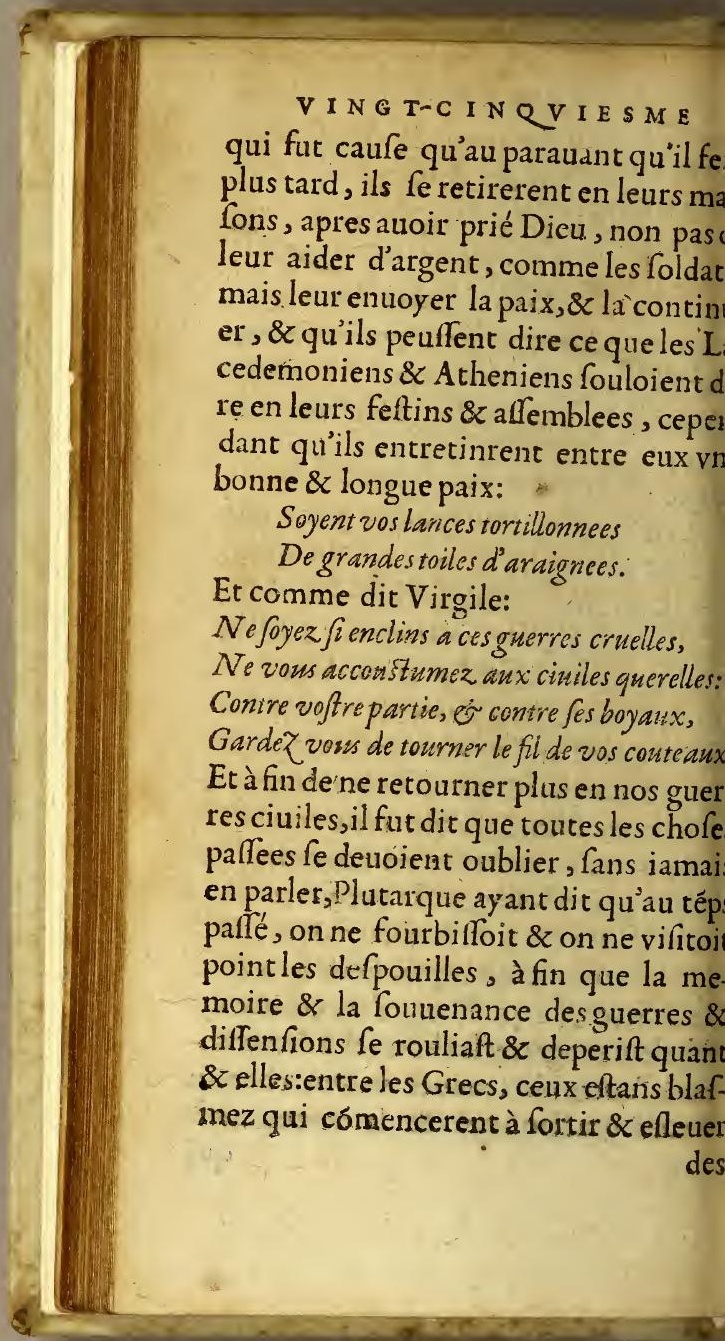


$s$ trophees de pierre dure: Seruius fur rgile, difant que les Anciens ont peint Dieu lanus a deux vifages, pour nous nner à entendre que des quón va à la erre, il faut penfer à la paix.

VINGT-SIXIES ME SER E E. * Desperfunnes groffes ef graffes.

(D) E me trouuay à ce fouper $\&$ à cefte Seree, fans toutesfois y auoir elté uité \& sás crainte d'ếtre appellé mouze,ou voifin Miconien, cóme on nomceux qui vont aux báquets fans eftre nuiez, à caufe que nous practiquions que dit Socrate au Sympore, qu'à la ble des gens fçauans $\&$ vertueux, les ctes $\&$ gens de bien y font toufiours bien venus, encores qu'ilsn'ayent éinuitez. Que fi on mereplique que ne fuis de ceux là, fi eft ce qu'on m'ait appris vn vers Grec de Homere, que yant dit en me mettant àtable, i'ctoois fort Bien receu, \& n'apprins iamais ofe qui m'ait plus feruy. Le vers de omere veut dire( a ce qu' on m'a dit) $V_{1}$ boni non vocati,ad bonorum conuinia accedunt 


\section{VING I-S IXIES $M$}

dunt. Si on replique encores, qu'll peutarriuer vn inconuenient, de ce $q$ polfible il n'y aura pas affez de viun pour tous. Ie relponds, que fi les pi fonnes quï affiftent à ce banquet fo honneltes, ily en aura affez pour tou - sils font autres, il n'y en aura que tro Et puis fion ne fe trouue bien à la tab \& à vn feltin, 1 l eft permis, fans offenl perfonne, de fe leuer, $\&$ de s'en aller, Itant vne fotte fuperfition de penf que laiffer la table auant que la nap foit oftee, porte mal-heur, comme ont Atimé les Anciens, auffi bien comn anciennement on trounoit qu'êt: treize à table eftoit vn mauuais augi re, \& qu'vn des treize ne verroit poiı lebout de l'an, ce qui dure encores al jourd'huy, mefmes entreles plus granc qui font affeoir vn de leurs feruiteur: eftant bien meilleur d'en ofter vn de ce treize. Outre que les doctes \& vertueu eltoient bien venus en nos Serees 8 foupers, nous auions encore cela de bon que ceux qui y eftoient conuiez ne faifoient attendre, eftant vne chofe faf cheufe, \& qui fent trop l'homme qu 
faire du grand, que de fe faire atdre, \& venir long temps apres les auA ce propos, nous lifons que les. ciens, qui nauoient point de maqueux horologes, quand ils conuioient lg!n'vn à fouper, leur difoient à dle ombre du Soleil il falloit fe trou, \& li ils n'en difoiét rien, ceux qu'on itoit leur demandoient à quelle liil falloit venir, à fin de ne venir auát emps, ayant en cela incommodité ar ceux qui appreftent le feitin, ny Ii apres l'heure, de peur de faire atdre, \& celuy quile conuie, \& les con$\mathrm{z}$, qui communement attendent les itez,comme auffi fait celui qui faitle in : car ce feroit fatt en Prince à celui donne le banquet, de n'attendre conuiez : les Anciens ayans efté fi ieux en cescholes, qu'ils ont eftivn grand vice de venir en vn feltin g temps apres les autres, car nous uuons que Policharmus rendant aux neniens raifon de fa vie, fe vante de ieftre iamais faict attendre là où il a inuité, eftant vne reigle fort comne en toutes affemblees, qu'il touche 


\section{VINGT-SIXIES ME}

che aux moindres de fe trouner to iours les premiers à l'affignation, d'au qu'il eft mieux deu au plus apparent fe faire attendre. Mais encores , tout cela fuft practiqué entre nous, $f_{1}$ peut on faire qu'vn des conuiez tre faillift : toutesfois eftát tard, on ne la à fe mettre à table, fans aucune ce monie, comme c'eftoit vne de nos bx nes couftumes. Ainfi que nous efti aux prifes, \& que chacun commenço: máger, ie fius tout efbahy que le mail de la maifonva dire tout haut, Godem \& lors chacun ceffa de manger, demı zans tous comme ftatues. Qui fut eft né ce fut moy, car ie penfois à vinef que cela fe fift pource que i’eftois là . nu fans eftre conuié, à l'autre, ie dif que c'eftoit à caufe que ie tenois la pl: des niais.A la fin,ie dis en moy-mefm voyant que ce feul mot de Godemar auoit rendu immobiles, \& que ce qui ftoit fur la table fe gaftoit, fans que $p$ fonne y touchaft, que Godemar eftoit mot de Magie \& Sorcelerie, lequel efta prononcé on fe trouuoit fibien encha sé qu’on ne pouuoit manger ne boi 
ftre holte me voyant plus efbahy les autres, qui fçauoient bien que loit dire Godemar, me va dire que uy qu'on auoit tant attendu venoit, qu' à cefte caufe, à fin qu'il trouuaft à rger, \& dequoy fouper, il auoit faict demare. Ce dernier venu ayant prins ce, fans que perfonne bougealt de la nne, \&zle Godemare eltancleué, cha$n$ fe prend à ce qu'il aimoit, \& à mancomme ils auoient fait à l'entree de ole. Et me founient que ce dernier vefut fafché quand il veit que perfonne mangeoit pour l'attendre, \& de peur les faire attendre dauantage, il refufa au qu'on luy prefenta pour lauer fes ains, en difant, Ie me fuis laué des le ain, penfant tout incontinent que ie rois laué,ne mettre à table, comme on foit aux Saturnales. En foupant, ie ie noftre hofte, qui eftoit aupres de oy, ou bien i'eftois aupres deluy, de efelercir dont venóit ce mot de faire odemare. Lequel me refpond auoir un en thitoire de Bourgongure le nom l'vn de leurs Roys, qui auoit nom Gomar, \& que ce Roy Godenar fut affailly 


\section{VINGT-SIXIE"SME}

affailly \& furprins en la ville d'Au par Clotaire : \& qu'on n'auoit ian ¿ceuà la verité s'il fut l'a tué, ou s'il chappa, Gaguin alfeurant qu'il fe fau homme vaillant \& hardy entre les $F$ -çois mefmes, qui le craignoient fif qu'en pillant \& faccageant la ville d' tun, ou il fut furprins, au premier br ouy, \& Godemar nommé, chacun la foit à piller, \& tous fufpens preftoys l'oreille, fans ofer rien prendre ne tenter. De façon, me difoit noltre Ate, que par longueur de temps, chof ferieufe eft paffee en ieu, mefmemen la table: où fi quelqu'vn dit Godemar, face Godemare, tous les autres qui fo. à table fe deportent de máger \& de bc re,iufques à ce que le Godemare foit lel $\&$ eftant ofté, chacun eft mis en liber d'acheuer fon repas le Haro de Norma1 die eftant de mefme inuention:car quá deux s'entrebattent \& on crie Haro, s'i. font puis apres quelque force, le $\mathrm{Har}$ eftant crié, c'eft affez pour leur fair perdre la vie, eftant Haro autant à dir commequi, diroit, ha Raoul, où eftes * Fousspurla gande iultice que ce Du vifit?

faifoit. 
foit. M'aiant acheué de conter dont noit faire Godemarě, ce dernierves'excufe à ceux de la compagnie d'ee arriué apres l'heure, remerciant nohofte de ce qu'en fa faueur il auoit t Godemare, \& s'accufant foy-meres, va mettre en auant qu'ilferoit bon faire payer l'amende à celuy qui par apres, eftant inuité, viendroit le derer au conuy, non point de punition rporelle, difoit-il, comme faifoient François à celuy qui fe trouuoit le nnier en leurs affemblees publiques, is de quelque amende pecuniaire, apcable à la bucolique, \&z au mafquaret. ut repliqué à cela, que ce n'etoit pas raifon que celuy qui venoit apres les tres fult taxé, mais qu'il faudroit istolt mulzter les premiers venus atz upper, comme les plus friands, \& urans viftement:à la fouppe, ayant and peur de ne trouuer rien, lefquels at femblables aux parafites, qui ne fonnt quà l'ombre folaire pourlemoins dix pieds, tant ils ont grand peur de illir au banquet. Il fut refpondu tout contraile, \& que le dernier venu eftoit bien 


\section{VING T-S I XIES M E}

bien plus fuiet à fa bouche, que cel qui vient des premiers, le dernier ve ayant des affaires qui le retardoier oubliant tout ne laife pour cela à y nir, \& eftant tard, il s sauance \& cot plus à la fouppe, que celuy qui vient premier, lequel pe laiffant point fes a faires, $y$ vient à loifir:ayant ceft aduant ge le premier venu, de fe mettre à tab où bon luy femblera, d'autant qu'il s'o ferwoit en nos Serees \& feftins, que ch cun prenoit fa place à la table, fans cer monie, \& fans attédre le nomenclator d Latins, ne fon roolle:n'y ayantrien nos banquets qui oftaft plus la confuf $\&$ defordre, que ce bon ordre : l'a my qu nous bailloit à foupper, recevant to les amis efgallement, \& les faifant tor pareils, fi ce n'eftoit qu'vn Sophifte 1 voulant mettre aupres d'vn autre: ca le maitre du feltin n'enduroit iamaj deux Sophiftes fe mettre à table l'vn có tre l'autre,à l'imitatió des anciens. Tou tesfois, encores que le mailtre de la mai fon n'eut point l'ennuy de bailler le places aux conuiez felon leurs qualitez il ne laiffoit pourtant à refpecter le eftran 
$S \in \mathbb{R} E$.

angers fur tout, les gens vieux,mala\& \& mal-aifez, \& les femmes grofles, on mertoir en la place la plus comde, comme noftre holte fit en cefte ee à l'endroit d'vnefemme enceinte, quelle on eut efgard, ainfi qu'enten$z$, l'ayánt fceu, vous iugerez la caufe ir laquelle on parla en celte Seree des fonnes groffez \&r graffes, defquelles it noftre hofte. Or fçachez que dés commencement du foupper noltre te aduifa qu'vne femme groffe n'etgueres à fon aife affife a la table, qui it trop haute, parquoy c mmanda à de fes gens d'apporter vn tabouret, Ir mettre fous les pieds de cefte femgrofle, nollte hofte eftumant la moidu repas eftre áfís bien à table à fon . Ce feruiteut fuifant du bon valer, \& nime le feruitenr du diable, qui fait is qu'on ne liry commande, apporte ix tabourets, \&x en met l'vn fous les ds de fon mailfre, \& l'autre fous les ds de la femme enceinte. Son maiftre sluy dit, ce n'elt pas pour moy, c'eft ur cefte femme groffe que je demande tabouret. Pardônez moy, va dire fon Liu.iij. 


\section{VING T-S I XIES M E}

feruiteur, vous en auez plus de befoi qu'elle n'a, car vous auez le ventre $p$ grand. La femme grofle alors fe pr tant à rire, que nous auions grand pe encores plus noltre holte, que de for de rire la chaleur eltant augmentee, dilataft tous les conduits, \& deffer tous les cotyledons. Les tables leu felon ce quien dit Sulprcius, qui ne v pas qu'on laille les tables, ains quion leue,on ne parla que des perfonnes gr fes \& gralles. Le premier qui en parli, foit que les persónes chargees de grai \& fort grolies eftoient gens de bie monfrans à tout le monde bon vifa aimans à rire $\&$ faire bonne chere, $c 0$ uertiffans rout ce qu'ils mangét en far qui elt la vraye pafture de ioyeufeté, th moing le Roy Loys onziefme, lequ fetoya les Anglois à Aniens, a l'ande ie ne fcay combien de gros homm choifis, qui beimoient foubs la por feitoyans les eftrangers, \& leurs tena tableronde \& ounerte t̀ toutes fins, leur portant fort bon vilige. Que gras foient bonnes gens, cela ef́ co fumé par vn Conful de village, lequ 
ant delegué par ceux du bourg pour er choifir vin bon prefcheur, homme bien, \& Sçauát, luy qui eftoit boucher, nntra que les gras, à fon aduis eftoient meilleurs \& plus doctes, comme i'ay uuué en vin peticliure:

Vn boucher Conful de village

Fut enuoyéloing pour cercher

Vn prifshetir, tocte perfonnage, Quivient en Carcjme profcher:

On en fit de liny approcher

Demy douzaine, n vn conuent,

Lepliz gras fut prins du boucher

Cuidant quìil fuff le plus Scanant.

attre qui parla des perfonnes groffes graffes, en diet encores plus de bien, iftenant telles gens eftre fans aucune arice $\&$ enuie, inay ans point vne cho. en la bouche, \& l'autre au cour, come ont les maigres, affeichez, baza$z$, iz melancholiques : Erafine apllant en fes Chiliades vn homme de en 2 unadratus homo. Ce que Cefar donbien à entšdre, difoit ceftuy-cy, quăd dit quil ne craignoit point ni Antoi, ni Dolabella, lefguels eftoient gros gras, mais ouy bien Cafie \&6 Brute, E 2 


\section{VINGT-S IXIESME}

maigres \& defnuez de chair \& $\&$ grailf à celte caufe les Gordiens eflifoiet pour leur Roy, le plus gros \& le pli gras qui fe pounoit trouuer entr'eu: ingeans par le dehors ce qui peut eft dedans. Lors quelqu'vn de la Seree demander, $N$ e feroit-ce point la cau pour laquelle les Allemans \& Suylle cóme autresfois les Scythes \& Thrace Cont appellez pour la garde des Rois Princes? Non que ces Princes fe defie dela fidelite de leurfubjects, non pl que de leur force \& hardielfe: nais pai ce qu'ils voyent qu'en celte grolle grande malle de chair, 1 n'y a pas beat coup de malice \& de finelle, n'ayant pa grand efprit pour conduire yne me chanceré \& trahifon, à caufe que la grol feur du corps diminue \& opprime beau coup l'efptit des perfonies giolies \& grafles, les Philofophes ayans forit,qu pinguis venterning generat fenfirmonuem, 8 aufi qu'Avitote dir, qu'il y a moins d chait en la telte de l'homme (nù toutel force du iugemác $\&$ de la raifon ent) qu en la tefte de tous les autres animaux frifancproportió geometrique del'vn 


$$
S E R E E \text {. }
$$

'autre:tout cela eftant cófirmé par Pliqui dit que les gés gras font de lourd prit, mais auff qu'ils sót plus apperts \& oins fimu'ez yue les chiches-faces , \& ie-froidure de mingrelins \& affechez malice. Vn Franc-à-tripe alors nous faire foutuenir de la mort d'vn de fes jifins, des plus gras \& caillez de fa ruë, auffle neilleur \& plusioyeux, qui ruoit beaucoup à toute noftre ville à feigner liberalement ou eftoit le bon. in, \& ò il faifoit feur, parquoy eftant gretté de tous les gens de bien, ils fuent contraincts de dire que l'horologe e leur eftoit pas fi neceffaire que cent omme de bien, qui leut enfeignoit où emeuroit ceft hóme qu'ils cerchoient, ins que perfonney funt tropé. Parquoy fut honoré d'vn Epitaphe fort gaillard: rais il ne me fouvient que des deux deriers verfets, ou ily a:

Marris en furent fos voifins.

Car ilenfeignoit les bons vins.

In Medecin qui eftoit en cefte Seree, a lieu que nous penfions qu'il deuft endre raifon pourquoy les perfonnes rolfes \& grafles fe plaifent plus à eltre E 3 


\section{VINGT-SIXIES ME}

fouldats \& gens-darmes qu'à commas der, \& eftre grands feigneurs, eftans fid les \& fans fard, va commencer à difcol rir dont venoit la graifie des gens gra en difant qu'elle eftoit faite de la pls groffe partie onctueufe du fang, con me de caufe materielle, \& que Pefficier te eftoit la froideur, qui cailloit ceft onctuofité de fang, eftant fortic hors de vafes. Vn Phy ficien, lequel aufie eftoite cefte Seree, luy va demander, dont vier donc qu'au cour, là où eft le principald noltre chaleur, il s'engendre de la graiffe Noftre Medecin luy va refpondre, qu cela fe faifoit par la froideur de l'air qu nous attirons pour rafraif chir les efprit vitaux qui font en nous, \& pour modere la chaleur de noftre cœur. Lors noftr Phificien luy repliqua, le vous prie no vous couurir d'vn fac mouillé, de peu de vous morfondre, \& refpódre à ce que dit Monfieur Ioubert contre Galien, \& contre toute voltre efchole de Medecine, que la graiffe ne vient pas de froid, ou par faute de chaleur : mais que pluftolt c'eft la chaleur qui fepare la portion aëree \& huileufe dufang, ¿r la mouue $\& \operatorname{tran}$ 
tranfporte çà \& là en forme d'vne otle \& ef poulle vapeur, iufques à tant ¿elle s'ar. efte \& efpoiffiffe en la denfides membranes, \& non pas que de ur froideur elle fe concree \& forme grailfe, les parties fpermatiques ayans aucoup pius de chaleur que les fanines, ce dit Monfieur loubert, conla commune. Le Medecin demelirát urt, cela n'eftant point en fon $\bar{V}$ ade $m e-$ $m$, \& n'ayant iamais ven recepte où il ntraft de telles drogues \& marchandis, en lieu de refpondre, il va dire qu'il e falloit pas fi aifément reprendre les nciens, \& v ne commune opinion fouenuë par gens doctes \& fçaunis. Ce ue balla, difoit-il, à cognoiftre Ciceró, ui aima beaucoup mieux quon mit au emple de Pompee, Terr.Conful,ou I.l.I. Conful, que Tertium Conful, de peur le condamner toute l'antiquité , \& eaucoup des plus doctes de Rome, qui unoient toufiours dict Tertio Conful. Voltre Medecin penfant honneftemen: e retirer,fur interrogé s'il fçauoit poins que c'eftoit que gladiatoria $\int a g$ ina:mais il demanda terme pour en venir, \& iur-

E 4 


\section{VIN G T-SIXIE S M E}

ques à ce qu'il euft veu Lipfius en fes $S$ turnales, Il y auoit en celte Seree desf mes qui s endormoient, ne prenăs poi de plailir à ces difputes, n'y entendal rien, parquoy on fut contraint, pour efueiller, de mettre en auant des vier contes de la Cigoigne, qui parloient di groffes \& grafies perfonnes, lefquels ront noutueaux, pour le moins, à ceu qui ne les fçauent : car qui eft celuy qu fcache tout? M'amie, commençe à dir quelqu'vn, il y auoit vne fois vn moyn bien gros \& gras, y eftans fubjets à cauf qu'ils viuent oifeux : ie croy bien m'amie, que quand il alloit par la ville les femmes eltans toufious apres luy demandoient à ce fratre: Et bien beaupere, quand accoucherez-vous ? Et i] leur refpondoit, Quand i'auray trouué vne fage femme. Or il arriua, adiouftoit-il, que ce mefme ventre omnipotent fe met à piffer en belle ruë : mais parce qu'à caufe de fon ventre il n'approchoit gueres de la muraille, il monfroit tout ce qu'il portoit, \& auffi que ne voyant point foncas, il penfoit que perfonne $\mathrm{n}$ s'eut fceu voir. Les fem- 
es le voyant ainfi piffer, ne fe pouient tenir de rire, \& de luy dire, vous rez tantoft où vous voulez aller, car us auez prins le plus court.L'autre luy foit, Beau-pere,puis que vous auez, \& nez du menu, ie vous prie me bailler change d'vn cfcu. Ce gros ventru fe utantbien qui les faifoitainf rire, fe urnant vers ces femmes, leur va dire, commandez-moy bien à luy, il y a deflong temps que ie ne le vy, que le grăd. able qui vous fait rire, vous puiffe cner dedans le corps. Mais entre ces femes qui regardoient piffer ce beau-pere s'en troutia vne moins folle que les alies, quiluy va dire, Hé! Morifieur,catez voftre pautieté. Et de vray elle we entoit point : car ces gens gros \& gras font bien pauures. Celuy qui auoit ict ce conte, voulant rendre la raifon ourquoy les perfonnes grolfes \& graf. $s$ font mal emmanchees, fut empefché Ir les Dames qui effoiét en cefte Seree, i iurerent leur grand ferment de s'en ler, fi on parloit d'autre chofe : fe contant de dire, que fuituát le racourcifleent ou allongrffement du nombril, te E 5 


\section{VING T-S I XIES ME}

membre tant de l'homme que dela fer me deuientlong ou court. Lors vne fer me de la Seree, fage \& bien apprinfe, f: fant femblent de n'auoir rien ouy, \& r uenant à ce beau-pere, qui piffoit en bs le ruë, va dire que cela ne eftoit point $h$ nefte ne beau de piffer par les ruës, que les Turcs le troutuoient fcandaleu \& en eftoient honteux, fi de force ille arriuoit, \& que mefmes les Romain exemplatres de toutes bonnes chofe auoient certains lieux, où il y auoit $\mathrm{d}$ vaiffeaux és carrefours des rues, pour apprefter à piffer aux palfants, fans eft veus, la où ils deflachoient à couvert $\mathrm{c}$ me les pifoles dẹ Brunfuich. Et fi cel femme nous apprint, que pour refair \& raccoufter ces vaiffeaux, Vefpafia mit vne dace \& vn tr but fur Rome,no passdifoit-clle, comme plufieurs ont di que ce fut fur l'vrine. Vne Feffe tondu $s^{3}$ addreffant à cefte femme, luy va dir gu'il y auoit des femmes auffi groffes: graffes que des hommes, $8 z$ qui aimer anffr bien à rire, \& à dire le mot, \& re pondre auffi gaillardement qu'ils fçal

*olentfaire. Qu il foit ainfi, difoit-y 
$S E R$ E E. contez, qu'il n'y a pas long temps que rencontray vne femme hi graffe, \& $\mathrm{fi}$ eine, que ie ne me peux contenir's yant quelle me portoit $\mathrm{h}$ bon vifa,de luy demander, combien il y auoit elle n'auoit veu fon noc, ime doutant en que ie ne ferois pas fans refponfe, s perfonnes fraifches \& caillees eftant illards \& iouialles. Cefte femme fe utant bien que ie voulois rire, me va re: Parmon ame, Monfieur mon amy, y a plus de fix ans que ie ne l'ay veu : Ie ous prie, luy dis-ie, quád vous le verrez, merecommander bien à luy . Ouy en me foy, me refpondit-elle, ie ne fey faute à vous y recommander, \& à in voifin par le marché. On ma dit deais, adiouftoit-il encores, qu'elle eftoit ariee à vn homme aflez vieux, \&zauffi tas qu'ellé, \& que tous les jours, fans onfideration quelconque, il difoit à femme, que leur clerc etoit bon à ler fur la mer, eftant bien enuitaillé. Il y difojt fi foutuent qu'elle eut vn iou auie d'en fçauoir la verité, penfant que m mary futt allé aux champs : mais fe outant de 1 a femine qui le preffoit it 
VING I S I XIESM :

fort d'y aller, 1 l fe cacha en fa maifor où il veid que fa femme força le clerco luy montrer fon aiguille, qui eftoit $\mathrm{ft}$ le midy, ce qu'il fit, à la condition que maiftrefle luy montreroit fon quadras Le clerc va lors dire à madame : Ie vot prie que les facions baifer l'vn l'autr. Le mary qui s'eftoit caché, ayant veu? ouy tont cela, en fortant va dire, c'eft a fez de fe voir, fans faire autre approch Ayant chaffé fon clerc, \& fa femme s ftant affeuree de ce que fon mary luy : noit tint de fois dit fans ancune railor on the laifla a dire, que ce maittre, er cores guill fut gros \& gras, ne laifo a anoir rn beau membre, mais que fo derc le portoit. Le maiftre de la maifo qui eftoit des plus gras, \& 2 pour ceft caure on le nommoit l'enfant caillé, $v$ demander à fon Medecin Rondibili aufin gras \& caillé que luy, s'il y àuó point moien de le pounoir amaigr tant parce que les femmes n'aimer gueres ces ventrus, commen'eftăs gui res aptes à la generation, pour auoir I membre petit, \& par faute d'efprits \& de fenerice, Atifote difát qque tout ani 
S E RE E.

a qui eft fort gras a peu de femence, le pour eftre plus fubjects à maladies ie les autres' car nayans ces perfonnes affes gueres de fang, elles font plus oleftees \& de chaleur \& de froideur, re ceux qui font margres: \& par confelant de moindre vie, mefmes qu'onles jit mourir fubitement dés leur ieunef, à caufe que ces graffets \& douillets at les arteres tellement eftroictes \& flerrees par la graiffé, que l'air \& l'efritn'y peutuent librament paffer, dont aduient que la chaleur naturelle, n'aát ancune refrigeratió de l'air, par fore s'auortit \&c efteint. Rondibilis baillát on courage à noftre hofte luy refpond, u'il eftoit bien pl us facile d'amaigrir vn orps gras, que d'en engreffer vn maigre, noyentmant que ce corps foit maigre de thaleur \& ficcité naturelle, parce que tous poutons facilement ofter quelque chofe a nature, eftant bien plus difficile d'y adioufter, \& fi faut beaticoup plus de temps à humecter qu'à deffecher. Alors vin dela Seree demanda à Rondibilis.s sil wouldroit eiatreprendre d'ofter la grailfe d nottre hofte, veu que la graiffe ñ athE ? 


\section{VING T-S I XIES M E}

cun fentiment en quelque animal qu ce foit, $n$ 'ayant ny veines ny arteres, $L$

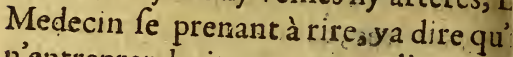
n'entreprendroit pas vne telle chof mais qu'il luy diroit bien pourquoy eftoit plus gras au vétre qu'en autre par du corps, à caufe que le ventre eft plu voifin de l'eftomac où fe fait la digeftió Si elt-ce, fut-il repliqué, que nous trou uons quivn Lucius Apronius, ayantv fils fi gras qu'il ne pouuoitbouger d'vi lieu; tant eltoit pefant de graifle, luy fi defcharger le corps, \& luy fir feulemen laiffer la graiffe qui luy eftoit neceffair pour viure, Rondibilis n'en voulát rien croire, va s'addrelfer à noftre holte, qu'ó appelloit l'enfant caillé, \& luy va dire, puis qu'ettes, marié, il elt bon qu'ayez fouuent affaire à voltre femme, $n^{3} y$ ay ant chofe $q$ ii delfeche $\&$ amegriffe plus que cela, que fi elle eft maigre encores mieux, car elle attirera toute voltre graiffe, tout au contraire de la perdris qui s'engraiffe à couurir la femelle. Et me doute bien, difoit-il encores à noltre holte, que fi voltre femme veut dire verité, elle dira que fi vous l'eufliez voulu croire, vous 


\section{$S E R$ E}

fuffiez pas la moitié fi gras que vous es, \& luy confeille, fi elle vous aime, voltre fanté, de mettre peine que par moyen vous puiffiez laiffer de voltre aiffe, n'eftant pas la premiere recepte i i'ay baillee aux feinmes qui auoient urs maris outrez de greffe, qu'elles ont en retenue, \& fait practiquer à leurs aris, aumoins celles qui les aimoient éfort, difans à leurs maris, fçauez vous as bien que le Medecin a dit? Penfes ous, difent elles à leurs maris, qu'ō vous feille cela pour noitre plaifir?nous no? ucions bien d'vne fi belle befongne. Si ous ne voulez nous croire, vous vous trouuerez mal, \& $z$ nous auffi:car vous euiédrez fi gras \& replets; que la graiffe ous eftoufera, \& Dieu fçait, difent eles à leurs maris en pleurant, fi ie viuray ong temps apres vous! Noltre hofte outefois, à qui on parloit, fe ckefendoit l'ordonnance de Solon, qui n'oblige e mary d'aller veoir fa femme que trois ois le mois. Cefte f̧̧aulante femme qui eftoit meflee de reprendre ceux qui tóent de l'eau en la ruè deuát tout le mondesva repliquer au mailtre de la maifon 


\section{VING T-SIXIESME}

qui s'excufoit par la Loy de Solö́,qu'e ne s'entendoit pour la volupté, \& qu'، n'en fçauroit dóner de reigle: mais qu vouloit que trois fois le mois on reno uelaft l'alliance des nopces par les pr pos que l'on s'entretient en telle carel \& vifitation, ainfi comme lesvilles $\mathrm{r}$ nouuellent par interualles de tempsl, alliáces qu'elles ont les vnes auec les a tres. Celuy où eftoit la Seree ne pouua rien repliquer à cela,va dire haut $\&$ cla qu'on ne luy en parlaft plus, \& ques' deuoit creuer de graille, il ne fçauroit faire dauantage. Rondibilis continuan fon premier propos, va dire qu'il falloi marier les enfans gras \& caillez bie jeunes, fil'on auoit peur qu'ils deuinflé trop gros, l'embraffement des femme les rédans maigres, \& aufil que le foucy qui le plus foument eft compagnon di mariage, deffeche le corps, \& empef ch le dormir, le veiller corrompant la nature du corps par froideur \& ficcité, \& fi engendre la cholere qui deffeche fort Et fur tout de peur d'engraiffer, il fe faut garder de dormir la graffe matinee : car il n'y a rien qui noumrifle plus la graiffe à 
ufe que le dormir fauorit plus la fecócoetion (qui eft generatiue du fang, quel prouient la graifle, qui fe fait au tin) que la premiere, qui fe fait au foir ribien que s'aller coucher fur fa vian\& la digerer en dormant, engraiffe t. Il faut auffi, difoit noltre Medecin, e ceux quí ont peur d'engraifler mandes viandes où 1 ls ne prenét pas grand etit : car ce qu'on mange fans gouf, nourriffant gueres, defleche: comme If faict ce qu'on mange qui engengros fang, \& tout ce qui eft chaud $\& z$ toutes ces viandes deffechans les huurs, fi on endure tant que l'on pourra oif, car les chofes graffes \& douces, uelles on prend plaifir, \& boire fou, engraiffent bien fort. Aucuns ont , adiouftoit-il, que le fourmage vieil falé emmaigriffoitla perfonne, auffi $n$ que les fueilles de freine, fi elles t broiees \& prinfes en vin. Les autres alfeuré que tout ce qui eft laxatif prouoque les vrines, eftant chaud \& , deffeche grandement, rendans les s, maigres, auffi bien que la medelaxatiue foument repetee, qui diminuë 


\section{VINGT-SIXIES ME}

nuëla digeftió. Il en y a, difoit-il encor qui afferment qu'il n'y a rien plus fo uerain pour empelcher la graifle, que xercice fur en trauail, \& au Soleil, \& temps chud, ayant grand faim \& gra. foif, le corps le deffechant par la gra de exhalation des efprits : ce que fai l'huile de noix, fi on s'en frotte auec $c$ linges qui aurót recueilli la rofee:car 1 a reftraindra \& refferrera la trop de ch nure \& corpulence : cóme auffi il pe eire que prendre tous les iours chem blanche amaigrit bien fort. Ceux-de Seree alors fe prindrent à rire de noft Me lecin ,lequel fuiuant Epicurus,auc touliours fon, on dit, fon, il peut eft fans rien affeurer. Ce qui fut caufe qu parla autrement \& prenant Card pour garent, va dire qu' il auoit laiffé $p$ efrit,qu'vn Roy d'Efpagne eftant fi gr qu'il fe farchoit de viure, appella vn m decin Africain, lequel le guerit auec femence de lingua c nis cóme il luy fen ble. Et puis alleguant loubert, il mit auant que le ris augmentoit la graiffe, que ceux qui craignent de deuenir tro replets fe doiuent garder de rire, tai 
Is pourront, le ris dilatant les porres, fchaufant le corps, rarefie toute fa Ge, \& par cela le fang eftant attenué ondu, il eft aifement refolu en grofle eur, dont vient la graiffe : 8 auffi que is exceffif eft plus dommageable aux s qu'aux maigres, à caulé qu'il fait aft \& diffipation d'efprits, defquels gras ont petite prouifion, \& ainfi fament la chaleur naturelle \& les efis peuluent eftre fuffoquez \& eftoupar vie compreffion \& furcharge. is demanda noftre hoite, qui eftoit olifimus vir, quand i'auray faict vne tie de ces receptes/ car ie ne fçaurois tantage practiquer celle qui dis qu'il on d'auoir foutuent affaire à ma fem) \& que par icelles ie deuienne mai,y aura-il point en moy mutation umeur \& de complexió? A u lieu que me à me tenir ioyeux $\&$ dehet, $\&$ que rés le meilleur ieu que ie me puis dó$\therefore$, deuiendray-ie point chagrin, faux, auaricieux \& melancholique:Au 1 que les compagnies me font viure, urray-ie point tout feul en les fuiant? te fi l'efprit \& temparature fe mië auec 
VING T-S I XIES M E auec le corps, mes complexions fe cha geans à leur contraire, $i$ aime mieux menrer ainf que ie fuis, \& faire bon vie \& courte, que de languir \& viure temps. Et qu'on fe mocque, tant qu' voudra de moy \& $z$ de mit pance, ie tiendray tant que ie pourray gaillard ioyeux, n'y ayantrien qui tant excite chaleur naturelle, ne qui tant temp les efprits \& les purifie, ne qui tant robore la verru, que la ioye, Ce n'eft de maintenant, repliqua quelqu'v quion fe raille des perfonnes groffes grafles, car nous trouuons, \& c cela eft: fez commun, qu'il fe prefenta au trib nal des harangues vn fort gros \& gt homme, pour perfuader aux Athenie la paix $\&$ concorde entre cux: mais qu ils virent ce gros bouffare, \& 2 trompet du iugement, en chaire, ils fe prindre tant à rire qu'il ne pouuoit eftre efcoul Prenant fon argument de ce de quoy rioyent, il commença à leurs dire. I' chez nous ma femme, qui eft encor plus grolle \& $z$ grafle que moy, fi vous l' uiez veuë, il y auroit bien àrire d'aua tage, mais ie vous dirai, quád elle $8 \mathrm{~m}$ fomm 
mes d'accord, \& en bonne paix, nous s rangeons bien en mefme lit, que if is formmes en noife \& debat, nous ne unons nous ranger $\&$ demeurer en mefme maifon: les Atheniens endirent bien ce que ce gros homme loit dire, \& iugerent de luy que la iffe ne luy auoit aucunement fuffofon efprit. Vn de la Seree va dire les gens gras eftoient cómunement eux, prenans en bonne part ce qu'on d'eux, eltans auec cela raillards, moeurs, \& gaudiffeurs, fi on s'adreffe à , ne pouuans gueres faire autre choQúlil fo tainfi, difoit-il, regardez Courtifan, la replique d'vn gros hom, auquel on dit eftant à cheual, en ennt en vne ville, vous faites au contraide tous les autres, vous portez voftre Hle par le deuant, quád il leur réfpond, fait ainfi en la terre des larrós. Notez fil la refponfe que fit le confeffeur du y Loys douziefme à vn Legat, lequel yant ce confeffeur s'endormir,va dire Roy, Sire, regardez comme voftre urceail prend fes aifes. Le confeffeur, cores qu'il fuft bien gras, ne dormoit 


\section{VINGT-SIXIESME}

pas fi ferme qu'il ne repliqualt, I'ait mieux eftre pourceau qu'afne. Quelq autre de la Seree affez gras, prenant parolle, \& defendant fon party, diff qu'eftre gras de bonne forte denotoit vie affez longue, pour autant que $r$ ture n'engendroit point la graifle fint apres qu elle auoit reftauré \& nourry] autres membres, n'eftant la graiffe vne fuperfluité de fon propre nourriff ment, \& auffs que les gens maigres fo. facilement offenfez par lechaud \& $p$ le froid, leurs membres n'eftans guer couuerts contre les iniures externes, $q$ ? s'il fe trouue des persónes graffes \& ple nes qui craignent le froid (combien qu toute greffe foit chaude) cela procede $c$ ce que les membres externes font bie efloignez de la chaleur du dedás, à cau de l'efperfeur de ce gros corps: \& encos adiouftoit-il, que les gros \& gras foier plus fuiets aux caufes \& maladies inter nes que les maigres, comme aux fieure. aux oppilations, aux defluxiơs, catharr \&zapofthemes, à caufe des conúuits qu font oppilez \& eftoupez, toutefois, en cores fait-il beaucoup mieux voir vn 
air gralfe \& fraifche, qu'vne defchar, aumoins ce dit vn grand maraut de eux, qui eft en celte ville quafi tout $d$, lequel aime mieux tout manger \& ire, \&z fe tenir frais \& caillé, \& en bon int, que de fe veftir, que fi on le repréd cela, il refpond, puis que Dieu veut e ie montre ainfi le cul \&les felles, ime mieux qu'on les voye graffes \& aictes, que maigres $\&$ affechees. Vne Ce-tondue de peur de s'endormir nous affeurer d'auoir veu vn homme fi is que iamais on nele peutfáire enr en la prifon par la porte, toutefois fut pas fi pefant qu'il ne s'ofaft du min, cependant qu'on difputoit s'il loit demolir deux ou trois portes de la fon pour le faire entrer : \& comme tuy-cy, adiouftoit-il, ne pounoit entrer la prifon par les portes, i'en ay veu vin re qui y eftoitbien entré, mais eftát dedás prifonnier, eftoit deuenti figros fras, quon ne le fceut iamais taire tir de la prifon par la porte où il eftoit Et combien que les prifonniers yent point la peine \& le foucy de ferr les portes, on ne les fermoit point à celtuy. 


\section{VING T-S I XIES M.E}

ceftuy-cy, fa prifon demeurant iour nuict outerte : la difpute eftant grand luy eftant eflargy, aux defpens de qui romproit les portes pour le faire forti Dás les hiftoires prodigieufes, il fe trol ue vn grand $T y r a n$, lequel deuint $f$ ig \& montrueux qu'il n'ofoit fe manif Iter au peuple, de peur d'eftre moqué: demeurant ainfi reclus, il enfla fi biens graiffe qu'il eftoit cótraint iour $\&$ nuì fe faire appliquer des fangfues fur membres, pour luy tirer l'humeur qui rendoit's'i gras, autrement il euft èttouf Galien efcrit le femblable d'vn Nich machus Smyrnien, lequel deuint fi gra qu'il nefe pounoit remuer. On dit aut que Maximin Empereur fut $f i c h a r g e ́ c$ cuifine, qu'il euft bien fait tournerv moulin à vent de force de fouffler, qu'il auoit couftumierement deux hor mes deuant luy pour luy porter le ver tre, \& deuindrétauec le temps fes men bres fi chargez de graiffe, que les bract lets de fa femme luy feruoient d'at neapxà fes doigts. I'ay vn mien voifit va dire vn Drolle, qu'on nóme l'enfar caillé, lequel comme on luy reprocho 
$S E R E$.

iour qu'il eftoit trop gras, va refponque feroit-ce dóc fi je couchois tout l:Mais il luy fut repliqué, tu ne ferois figras, car tu mourrois de faim, d'aut quijl auoit efpoufévne vielle femqui le nourriffoit \& l'étretenoit aina bon poinct,à cefte caufe quand ceft ant caillé fe maria, on ne difoit point, tel c'eft marié, mais on difoit-il s'eft a nourrice. Si eft-ce, luy fut-il repli, que les vielles femmes \& feiches ne ireffent gueres à ces grands ventres, font flacques \& mols, \& pleins de its, ce qui me fait efbahir de ce que hommes quiveulent apparoiftre gailis, \& fe veulent marier, embourrent r ventre de cinq ou fix lizures de cotó, que les femmes n'aiment pas ces fies pances, \& que nous monftrós par veftemens que nous ne fommes ny is foldats de Mars ne de Venus, delát en nous tous les fignes qu'on cerpour eftre propres à ces guerres. Et fi c cela, nous fommes defceints, \& fans nture, \& d'ancienneté ceux qui n'eent point ceinturez eftoient reptmols, lafches \& coiiards, \& ceux Liu.iij. 
VINGT-S I XIES M E qui eftoient bien ferrez \& ceints, eftoie eftimez courageux $\&$ gens de guerre, centure eftant prife pour la force $\& v$ tu, parce que celuy qui eft ceint, mieux appoinct \& libre pour fai quelque chofe, que le defceint. $R$ gardez, ie vous prie, adiouftoit-il col bien nous fommes variables \& inco Itans, veu qu'au vieux temps des Ga lois, leurs Magittrats anoient vne cei ture, que fi elle ne pounoit ceintur quelqu'vn, celuy-la eftoit deietté mefprifé de tous. Et Cefar dit en fes $C$ mentaires,que les Gaulois portoient ! accouftremés vnis \& preffez fur le cor rapportans la propotion \& beauté d membres au contraire des Allemans, 9 portoient leurs habillemens amples larges. Et maintenant c'eft toute la gra d'eftre bien vétru, tant foyons-nous ie nes. Encores sils y auoir quelque cor modité en s'habillant en ceitte forte, ie trouuerois bon, mais ie ne fçay comn l'Efté ils peuuent durer,eftans enuelopi entre du coton, quils ne foient cuits fuffoquez par trop grande chaleur. $Q_{1}$ finous regardons côme les Grecs fe go uer noien 
$S$ E R E E.

noient, les Lacedemoniens haiffoiêt it ces grolfes bedaines, quils firent des $x$ contre ceux qui auoiét le corps trop s \& gras,çar il falloit que ceux qu'on. elloit Ephébi, c'eft à dire adolef cés, fe infraffent tous nuds deuant les Ephoque fi on les trouuoit par trop bonne ere \& oy fiueté trop chargez de graiffe, les puniffoit, auffi bien que faifoient Romains, lefquels priuoient de chel'homme d'armes trop gras. Vn aude la Seree, s'accordant auec celtuycoinmença à dire:le me fuiș founent hy comme la plus grand' part des inçois, \& des plus nobles, \& des plus hes, \& des pauures, a peu endurer \& $\&$ tter fi grand charge \& embourrement leurs ventres, \& qu'ils ne fé foiét pluft enbaltez \& embourrez par le derric\& furl'efchne, comme font les autres tes, que fi tontés les beftes, \& tous les ies portoiét charges, ie m’alfeure qu'il auroit perfonne d'entre enx quis ne mbourr: ft bien pluftoft le dos, que le ntre, oub bien il y en auroit à qui l'efine feroit bien efcorchee. Et me fem.difoit-il encores, que les femmes en 


\section{VING T-S I X I ES M E}

cela ont efté mieux aduifees que les hi mes, lefquelles ont mieux aimé, auoir $v$ gros derriere qu'vn gros deuant, \& s'en bourrer le cul que le ventre.Eft-ce poin demanda vin Franc-à-tripe, que les fen mes ayant froid en celte partie, à caul du vent de bife, quile plus fouuent fou: fle-là? Et encores que ce gros cul empe che les femmes qui le portent fi eft-c que quand elles veulent, elles le laiffent $\&$ le prennent, \& en ay veu plufieurs qu difoient,apportez moy mon cul, i' ay lai. fé mon cul a la maifon, \& me fuis tar. aduancee que ie fuis icy venue fans mo cul. Mais repliqua vn Drolle, files ferr mes poutoient laiffer leur cul natur aufi bien que l'artificiel, ie les trouut rois bien plus à mon gré honneltes 8 gentiles, encores qüelles penfent le gro cul eftre plus beau que le plat, \& ie é quec cent pourcequ'on dit, c'eft vn culd mefnage, ily a à boire 8 à manger, 8 qu'elles péfent que tant plus leur cul fe ra gros \& ample,qu'jl y aura plus à man ger \& à boire là. l'ay veu des femmes iepligua Meffer Panthalon, qui eftoiét ferfuès, gque vous n'euffiez fceu dire fi el. 
S E R E E.

auoient deux culs ou non, fi vous euffiez mis voltre nez dedans, \& lors il it elté aiféa fentir que pour le moins, nt minces foient-elles, quelles en ont , \& que c'eft autant que fi elles en oient vn cent. Vndes plus aduifez de Seree, va dire, Ne voulons-nous point onftrer par ces embourtemens de ven, que portent les hommes, \& par ces naillons de reuefche, dequoy les femes grofilfent leur cul, metrans vin cul $s$ vn autre(où il n'y en auroit que trop in ) qu'il n'y a point de malice ne de fiffe en nous, non plus qu'és perfonnes ii font grolles \& gralfes, lefquelles cóunément ne font doubles ne diffimues, ne malicieufes \& mefchantes ? Ie en fçay rien,refpondit quelqu vn, ${ }_{2}$ mais lçay bien que nos prefcheurs ne trouent pas bon ceft accouftrement de cul, quà ce dernier Carefme vn predicaur reprenant, \& à bon droit, la fuperiité, lafciueté \& puantife des gros culs s femmes, leur difoit : Mes Dames, us fçauez qu'il n'y a que deux chemins ril faut tous aller, l'vn eft large qui eft luy de damnation \& d'enfer, l'autre E 3 


$$
\text { VI NG T-SIXIIS M E }
$$

eft eftroit, qui eft celuy de faluation, de Paradis, anquel yous ne fçauriez pa fer, à caufe quauez le cul trop gros. $\mathrm{Pa}$ quoy, ie vous confeille, difoit ce pre cheur aux femmes, laiffer vos gros cul car ne pouuás paffer par le fentier \& ch min eftroit,dônez-vous garde d’aller $\mathrm{p}$ : le grand \& large chemin, qui e? de pe dition. Puis leur difoit, vos gros culs ail fi enflez, femblent aux panier des cha fes-marees, \& prouifeurs, qui font brau ment couuerts de counertures de liure mais par le deffoubs vous n'y trounere que de vieilles rayes puantes, de la ma: gre ou de la feche, fentant bien fort maree. Mais eftant tard, \& quion n pounoit en matiere de gros culs donne fentéce qui rien valluft, la Seree fus cel fe departit, apres qu'vne Dame d'icell eut retiré des verts qu'elle auoit appri des cuures d'vn de nos modernes, \& c pour refpondre à ceux qui veulent refor mer les habits des fernmes \& des fille: auec leurs gros culs, difant qu'en matie re d'habits, on eltimera toufiours fot 8 lourdau celuy qui ne s'accouftre à la mo de qui court.

Homme 
Hommes ingrats, vn iour le temps fera e voftie orgmeil fa recompenfe aura, qui vou dra bien pe fer voftre affaire tre confeil à vous mefmes eft contraire: zous tafchons nous veftir proprement, à nos corps donner quelque ornement, ce pour nous que prenons cefte peine in qu'à nous le plailir cn renienne? tes nenny c'eft pour vous plaire mieux, eulement pour contenter vos yeux. minuans doncques en cefte forte beaux atours que noftre fexe porte, ur feulement rendre l' bomme contant, tre plaifor diminuë d'autant.

ila comment le mefchant, quand il penfe nire à autruy, luy-mefme il s'offenfe, mbant luy-me me au foffe gri il a fait, renangeant luy-mefme fon forfait.

F 4 
VINGT-SEPTIESME SEREE. Des Barbiers, or du mal de dents.

Efte Seree fut faicte en la maif 12.2 d'vn de notre compagnie qui no auoit conuié à foupper, pour folennif fa Natiuité, laquelle eftoit à ce jour. 1 comme c'eftoit entre nous la coufum Or il arriua que celuy qui faifoit la fell atroit ce foir grand mal aux dents, con me nous voyons qu'à chafque bout d champ, il y a le plus founent trois lieu de torfe, \& de mal-aifé, que fi vne fortu ne nous rit, l'autre nous menace, comm 2 bien efcrit Plaute, difant:

----Ita Dysplacitum

Voluptativt moeror comes conifeguatur. Dont l'on pourroit bien à bon droit dir cecy, qui eft aux Tragedies:

Plufieurs cas y a de fortune

Ce dont n'as esperance ancune, C'eft ce que les Dieux font founent: Mais ce qrion penfe eftre à la veriè, Et dont l'eperance eft conceriè, Se met à fin bien rarement.

Aus commencement de ce feltin natal, or 
fe faifoit que rire du mal de noftre te, \& luy difoit-on que files dents luy oient nual, que fe deuoient eftre les tres, qui officioient fi bien \& non pas fiennes. Mais voyant que durant le pper, il ne pouuoit manger, \& nous e bonne chere, comme il auoit de ine couftume, \& fçauoit bien faire, cun le commençà à plaindre, \& à orer des remedes, tout le monde eftarie decin au mal des dents, ainfi que prouua Gonelle bouffon du Duc de rare. Aucuns ordonnoient des reces pour les auoir practiquees en eux fmes, les autres, plus heureux , pour auoir ouy dire, ou les atioir leuës és li$s$, les vins \& les autres plaignans tant tre hofte, quils dirent que Pline it efcrit qu'vn homme seftoit ietté vne feneftre en bas, pour la rage des. tts. Vn Drolle, qui à mon aduis n'ait iamais eu mal aux dents luy bailvne vieille \& commune recepté, it , dit-il à noftre hofte qu'il faut par: pace de neuf jours dire tous les mas vn Paternoster, \& vin Aue Maria, \& acun de fes iours bailler vne aumofne: 


\section{VING T-SEPIIES M E}

à vn pauure, felon voftre puiffance $\&$ culté,\& au bout des neufs iours, difoit à noftre malade des dents, vous. ferez figne de la croix fur la doubleure du fa. ou cafaquede cepature, en baifant ce doubleure par trois fois. Et fi fon fay repliqua noftre hofte, $n$ 'eft point doul ou qu'il n'en aị point, où le baiferayBaifez-le au cul, luy refpond le Droll Tous ceux de la Seree fe prenans à ri feletierent de tible. Les tables leuer four foulager noftre hofte de fon $\mathrm{m}$ qui rioit encores de ce qu'on l'auoita finé, on fe printà parler du mal des der $\&$ des Barbiers qui les arrachent. D'e tree de ieu, quelqu'vn va conter, pour ‘ iouir noftre hofte, \& le faire penfer autre chofe quà fon $\mathrm{mal}$, qu'vn io eftart en la boutique d'vn Barbier il v arriuer vn homme des chăps, qui pria feruiteur de luy arracher vne dent, $q$ le faifoit courir les champs, le priant le traicter dourcement. Le Barbier me: tant comme vn arracheur de dents, $h$ promet de larracher fans, aucun m: mais il arriua que ceft apprentif au lis de luy arracher vne dent, il luy en of 
is, auec vn inftrument quion nomPolican. Ce pauure homme voyant on luy auoit arraché trois dents en I d'vne, deux defquelles ne luy auoiét nais faict de mal, n'eftás point gaftees plaint fort, en appellant ce Barbier urreau, qu'il n'entendoit point fon ti, qu'ils'en plaindroit à fon maifte, en auroit la raifon par luftice. Ce mpagnon de boutique, cognoiffant $f_{2}$ ite, luy va dire, taifez-vous de par tous grands diables, fi mon maiftre vou's tend, il vous fera pay er l'arracheure de is dents. Le maiftre fe doubtant bien fait, ayant oui ce bruit, vient à la bouue, demandant que c'eftoit, ce paue edenté luy va dire, c'êt voftre feruiar qui m’a arraché vne dét. Quoy vne rt, repliqua, le maittre, ay-ie pas ouy rler de trois? Non, Monfieur, refpond villageois, il ne m'en a arraché qu'vne, nez voilà ce qu'ils vous faut. Noftre ifte ne laiffa à rire auffi bien que les au es, \& nous afferma que ce conte luy oit allegé fon mal, les efprits qui don:nt le fentiment eftás dinertis ailleurs, iant celuy qui,auoit acheué for conte F 6 


\section{VINGT-SETTIESME}

de continuer, ce qu'il fit en celte fort Ce maiftre Chirurgien accompagnar cefte gentilefle d'vne autre, \& ayant vr. femme quiluy pefoit fur les efpaules, fut contraint, comme eftant le dernit maiftre, d'aller à l'hof pital des peftifere: ce qu'il accorda, à la condition que! femme iroit à la fanité auec luy, pour traicter fi d'anenture il tomboit malad Il fut ordonné que fa femme iroit aue luy encores qu'elle remonitrât que fo mary n'en vouloit que la depefche, qu'il mettoit fa vie en dangér pour la fa. re mourir. Ce qui arriua, car tanto. apres elle mourut de lá contagion : $L$ mary royant qu'il auoit perdu ce qu'i vouloit perdre, fit tant enuers Mel freurs dela ville, quil en fut mis vn au tre en fon lieu, \&r ainf fe mit à fon aif affez honneftement: toutesfois ce Bar bier ne peut euiter le mauuais brui que luy donna tout le peuple, car com munément il aduient, ce dit Plutarque que les fautes que l'on commet contr les femmes, font plus diuu!guees parm le móde, que celles que font les femmes Ce barbier mefme, acheua-il de dire, er 
puny, mais non pas comme il meri, car fe troumant en vne foire, il rentra vi homme; quil luy dict, Vois-tu bien celuy-là qui dort la bouche oute, appuyé fur fon fac, ceft vn mien ent qui enrage du mal des dents, ache luy celte grofle que tu vois tre les autres, tié voila vn tiers d'efcu, eure-toy que quand il fera efueillé, 'il t'en payera bien, prens cela paradnce. Ce barbier prenant l'argent, luy cache cefte dent dextrement. Le bon mme fentant la douleur par la perte fa dent fe met fibien à le battre, qu'il t ce que les Barbiers demandent, ayes \& bolles, nonobltant que ceft archeur de dents luy dict, qu'ill luy anoit raché celte dent par le commandement va fien parent, \& $q$ qu il crioit ainfi, à fin ne le payer point d'vin chef-d'outure uil auoit fait, de luy auoir arraché vne ent en dormant. Depuis on m'a dit que - Drolle voulloit mal à ce dormeur, \& a Barbier, \& qu'il s'eftoit vangé en vo oup \& dél'vn \& de l'autre. Ces contes çheuez, quelque autre commença à di$e_{2}$ On dit en commur proverbe, II ment 


\section{VING I-SE P T IES M E}

cóme vn arracheur de dents, or les ch rurgiens \& barbiers communément arrachent, ils font donc gráds menteur or adiouftez qu'ils font auffi grands cai feurs \& babillards, le babil \& le ment s'entre-fuiuans, cöme le Roy Archela nous a enfeigné, reprenant le babil d'v barbier, qui lui demanda,Sire, Commer voulez-vous que ie vous face la barb. quand illuy refpondit,Sans dire mot. $E$ n'elt fans occafion, ce dit Plutarque,qu les Barbiers. font ordinairement grand babillards \& caufeurs, pource que cou fumierement les fuit-neans $d^{\prime}$ vne ville \& les plus grands caufeurs fe trowuen \& fe viennent alleoir aux boutiques de Barbiers, \& de celte accouftumance d les ouyr caqueter, ils apprennent à tro parler,ce que pourrés entédre par vne hi Atoire de Plutarque. Vn Barbier, dit-il, le quel auoit fon ouuroir de barberie fur le port de Pire,en la ville d'A thenes,entendit de là par vn Ef claue qui s'en eltoit fuy, la deconfiture des A theniens en Sicile, lors ce Barbier prenant fa courfe s'en vint à la ville apporter celte desfaite. Soudain le peuple eltant eftonné, com- 
Inda qu'on fceuft qui auoit femé ce ait, le Barbier fut amené, qui ne peuft e le nom de qui il auoit entendu cefte uuelle : Le peuple fe mutine, \& comence à crier,qu'il ait la gehenne, qu'on torture, il a menty, il a controu ué ce, qu'on apporte vne roue, là où il fut que au foir que le bourreaulevint de:r, \& encores ce Barbier ne fe peuft te$r$ de demăder à celui quile detachoit, inme leur Capitaine Nicias auoit efté é ; tant ce vice de parler par accouftulance deuient incorrigible. Et la raifon ue baille Plutarque pourquoy ce Barier fut mis fur la rouë eft, que tout ainfi ue ceux qui prenent medecine, haifent puis apres les gobelets où ils les ont etuës, auffi ceux qui apportent mauaiis nouvelles, font couftumierement mal oulus de ceux à qui ils les apportent. Toyez,repliqua vn de la Seree, par ce cóe de Plutarque, que les premieres nourelles ne font gueres vaines, \& n'eft fans ropos ce qu' on dit, vox populi, vox Dei: equi eft confirmé par ces deux vers. Iamais en vain publiaue renommee. Ne fe tronua anoir efléfemee. 


\section{VING T-SE P T IESME}

Il y auoit en cefte Seree vn Medecin, I quel n'eltát point chiche de fes drogue laiflant les Barbiers, \& retournátaum des dents, va dire que pour bien guer. ce mat, \& en ofter la caufe, il falloit $f_{c ̧:}$ uoir fil la fluxion eftoit chaude ou froidi l'vn \& l'autre eftant la caufe du mal.Qu fi la fluxion,difoit-il, eft chaude, venan founent du cerueau, elle fera vn tumeu à la racine de la dent, \& fi la douleur fer fort aigue, le lieu fera rouge, l'eau froid، mife en la bouche federa la douleur, dau tant contraria contrarys curantur. Au con traire fi la fluxion eft froide elle ne fer: point de tumeur, la douleur ne fera pa: forte, les chofes chaudes qu'on y appli quera, feront celfer la douleur, Ayant cogneu, difoit noftre Medecin, par ces chofes, l'humeur qui peche, \&z fa qualité il faut diuerfifier les remedes, en quoy tout le peuple qui eft mèdecin pour les dents, \& mefmes mes compagnons, faillent ordinairement, ne baillant qu'vn remede tant pour la fluxion chaude que pour la froide. C'eft vn grans cas, repliqua quelqu'vn; qu'encores que les dents feules refintent au feu, \& ne fe bruflent 
c le refte du corps quád on le brufle, neantmoins vne fimple diftilation heume ou de caterre les confume, \& irrit: On m'a dit autrefois pourtant les Indiens nounellement defcouts, auoient vne certaine drogue pour feruer leurs dents, \& les empef cher pourriture \& corrofion, \& d'y auoir un mal, laquelle ils font de coquilles uiftres, de celles qui produifent les les, qu'ils font brufler, mais aufi, dit-il, les dents leur deuiénent auffinoique charbon, \& fi ces barbares, entre res les Cumanois, font grande gloire uoir leur dents noires, comme nous fons de les auoir bien blanches, aplans femmes $\&$ effeminez ceux qui ont blanches, \& beftes ceux qui ont la barbe. Pleuft à Dieu, va repliquer tre hofte, fçauoir cefte compofition, a peine dauoir les dents auffi noires e les Mores les ont blanches, \& qu'on eut pluftoftapporté de ce païs là,parant incogneu, ce bon remede, \& de nnes receptes, pour les maladies de ftre Europe, que d'autres maladies de ioy on n'auoit iamais ouy parler parde $\mathrm{Cqa}_{2}$ 
VING T-S E P T I ES M E ça, qui toutefois leur font communes. poffible, va dire vn autre de la Sere noftre hoft:, que la recepte des Indie que deman dez, eft celle que met Plir quand il dit que la cendre faicte des, cailles des huytres fait blanchir \& $\mathrm{n}$ toyer les dents, eftans frottees de cel cédre calcinee : mais ie me doubte bie. adiouitoit-11, que la recepte de Plines fait que blanchir les dents, $\&$ que cel des Sauuages, que vous fouhaitez, guer le mal, en emperchant la caufe du mal.i defendant les dents de toute maunai: fluxió.Ie me fierois plus, repliqua noft hofte, en la cópofition des Negres \& de Indiens, qu'aux billets \& paroles Diabc liques qu' on baille aniourd'huy contr le mal des tents, où il y a efcrit, Galbes galbat, gaides, galdat: \& qu'en ce fo dictuin \& breuet qu'on péd au col, ou f trouue efcrit, Strigiles, falcéfque dentatt détium dolorem perfanate, encores que $\mathrm{Au}$ ger Ferrier en $f$ ice vn grand cas: $\&$ qu'es ces parolles prononcees durant la Meffe qui font os non comminuetis ex eo, \& qu'er l'applicatió d'A pollonius, qui dit que le mal des dents eft guery, fi on farifie le: genciues 
ciues auec la dent d'vin homme qui elté tué. Vne feffe-tondue, à propos oraifons \& des mots qui font guerir al des dents, nous va conter vne gaile hiftoire d'yne nounelle mariee, qui aifla d'auoir mal aux dents le foir \& uift de fes nopces, encores qu'on die ommun prouerbe, rage de cul paffe al des dents, figrand mal,dy-ie, que e pauure mariee perdoit toute pace, mefme alors qu'elle fuft couchee oir de fes nopces auec fon mary, leIfe voulant aprocher d'elle, \& fe ër, elle le pria d'attendre vn peu iufs à ce qu'elle euft dit quelques ceris mots, \& quelques oraifons qu'elle it accouftumeé de dire toutes les fois le mal des dents luy prenoit, \& $q$ que ayant dictes, fon mal la laiffoit inconent : ayant apprins ces breborions de rand mere, fort fubiecte, auffi bien elle, à la rage des dents. Son mary ne voulant reffufer cefte premiere reeite, la laiffe dire ces audinos:mais cendant qu'elle les difoit, le marié qui ait efté de la fefte, s'endort. La mariee i n'eltoit point endormie, tant pour la

rage 
VING T-SE P T I E S M

rage des dents que du cul, ayant ache fa vernedé, \& eltant allegee de fon $\mathrm{n}$. va dire à fon mary, Michau, $i$ 'ay dit, $\lambda$ chau,i ay fait. Voyant la mariee que 1 chau ne faifoitrien, \& qu'il ne s'app choit point d'elle comme il auoit fa d'entree, en le pouffant va crier enco: plus haut, Michau,i'ay fait, Michau,i dit, Michau, mó amy i’ay acheué:maj: dormoit fi fort, \& auoit fi bien bridé. puces que celte pauure mariee ne peut iamais refueiller, les fentinell ayant rapporté que $\mathrm{Michau}$ nes'efue la qu'au matin, combien que fa femr. toute la nuit n'euft fait autre chofe q le pouffer, \& luy crier, Michau, $i^{*}$ fait, Michau, i'ay dit, \& fi cefte mari confeffale lendemain à ceux qui auoi fait la fentinelle, \&rà ceux qui les auoi leuez, \& à la ronde, qui en fe raillant le difoient, Michau, ol'eft fait. Michat o l'eft dit, qu'elle auoit enduré plus c mal cefte nuict, que les dents ne luy e. firent iamais, Noftre hofte fe fentant $\mathrm{v}$ : peu allegé par l'efmotion de rire de $c$ Michau iay fait, nous va demander. les dents \& les os auoient fentiment, \& 


$$
\text { S E R E E. }
$$

it bien parlé quand on dit, les dents font mal. Les vns foutenoient l'oon de Galien, qui ditque les dents t point de fentiment quand à la parui eft d'os, mais ouy bien quant à racine, où elt le nerf fenfitif.Les autenoient, auec Ancienne, \& felon hyliciens, que les os, encores qu'ils ent nul nerf, ne font pas fans fentit du chaud \& 2 du froid, d'autant, di$n t-i l s$, que les efprits qui penetrent les pores des QS, \& des dents, peubailler fentiment. Et à ce propos vn le homme de la Seree va demander fre Medecin, pourquoy c'eltoit que dents, qui font plus folides quela $r$, fentent plus toft le froid quela ir, qui eft rare, veu que ce qui eft rare oit plus tof eftre offenfé, que ce qui olide. Ou pource que le Medecin \& hyficien ce font deux ence temps, \& leuoient eftre qu'vn, comme au téps e. noftre Medecin penfant efchap, fe met fur les diftinguo, mais parce Is n'eftoient à propos, le Phyficien contraint de faire le preftre Martin, e fe relpondre luy-mefine, difant, les dents 
VINGT-SEDTIESME dens font plus offenfees du froid que chair, parce qu'elles font enracinees les conduits \& pores, qui font fi pet qu'il n'y peut auoir là grande chaleur: quelle eltant petite, elt facilement montee par la froideur, qui cause la di leur, au contraire la chair fent plutt la chaleur que la froidure, $\&$ en eft $p$ ftoft offenfee, parce que la chair contil en vin temperament mediocre, a plus chaleur que de froideur, qui eft cal qu'elle n'eft point $f i$ toft offenfee de froideur que la dent, laquelle a plus froideur que de chaleur. Noftre hofte terrompant cefte difficu'té, va dire qu ne fe foucioit point fi le froid faifoit $\mathrm{pl}$ de mal aux déts qu’à la chair, mais feui ment il les prioit de le guerir, ou pour moins de faire ceffer la douleur. Le $M$ decin va refpondre, qu'il n'approuuo point les receptes communes qui fo anodines, ne faifans quappaifer la dor leur, mais qu'il vaudroit beauco mieux en ofter la caufe, eftant bien mei leur de monter fur la maifon pour en pefcher de pleuuoir dás le logis, \& rabi ler la goutiere, que fe contenter de me 
In vailfeau deffoubs, Puis noftre Me- in ayát regardé au $\mathrm{mal}$ de noftre hoeva affeurer que le mal qu'ilendune venoit point d'vne grande flun, mais d'vne humeur acre \& pourry luy rongeoit les dents:parquoy il luy feille, a fin d'euiter cefte erofion, que sles matins il prene fur la langue du \& quand il fera fondu, qu'il en frotte. tents, ou qu'il fe laue tous les moys fois ou deux de vin ou de vin-aigre, dels ait bouilly des racines de thithie, paffees $\&$ coulees en vn linge. Or ze que tout le monde eft medecin au de dents, comme il a efté dit cy der- \& confirmé par Gonelle bouffon du de Ferrare, chacun fe met à vouloir onner des receptes, les vris pour le des dents, les autres, pour complaire femmes, pour les auoir blanches, es, \& fans corrofion, n'ayant rien qui iidiffe plus que d’auoir les dents ga$s$ \& noires.Le premier qui commenordonner des receptes, nous va afer qu'il n'y auoit rien plus fouterain nal des dents, que de prendre vne ffe d'ail vn peu cuite foubs la cendre, $\&$ 


\section{VING T-SE P TIES M E}

\& l'appliquer fusla dent, \& dans l'ore le la plus chaude qu'on pourra endur Que ficela n'y fait rien, mettez furl: tere du temple au deffus du mal,vnees plaftre faire de poixrefine, meflé auec la poudre d'alun, \& noix de galle, la pc tát la nuit \& le iour Le fecond, appt chant de la recépte du premier, va di que trois teftes d'aulx broyeż en vin-: gre, allegeoiét la rage des dents, comn auffi faifoit leur decoction faite en ea en s'en lauant la bouche. Le tie nous donnoit tous aux drables, \& ni pasluy, que fi on dechauffeit les den auec la racine de panais, ou fe lauant bouche du ius tiré de la racine d'afperg ou prendre des capres cuites en vin-a gre, ou mafcher fa racine, ou mettre la bouche du ius tirć de lapatbum fauuą cuit en vinaigre, qu' on fe trouneroit al gé du mal des dents, autant en fait graine iaume deffechee des rofes, fi on $e$ frotte les dents, \& le laict du figuier fat uage appliqué auec de la laine fur la dé ou dedans; \& fa racine bouillic en vin. I quart Medecin n'eftant pas fi fage quel precedent, fe donnoit à tous les diable 
dedans de la galle mafché ne guerifle mal des dents, l'ayant effayé auffi que la decoction de feuilles de tais, \& celle de la racine de ronce, en lauant les dents, \& la racine de iufme mafchee auec du vin-aigre, $\&$ du plátain \&z de fes fueilles, la maft, ou felauant labouche de leurdeion, apres l'auoir fait bouillir en vin e Le quart medecin des dents vougager que la racine de veruaine maf, ou bien la mettant boutillir en vin, in fe lauant la bouche de cefte deion, infailliblement apparfoit \& fela doulcur tant poignante funt-elle, acines de quinte fueille cuites en ou vin-aigre, infques à la confomde la tierce partie, en faifant autát les laue d'eau falce auant que les re au feu, tenant longuement cefte ction en la bouche, ou bien fe frots dents de ceridres de quinte-fueiluflee. Le quint medecin affeure, Pline, que la poudre de coloquineflee auec fel \& aluyne guerifloit le des dents, \& que fon jus attiedy auec igre, affermoit les déts qui branntét Liu.ijj. G 


\section{FINGT-SE TIES M E}

la racine debouillon cuite en vin ou laue-dent de hylfope, $\&$ de jus de pen danum, auec de l'opium, faifant auff s fer toute douleur des dents. Le fixiefr. attribuát toutes les guerifons à vne la te \& occulte facultédes fimples, main moit qu'il n'y auoit rien plus fouver pour cefte rage que la racine du mug blanc, bouilie en vin aigre, coupee rouelles, fe lauant la bouche de cefte coction tiede: \& quautant en faifo: racine de l'efclaire, broyee en vin-aiq \& tenuce en la bouche, \& l'elleboren misen la dent creule, ou bien pren In racine de l'arreftebocuf, dite des $\mathrm{Gt}$ Anonis, cuite en eau \& vin-aigre s'en uant la bouche. Le feptiefme mede de Rondibilis vadire en loiiant fes inedes, que fi on frotte les dents quek remps de fang de torruë, quion n'y a jamais malnon plus que fi vous pres de la vieille tounine bien lauee, $p$ broyee, $\&$ s'en frotter les dents: mefn difoit, que fi de tous poiffons falez,v en prenez les aieftes \& efpines, \& les faciezbrunter \& calciner, en vous frottant la dent, on en fera tota 
SERE E。

nt guery :aufi bien que fi appliquez la dent toutes fortes de bitumes des feuilles de laictues de cheures, font laictues ameres, broiees en vinre s'en lauant la bouche deux fois le is. Le huictief me va dire que fa grăd" re gueriffoit tout le monde auec de la adre de coloquinte, meflee auec fel \& ine, ou bien en prenant la racine de lue qui ne iette qu'vne tige, \& en fcaer la dét, \& confeilloit de fe lauer fouit la bouche de vin-aigre, \& tous les, tins prendre vn grain de fel,pour emcher toute erolion \& putrefaction: if les dents vous font mal, pour fela douleur, il faut lauer $f_{a}$ bouche de e \& de vin, y adiouftant vn peu de ure. No:tre Medecin reiettant tous remedes qui ne sŏt qu'anodins, nous dire que le plus fonuerain, pour emcher que le mal ne retournat, eftoit farre arracher la dent, \& quie cela fe it sás douleur fi vous mettez au peride la dent creufe de la cendie des ide terre calcinez. Franc-à-tripe lors s va conter qu'il y auoit vn mareflen fon païs, qui arrachoic les dents 


\section{VING T-S E P T IES ME}

fans vous toucher ne faire force, mefn que le patient fe l'arrachera luy-me me. Il prenoit, difoit-il , vn filet, qu mettoit en deux ou trois doubles, \& lioit la dent, \& l'autre bout il l'attacho à fon enclume, puis il mettoit en fa for vn fer, \& toutes les fois qu'il faifoir for fler fes foufflets, ce marechal difoit $g$ mara.Quád ce fer fut bié chaud, \& to ardant, ille tire de la forge, puis va di au patient qui eltoit attaché à l'enclun par fa dent, ouure la bouche bien gra: de, \& faifant femblant de luy mettre fer ardant en la bouche, Dieu Çait s'il fit prier à s'ofter de là , \& s'arracher lu mefme la dent, le marefchal luy crian Difois-ie pas bien que vous arracheri voltre mefchante dent de vous-mefme Ce forgeron en vfoit aurrement poi luy, car fe youlant arracher vne dent, $q$ luy faifort mal, il bảdoit fon arbalefte, attachoit à la corde de l'arbalefte vn fil bien fort, qu'illioit par l'autre bout à dent, puis debandoit fon arbalefte, \& difoit que cela fe faifoit fi fubtilemen quiln'enduroit nul mal. Quand on et vn peury, les Dames qui eftoient en

Ite Serer 
Seree, prierent ces medecins de dents leur donner des remedes pour auoir dents belles \& blanches. Le premier dire qu'il falloit auoir vn dentifricium ui (e nomme ainfi en Latin) de miel alé auec du charbó de vigne, qui n'auiamais portéde raifins, fi mieux on ne ut prendre la cédre de corne de bouf, $n \&$ l'autre rendans les dents blanches polies, foit en vous en frottant les nts ou en vous lauant la bouche. Vn tre affeura anoir approuué quil n'y oit rien meilleur pour blanchir les nts, que fe les frotter auec de la cenedu taló d'vn pied de bocuf, auec myre; les os d'vn onglon de pourceau en fansautant combien qu'aucuns prerent à tout cela les cendres d'orge bruf. incorporees en miel, auec vn peu de , ce qui fert auffi à faire botine halei- Apres ces detrx, le tiers ne reiettant sdu tout ces remedes, mais entimant alicoup les fiés pour les auoir apprins Medecin d'vne grand' Princelle, va diqu'il n'y auoit rien plus fonuerain, ne digafte moins les dents, ne quiles bláiffe mieux \& nettoye, que 1 a cendre 
VINGT-SEPTIESME

des coques d'œufs calcinee en oftant 1 pellicule de dedans, autant en faifant cendre de nitre calciné, \& la poudr d'yuoire. Que fi nous atuions, difoit-i\} la compofition d'vn onguent, que le Anciens appelloient Odonftimma, il n'e: faudroit point cercher d'autre, nais e. fon lieu nous pouuons v fer d'vn onguer. qu'on appelloit Omphacium, lequel en rretient les dents en leur blancheur, 1 on le tient en la bouche, eftant auffi for bon pour affermir les genciues \& le denss tremblantes, fi ordinairement of fe cure les dents apres le repas auec $d \mid$ bois de lentifque, ou du myrrhe, $\& d$ tout autre bois aftringét. Sur tout il de fendoit les reforts, comme gaftans for les dents, que fi on en veut máger, il fau apres en auoir mágé, vfer de poudre d'y uoire. Que fi vous auez les dents agacee. (adiouftoit-il) que les Latins appellen dentium ftuporem. \& les Grecs, ainfi qu'or m'a diat, Emodiam, il ne faut que mangel du creffon. Ceux de la Seree s'ennuyan: de tát de remedes, \& fil longs, fentás plu: fon Medecin, \& fa medecine, que tout autre chofe, ne l'ofoient dire, à caufe que notter 


\section{SEREE。}

re holte, qui ne demandoit que gue$n$, difoit qu'il eftoit boin fçauoir dis remedes, dautant qu'vne recepte en. rra guerir vn, qui ne guerira pas l'auà caufe des complexions \& humeurs font diuerfes. Sur la fin de ces reces, quelqu'vn va dire qu'il n'y auoit i plus dangercux pour les dents, que ger founét du laict, car le laict, difoitrend les genciues fi humides que les its en font plus fubjectes à erofion \& refaction. Que fi on aime le laict, il $t$ fe nettoyer \& lauer la bouche, apres on en aura mágé,auec du vin pur, \& cores fera meilleur, fi on melle vn peu miel parmy le vin, mefmes on dit que laict danelfe elt fort bon fi on s'en eles dents, \& qu'on les frotte puis es auec beurre $\&$ miel mellez enfemElt-ce point le laict, luy demanda vn tre, que tetent les petits enfans, qui ir caufe fi grand mal quand les dents, ir percent? Non, va dire noltre Mede.,, 'eft vne matiere aiguë \& chaude qui ent deuant que la dent forte, \& auffila lution de continuité,qui caufe la douir aux petits enfans quand les dents 


\section{VING T-S I T IES ME}

leur viennent à percer,à celte caufe no voyons que les enfans ne font pas fim hades des déts en hyuer qu'en Efté, par qu'en hyuer la matiere n'eft pas î aig qu'en elté, \& bien foument fi les den viennent l'Eftéaux enfançós, ils font danger de leur vie. Les femmes de Seree lors vont prier le Medecin de le donner quelques remedes pour empe cher le tourment que ce percement dents dóne à ces petits innocens. Lequ leur va cófeiller de faire la recepte con mune, c'elt de leur frotter les genciut auec ceruelle de lieure ou de connils, ca bien que Pline le face auec ceruelle mouton. Vn Drolle lors va promettre ces feinmes vn remede affeuré, \& exps rimente, \&z fur fa viel'affermoit, leque garantiffoit les petits enfans du mal d dents \& de la teigne. Les femmes prerent à ioinctes mains, voyant qu' en iuroit, de leur enfeigner cefte recepte Mes Dames, commença-il à dire, fi vou! voulez que vos enfans foient exempts di mal des dents, \& . de la teigne, incótinen qu'ils feront nais, prenez les, \& les paflez dans le pertuis de la rouie où paffe l'ef- 
eil de la charrette. Ces bonnes femes, y allans à la bonne foy vont luy reiquer, Et comment, il n'y fçauroient trer ? Alors ce bon compagnon, fe enant à rire: Que diable voltre cas eft nc large. C'eft bien, difoit-il, conaucuns qui vous a ppellent auares \& frerrees, mais à ce que ie voy, vous eftes en liberales \& larges. Norte hofte res auoir ris, nous affeura que fon al eltoit allegé de la moitié. Et pour us le monftrer, va defcoumrir que ux qui naiffent auec les dents, font ureux, comme ils'en ent trouné:mais as heureux, difoit-il, ceux qui n'en t point du tout, à caufe de la rage que nt les dents à plufieurs : car encores le vous ayez des dents dés voltre naifnce, aufíl les perdrez-vous bien tolt, autant que nature faifant quelque ofe pluftof quil ne faut, \&z auec us de matiere, far la fin ellen na rien e fournir pour entretenir ce quelle trop auancé. Conme ceux qui naifnt auec les dents, repliqua vn de la ree, font micux fortunez que les au$s$, fi nous croyons les anciens \& G 5 
VING T-SEP T I ES M E

l'experience, le contraire eft des filles qi naiffent endétees, lefquelles portent $v$ tres-mauuais prefage,auffi biế que cell qui viennent au monde aurec du poil a deffus de leur cas, comme m'a affeu vn gentil-homme, qui dit auoir veu ? tenu vne fille, laquelle au fortir du ver tre de fa mere auoit fa motte tertree ? chargee de poil. Qui fait, demanda v autre, quon a touliours obferué que $l^{\prime}$ enfans nais durant la pefte, ont deux dé: moins que les autres, \& fi font plus deb les? Le Medecin eftant hors de fon C: tholicon, laiffa parler le Phificien, qt va refpondre par vne autre interrog: dion,en demandant, ne feroit-ce point caufe de la debilité des produifans, pro cedee d'humeurs ardantes, qui regner en temps de pefte, \& ont confume l'h midité radicale, dont viét que les enfar nais en temps de pelte ont deux dent moins, \& font debıles? Et de là vier. qu'on tient auec Ariftote, que ceux ql n"ont gueres de dents, \& les ont claire les doigts fort longs, la couleur plon: bine, \& ont plufieurs lignes en la mair qui font interrompues, we viuent pa 
guement. Ce qui eft confirmé, quand x dents, de ce que nous voyons que beltes tant plus elles ont de dents, tant is eft longue leur vie: parce qu'elles ondent en humeur radicale. Et de là ent auffi, que les hommes viuent plus eles femmes, dautant qu'ils ont deux nts dauatange, pour auoir plus d'hueur radicale, \& plus de rang \& de chair, \& aufi que les hommes qui ont te deux dents viuét plus que ceux qui ont moins.Pline auffi dit, adiouftoitque les femmes qui ont les dents ceiles de deffus doubles du colté droikt, e celeur eft figne de bonne fortune, afi qu’apparut en Agripina, que fi elles nt doubles du coftégauche, c'eft prefad'infortune. Ie fuis content, repliqua telqu'vn, de croire cela pour vous faire aifir, mais ie ne puis croire ce que dit Atre mef me autheur, que les mirouc̈rs terniffent de la veuë des dents d'auns hớmes, les pigeonneaux fans plume mourans auffi. le croy de ma part, va re noftre Medecin, que quand on dit le ceux qui ont les dents claires ne viint gueres, que c'eft parce que ceux qui 


\section{VING T-SE P I IES M E}

mafchent mal, font mauuaife digeftion la premiere digettion fe fuifant en mar. geant, \& auffi que ceux qui ont les dent clair femees, font de debile complexior mefmes en leurgeneration, que s'ils eu fent efté de bonne \& forte difpofitior ils n'euffent pas eu les dents ainfi clai res. Monfieur de Montagne dict qu on a veu de fon temps à Conftantinc ple vn homme qui auoit les dents bonnes \& fortes, lequel feulement de dents bridoit \& harnachoit fon che ual. Encores que les dents, fut-il tepliqu feruent à la digeltion des viandes, fi e ay-ie veu qui fe les failoient arracher encores qu'elles fuffent bonnes ?les vin pour auoir la voix plus molle, grafle, 8 mignarde, les aurres pour les arrange en meilleur ordre, les antres pour ioüe mieux de la flute. le ne fçay, repliqua vi de la Seree, pourquoy il en, y a qui f fontartacherles dents, veu que le fot de h voix fe romptpar les dents, com me le fou de l'inftument par les cor des, carles dents font les cordes, \& la langue eft le plectre ou archet auec le quel re rompt le fouflement \& la voix 
i fort dehors, \& s'en forme la parole. veu aufi vne ieune Dame, qui fe fit acher vne dent,ou parce qu'elle eftoit tee, ou mal fituee, puis s' en fir remetvne autre, qu'elle fit arracher à vne nne Damoifelle, laquelle reprit, \& uit comme les autres,eftant vne granbeauté à vne femme que d'auoir les nts luifantes, tout ainfi que l'yuoire Homere frefchement coupé, \& que vnes ne furpaffent point les autres largefle, ni en hauteur, fans cheucher les vnes fur les autres, les dents ans efgalité par tout, mefme couleur, ef ne grandeur, \& mefme rang. Vn de Seree, va dire qu'il croyoit bien qu'vfemme, pour ettre belle, fe pourroit ire arracher vne dent, veu qu'vne ame de Paris fe fit efcorcher pour feunent en acquerir le teint plus frais ne noutuelle peau.-Mais demanda vn tre, comme eft-il poffible que les dents ous durent tant, eftans fi foument froifes l'vne contre l'autre? Il faut bien di, luy fut-il refpondu, queles dents ne nt pas faintes de mefme matiere que s os, \& qu'encores qu'elles foient de G 7 


\section{VING T-SE P TIES ME}

matiere phsture, fi eft-ce qu'il fau confeffer neceffairement que la matie re dont elles font faictes croift tou jours, ce que ne faict la matiere de autres os, autrement par le frequen mafcher elles feroient conuerties rié, \& auec le temps il n'en demeurero rien, mais les dents eftans engendree del'humeur motif, qui croift de iou en iour, cela faict quelles reuiennent \& non pas les autre os, lefquels fon engendrez \& faicts d'humeur naturel le au ventre de la mere. Ainfi les dent reçoiuent accroiffement fans ceffe, pou fuppleer à leur charge, qui eft mafcher viande. Vray eft qu' ils femblent demeu rer en me fime eftat, mais l'accroilt fuit l, decroift d'iceux par le moyen de la cha leur \& nourriture continuelle qu'iceu: reçoiuent. Croiffent les dents, va repli quervn Drolle, ou ne croiffent point fe corrompent ou non, $i^{\circ}$ en ay affer pourmanger tout monbien, mais que Dieu me garde celles que i’ay. On dema. da à noftre hofte s'il fentoit toufiours douleur aux dents. Ayant refpondis que fa douleur en partie eftoit ceffee. 
$S$ E R E E.

rs quelqu'vn luy va dire, qu'il luy cólloit, pour eftre du tout guery, d'aller ez le barbier qu'il fçauoit, \& qu'il luy oit faire tellediete qu'il ne craindroit cune fluxion: \& qu'il n'y auoit pas lóg nps que ce barbier auoit fait faire teldiete a vn de fes pigeonniers, que de m il auoit mangéfes emplaftres, \& de if il auoit beu fes vrines, l'eftomach ide appetant \& demandant la nourrire du dehors, \& qu'on le rempliffe. Noe hofte luy refpond que iamais il n'ait eu la gráde verolle, mais bien qu'on uoit accouftré comme vn homme qui noit, m'en reftant ceft aduantage, diit-il, que i'ay vn Almanach perpetuel, ii me durera toute ma vie, mais que ie ie bon mefringer, qui me fert, \& à tous ux de la rue pour çauoir quand il fait un faire la leffiue. Là deffius on fe mit à fputer fil l'argent vif faifoit dommage 1 corps, comme plufieurs en ont eu opiion. Ce qu'ont affermé les Medecins mperits; qui le deffendoient aux riches zgrands Seigneurs, \& le confeilloient ux pautes. Et pour conclufion, il furt rrefte que ta fubftance de l'argent vif nentroit 


\section{VIN G T-S E P T I E S M E}

n'entroit point au corps, mais feuleme fa qualité \& a ation: pource qu'aux plaftres on le trouue en la mefmequa tité à la fin de l'operation, que quandi efté premierement appliqué, auff qu n'a nul venin, plufieurs en ayans aua fans aucune lefion: comme en l'iliaq paffion beaucoup en vfent, fans eftre 0 fenfez, fa ponderofité deitournant l'int ftin, qui elt entortillé,en pouffant la $\mathrm{m}$. tiere fecale en bas., l'argent vif eftal chaud par fes operations, car il incife,a tenuë, penetre, \& refoult, \&z outre to cela, par vne vertu occulte, il eft du tou contraire au venin de la groffe verolls quelque chofe qu'on en ait voulu dir Dieu tout bon en donnant des maladie aux hommes, que le plus fouuent eu mefmes fe pourchaffent, produit auf des remedes necelfaires à leur fanté 8 conferuation. Le Phy ficien prenant parole va dire: puis que celt vn veni cauféde l'influence du ciel, n'y a pas en cores lög temps, il me femble, qu il pren dra fin: auffi veoit on qu'auec le temp ce venin s'adoucift, tant à caufe des re. medes, qu'à caufe de l'influence du cie 
del'air : tellement que cefte maladie erdra auec les annees, comme fit la ntagre, luy reffemblant, qui affligea me du regne de Tybere, \& la lychequi foubs Claude, molefta toute l'Eu: fi en appaifant lire de Dieu (qui nuoyé cefte maladie pour punition) us corrigeons nos paillardifes \& mefincetez. Vne Feffe-tonduë, pour faire olier le mal de noftre hofte, comnça à nous conter vn plaifent conte n pigeon fuyart, qui eftoit n'y a pas g temps au colombier d'vn fien voifin barbier. Ce pigeon dedié au feruice de nus, eftant en ce colombier tenu fort audemét, il arriua qu'vn de ces matins ntendit qu'en la ruê on crioit, à mes aux chouls gelez, qui dit, qui en veut, nes bós chouls gelez. Luy tout efbahy dire,ie ne fçay en quel pays demeurét gens qui vendent des chouls gelez, là où ils croiffent, \& où ils fe cueillent ne fu-ie iamais en pays ne lieu où il figrand chaud qu'il fait icy. Ce foladuantureux fe faifant penfer honitement de ce coup de fauconneau, di$t$ à ceux qui eftoient de fa chábree, Ie feray 


\section{VINGT-SEPIIESME}

feray bien mentir celleq qui eft caufe de quioy ie fuis icy: car onques puis ie n l'ay veuë qu'elle me difoit que ie la lai rerois la apres m’auoir fait plaifir, \& qu' ne me fouluiendroit point d'elle , ma: ie vous affeure que ie nel'oublieray ic mais, \& qu'il m'en founient bien, men fouuiendra toute mavie. On n'? uoit pas a heué de rire, quád quelqu'v fe mit à conter qu'vn Gentil-höme aud que fe vouloir mettre en penfion en $c$ pigeonnier, affembla les plus fameu Aduocats de Poictiers, pour faire vn confultation, leur propofant vn doubte affanoir mó fil la verolle l'auoit prins, ol s'ill'auoit prinfe, $y$ faifant grande diffi culté:car, leur difoit-il, fi iel'ay prinfe, ii la laifferay quand ie voudray: fi elle m? prins, ie ne fçay quand elle me laiffera Les Aduocats voyans la moquerie, for. tét hors, encores qu'on les vouluft payer sils euffent dit leur aduis, Noftre hofte fe print fi fort à rire de ces contes qu'il ne parla plus de faire arracher fa dent, \& auffi que noitre Phy ficien luy anoit dit, qu'encor que la dent fuft arrachee, quali ne laifferoit d'autoir mal en cefte partie.

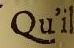


il foit ainfi,difoit-il, vous trouuerez perfonnes à qui on a coupé vn.memqui diront sétir mal à la partie qu'ils it point : car ils fe plaindront d'amal au talon ou à la cheuille, encoqu'ils n'ayent point de iambes. Le lecin, auec ceux de la Serce,ne pouts comprendre cela, prierent le Phyin d'en dire quelque raifon. Quiva er ainfi, comme n'en eltant pas afé. Eft-ce point que le patiét par imation, \& regrettant le membre qui efté coupés penfe toufiours à iceluy, at la vraye douleur en ce qui refte du nbre, ou par froideur, ou chaleur, ou ion: Ou bien, adioúltoit-il, feroit-ce t'efprit fenfitif, lequel difcourant les nerfs reprefente le fentiment des ies retranchees,aufquelles il fouloit uer ou s'eltédre? Et ores qu'il n'y puifaruenir, il fait vne reflexion à l'enit du retranchement, comme en vn cuër : \& là fe fait certaine reprelenon des parties retráchees, aufquelles ttribue la douleur, le fens commun s s'accordant auec l'imagination de hole qu'on a perdue, l'opinion faifant certitude 


\section{VING T-SE P T I ES M E}

certitude \& affeurance de ce qu'ils imaginé. Su roit ce point plus tolt, duf il encores, que fi on plaint le pouce $q$ a perdu,qu'on ait veritablement la do leur au bout coupé des mufcles, nerfs, oulig ments fenfibles, qui loyent paruenir à la particule du mél que l'on plaint: Ce qui fit fortir le Phy cien vn peu hors dela Seree, fult nol hofte, qui ne pouuoit comprendre plaindre vn mébre qu'on n'a point. $P_{i}$ quoy en fe remettans en leur prem: fentier, vn de la Seree vâ commanc ainfi : Nous eftions vniour en la bou que d'vn barbier, \& ne craindray poin le confeffer, encores que ce foit le lieu, les perfonnes plus abiects fe trouue: pour deuifer,comme les plus honnefte vertueux,\& doctes chez les Imprimeu \& Libraires. Eftans en cefte boutiq (Theophraite appellant les boutiqu des barbiers, banquets fans vin) voicy a riner vn Franc à tripe, qui fe fait penf vue mefcháte main de gorre qu'il auo Or parce que tous le cogno ffions, 0 ne fe peuft tenir de rire \& moquer de yilaine main, tant elle eftoit croufte-1 
\& vlceree. Ce chiragre nous voyant \& moquer de fa main, la monftrant ores d'auantage, va dire, vous riez de e main ? le vay gager au plus hardy, I en y a en la cópagnie vne autre plus chante, plus cicatricee, \& gangrenee n'eft cefte cy. Vn de la troupe va gaque non, \& ie gardois les gages. Lors cun de nous montre fes mains, fans aparaifon plus belles, nettes \& faique celle qu'il auoit fait penfer, nonftree à tous. A infi tous iugerent ce Franc-à-tripe auoit perdu, ne trouuant point en celte compagnie main plusvilaine que la fienne, quád exhibant fon autre main va dire, cefte eft elle pas plus gafté, \& mefchante l'autre que ie vous ay montré preerement? Il fut lors affez long temps puté qui auoit gaigné : car celùy qui ít gagé qu'on ne trounerroit point de ilaine main en toute cefte troupe, diqu'il s'entendoit d'vne autre main des frennes.Le Franc à tripe au conire repliquoit,que la main qu'il auoit ftéla derniere n'éftoit pas celle qu'il it móltré la premiere, \& qu'on auoit penfé, 
VINGT-SEITIESM penfé, \& que c'eltoiét deux mains, l'v droicte, l'autre gauche, \& que la ma droicte n'eltoit pas la gauche. Ie ne $f_{\text {ç }}$ adiouftoit celuy qui auoit fait le con qu'il en fera dit, cependant ie garder les gages, \& ne m'en deferay pas fiail ment. Vn de la Seree, en repliquát, va c re, Si i'eltois en quelque Republique b policee, la gageure feroit appliquee at pauures,ou au public,à caufe que les $R$ mains reiettoiét toutes gageures, qu' appelloiét ludere in pecuniam, fi elles n' foient faites, ou pour la courfe, ou pot faulter,ou pour luiter, ou à qui iettero mieux le dard. Mais cependant, ie vol prie, difoit-il à celuy qui gardoit les gi ges de ne iuger de ce different, iufques ce que ie vous aye faict vn autre conte qui arriua en la mefme boutique, chez 1 mefme barbier, où il y a aufi de la diff culté ? puis anec ceux de la Seree, iuge du tout, encor que ce foit le ventre pleir: car íay trouué en la Ciuile conuerfarion que le prouerbe ancien dit, que le meil leur confeil fort \& procede du vétre qu eft plein,nonoblát que l'efprit de l'hom me foit plus própt \& deliure, \& plus ef 
é à faire quelque chofe fpiriruelle, où aut de l'entendement, quand le corps ieun, que quand il eft remply. Et là is trouuerez les deux eftre veritables, It à fçauoir l'effrit eftre plus prompt a deliure lors que le corps eft vuide, e confcil meilleur apres le repas, s'il nt de perfounes iuftes, equitables, \& nplies de vertu. Pource, dit la Ciuile unerfation, qu'eltans à ieun, \& voulăs re quelque mal, nous y procedons c plus de malice, mais apres le repas Tis'appefantit la fubtilitéde noftre ef$t$, \& s'appaife en partie la volonté de 1 faire eftans plusioyèux ayans prins tre repas, \& refpondans plus gracieunentà ceux qui parlent à hous. Caton que le confirmant, quand il dit, que far alla eftát fobre à la ruine de l'eftat la Rep.Rom. entendant par ces mots, e iamais vn homme faoul n'eult efté fi tel \& inhumain, que de faire ceft' enprife. Ne differez donc, va il direà ix de la Seree, encores qu'ayez le venplein, de decider ces deux doubtes. us auez oui le premier, efcoutez le fead.l'eftois vn de ces iours, commença 
VI NG T-S E ITI E M E il à dire,en la boutique de ce maiftre ba bier, où il arriua vn homme d'affez boi ne façon, pour faire fa barbe, ou pour deffaire lequel vous voudrez. Elle n' ftoit que demy faicte, que voicy arriut vn chicaneur auec fes fergens, \& fes $r$ cords, qui luy mettent la tnain fur le co. let, pour le mener loger au logis des gét de pied, là où lon n'a foint la peine d fermer les portes. Celuy qui faifoit 1 barbe, fe voyant furprins, il demande ce chicaneur (qui eftoit fa partie)s'illu vouloit bailler quelque terme : leque luy repliqua, quel terine voulez vous? L debteur luy rerpond, ie ne demande qu vne lieuë de terme, Les Sergens voyan qu'il vouloit rire, le vouloient enleue de la boutique,n'euft efté que ce debteu obligé a fecoudet pria fon crediteurd luy bailler terme de payer, iufques à qu'il euft acheué de faire rafer toute f: barbe,qui n'eftoit qu'a demy coupee. C. quiluy fut accordé par monfieur le chi quaneur, qui fortant de la boutique l'attéd auec fes fupofts, iufques à ce qu'il ai achetié de faire fa barbe. Ce debteur lors prie fon barbier de laiffer ainfi fa barbe à demy 
S E R E E.

yrafee, \& le paie conme fi elle euft toute faicte \& abbatue:le barbier nt qu'il ne faifoit faire fa barbe que colté, à fin de nauoir occafion de ir dehors, \& par ce moyen eftudier, me faifoit Demofthene. Ceftuy ant fde la barbe que d'vn colté, \& à i faite, fort en la rué:le peuple fe met au tour de luy, cŏme par vne granouneauté, le voiant ainfi bigarré par fage. Le chiquaneur \& les fergents ulant prendre, \& mener en mariee, deffend fort $\&$ ferme, $\&$ dit à fa parju’elle luy a baillé refpit de paier iufa ce que $f \mathrm{a}$ barbe fuft acheuee de fai: qui elle ne l'eftoit pas; \& qu'il n'y en t eneores que la moitié de faite: en sappellát tous à tefmoings $f_{1}$ fon ade partie ne l'auoit pas ainfi promis. ietple là affemblé, qui n’aime la chiaerie, ne les chiquaneurs, soppofe à pture, \& à force de gorrettes, \& de s orbes, font lafcher la prinfe à ces eurs, leur baillás des nopces de Baftellement que le fergent, la partic, \& hiquaneurs furent bien battus en la ence de leurs records : proteftás touLiu.iij.

$H$ 


\section{$V$ I NG T-S EP T I E S M E}

tesfois de la force qu'on faifoit à la Iuf ce, \& de tous leurs de (pens, dómages intereft foufferts \& à fouffrir, le tout adherant, \& les prenans à partie en le propre \& priué nom, comme d'atenta \& intimation all cas appartenant. de fait, adiouttoit celui qui faifoit ce c te, il en fut fait information, \& me fo viient qu'vn des records eftant ouy en i gement de cefte force \& batterie, difo au luge,Monfieur, ie ne receu iamais î beau fouflet à mon gré, que celuy q1 mebrilla vnde ceux qui no' empeich rent de mettre en prifon celuy qui n' tioit la barbe que d'vn cofté. Vous me tes fouuenir va dire quelquautre, parlant de ceftuy-cy qui n'auoit la bar que d'vn colté, de plufieurs nations $q$ ont fait vn grand cas des barbes, comn les ludiens qui celebroient vne felte iour que leur Roy faifoit faire fa barb Nous troumons efcrit que les Ancie par ignominie faifoient razer. les ch ueux \& la barbe à ceux à qui ils vouloi mal ou qui les awoient offenfez, con me fit Hamon aux meffagers de Daui Les Argiens ayans efté vaincus par 
S E R E E.

edemoniens, fe firent tous raire, cöfit Varro apres la bataille perdue cóHannibal.C'eft donc à dire, repliqua le la Seree, que de ce temps là les Rons portoient la barbe longue, mais ie çay qui la leur roignoit: car ils n'euà Rome de barbiers que quatre cés luantequatre ans apres qu'elle fut iee, \& fi ne fçay, quand ils eurent des iers, pourquoy la Loy des douze tadefend aux femmes de faire la barux hommes auec des rafoirs, fi nous uftons foy au rraducteur de Pline, plus quie ie ne fçay pas la raifon des ciós de iour's, \& pourquoi il fait meilcouper fes cheueux, faire fa bar\& rongner fes ongles en vn temps Lutre, ce qu’à obleruél'Empereur ere, qui ne faifoit iamais faire ou re les cheueux, ny la barbe, que la e ne fuft en conionction auec le Soauffi que Marcus Varro difoit, que garder de tomber les cheueux, qu'il ailloir toufiours comper apres la Lune:\& de là les farfeurs d'Almas ont remarqué en leurs Diaires les aufquels il fait bon fe faire tondre,

$\mathrm{H} 2$ 
VI NG T-S E P T IES M E

de faire fa barbe, \& $z$ rongner les ongle la plus-part n'y touchant qu'à ces iour là.Mefmes i'en ay veu de fi fuperftitieus qu'ils n'euffent iamais rongnéleurs or gles à iour de foire,ou de marché, \& faifoient grande confcience de parle quand ils le rongnoient les ongles, 0 quand on leur rongnoit, commençat toufiours par vne grande obferuation fe les rongner áu premier doigt, laiffar le poulce le dernier, ce qu'ils difoier auoir apprins des anciens par vne ce tainecaballe, que sils euffent faict a trement, ils auoient en opinion qu cela leur euft apporté quelque malheu Et aufi, adiouftoit-il, i'en ay veu pl fieurs qui adioultoient foy à vn vers a cien, qui et fans autheur, \& fe gouue noient felon iceluy, ce vers nous appr nant à quel iour il faut faire $f_{a}$ barb couper fes cheneux, \& rongner fes 0 gles.Monfieur de l'Efcale contre ce ver où il ya:

Vingues Mercurio, barbam Toue, Cypri crines,

Et le reprenant, a mis en fes Scholies Aufonne ces huid vers: 
Lercurius furti probat vngues femper acutos, Articulifgue aciem non finit imminui.

arba Ioui, crines Veneri decor:ergo ncceffe eft $V t$ nollent demi guo fibi viergue placct.

cauors imberbes, of caluos Luna adarnafi, Non probibent comi tum caput atc; geras. of Saturnus nibit obfant onguibus : ergo Non placitü Diucs, tolle monostichinm. ors s'efleuát vne Felle-tonduë, va dire, s'en va tard,\& feroit meshuy temps de ous retirer,mais ie vous prie auant que artir d'icy, d'oüir ce qu'à efcrit S. Auguin des chemeux, puis ie vous feray vn onte de la barbe.S.Auguftin, cōmançaa dire, nous affeure auoir veu vn homhe, lequel fans remuer la tefe, \& fans y oucher des mains, foulleuoit tous fes heueux, \& les iettoit fur fa face,puis les eleuoit \& retournoit derriere fon chef. oila pour vous efmerueiller, \& voícy our vous refueiller, \& $<$ faire rire. La cou ume a eftédifoit-il, de porter les barbes outes rafes, ce qui a duré vn long temps. it lors que les plus gaillards commenceent à vouloir porter la barbe longue , \& ontreuenir à celte couftume, commanlemens furent faits 2 cry public à toutes. 


\section{VINGTSE P TIESM E}

persŏnes de faire raire leurs burbes. Si quoy fut prefenté requefte par vn bo Drolle, tendant a fin qu'on luy interpe taft de quelle barbe s'entendoit le $\mathrm{cr}^{\prime}$ \&z quevouloit dire le criarit, parce qu'e fe voulant raire vne autre butbe que ce le du menton, il s'ertoit bleffé iufques a fang. Ii faut bié, adiouita-il, qu'il y aite la barbe quelque dignité \& myitere,pui quaucuns la permettent, les autres 1 defendent aufri que i’ay leu en Antoin Ientrinfon, Anglois, en fa defcriptios nonuelle de Mofcouie \& Tartarie, qu les Medes \& les Perfans, encores quil foient Mahumetans auffi bien que le Turcs \& Tartares,ne laiffent à fe fairek guerre les vns côtre les autres, tát à cau fe de leurs ceremonies diuerfes $\&$ diffe rentes, que principalemét parce que le: Medes \& Perfans ne veulent pas fe fair rafer la mouttache, comme font les Tartares \& les Turcs. Quine fçait, va dire quelqu'vn qu'il n'y a pas long temps que les grands cheueux eftoient l'ancienne marque de beauté $\&$ de nobleffe, mefme eftant defendu aux roturiers de porter les cheueux longs? Toutesfois depuis on 
It moqué des grands cheueux. Ce qui iua dece que le grand Roy François fit tondre pour guerir vne playe qu'il oit en la tefte, \& foudain tout le peufut tondu, tant nous fommes imitairs de ce que font nos Princes.

ING T-HV IC T I ES M E SEREE。

Des Pcintres of Peintures.

L fe trouyoit en nos Serees vn de OS noftre ville, lequel encores qu'il thofte n'auoit laiffé à eftudier \& hanles gens fçauans, outre ce qu'il eftoit illard \& ioyeux, aimant cópagnies reeatiues \& facetieufes: \& ne fant s'e hir de ce qu'aux plaifantes affemblees, if fe font pour recreation, \& pour s'efudir, \& reltaurer des trauaux \& enis paffez, on fuit les perfonnes fafteules, rioteufes \& difficiles, \& qu'on accompigne d'hommes gaillards, efillez, rians, \& pleins de gayeté, pource l'efprit de tout homme eft grandeent recreé,oyant \& voyant chole plainte \& aggreable à l'oreille \& à l'œil,

$\mathrm{H} 4$ 


\section{VING T-H VICTIESME}

à raifon quil y a bien grande differenc entrel'affemblee \& conuerfation qui faict pourle plaifir, \& celle qui eft $f_{a}$ cte pour traicter \& capituler affair d'importance. Que fi quelqu'vn, con me dit Promethee à Mercure dans. $\mathrm{L}_{\mathrm{l}}$ cian, reiettoit les ioyeufetez des bar quets, à çauoir la tromperie, les bre cards, les moqueries \& rifees, feulemer seiteroit l'yurongnerie, la gourmandif le filence, triftefles, abfurditez, \& chc fes qui ne conuiennent en aucunem: niere aux repas.Parquoi ne faut s' efmet ueiller fi nous allions fouvent fouppe chez ceft holte, qui eftoit fort recreatil \&zde bonne compagnie. Or vn iour d'Hy uer eftans entrez en fa falle pour foup per, \& nous approchans du feu, nou voyons au manteau de la cheminee vn femme en peinture, bien belle, \& bie elabouree, qui fembloit dire, Ma cham briere eft par le derriere, laquelle ef plus belle fans comparaifon que moy $\checkmark n$ des noltres ne faillit pas incontinen d'aller regarder dans la cheminee ${ }_{2} \&$ fan crainte du feu, va voir fi la chambrier eltoit plus belle que la maiftreffe,y ayant bien 
in regardé, fe print à rire, \& nous va eurer que la maiftrelle difoit vray. La is-part de nous voulans. voir ce qui en oit Au lieu de cefte belle feruante, on uua elcrit en grolfe lettre : Sotart, tu unes tes chauffes. Auffì à la verité,'c'eient bien de grands badins de penfer ir en vn lieu fi fumeux vne belle pein-re.ll eft vray que i"y fus comme les auis, mais c'eftoit pour n'eftre veu mefifer noftre hofte, à qui fon inuention tifoit. De là, on printoccafion de pardes peintures, \& des peintres, \& de la urtraicture, apres auoir ry de ces fois, mais non pas beaucoup, parce que luy qui auoit fait cefte pourtraiture \& inture eftoit decedé il n'y auoit pas lóg. mps, lequel viuant nous tenoit bonne: mpagnie en nos Serees, homme aimae \& fingulier en beaucoup de chofes, cores qu'il nè beuft que de l'eau. Et dii, fans mentir, qu'il entendoit fort bien: blafon des armoiries, l'ayant veu reendre les peintres du Roy, \& les peines de l'ordre, és armoiries d'Elpagne, rs quele Roy Henry tenoit fon: ordre S.Michel à Poictiers. Ce peintre auoit H. S 


\section{VING T-H VIC T I ES ME}

cela de bon, qu'il ne flattoit point les $h$ mes en fa peinture, ne les pourtraya plus beaux qu'ils n'eftoient, car il fe tro ue des perfomes qui prennét plaifir d' ftre flatees \& deceuës, mefme en la pei. ture,aimans les peintres lefquels les o peints vin peu plus beaux qu'ils ne fon \& fr en y a beaucop qui cómandent à te ouriers qu'ils oftent quelque deform té deleur face, ou grandeur \& petiter de leurs nez, defirás qua'on adioulte que que chole aleur beauté,ou qu'on les fac gráds s'ils sót petits. Ce qui n'elt pasme mes permis aux vainqueurs des Olym piades, aufquels eft defedu de faire dre fer des ftatues plus gráds que leurs cor ne font, car en ces ieux, ily a des cómi faites qui ont charge \& foinde necerche qu'il n'y ait aucun qui temerairemét ex cede la verité, \& procurent que la ftatue qui eft erigee à l'honneur du vainqueur foit exactemét correfpódante à l'hiftoir du combat de chacun luteur, \& à la me fure de fon corps. Parquoy il faut regar. der que nous ne preniós oscafioin de mé. tir en la mefure, \&z en la beauté, \&z en la proportion des mébrés, de peur que puis 
- s e:R e e.- : * 7 84

resles Surintendans \& Premofts renrfent noftre ftatuc. Pour vous monfter e ce peintre eftoit accort $\&$ d'efprit, ux de fes rencótres vous en afleurerót. premiere, eft d'une religieufe \& dcuoeufe fille, laquelle ayant deuption à vn inct, cómanda à ce peintre de luy faire atableau, où il y cuft vn S. lerofme; de atlequel elle feroit à genoux, les mains intes, cóme vierge \&r pucelle. Le pourait acheué, il fut apporré à cefte ieune le, lequel elle trouua bien faict, eftant bien reprefentee au vif, hors mis qu'eltromua celte fille pricelle, qui eftoit au blean, \& qui la deuoit represéter, trop etite, \& qu'elle eftoit plus grande que effigie quila reprefentoit dansla pein" rie. Le peintre lors va dire à cefte deuofille, que puis qu'elle votuloit qu'illerefentaft denant ce Saind vne vierge \&z ucelle qu'oninen tíounubit point ence emps, qui ne fuf bien petite \& auffi eune, \& en l'aage \& grandeur qu'ill:aoitpourtraite, que s il euft fait cefte flle lus grande, \& de mefme grandeitrque He eftoit, \& de inefmelage, on ' n'ent ámais penfé qu'ede eunt efté vierge $s x$

H 6 


\section{VING T-H V IC T IES M E}

pucelle, comme elle vouloit eftrérepr fentee. Ce qui contenta cefte deuotiea fille, qui recompenfale peintre defonk beur. Ceux de la Seree euffent ris dauar. tage, n'euft efté la founenance de la mor de celuy qui auoit faict la peinture, $\&$ la rencontre, qu'il fallut pourtant enco res renouueller, pour cóter qu'vn autre foisil peignit les armoiries, d'vn vilai nounellement annobly, où il y a toul iours à mettre \& à ofter,car on dit: qui les armoiries d'vn vilain, font faites : plaifír. Si bien qu'en peignát ces armoi. ries,ce vilain, pour qui elles eftoient, $n t$ fe contentant iamais, le peintre futcontraint de luy dire, Ie ne fuis iamais plus empefché que quant ie fay les armoiries d’vn vilain, il y a toufiours à redire. Vne Feffe-tondue, pour nous ofter la memeire dece peintre, qu'vn chacun regretoit nous va conter qu'il anoit véu iouër la paffion à Saulmur;où il y a encore quelque refte de theatre ancien, \& qu'entre autres chofes fort fingulieres qu'il auoit remarquees en ces ieux, c'eftoit que le Paradis eftoit fi bean, à caufe de l'excellence de la peinture, que celui quil'auoit

faicts 
S E R E E.

$c t$, fe vantant de fon ouurage, difoit z̀ us ceux qui admiroiér ce Paradis, voisien le plus beau Paradis que vous vis iamais ne que vous verrez. Puis us va cóter cóme ce bon peintre auoit lenélà deux de fes enfans; qui n"eftoiêt eres beaux, \& fi eltoient fort petits, iiets \& minces, \& que quelqu'vn luy unt demandé pourquoy il les faifoit fi ds, \& fi chetifs, veu quail auoit faict en Paradis de fi beaux i mages, \& belles atures, qu il auoit refpódu, Ie fay mes. ages de beau ionr, \& mes enfans de it, s'ils sót maigres\& chetifs, auffi fuis eul a les faire.Ie ne fçay, va dire quelvn, fil les peintres, anciés \& Itatuaires foient leurs ounrages, de iour ou de ict; ou s'ils. les fabriquoient fans aide, is il me:femble, à ce qui en refte, qu'ils uailloient bien lourdement, eftans rs.ftatuës \& peintures plus grandes \& ffes, que le naturel,fans garder les prortiós du corps, car il fe trouue que les tuaires\& fculpteurs d'Egypte, eftoient dextres à mefurer vn corps humain, e par vne dimention certaine, encore ils fufsét en diuers. lieux, ils formoiêt. 


\section{VIN G TIK VICTIESM E}

les membres d'vne ftatuë de diuerl pierres, \& chacun failoit le fien, fans c muniquer les vins auec les aurres, \& pu les mettoient enfemble, \& 2 eftoit cho fibien faicte, qu'il fembloit qu'elle $f$ toute d'vne piece, $\&$ d'vn feul ouurie Il fut repliqué, que les anciens ne fa foient ces ftatuës \& pourtraitures ain à l'aùenture, ou par ignorance, ou $p$ negligence, mais auec raifon. Que fil peintres, fculpteurs \& Itatuaires vieux temps ont faict les hommes plt grands \& gros en ce temps-là,que not ne fommes maintenant, \& qu'on ne lo peint pour le iourd'huy, c'eft parce qu ils eftoient plus grands \& puiffans qu nous ne fommes maintenant, dautăt, $d$. foit-il, que de temps en temps, \& d'aag en aage nos corps diminuent: Ce qui e tout clair, fi nous faifons comparaifo des offemens de nos majeurs, que nou troukons tous les iours, \& tirons d terre, aux noftres, \& à caux de ce temps fe faifant la diminutionide nos corps de la chaleur bruflante 5 qui confom me \& defleichel' affluence ide nof tre fe mence. Vnatutre rendantvne autrerai 


$$
\text { S E R E E. }
$$

$n$, difoit qu'anciennement on reprentoitles perfonnes grandes, non que les fuffent telles, mais pour monftrer ielles auoient fait quelque grand cas us que les autres : a fin que celte pouraicture grande denotalt que ceux qui t merité quelque loiiange $\&$ honneur uoient exceder en grandeur tous les tres. Ainfi les Anciens, pour denoter 'aduenir leurs Republiques auoir efté en grandes, baftilfoient de grands ololies, qui eftoient ftatues de demeree hauteur, dreffee par eux en l'honur de leurs Dieux. Et auffi faifoient 1a, pour demontrer que leurs Dieux toient grands, comme à Rhodes ils ftirent vn Coloffe du Soleil, fi grand \& perbe, \&z de tel artifice, qu'il fut remmé entre les fept merueilles du onde. Voila pourquoy, difoit-il, les omains, fuimant les Grecs pluftolt de les Egyptiens, faifoient leurs peinures, ftatues, portraits, ,images, idoles, femblances, grandes, felon qui ils eftioient que leurs faits fuftent grands, \& Ion qu'ils auo ent merité de la. Rep. ià eft venu, adiouftoit-il, ce que difoit Ciceron: 
VING I-H VICIIES ME

Ciceron de fon frere Quintus, le voya: portrait, en la prouince qu'il auoit go uernee, feulement iufques à la ceintur Mon frere n'eftant que demy, eft pl grand que tout entier : eftant Quint. , petite ftature. Vn autre parlát pour l'a tiquité, difoit fi nous voyons. les imag \& ftatues des Anciens f frgrandes \& los gues, que c'eftoit comme il auoit leue Bodin, que nos predeceffeurs ont eftir les vifages plus longs, les plus beaux , ? qu'à celte caufe les fages-femmes dec tempslà, reduifoient les vifäges des er fans recentement nais, à la plus grand longueur qu'ils pouuoient, comme le Perfes faifoient du nez. Or ayant le vifa ge ainfi log $g$, il falloit que les autre mem bres fuffent proportionnez àleur vifag long, non pas qu'ils les euffent naturel lement filongs.. Ie ne croy pas, va repli quer vne ioyeufe féme de la Seree, qu'o1 puiffe ainfiallonger les membres des pe tits enfans quine font que de naiftre,ca ficela fe pounoit faire, les femmes dt iourd'huy allongeroient bien pluftof quelque autre chofe, \& n'euffent pas laiffé les membres comme ils font. Enco- 
que toute la compagnie fe print à riauffi bien que cefte gaillarde dame, fi -ce que le propos fe continua, quel'vn cómançant à dire; I'ai veu d'autres intures \& ftatues fort deliees \& lon. ettes, iene fçay à quelle fin veu que les rfonnes du téps paffé, non plus que de Ituy-cy, n'eftoient pas ainfi longues \& nces. Illuy fut refpondu, que les Ansne faifoiét pas fans raifon les images "guettes $8 r$ " grefles, n'ayans gueres de rps, mais que c'eftoit pouridemonftrer ce la Diuinité n'eftoit point vne chofe rporelle\& quà cefte caufe les Egyptiés ui de tout temps ont eu en grande remmandation vne Diuinité) ont faiqué leurs ftatues $\&$ images non grofs \& amples, ayans bien per de corps, ulans demonftrer par là, que la Diuité eft vne chofe fpirituelle, \& non int materielle ne corporelle. Vn de la ree fe meflant parmy cefte difpute, sus va dire, qu'il falloit regarder de del païs ont efté les artifans, qui ont int les images \& Atatues, \& quels :uples ils ont voulu peindre \& cone-faire, auant que les reprendre des propor 


\section{N G T-H V I C T I E S M E}

proportions, que nous penfons auc eltémal gardees \& obferuees, eftant $v$ chole certaine que le vifage des hor mes fe varie, \& que la grandeur \& pe teffe des autres membres eft diuerfe lon la fituation dont ils font, \& lat gion qu'ils habitent : auff bien que no voyons les bettes d'vn païs different decelles d'vne autre contree, encor qu'elles foient de mefme efpece. Et 1 roit vn maunais oumrier, difoit jl,qui f roit le vifage des hommes de paiis loin tain, de melme groffeur, grandeur largeur que ceux de noftre Europe. $C_{i}$ files peintures \& ftatuaires veulent bie reprefenter \& $\&$ pourtraire vn habita! d'Áfie, il faut luy faire la tefte longut comme ils liont, non pas naturellement mais artificilement, pource qu'ils eft ment cela beau, \& 2 eftre figne de bon ef prit, comme aux Perfans le nez aquilin A celte caufe les Grecs appelloient ce géslà Macrocephaly, comme on mia fait? croire. Qưe files bons ouuriers veulent contrefaire vn Indien, ils ne doiuem garder les porportions communes des autres peuples : ayans ceux-cy:levifage $2 x$ 
long, \& la face plus platte nature!ient : que s'ils veulent reprefenter More, 11 faudroit de mefme le faire camus qu'vn de ce païs, \& plus noir, int les leures groffes, \& les dents plus hes, auec les cheneux frizez \& recoIlez. Que fi vous eftiez, adiountoit-il ores, en la terre des Negres, vous verqu'ils peignent ordinairement les fonnes quils veulent reprefenter plus belles, lesplus camufes \& noiquill leur eft poffible : commenous pourtraions blanches, fans eftre caes, Pour celte raifon, les Mores forrt eignent leurs Anges noirs, comme ont,difans qu'ils s'apparoiffent à eux fours noirs, \& font les diables blancs ame nous fommes, \& difent qu'ils fe iftren:\& apparoiffent à eux toufiours ics, contre Monfieur Bodinqui dit en emonomanie, que les diables font rs : car les diables apparoiffent blancs noirs, \& fe prefentent à nous, qui imes blancs, tous noirs: \& celuy femaukais peintre \& fculpteur, qui efenteroit vn Ange Ethyopien blane vn diable Ethyopien noir. Que quand 
VING T-H VIC T IES M E quand mófieur Bodin dit que Leon frique efcrit, que les forciers \& $\mathrm{M}$ ciens de fon país inuoquent les deri blancs, ie croy 'qu'il veut dire qu pellent les mauuais demons. diables, parce que les Affriquains. peignent blancs, comme nous les re fentons noirs. Et ne s'enfuit pas que Affriquains n'appellent les diables leur Magie \& Nigromance, auffi b que les Enchanteurs de pardeça, en res qu'on die quails n'vfent que de Magie blanche, \& qu'il n'y a que la n re deffendue, dautant qu' ils nomm

- cefte Magie blanche, non pas qu'ellel permife \& bonne, mais parce que ce de qui ils s'aident font blancs : tol Magie, foit blanche ou noire, efta contre Dieu, \& pleine d'impieté. $M$ pourquoy, demanda vn de la Seree, ce, que les peintres font les diable foient noirs, foient blancs, , i horribles cötrefaits? Seroit-ce point, luy fut-il r pondu, qu'ils ont perdu cefte beauté, $q$ fit monter Lucibel en fi grand orgue Puis fut demandé, reuenant à la gra deur des images, pourquoy és voult 
Eglifes lon trouuoit affis en vne ire vn homme en peinture fi grand gros, que ceux qui entrent és Egliont peur qu'il feleue debout, pouen fe redrellant ruiner toute la vouIl fut dit que cela n'eftoit point ainfi rtraict fans caufe, les peintres \& les gers s'accommodans toufiours au ple peuple : comme pour montrer slegende, que Sainct Sebaftien a elté rtyrizé auec des fleches, \& que celuy en eft lardé par tout le corps, eft $\mathrm{S}$. aftien, il eft peint ayant des traicts tout fon corps: \& en y a beaucoup ne cognoiffent pas vn Sainct, finon marques queles peintres \& ftatuaileurs donnent. Vin Franc-à-trjpevot qu'on auoit efté long temps faris ritoutesfois fans fortir hors du propos a Seree, nous va conter vne hitoire n peintre \& de la peinture. l'ay cou vin peintre, cornmença-il à dire, leel ayant peur qu'on luy aydaft à faire images vifues, s'en voulantaller aux ips pour faire quelquebefongne enprife, fe doubtant de fa femme, \& vn autre oumrier vint befongner à ron 
VING T-H VIC T I ESME vint befongner à fon haftelier luy peindre fur le vétre vn afne, luy difant cognoiftray bien fi tu fais la folle, \& on frotte fon lard contre le tien: car vous iouiés à ce ieu,ie trouueray toute peinture effacee \& barbouillee, \& co gnoiftray bié fi vn autrey a mis la mai tant excellent ouurier \& parfaict ma fre puifle-il eftre. Ce,peintre, qui s'a feuroit qu'on n'euft fceu refaire celt alr qu'il ne l'euft cogneu,s'en eltant allé, $v$ autre, pria la femme de ce peintre, de laiffer befongner à fon haftelier, \& $\mathrm{P} a$ feuroit que fon mary ne befongnoit pa fi bien que luy. Elle luy refpond, pui qu'il eftoit fi bon ouurier, quelle le vou droit bien:mais, luy difoit elle, mo mary auát que fans aller m'a faict, peint \&z portrait vn afne fur le ventre, qui s'ef faceroit, encores qu'il foit a huile, \& pa là il congnoiftroit que nous aurion joiié à ventre contre ventre : car il eft I excellent en fon art, qu'on ne fçaturoi imiter fon ouurage qu'il ne le congnoif fe. Ne te foucie, va repliquer ceftuy qu difoit en fçauoir autant que le mary Monfte moy ton ventre, \& que ie voye 
maiftre afne : ie malfeure, lors que mary deura reuenir, de t'en faire vn ibien faict, \& auffi au naturel, \& fi blable au fien, qu'il penfera que ce celuy mefme. Ayant veu l'afne, il figrand' enuie de monter deflus , \& uaucher l'afne, qu'il ne regarda pas eftort bafté ou non. Parquoy, eftant ne tout effacé \& barbouillé, \&le mary nt preft à reuenir, quand il fut quende refaire l'afne qu'ils auoient deaturé, en lieu qu'iln'eltoit point bace bon maifte lans y fonger $v a$ batter angler celuy-là qu'il luy fit, en meflieu où eftoit l'autre : la féme le trou$t$ fi bien fait, \& fi fembable à l'afne on mary, qu'elle s'afleuroit que fon y n'y cognoiftroit rien. L equel eftant enu, voulut fçauoir, auát toutes chofil'afne eftoit en fon entier, auec fa ture: mais voyát qu'il auoit vn baft, i'il eftoit fanglé, il va dire tout haut, ous les diables l'afne, \& celuy qui afté, \& voila dont eft venu le probe François , A tous les diables l'af, \& qui me l'a balté auiourd'huy. 
VING T-H VICTIES M E Ce conte acheué, quelqu'vn va dema der vne chofe, à quoy poffible beauco n’ont pas pélé:ce'eft pourquoy il y a à l'e tour des excelléts ourrages, \& z bien e boureztableaux, des chainettes.ll fut $r$ pondu, que quand cesbons maittres vo loient monitrer vne piece eftre parfai \& exquife, \& là où il ne falloit plus mı tre la main, qu'ils mettoient à l'ento de ces diuins ouurages, des chainettes liens, pour donner à entendre aux $\mathrm{pl}$ fpirituels, que ce tableau eftoit faict tel artifice \& indultrie, que s'il n'eft retenu \& enchainé,il pourroit s'en alls comme s'ils euffent voulu empe Tch $^{2}$ ceux qui eftoient auiez en ce tableau , bouger de là. Ce que faifoient auffi, a iouftoientils, les Atheniens, au fimul cre de virtoire, \& fila peignoient, enc res qu'elle fuft enchaince, Ians aifles, $\mathrm{cr}$ gnans qu'elle s'en volaft aux autres, $\&$ i la vouloient retenir pour eux, mefin les Tyriens, eitant leurvilleaffiegee, ei chainerent les images de leurs Dieux; peur qu'ils s'en allaffent. l’ay veu va dil quelqu vn, vne fois en ma vie vn tablea où il y auoit, comme vous dictes, $\mathrm{d}$ t 


$$
\text { S E R E E. }
$$

s \& chainons à l'entour de la peintulà où il me femble qu'il n'en failloit t, d'autant que dans ce tableau il y it vne femme qui fe mouroit, dont e deuoit craindre qu'elle s'en allat, plus que fon fils, à qui elle donnoit act de fa poictrine. Ce tableau, di-il, eftoit libien faict qu'il reprefenvn enfant prenant la mammelle de ere, laquelle fembloit moutir d'vn d'efpee qu'elle auoit receu en la te, que ce petit cnfant fucçoit, mais seufiez dit gue cefte mere fembloit ir \& craindre que fon enfant ne fucfon fang, quand fon laict le mouroit clle, vous alfeurant que ceux qui vice tableau, auec moy, furent fi efis de pitié, que pour rien du monde ieuflent voulu le retenir en leurs fons, tant cefte peinture attriftoit qui la regardoient, encores qu'ils euft au möde vne telle piece, \& quád ne la donneroit, difoit-il, iofterois iens \& chainettes qui femblent les nir, à fin que cette mere, qui femble irvn peu devie, emportant fon fils fuif de deuant mes yeux, tant 1 'auois Liu.iij. 
VING T-IF VIC TIES M E grande pitié \&z de l'vn \& de l'autre. ne faut, adioultoit-il, trouner ce tabl eltrange, veu qu'en Syracufe il y auoit tabieau, où eltoit peint vn boiteux, fembloit auoit figrand mal aux iam que tous ceux qui le regardoient f bloient endurer partie de fon mal. veu aufi, va dire vn autre, vn tableau Medee tuë-enfant, non moins clabor ayant desliens à l'entour, qui eftoi bien faict, qu'il fembloit que $\mathrm{Me}$. (combien qu'elle fuft bien furieufe tuer fes propres enfans) craignilt de occire, \&z qu' elle ne les túoit qu’à regr \& comme forcee : fon vifage fembl. enfurié \& pitoyable tout enfemble. y auoit deffoubs ce tableau ces qual vers, que i'ay laiffé Latins, parce qu' neles fçauroit fi bien mettre en Fra çois:

Q2uod natos feritura ferox Medea, moratw Prafititit boc magis dextera Timonachi. Tardat amor facinus, frictum dolor inci enferm,

Vult, non vult, natos perdere of ip $\int_{a}$ fut Et au deffoubs des vers Latins, il y en. uoit quatre François, de mefme fubjeć 
icy la face de Medee

c deuxpafions agitee, $n$ le cognoijt bien a jes yeux,

on eft doux, l'antre furieux.

oy difoit vn autre, $i$ 'ay veu Venus fi fendormie, qu'vn chacun craignoit refueiller, außi le peintre auoit mis ed du tableau:

uis gu'endormie icy, Apelle, um' as faicte, ie dorrniray:

autrement ie fortiray

e ton tableau. fil'on m'efucille.

e n'eitrien de voltre Medee, repliindela Seree, ny de voltre Venus rmie, au prix d'vn Dauphin, que it Arion, eftant ce Duuphin fibien quion poutuoit iuger qu'il prenoit it au fon de l'infrument d'Arion, \& regret ce Dauphin atriuoit au port ece , \& qu'il euft voulu eltre plas du riuage, pour iouit plus long s de ceite harmonie, ce tableau ayăt ndu ces quatre vers de du Bartas: auphin de founrä le bord tant foubaité, irrnente à part foy de s'cftre tant hasté, ur pius longuemet humer cefte harmonie roit cent fo is plus loin $\int c_{\xi} \pi$ uir $\int a$ Laconie. 


\section{I G T-H VI G T IES ME}

I'ay vn tableau en ma maifon, nous dire quelqu'autre, qui eft fi bien po trait, que i' $y$ ay fait mettre des liensts à l'entour, de peur quiv vn homine gui dedans s'en allaft, \& haiffait le table xnuide, combien que ceft höme eft $f_{i} b l$ fé qu'on le void tirer à la mort, mais faict auectel artifice, qu’ony peut: marquer combien de fouffe il a encos au corps,\& le temps quil a à viure. ( diuins tableaux, repliqua vn de la Sert font faits ou de la main de maitre: mon, qui fit la pourtíaicture de Madat Laure, quePetrarque portoit par tout il alloit, ou bien de la main de celuy $q$ ennoya le feigneur de Rimino en Are pour peindre Petrarque, ou bien de ce de meffer Raphaël d'Vrbin, qui a pei. le banquet des Dieux, ou de la main. Michell'Ange, qui s'eft rendu admir ble en la peinture de fon i igement, $c$ de celle d'André de la Montagne,qui e ri excellent en fa Iriomphe. Ma raifo eft,adioufta-il, parce que ces tableaux i beaux ouurages, que vous auez nomme cy deflus, ne peunent eftre faits du pin ceau de Polgnot, lequel peign it gratui 
ent le Portique d'Athenes, dit Pre, où les Stö̈ques demeuroient tout ur, ne de Paufanias, qui reprefenta amie Glicera bouqueriere, fi bien fee de guirlandes \& chappeauz de rs, quel'art combatoit auec la natue de celuy de Protogenes, lequel peila figure de Ialyfus, où il fut fept ans us, ne d'Apelles, qui fit vn tableau ftoit peinte Venus fortant de la mer ${ }_{3}$. iel fut mis par Octauian au temple ules Cefar, \& eltant galté, en vn enit,il ne fe trouua iamais homme qui l'hardiefie d'y mettre la main pour acouftrer: encores moins d'acheuer ourtraict d'vne autre Venus parluy umencé, \& non acheué, defefperans. e rendre conforme à fon commenint, ne du pinceau de Timanthe, peignit Iphigenie prefte à facrifier; dant les affintans \& regardáns fi tri\& troublez, qu'on ne l'ofoit regar\& qui fit auffi la pourtraicture d" $A$ aemnon la tefte enuelopee en fon nteau, fa main ne poutuant fuffifam: nt reprefenter la defolation paterle,ne de celuy de Zeufe, qui prefenta.

$$
\text { L. } 3
$$


VING T-H VICIIES M E vn tableau, où eftoient deux raifins, trompoient les oifeaux, ne de la bo que de Parrhafe,lequel trompa auec rideau,le mefme oumrier qui auoit péles oifeaux, ne de la main d'Ephra qui peignit le vifage de Paris, auque vn temps, \& tout a la fois, il apparoil iuge des Deefles, amant d'Heleine meurtrier d'A chille. Ie dy donc, adi Aa il,que ces beaux tableaux quon a inez cy deffus par excellence, ne $p$ uent efre du pinceaure de la main ces diuins peintres, dautant qu'il. long temps que leurs tableaux font ftez, pourris, \& vermolus. Vin dela ree repliquant, va dire $: E t$ pourquoy tableaux de ces grands maiftes ne po roient auoir duré iufques en ce tem eftans fi curieufement gardez, à cal de leur excellence, de l'eau,du feu, de l': \& du vent ? Nous trounons les Pyran des d'Egypte eftre encores prefques leur entier, combien qu'ily ait trois n ans qu'elles ont efté faictes. Et puis dit que le buis, le cedre, l'ebene, 1 : le geneure, dequoy eftoient faicts $c$ tableaux n'enuieilliffent iamais, \& n' 
fubjectsà quelconque pourriture ne moliffure, les arbres amers n'eftans ais mangez de vers, comme le cy$s$, ni ceux qui font durs, commele $s$, \& fur tour on eftime le cypres pour uree, ne fentant iamais la vieilleffe. cefte caufe Platon dit que les Loix Igranoient en tables de cypres. Et que peintres apprennent, adiouftoit-il, tous ces bois fe doiuent coupper, in duter à iamais, lors qu'ils font en e, \& qu ils commencent à jetter, quăd veut vfer de leur rond, fans les fendre efquarrer, les autres bois quion efarre, fe coiluent conper entre Decem\& Feurier 'quandle vent fueillu cónce à regner. Et qui perpetuè encores is, difort 2 ill les matieres dont on fait tableaux, les ftatiës, \& autres chofes, t vne efpece debitumen, que fi vous frottez quelquie chofe que ce foit, le 1 , nel eau, ne lavermoliffure, ne la iille, ne la fçatroient iamais empirer, ter ne cófommer. Ft de fai t, il y en a aucoup qui difent qu'on tronue encodes armes des Amafones, gardees par bitume, \& auffi que de noftre temps 
VING T-IV I C TIESME on a trouuéaux ruines de Romevne tuë d'artifice tant accomply, qu'il eftimé diuin par les excellens fculpte Etne doute-on point que cefte ftatuë foit de Praxitelle, parce que nous lif en Paufanias, \& $x$ és harágues de Cicer \& en Pline, que Praxitelle fit trois Pat $_{1}$ de Cupidon, \& $x$ celle qui s"eft trouuee reprefente dormant en vn berceau do fur vne peau de Lion, nud, auec l'arc \& troulfe au colté, vn peu charnu,en l'aa de dixhuict mois. Noftre Meffer Pant lon, ayant noté ce qu'on auoit dit, col mença à nous dire, Vous auez mis $\mathrm{N}$ chel l"Ange entre en les meilleurs pei tres des modernes, comme à la yerité eft, toutesfois fi l'ay-ie veu reprend en vne finne image \& pourtraicture la Vierge Marie, qui eftoit au Vatica tenant fon fils mort entre fes bras, pa ce qu'elle eft là trop ieune, l'aage qu'el femble auoir ne refpondant aux ans fon fils. Ne vous amufez pas en.fi petit chofes, repliqua quelqu'vin, veu qu nous troumons que tous les peintres or bien pourtraictles eftoiles à cinq rayor \& poinctes, encores qu'elle foient ron 


\section{S. E R E E.}

, que s'ils les ont peintes ainfi pous nóftrer leur brilláte lueur, fi eft ce que lus grand part des eftoilles ne brillét ieftincelent pas. Et attendu la fuffice des anciens peintres, ie ne croy qu'ils ayent peint le Pelican auecvn: aigu, comme font ceux de ce temps, ce qu'ill'a mouffe \& plat, ce que mô. fon nom, qui eft Grec, \& qui fignine ache \& doloire,comme on $\mathrm{m}^{\prime} \mathrm{a}$ Toutesfois, adiouta il, ce n'elt pas du rd'huy quion dit:

frours egal pounoir \& bardieffe ont bew. poëte \& le peintre, en ce qu'ils ont voulu cores quion ait mis en ces deux vers, dire vn de la Seree, \& le Poëte \& le ntre enfemble, caufe que Simonides: la pourtraiture eftre vne poëfie muet\& la poëfie vne peinture parlante, et-ce quel'vn a bien eu toufiours plus çauoir que l'autre, car on ne fçauioit que les peintres de ce temps ne refnblent la monnoye rongnee, eftans ss lettres. Ce qu'on peut cognoiftre li. at ce qu'ils mettent furles fepulchres, aux pieds des tableaux, les tableaux efmes eftans fimal faicts, qu'on ne reI. 5 


\section{VING T-H VIC T IES ME}

cognoift point ceux quion a voulu pou traire au vif, comme c'eft voulu joï quelqu'vn par deux quadrins:

Quand le pintre ent faict ce tablea Pour recognoistre ta figure, Il denoiten vn ef criteau Aettre, que cefo foit tapeinture.

Sile peintre n'euft pas efcrit

2) we c'eftoit icy ta peinture, Affeure toy que l'on euf dict Que c'efto it vne autre figure.

le me doubte bien, repliqua vn aut: que les anciens paintres \& Atatuair ont efté plus fçauans en leur art,qu ceux de noftre temps, mais non pas tol \& y en amoit d'ignares, car nous trot uons qu'Alexandre n'a fouffert que fo image fult iettee en bróze par autre, qu par Lifippe, tiree auec le pinceau d'au tre que $d^{3}$ Appelles, grauee en marbre burinee d'autre que de Pirgotele. Que à l'imitation d'Alexandre, dit Equicola d'Alueto, Amour n'euft ếé depeint qu par bons mailtres, qui euflent enfuiu Jes doctes, on ne luy verroit pas le ban deau deuant les yeux. Qu'il ne foit poin aueugle, dit Equicola, on le fcait de qu'er 
S R E E. $\quad 96$

en la proclamiation, \& cry de Venus, poëme de Mofcus, où elle propofe et à celuy qui trotiueroit Cupidón du', en defcriant fon fils, il n'eft faict cune mention qu'ilfoit aueugle? \& le uerbe porte aufi, qu'Amour naift voir,\& fi Platon \& A phrodifee ne luy nent aucun bandeau, $\&$ ne le font llement aueugle. Que fi Virgile, dit uicola, \& Catule appellent A mour eugle, ils entendent caché \& fecret, \& el'amour aueugle le ingemét, \& non int que Cupidó foit priué de la vetiè. ze sil euft efté auengle, tous ces anis, \& bons peintres, \& tous les excellés tuarres ne l'euffent pas oublié: car ils. la:foient rien à exprimer tant petit -il:Car Ly fipptis faifant la ftatué d'Aandre, n'oublia point à luy tourner la ce vers le ciel, côme il anoit accouftude tegarder tournant vn petit le col, ne il fit fon profit,y mettant ces quatre rs:

Ce bronze estant d' Alexandre l'image Iettant à mont les yeux ê levifage, A Inpiter formble dire: Pour roy Retiensle ciel, car la terre ef pour moy.

I 6 


\section{VING T-H V IC I IESME}

$I$ ay veu va dire vn autre, vne fatuëa tique de bronze, d'vn enfant, qui elt fi bien fait, que volis euffez dit qu' il s ftoit vne efpine du pied, \& faifojt piti ceux qui le regardoient.parquoy, le pei tre auoit mis au pied de ceit enfant:

Si ceft enfant te farict pitić

2, A A caule de fos triftemine,

Helas tofte luy gefte espine.

Quile pique dans le pied,

- Et apres il t'en rendragrace

Anec vne riante face.

Vous trounerez; adiouftoit-il; qu'vn blius peintre, peignit fi bien fa chate, $q$ Martial dit:

Aut vtramque putabis effe veram, Aut vtramque putabis effe pictam.

Lequelartifice, repliqua vin de la Sere eftoit faicte la vache de Miron, qui tri poit \& les homnaes \& les bettes, encort qu' elle ne fuft que d'airain, fi approchar te du naturel, que les thaureaux, col soient contre pour l'affaillir? Ce qui n' pas eité oublié, ne des Grecs, ne des La rins, ne des François, comme vous trou uertez en Ronfard, \& ailleurs, \& ne fç par:cour quje ces quatre vers: 
S. E R E.

In tan,en voyant la figure

De cefte vache, fut mocqué:

Te na'y iamais (dit-il) picqué

$V$ ache qui euft la peau $f i d u r e$.

faifoit, va adioufter quelqu'vn, comi'ay apprins de Henry Eftienne, fi ande eftime des ouurages antiques, \& incipalement de ceux des peintres $\$$ alpteurs, que quand on parloit d'vm leau ou d'vne ftatuë d'ounrage antie, on entendoit d'vn outurage exquis par confequét qu'on tenoit fort cher; qui eftoit de grand prix, fibien qu'on Nibil antiquius babui, c'elt à dire, ie n'à rien en plus grande recommádation, plus cher:Voulans dire que les chofes tiques font mieux faites que celles de temps, \& auffion void qu'on les chere, \& qu'on les achepte bien cheres, \& urce qu'elles.sót antiques, on les nomantiquailles : \& dit-on, Il a de belles cheres antiquailles.Apres que chacun fut efforcé de loiier les beaux ouura$s$ de la peinture, $\&$ de l'art ftatuaire, on met à direl'honnefteté \& pudicité des intres, \& des fculpteurs, vn de la comgnie commençant ainfi: : Nous trouI. 7 


\section{VING T-H VIC T IESM E}

uons que les peintres, qui s'entenden aux blafons \& peintures d'armoiries, lesblafonnans ne diront iamais vne pa role diffoluë. Car s'ils veulent dire,port du fynople à vn Lion d'argent, fansmé bre \& $x$ tefticules, diront ainf 1 ,porte de ly nople à vn Lion d'argent, fans vilennie Aufi trouuons-nous difoit-il, que Mat tia, fille de Varro, excellente en l'art d peinture, fut fi pudique $\&$ honteufe qu clle ne voulut iamais peindre homm ne femme nuds, de peur que l'ouurag demeuralt imparfaict, auffi que la plu part des peintures \& 2 tatues des Ro mains eftoient veftuès, pour ne mon. Irei les parties honteules, fignifiás touf jours quelque mytere, comme celles de Grecs eftoient toutes nuës. Ce qui ef côfirmé parAphrodifee, qui efcrit quan ciennement les images, peintures, \& $\mathrm{Ata}$ tuës des Dieux, des Rois, \& 2 des Graces, furent foument faites nuës, pour demonAtrer qua la puiffance d'iceux eft ounerte \& manifelte à chacun, eftás nuds \& non counerts de dol \& fraude. Que s'ils ont peint Venus toute nuë, \& faict fa ftatuë sás robbe, ce n'eft pour inciter \& prouo- 
er à lafciueté ceux qui la regarderont, pour fignifier que le plaifir de Venus igmente entre ceux qui font nuds: is c'elt pour nous enfeigner que l'efde la luxure n'elt iamais celé ne caSı faut il bien, repliqua vn de la Seque Zeuzis, ce bó peintre,euft peinct ourtraict la vieille toute nuë, quile fi enormement efclater de rire, que ercice de la ratelle lui tollit toute refation, \& fubitement mourut, pour ir regardé la pourtraicture de cefte ille, que luy mefme auoit faite, ce dit Verius Flaccus:car eftant couuerte, ne voy rien quile deuft faire mourir rop rire :mais cebon ouurier apres oir acheuree, la voyant nuë \& vieille, trouua la mort par le derriere, auffi qu'acteon voyát la Deeffe chalfereffe fe baigner en vne fontaine. Et puis, es que les peintres $\&$ fculpteurs font oneftes? veu que nous trouuós qu'vn ricus, excellent peintre, au contraire Martia, ne fe plaifoit qu'à peindre les ties les plus fales \& cachees, \& fur t, les parties cafuelles des femmes : \& ite caufe on l'appella Rhyparographiss. Et $\mathbb{R}$ 


\section{VING T-H V I C TIES M E}

Et fin'y a pas long temps,adioufta-il.q $\checkmark n$ bon peintre entreprit de peindre vifle cul d'vne trefbelle damoifelle, iamais il n'en peuft venir à bout, ny à $f$ honneur : \& pour toute excufe va dir la damoifelle, luy rendant fes arres, qu ne pounoit faire au vif ce qui efto mort. Celuy qui fouftenoit les peintre va repliquer qu'ilne croyoit point qu'c peuft trouuer de bons peintres \& $f$ tuaires, qui vouluffent mettre en euid ce $\&$ veuë les parties que nature a chees : \& $\approx$ auffi que les peintures laficiur corrompent l'efprit \& les yeux. Dequa fait clair tefmoignage celte $V$ enus $\mathrm{Gn}$ dienne, ouurage de Praxitelle, deflore \& la fatue de Fortune, laquelle comm efcrit Elian, fus $f$ ardemment aimee vn ieune Athenien, qu'il mourut aupr d'elle, pour ne lauoir peu auoir par a gent. Ie vous prie, repliqua quelqu'vi que ie vous dife des quatrains qui or efté faits de cefte Venus Gnidienne, par ce que ie les trouue bien faits, monftiar. l'excellence de celuy qui l'a fabrique voicy ce qu'ils en ont dit \& exprimé es plufieurs fortes: 
Fenus dit, voyant ce pourtraict, Q2uilareprefente fibelle: Pour faire vn tableaw ip arfaict En quel lieu me vi Praxitelle:

Prifgue perfonnene m'a ven, Pourquoy me fais-tu ceft untrage. D'affenrer que quelgnion ait pers Bien reprefenter mon image? Anchifes, Adonis, of Paris A'ont verue nuë, mais Praxitelle. Iamais nuë tu ne me.veis, Comment $m^{2}$ as tu groméfi belle? Il faut croire que Praxitelle Iadis ce marbre figuroit Selon quelqu'vne quil aimoit, Car ie fuis:mille fois plus belle. 1 Venuss.zoyant ceffe Verass Dit dedmiration rauie, Lepeuple ne me priroit plus, SicefteVenus auoit vie. Venus dit,ayant apercen $V$ enus furl'autel de Gridie, Imageur,dy moy, ie te prie. En quel endroit tu manois ven. Quand Iunon of Monerue virent Cefte belle image,elles dirent. A grand tort nous auons repris Le ingement que fit $P$ aris. 


\section{YINGT-H V IC T IES ME}

Celuy qui parloit pour les peintres ftatuaires, en reprenant ce qu'on auc dit de leur honnefteté, parla pour eı ainfi : Encores qư il fe foit trounć que ques vns qui ayent pourtrajct desch fes deshóneftes, comme on dit que $\mathrm{Ch}$ reqhanes contrefit des lafcifs \& impud ques embraffemens d'hómes $8 x$ de fen mes:ce n'elt pas qu'on loiie le fait en fo \& ce dequoy on faict la prefentatio mais on admire l'artifice de celuy quil peu fi ingenieufement reprefenter:con me quand nous voyons vin Singe, oul face de Therfites, bié peints, nous y pr nons plaifir, \& loiions à merueilles, no comme chofe belle de foy, mais comm bien contrefaite aptes le naturel. Vou en direz ce que vous voudrez, repl qu vn autre, fi eft ce que ceux qui rennen plaifir à peindre ces parties honteufe ou à les voir, monftrent l ur naturel. E comme pour juger de la honte \& frian dife des viădes, le plus apre eft celuy qu les aime le plus. On dit aufri, a dioulta-il que quand Androcydes le peintre pei gnit le goulphe de Scylla \& Charibdis qu'il ne fit rien de fi bié fait que les poif fons 
is d'alentour, lefquels il auoit fait ec plus d'affection, \& mieux au vif \& turel que tout le demeurant, pource il en eftoit friand. Comme pourrezus fauuer Zcuzis d'impudicité, \& qu'ilimaft les femmes: Nous trouuons, dit-il, que ce Zeuzis voulant faire vn leau, i mpetra des Agrigentins de voir Irs femmes nuës, \& que de toutes il en oifit cinq, quiluy fembloient les plus les, \& les mieux formees de tous més, \& tirant de chacunes d'elles la parqui luy fembloit la plus belle, il en ma celte excellente peinture, de laelle il fe contenta en telle forte, qu'il $t$ deflous, Il fera plus facile â celuy i verra cecy d'en auoir enuie, que de niter.Celuy qui parloit pour les pein$s$ va dire qu' il n'en croyoit rien, parce e les Grecques de celte ville la n'eient point fi deshontees 2 barbares, fent elles publiques, de fe laiffer voir es aux hommes: d'autant, comme dit ges en Herodote, que la femme ayant pouillé fa chemife, fe deueft pareilleint de hóte \& modeltie: \& S. Cyprian rit que l'honneur du corps \& la,vergongne 


\section{VING T-HVIC TIESME}

gongne font mis enfemble auec la cc uerture de la robbe, trouuant mauu: aux femmes de fe defpouiller $\mathrm{nt}$ entrans dans les bains \& eftuues. ce propos, adiouftoit-il, Balde dit, $\mathrm{q}$ la crainte de la hôte, bien prouuee, fuff à faire refcinder vn cōtract, iaçoit q̣ n'y ayt crainte de mort ou de tourmes comme fi quelqu'vn defpouilloit $v$. femme, la menaçant de la ietter deho toute nue. Mefines, pour monftrer $q$ Zeuzis ne fit point ce beau pourtrait les femmes Agrigentiues, nous tro uons en Plutarque, que les vierges $\mathrm{Mi}$. fiennes, qui par vne folie fe pendoie: \& eftrangloyent, furent retirees de tuer, par vn Ediat, par lequel il fut di que fi pasvne d’entre elles fe pédoit plu qu'elle feroit defpouillee toute nuë,i portee ainfi au beau millieu de la plac pour eftre veuë de tout le monde : les fi les prenans de cela vne figrande frayel que l'humeur qui caufoit en elles l'enui de mourir, ceffa tout à coup, craignar. plus le deshonneur \& l'infamie, quel mort \& la douleur, ne pouuans fes fille fupporter vne imagination de villenni 
honte, qu'elles ne deuoient encores euoir finon apres eftre mortes. Et aufeft efrit que Lais, combien qu'elle courtifanue, ne felaiffoit point voir Ite nuë,difant A thenee, qu'elle eftoit ice d'vne beauté fi parfaicte, queles ellents peintres venoient expres la $r$ à Corinthe, pour contretirer feuent $\& z$ prendre vn patron $\&$ deffein on vilage de festetins, \& eftomach. de cefte Lais, les Corinthiens s'eftiient en porter beaucoup de gloire, \& efre grandement honorez, lailfans efcrit qu'elle eftoit nee en leuir pays. uy qui aimoitles peintres,adiouftoit il ne s'efbahifloit pas files peintres efté fi homneltes, veu que ce louiable icice de pourtraiture a efté fi recomndé des anciens, qu'iln'y auoit que. nobles quile penffent exercer. Que fi lques vins s'y addönoyent fans auoir iltre de noblefie, cela leur faifoit obir ce priuilege d'eftre mis au rang des tils-hömes: eftant permis aux Grecs nettre la peinture au nobre des arts raux, \& defendue par Edict public leruiteurs \& efclaues. La peinture, mefmes 


\section{VING T-H VIC T I E S M}

mefmes de noftre temps, a elté en fi gra de eftime, qu'il ne s'en fallut gueres q1 le Pape Leon, qui crea pour vin coup tr te Cardinaux, ne fit,auecles autres, $R$ phael d'Vrbin Cardinal, peintre exce lent, l'an 1517. Et pour montrer l'exe lence de la peinture, difoit il, les bos peintres ne prenoiét point de difcipl à moindre prix que de fix cens efcus, fi Zeuzis eftimoit tant c'eft art, qu'il a: moit mieux bailler pour rien fes tabli aux,que d'en prendre petits prix, difar qu'ils ne fe pouuoient achepter à pr: quelconque.Ce que möltra bien le peiı tre de monfienr Pafquier, qui ne voult iamais le peindre fans mains, pour de monftrer qu'on ne f̧auroit trop donne pour tels ouurages, \& que s'il cut pein möfieur Pafquier fans mains, qu'il efto en grand danger de n'en pounoir iamai rien auoir. Quant à la nobleffe des pein tres, adiouftoit-il, elle eft affez approuue en ce que fi ceux qui peignent les vitre aux, \& font des figures, ont mangé de aulx ou des oignons (qui eft la viand du bas peuple) la peinture ne tiendr nullement fur le verre, non plus qu 
sencençoient, \&z euffent le nez ou aleine puante, cela n'elant pas plus ange, que ce que l'on tient pour tout uré, qui eit:que l'ammanc frotté d'vn oerd fa vertu, \& que fi les mariniers mangé des aulx, que cela empefche feruer la route de leur nauigation. e a tant eftiméla pourtraiture, va din de la Serce, pour confirmer ce auoit efté dit, qu'il a laiffé par efcrit, Appelle auoit cela de fingulier de fai$s$ pourtaits fi pres da naturel, qu'vn ain Phyfiognomifte, \& difeur de bonortune, iugeoit au vray de la vie $\&$ mort, de la fanté ou maladie, de la ireté \& richeffe, tant du paffé que de renir, de plufieurs qu'il auoit veu its de la main d'Appelles. Quand cecy vit qu'on rioit de ce qu'il auoit va dire qu'il auoit apprins d'Ariftote quand on veut faire à croire aux hövne chofe vraye, qui leur femble inable, qu'il en faut mettre en auant autre, laquelle fembablement au pant qu'on euft eu certain aduis de la é, fembloit incroyable, \& neantus depuis auoit efté trouuee veritable. 


\section{VINGT-FVICTIES M E}

ble. Et ayant veu les aduis de Lotin, $\mathrm{I}$ cita qu'vn Athenien, ayant dit au Cöfr d'Athenes, que les Loix auoient befo de Loix, fut incontinent moqué, \& q1 ceft Athenien auoit repligué à celte ! fee: Auant que wous eufliez fçeu \& a gnéu par experience, que le poiffon de zner en le cuifant demande plus de que celuy d'eau douce: \& que les oliue defquelles on fait l'huile, ont beforn, ce mefne huile, pour eftre an gouft pli asgrteables, vous en fuffiez aufi biémi quez:Neantmoins, fachant ores quair. eft, vous ne vous en efbahiflez ne mi quez. Vnde la Seree, voyant que ceftus cy entroit quafi en cholere, en loüat lexcellence de la peinture, nous va cor tèr que plufieurs grands feignieurs of eftéfi exçellés en la peinture quìls en o prins le furnom, comme Fabius, quif apuclléFubius Pjctor, \& leán d'Augi fils de Rainero, Roy de Prouéce, depe gnit toute vne fale de fa main, que lule Cefar auoit achepté des tableaux faid par A rifide quarante millĕ efcus, \& qu le Roy Cindaciles acheta de Bularchu au prix de lor, wn tableau de moyenn gra 
deur, \& que Demetrius ayant prins des, ne voulut permettre qu'elle bruflee, pour fauuer vn tableau de ogene, où Ialefius eftoit peint, \& Aratus fut emperché par vn de fes $s$ de brufler vn tableau exquis d'Ap, où eftoit repreferté Ariftrate, paru'il auoit efté tyran, combien qu'il it fort la peinture, toutesfois il haïltant les tyrans qu'il fut en deliberade le faire brufler : n'euft efté que amy, pleurant ce belourrage, luy dit, qu'il falloit faire la guerreaux ns, \& 2 non pas à leurs images. Nous uons auffi en Lucian, adiounta-il, que n bon peintre, porta aux. Olympies ableati, ayant en iceluy dépeint les es de Roxane \& Alexandre, de forle Proxenis (lequel les Grecs auoiét conftitué pour Preuolt des ieux) fe Otát à. l'excalléce de l'art, print Etion fongendre. Puis nous va conter la d'vne Courtifanne, quaimoit Prales, pour fçauoir lequel de fes taIx eftoit le plus exquis \& le meilleur il difoit auoir leu en Crinitus. Praes, commença-il à dire, eftant ạmouLiu.iij.

K 

reux de Phrymé, luy bailla l'vn de fes bleaux , à fon chois. Cefte femme fon any de Praxitelles de luy baille meilleure piece, de tant qu'il l'aym Ce qu'il ne voulut faire. Que faict le;Elle fufcite quelqu'vn qui va dire peintre, que le feu eftoit prins à $\mathrm{Ca} b$ tique.Lors Praxitelles, ef men de ce n fage, luy demande, fi fon Cupidor ftoit fautué. Et par cefte fineffe elle for bien lequel tableau eftoit le meilleut le plus elabouré. Vn Drolle va lors re quer, puis que les peintures \& les pe tres font en figrand' eft time, pourquioy ce qu'ó ne met les tableaux, \& ces be ouurages,és fales où les Magittrats \& ges rendent la Iuftice, tout deuant yeux des Prefidents, Lieutenans \& $C$ feillers, pour les auertir d'auoir Dieu, la Iuftice en recommandation ? Il fut fpondu qu'on mettoit ces peintures di riere le dos des Iuges, \& non par le c unant, à fin qu'ils ne fuffent rauis par pourtraits, \& queles peintures ne vi fent à defrober l'efpt it des Magittrats, s'amufant à les cótempler, \& fuffent pa la empefchez d'entendre le differento partic 


\section{S E R E E. ?: 3104}

ies, \& ce par l'inftitution de Lycur, qui defendit expreffément.qu'on it à mettre aucune image ou peinaux lieux qui eltoient deftinez Ire Iuftice, de peur que les luges, ent diuertis ailleurs. Par là, difoit noDrolle; vous fçauez bien poutquoy luges nont Dieu deuant les yeux, s Saincts, mais par le derriere. Sur de la Seree,vn dicelle nous va conu'on mift au marché le tableau d'vn lard, qui fe fouftenoit d'vn bafton, en faict, que quand on demanda à afique, qui le regardoit, combien il oit ce-vieillard, \& s'il ne le voupass bien auoir en fa mailon, lequel ondit qu'il n'en voudroit point de n. vie, encores quon luy donnaft rien : femblant le marguillier d'varroilfe: qui fe facha d'vn imager, uy auoit faict vn Sainct en vie pour rroille, ce frabriqueur pentant que image fult en vie, tant eftoit fait au toutesfois fereprenant, va dire au re que s'eftoit tout vn,car fi les parens, luy difoit-il, l'aiment mieux , il ne fandra que le tuer. $\mathrm{Vn}$ plus K 2 
VIN G I-H VI C T IES M E grand Seigneur que ce villageois, m non pas plus aduifé, cómanda vn tabl à vn peintre, luidifant, peignez moi a vnebelle contenance, \& 2 me faictes tout haut en vn liure que i'aurai en $m$ \&: me mettez en vn coing du table a fin qu'on ne me voye point, \& que voye tout le móde. Et celuy qui auoit té ces contes, voulant acheuer la Ser nous va encores côter l'excellence d' pelles, qui auoit cela de bon fur Pro genes, qu'il fe fçauoit bien ofter dec fus fa belongne, \& Protogenes n'en p uoit bouger : qui eft vn mot fort co derable, ce dit Pline, pour monfrer la trop grande diligence \& curiofité n quelquefois:cöbien toutesfois, difoi que noustroumons que Phidias fit bi quand premierement il mift l'image Iupiter en la rué, pout le faire voire Heliens: \& eftant caché derriere la po de $\mathrm{fa}$ boutique, efcoutoit ce qu'vn $\mathrm{c}$ cun des regardans y loiieroit ou repr droit : cependant qu'vn reprenoit po blele nez, comme qui eftoit plus g que de raifon, l'autre le vifage, pour e trop long, \& quelqu'autre reprenoit 


$$
\text { S E R E E. }
$$

inoit à vice quelquautre chofe.Puis es cela, quand les regardans s'en jiét allez, Phidiass'enfermant au dc$1 s$, corrigeoit \& racouftroit le tableau 'image à l'opinion \& iugemét du peru , n'eftimant pas qu'il fallut mefprifer confeil d'vn grand nombre $\vdots$ mais it toit perfuadé, que neceffairemét pluars verroient toufioturs mieux que n pas vn feul, encore qu'il n'ignorcit quil ne fut Phidias foy-nefme. Il adofta que Pline auoit efcrit que Turpir s feul s'eftoit troulué peignant de la in gauche, $P$ uis nous va dire, quilne uoit pourquoiles derniers oumages artifans, encores qu'ils foient imparcts, principalement és peintures \& tiës, sót en plus grád elti me que ceux i font paracheuez. A qui il fut refponque files ourages imparfaicts font mmencez par debons peintres, qu'ils nt plús eftimez que les pourtraits paricts des peintres groffiers, demeurans beaux tableaux imparfaicts, à caufe l'excellence de ce qui eft commencé parce Ciceron dit, que P. Rutilius oit ouy dire à Pxnetius qu'il ne s'eK 3 
VING T-N E V FIES M E.

Roit point trouué de peintre qui of parachener le pourtraict qu'Appel auoit commencéde Venus, la beauté fa bouche oftant toute efperance aux a tres peintres, d'y pounoir faire re f ponc toutes les antres partiesqui n'eitoiét faites ni commécees. Lors vn de la Ser des plus endormis, va dire, Ie fuis d'au. que fuivant ceffe methode, nous laiff nos difcours en l'eftat qu'sls font, fa autrement les acheuer, à fin quo on 1 troune meilleurs, cat peut eftre gu'en adiouftant nous gafterions tout.

VING T-NEV FIESM E SERE

Des Mores, des Negres, ou des Noirs.

D. $N$ toute cefte Seree on ne parl 3. Ex que des Noirs, que nous appellö Mores \&̀ les autres Negres, dautát qu'v. de la compagnie nous conta ce qu' auoit velu ce mefme iour, \& ce qui s'e ftoit paffé entre vn More $\&$ des gens de champs, lefquels rencontrans ce Mor par la ruë , du temps que le Roy eftoi à Poictiers, s'eftoient arreftez tout cour deuan 


\section{S E R E E.}

lant ce Noir, s'efmerueillans de ce ils n'auoient jamais veu, tellement e quelque part qu'allaft ce Negre, ils uiuoient, ne fe pouuans faouler de le arder, tant il leur eftoit eftrange. n de ces villageois à vne fois difoit, il falloit bien que ceit homme noir tmarefchal, ou bien ferrurier, puis reprenant, alfeuroit qu'il eftoit bien toft faifeur de poudre à canon, ou eur de noir à noircir, où teinturier, bien charbonnier. Son compagnon uloit gager que c'ettoit vn ramonur de cheminee du pais d'Aucere, ou bien que c'eftoir quelqu' vn qui oit ioüé à fainct Cofme ie te viens orer. Vhi autre villageois, lequel eltoit uprés de fairct Maixant, tenoit pour tain qise c'eftoit encores vin diable la diablerie de fon paï (car monfieur din dit que les diables font noirs ) qui oient fi bien accoufté le beau pere cretain, pour n'auoir pas voulu prefter e chappe du Cóuent a celui qui ioiioit ieu le pere à la paffron de fainct Maint, à qui les entrepreneurs, en faifant monftre,auoient dit,ọ que vous ioueK 4 
VINGT-N E V FIES M E rez bien, meffieurs les diables. Il fe tro wa auec ces ruftiques quelqu'vn, lequ ayant voyagé, leur difoit, fe moguant eux, quel'homme qu'ils admiroiét tan amoit paffé fous l'Equateur, \& que po en faire foutuenir, (pource que c'eft plus grand \& perilleux nauiguage $q$ l'on (çauroit jamais faire) les marinie l'auoient ainfi noircy, comme ils ont $\mathrm{d}$ coufume. Vin de ces champeftres va i reà ce More, barbouillé, il êt têps que। faces la leffue, car tu n'as rien de blác.( villageois voyant que ce More ne fos noit mot, va dire à fes compagnons, faut bien que ce foit quelque porteur $c$ mafquarade \& de moumó, qui s'elt air finoircy \& chaforré, puis qu'il ne parl point. Ce More, qui entendoit autant! Poicteuin que le François, $f$ fe farchát d's Itre ainfi regardé \& fuiuy de cefte band ruftique, les reculoit le plus qu'il pou uoit d'aupres de luy, ce nonobftát le plu. hardy d'entr'eux ne laiffa à s'approche de peu à peu de ce More, \& en le frappá fur l'efpaule, lay va demander en for Poicteuin: dy moy, petit, és tu nafqu jtau ? Le More lors entrant en cholere

(comme 
ime ils le font tous ) fe vint fi bien à lerer, que celuy qui nous faifoit le nous dit qu'il eutt fans luy outragé pauries gens. Tous ceux de la Seree unerent fi bonne cefte interrogation, I nafquu itau? qu' il n'y euft celuy leIn'excufaft la fimplicité \& curiofité es pauures Poicteuins, quelqu'vn des 5 aduifez de la ville s'y trompans auffi. nqueux, penfant que ce fuft quelque olomeni des Grecs, qui fe barboiil ent de fuye. La rifee de ce conte ceffa la difpute de deux de la. Seree, lefels commencerent à $s$ attaquier, pouf tuoir la raifon de ce que les Mores, en tes quils foient en vn autre paìs que eur, rie laiffent à engendrer des enfans irs, \& femblables à eux. Celuy qui atbuoit.la caufe des Mores at la chaleur, au Soleil,pluttoft quà àleur femence, le ouuoit ainfil. Le Soleil noircit vn home \& blanchit le linge, l'aptitude de la atiere eftant caufe de cecy: or les maeres de nottre corps efchauffees, difoit, font noircir le cuir 2 \& la peau ; dont il duiêt que les Negres, tant à çaufe de la halcur du Soleil, où ils fe tiennent, que 


\section{VIN G T-N E V F I E S M E}

par la difpofition chaleureufe de le corps, font \& engendrent les enfa noirs, dautant que la femence deleur neration eft chaude en eux, eftant auff matrice des femmes Mores tres-chau $\&$ feiche, \& qui eft caufe que la feme ce conceuë en eux, eftant digeree $F$ vne violente cóception, le fang du frui qui elt formé deuient adufte $\&$ beuf. l'humide fubtil eftant mis hors, \& lo ce fang brulé teint leur charr, qui ter auffi leur peail noirafte, ayant mefn raifon de la chaleur da Soleil à la chaler dufeu, pour noircir vne perfonne. Plu pour pronuer que le Soleil \& fa chales font les Mores ainfi noirs, \& non pas femence, il difoit encores, fi les Negre Mores, \& Ethyopien's muent \& char gent d'air \& de pays, leurs enfar auec le temps muent \& changent $d$ couleur, \& deuiennent blancs en Eu rope, où la chaleur n'eft pas tant vehe mente. Celuy qui tenoit le contraire repliquoir que la femence faifoir en ce la beaucoup plus que le Soleil \& la cha. leur, \& que fa difpofition faifoit le: Mores, parce, difoit-il, que les Noir: 


$$
\text { S E R E E. } 1 \% 108
$$

$i$ habitent en ce pays d'Europe, où Soleil n'eft point ardant, font \& enadrent auffi bien des Mores comme $x$, \& quelque part qu'ils habitent, ils it toufrours noirs, eux \& leurs en15 , \& au contraire, les blancs font les fans blancs, nonobftant qu'ils demeuen Ethyopie : encores que les Mores fent vne femme blanche, \& demeufent icy, \& les blács euffent vne More meurans en Ethyopie. Si eft-ce, replia vn tiers, que nature a voulu qu'ily it deux femences en la generation de omme, lefquelles mellees la plus puifate formalt, \& l'autre feruift d'entrenement $\&$ nourriture. $\mathrm{Ce}$ qui appert reveritable, de ce que l'homme noir grolfant vne femme blanche, ou vn mme blanc vne fernme noire, la creare tiendra de l'vn \& de l'autre, \& fera couleur brune : ou bien elle fera de ux couleurs, comme il fe troune en acian, que le fils de Lagus prefenta aux gyptiens en plein theatre vn homme detix couleurs, fi que la moitié de fon rps ég lement diuilee, eftoit parfaicteient noire; \& l'autre blanche outre me-

K 6 
VING T-NEV EIES ME fure.Parquoy, adioultoit-il, encores $q$ Ia femence ia difpofeey puille beauco ( non pas qu'elle foit norre, comme c Hetadote ) fi elt-ce que la femencer çoit fes dernieres impreffions par l'a deur du Soleil,receuans ceux qui fonta Soleil grande alteration de leur couleu qui faict que nous royons les peuples ftre plus noirs, ou moins, felon quils si pres des grandes ardeurs, ou plus loin Celuy qui fembleroit que la difpofitio de la femence failoit les Negres \& Mores, \& non pasl"ardeur du Soleil, v repliquer ainfi. Si la chaleur du Sole failoit les Mores, ceux qui demeuren foúbs l'Equateur, là où le Soleil eft pre d'eux,\& directemét fur leur tefte, layan pour leur Zenith, deuraient donc eftr plus noirs que ceux qui habitent foub le Tropique, où eft l'Ethyopie:toutesfoi qu'en Ethyopie foient les vrais Mores ceux quii demeurét foubs l'Equateur n'e ftans que bazannez. Son aduerfaire luj wa refpondre, que la chaleur eftoit plu: gráde en Echyopre, qui ent foubs le Tro. pique, qu'elle n'eft pas foubs l'Equateur: comb.en qu'ils foient pres du Soleil, par- 
difoit-il, que fous l'Equateur oules ons font perpendiculaires, le Zodiac aro $c$, \& non oblique, qui fait que le eil defcend pluttont deffoubs leurs ds, le Soleil n'y fairant pas tant de deure, le païs n'y eft pas fi chaud, dont nt que ceux qui y habitét ne font que annez. Au contraire, difoit-il, foubs ropique, où font les vrais Mores, le eil y faict plus de demeure, à caure de ortuofité \& obliquité, \& par ce les rs d'Efté y font plus long, le Soleil ne cendant pas fi tolt, ce qui faict que la leur y eft plus grande, \& par confeent les habitans y font plus noirs: \& $x$-là font les vrais Mores. Et auffi que oleil nous efchauffe plus parla refle$n$ de fes rais, que non pas par fon ap. chement : car quand le Soleil eft efleau Cancre, qui et le figne plus efloide nous, , es rais qui font dardez nous hauffent plus viuement, renforcez la reflexion, que quád il eft au Caprine, encores quil foit plus pres de 1s. Diodore efcriuant quen Egypte, fins des Troglodytes, le Suleil y eft. haud fur le Midy, qu'ils font cuire les:

$$
\text { K } 7
$$


(1.) VING T-NEV FIES ME viandes, les mettans "auec de l'eau vin pot, fans autre feu. Si cela eft vr: fut-il repliqué, que là où eft la gran chaleur ( foit par la prochainete dus leil., ou par fa reflexion, ou pour temps qu'il demeure fur nous) les ge y foient plus noirs, pourquoy eft-ce $q$ en la feule Affriquie on trouue des $M$ res, que nous appellons Ethyopiens, $v$ qu'il y a des autres terres \& regions ar fichaudes qu'eft Affrique? On fe reg: doit l'vn l'autre, quand quelqu'vn va i ré, que cela procedoit de la feule qual. \& condition de la terre, \& felon qu'e eft plaine, feiche, montueife ou cr: fe, \& felon les vents qui y regnent, faifoient les Morés, les habitans du m Megeza:en A ffrique eftans blács, \& ce de li plaine perits. A cefte caufe, difoitdautant que la Lybie eft vne terre tou vnie \& plaine, fans mót \& fans eaux, elle conçoit \& retient $v 1$ grande chaleur, qui êfchauffe merue leulement l'air à l'entour, \& faict, $q$ la complexion des hommes, qui y hab tent, eft tellement muee, quils font perfonnes noires, que nous appello

Ethy 
1yopiens, Mores, Negres, \& Noirsis vn de la Seree vadire, que la plus $t$ de ce qui auoit efté dit de la caufe Mores, luy fembloit vne vraye chi anerie, \& comme dit l'adage, c'eft pervn grain de millet d'vn tairiere: paroy, l'opinion de Thenet luy femblant s fincere \& veritable, fouftenoit auec , que ce n'eftoit ne la femence ne la leur qui faifoit les enfans noirs en viopie, mais que c'eftoit le fang chault adufte qui caufoit la noirciffeure. 1elqu'vn contrariant à cefte propofi$\mathrm{n}$, va repliquer. Si eft-ce que fi la chaif de cefte terre Lybique peut caufer rizure \& crefpeleure de ces Mores, ans le poil ridé \& replié par vne ficcité haleur efficiente, pourquoy done ne urra la chaleur noircir; Et ne fert de n à dire que la frizure des cheueux int de la tortuofité des pores : car tant is que l'exhalation qui fait le poil eft neufe, de tant plus le poil fera recoillé \& crefpé par chaleur \& ficcité, ce i eft terreftre \& humide voulant defndre \& s'abbaiffer, \& ce qui eft chanlt fec voulant monter : \& pource que les 


\section{VING T-N E V FIES ME}

les Mores n'ont pas grande humidité, poil defleché par la chaleur fe retire? fément, comme il fe retireroit pár feu, la crefpeleure des cheueux n'efta: qu'vne conuulfion \& retirement à fau d'humeur, qui fe faict par la chaleur l'air qui nous enuironne. Et cela ce pre ue de ce que les cheueux crefpés $\& \mathrm{fi}$ zez font plus durs que ceux qui for droicts, les chofes feches eftans dure De là vient, que ceux qui abondent humeur, ou demeurent en vn air hum de, n'ont point les cheneux crepelu mais ouy bien ceux qui habitent és reg ons chaudes, comme les Erhiopiens:pol autant que leur cerueau, \& l'air quil enuironne, font chauts. Cefte chale fait auffi, adiourta-il encores, que I Mores font fort camus, \& diriez qu'c leur a coupé le nez fur le billot: cela pr cedant de la grande chaleur, quine pe met pas que les os \& les cartilages croi fent beaucoup,comme venans d"vne $m$ tiere inutile $\&$ vacante : les petis enfar le confirméc bien, lefquels êtás chaud font camus, ayans en leur ieunef le nez fort court. Er li faut noter que ar. 
res, \& tous 'ceux qui font camus; t choleres : \& qu'au contraire, les nds nez font plus patiens \& prudéts, ju'en la Bible quand on dit que quelvn à grand nez, les interpretes tourthatient: ce qui demonftre qu'en la fronomie y a quelque diuination de nplexion.Ie m'esbahy, repliqua quelautre, que nos mignons qui trauailtant à fe frizer, ne mettent aufi neà fe rendre camus comme font les res, \& à prendre leur teinct \& cou, pourtant qu'entre les Mores, la auferie, la couleur noire, \& auoir les ueux recoquillez \& frifez, leur eft au$t$ d'eftime $\&$ de beauté, que noftre nd nez, noftre couleur blanche, \& cheueux longs. Qu'il foit ainfi, difoit les Ethiopiens peignent leurs Anges rs, eamus, \& ayans leur cheuelure pee comme ils font, \& non pas blács, c le nez aflez grand, \& les cheueux gs \& vnis,comme nous peignons nos ges, tout ainfi que nous fommes, \& e nous penfons ceux eftre beaux entre us qui ont tout cela, principalement rance ne trouue pas beau d'eftre camus, 
mus, car au lieu que les Ameriqua font confitter la beauté de leursenf: à eftre bien camus, au cōtraire nous tri uons nos enfans plus beaux ay ás vn $\mathrm{F}$ le nez long, \& comme les fages-femn deleur pays efcrafent \& enfoncent nez de leurs petits enfans auec le po ce, tout auffi toft qu'ils font nais, co me on faict en France, aux petits chies nos mattrones a l'oppofite, tirent le n à la naiffance de leurs enfans, l'allc geant de peur qu'ils foient camus, \& peur quils reffemblent aux - Mores nez, Plutarque difant que celuy quia nez Aquilin, eft Royal, \& celuy qui a nez court, gentil s plaifant \& aggreab Mais qui faict,demanda quel lquivn qi les Ethiopiens ont les leures groffes? qui il fut refpondu, que cela procedo de la chaleur,aufi bien que leur camul rie, à caufe de l'air d'A ffrique, qui efte: tremement chaud: lequel par refolutic de la portion la plus fubtile, eqpoiffit le humeurs attirees en l'extremité de leu leures, la mefme chaleur caufant aul aux Mores Ethiopiens \& Abiffins leu pieds gauches, \& iambes ennelees, con ?"* : is 
la chaleur peut gauchir le bois, elle t. auffi difformer $\&$ corrópre le corps animaux auffi bien qu'elle faict le de la telte, la gráde chaleur bruflant bftance des membres, \& les faifant ler, comme le feu faict le cuir, par me raifon les Egyptiens eftans fort agreux, aiás les articles \& pieds fort ez, combien qu'aucuns difent cela ir de ce que le pied du Taureau, figne ite, fort de leur region, s'eftendant l'Ethiopie, parquoy en leurs lettres roglyphiques par le pied, de bouf, ils ifioient l'homme podagre, parce le beufy eft fort fubiect. Et non feuent, fut il adioufté, celte chaleur agift torps,mâs, qui ent bien plus, elle goirneles actions, dautant que nous ons tous ceux qui habitent vn païs chaud, ou trop froid, eltre barba\& auoir leurs humeurs brutales \& regad hideux, $1_{1}$ bonne tempera- de l'air profitant \&z feruant non feulét és corps des hommes, mais auffi actions de l'efprit $\&$ de l'ame : Arie affermant les trauaillez de chaleur de froidure eltre Barbares, d'autant dit-il, 
VING I - N E V FI ESM E dit-il, que la bonne temperature de rend les mours \& entendemens $m$ leurs, \& auffi que la nouriture des $\mathrm{E}$ ptiens faict beaucoup à les rendre | bares:car Solin dit quils fe nourriffos de locuftes, ce qui eft cófirmé par Sai Hierofme, file mot Grec ne fignifie auffibien autre chofe que des faute les. Ie penfe, repliqua vn autre, quilif droit beatucoup d'annees anx More: Negres, encores qu'ils habitaffent noftre region, pour leur faire perdre 1 barbarie \& brutalité, \& muer leurco plexion en la noftre, auff bien $q$ changer leur couleur, tant la forced femence humaine eft grande, quand le a receu en foy quelque ĝualité bi enr cinee: la vertu de la generation ay figrande puiffance, quapres beauco de generations diuerfes elle peut tourner, teillement que vous verrez, a iouftoit-il, que d'vn Æthiopien deme rant en Europe, \& ayant vne femt blanche, que poffible il n'en viend point vn More, mais que de fa fille, $q$ fera blanche, encores qửelle foit mari auec va blanc, il en pourra venir

Negr 


\section{S E R E E:}

gre : comme lon dit de Niceus Poëte $c$, lequel apres trois generations naf$t$ tout noir, parce que fon aieule $s^{3} e-$ $t$ accouplee a vn Ethiopien : \& comnous troutions qu'vne femme blandel'Europe, ayant enfanté vn More fon mary qui eftoit blanc, fuft accufee luy d'auoir eu à faire'à vn Negre: is à la fin il fe trouua qu'elle eftoit en quatriefme lignee defcendue d'vn re : Et auffi nous trounons que Hipurates fautua vne Princelfe accufee d'altere, par ce qu'elle auoit enfanté vn fant noir comme vn Ethiopien, à caudu pourtraict d'vin More femblableà nfant, lequel coultumierement eftoit aché à fon lict. Poffible, va repliquer eFelfe-tondue, que cefte femme bláe, qui accoucha d'vn Noir, eftoit Sorere, \& que quelque diable, auffi noir ur le moins qu'vn More l'auoit enoffee: car monfieur Bodin tient que Sorcieres peutent conceuoir d'vn able, \& qu'elles difent que les Diaes ontleur femence froide \& noire, mme Herodote affeure que les Ethioens l'ont auffi noire, \& pource il dit qu'ils 


\section{VING T-NEVFIE S M E}

qu'ils font leurs enfans noirs. Il fut pliqué, qu'il eftoit mal aifé à croire, cores que Bodin l'ait dit, que les diab puilfent auorr a faire à vne femme $S$ ciere \& que fi cela auoj lieu, qu'i auroit bié de la diablerie par les cham combien qu'il fenbleque Lactance $F$ mian ait creu que les demons eftoi capables de generation, mefmes qu' ausient engendré, Agrippe \& Card femblans auoir fuiuy cefte opinion. La fant là ces diables pour tant qu'ils valé quelqu'vn commenca aे faire vn con d'vne femme qui fe' fit engrolfer à v More, pour fçauoir s'il eltoit meillet mafle que fon mary, qui eftoitblan Les fages-femmes eitant bien empel chees pour fauuer l'honneur del'accou chee, le mary ne s'en pouruant contente. l'appaiferent, en luy demandant; Aue vous pas foutrent mon bon compere,pri Dieu quil vous donnat vn hoir malle eft-il pas vray ? Le mary ne le pouuan nier, \& confelfant qu'ouy : on luy repli. qua, qu'il auoit ce qu'il demandoit \& que c'eltoit vn hoir mafle que fa femme luy auoit faict, \& en deuoit plus toft re- 
cier Dieu, qui l'auoit exaucé,que de facher.Le mury lors fatisfait \& conprend ce petit More entre lesbras, mignardant \& le baifant l'appelloit pet it Moriyusut, fon petit noir madefi bonne grace que l'accouchee es m.trunes ne fe pouturient tenir de - Ceftuy qui auoic recité ce conte, \& efirce, voyant qu'on ne rioir point, lire à ceux de la Sereee, riez fivous lez, ie ne fuis badin ny fariné, \& fi ailferay à vous demander conment s pourriez tiret au blanc contre vn re.Ceux de la Seree fans rire encores, vont relpondte qu'on ne pouuoit tiau blanc où il n'y auoit que du noit. a lors repliquer, que pour tirer au c contre vn More, qu'il ne faudroit luy mettre vne coque au cul. Quelvn alors ne fe poumant tenir de rire, va demander, pourquoy c'eftoit que Mores ont pour le moins les dents ches, \& tout le refte fi noir, mefmes ongles, qui deuoient refifter à la chaauffi bien que les dents. Il va refpóque les Mores auoient les dents blans à caufe de leur fermeté, qui refifte - à la 


\section{VING T-N E V FIESME}

à la chaleur duSoleil,là où la peau n'e point dure, elle fe fait norre , \& confequent les ongles, qui viennen la peau. On demanda auff qui caufoi timidité aux Mores. On va dire, qu chaleur ardáte qui eft en leur region, brufle de telle forte que la chaleur int re fe diffippe aifémét, trouuant les c duits oumerts par la chaleur externe: lement que le dedans demeure fi fro que les Ethyopiens ont toufiours troutez craintifs : au contraire des ptentrionaux, qui fe trouuent hardis vaillás par la froidure de l'air, qui ref re leur chaleur interne at dedans, do ils font rendus courageux:cübien qu'a cuns Afrologues, fut-il dit rapporte la timidité des Meridonaux \& More Saturne, lequel domine en leur contre comme ils font lardeur belliqueufed Septentrionaux à la Planette de Mas fur lefquels elle a grande puiffance.Q la chaleur du Soleil brufle les Ethyopie fut-il adioufté, il appert par ce que d Afclepiades, qu'ils vieilliffent bien to \&z dés l'aage de trente ans, \&z qu'en A gleterre, qui elt vn päis froid, les homes vieilliffer 
liffent iufques à fixingts ans, le faifant contenir au dedans la chanaturelle, \& leurs corps eftans plus. $z$ ils viuent plus long temps, au cone des Ethyopiens, qui ont les corps rares, parce quils font lafches parla ur du Soleil. Il fut auffi recité, que ide chaleur faifoit que les Mores, \& qui habitent és pays chauds, auoiét \& crane fort deur, auec peu de fu, \& que ceux qui demeuroiét és recroides l'auoient plus mol, parquoy Ifure faicte au crane qui eft mol, eft dangereufe que la playe \& contulu teft qui elt dur, à caure qu'il faut de temps à pourrir \& alterer le teft ue le mol, \& par le teft dur \& $\mathrm{mol}$; it recognues les teites des Egyptiés re celles des Perfans, ayans efté \& ns $\&$ des autres tuez en vine bataildit Herodote. Ce ne fera hors de s, va dire vn de la Seree, fi en parles Mores, ie vous enfeigne comme aftrent \& feccent leur beftail, qui a polfible feruir à noftre pays. C'elt uand ils veulent chaftrer leurs ani,ils ne font que leur couper les veius. iij. 
VING T-NEV FIES ME nes qui font fous les temples, lefque eftans couppees, il ne peut defcendre cune humeur de leur cerueau, \& par moyen toute generation eft retranch Et me fuis foument efbahy, difoit-il, celte practique n'en eft venuë iufqu. nous, veu les accidens qui arriuent nos chaftrures. Quelqu'autre va dem der, fi la rencontre d'vn More eft , chofe malheureufe, \& fielle fignifie qı que malencontre, comme il aduir Brutus, \& à Seuere l'Empereur, El Spartian difant en la vie de Seuerus, la rencontre d'vn homme laid preit: la mort à celt Empereur. Il fut refpor que beaucoup de chofes fe difent $f_{i}$ raifon, qui ne font pas veritables, $c$ poutuant arriuer à deux ou à trois, , n'aduiendra pas à cent, n'y ayant rien certain, là où l'on ne peut donner de fon: mais, ie vous prie, difoit-il, qu't raifon fçauroit-on donner de ce qu dit que c'et vn bon-heur de trouuer premiere rencontre vne belle femme, vn mauuais, d'en trouuer vne l'aide? rencontre d'vn More, va refpondre qu qu'vn, denote malheur pour ce que $p$. 
s de ce païs deuiennent fecs \& ethipour toucher feulement à la fueur More, \& difent qu'il en peut autant nir à fa rencontre. Mais repliqua vn Seree, qui font les vrais Mores, de a rencontre \& la fueur nous menaequelque finiftre euenement? Car $t-i l$, nous appellos Mores tout homui eft noir, comme les Ethyopiens, Indiens de la Zone chaude, \& auterres nouuellement trouuees, ores es Mores de la Moritanie ne foient nunément gueres plus bruns que fpagnols qui font leurs voifins, fed'eux feulement par vne mer, qui as trois lieuës de large, tel endroit y fi abufons auiourd'huy, adiouftoitce mot de More, car les anciens Lappelloient iadis Africa, ce que nous lons maintenát Barbarie, \& la parcefte Barbarie, où elt le coing que la mer Mediterranee auec l'O cean, elloit Mauritania, \& l'homme de ce là Maurus, On va demander à ceyui auoit tant demandé, fi on n'apit pas vn homme barbare, lequel n'a d'efprit, qui eft inciuil, \& qui n'a L 2 


\section{VING T-N E V FIES M E}

nulle vertu \& honnefteté,de ce que ce de Barbarie font totalement priuez toutes ciuilitez \& gracieufetez, \& ple de tous vices \& cruautez. Quand ceft cy eut confeffé qu'ouy, \& que tous ce qui habitent les paîs trop chauds leurs mours brutales, auff bien 9 ceux quidemeurent en vne region tr froide, la temperature de l'air ferua autant à l'efprit quau corps, illuy va. mander, ficeux-là que nous appells Barbares, ne pourront pas anec le ten laifler leu Barbarie \& fe ciuilifer com nous le peñfons eftre, eftant mainten: leur pais peuplé \& frequenté, qui ner noit plus à cefte caufe eftre appellé $B$ barie, ne eux Barbares, le mot barbar leur langue ne fignifiant que defert. demande pas cela adiouftoit-il, fans fon:car le temps peut amender ou em rer vne nation, comme il fait les metat les. Ramains ayans appellé beaucoup peuples. Barbares, qui auiourd'huy fo plins vertueux, homneftes, accords, \& uilifez, quils n'eftoient de leur tem c'et ange icy produifant les efprits $\mathrm{pl}$ excellens \& meilleurs qu'il n'a faictp 
aflé : Et non feulement difoit-il enes, la nourriture \& les couftumes ont ffance de changer le naturel de queles particuliers, mais auff de tout vn uple, comme l'hittoire nous te faict r de la plus part des nations du móde, fmement des peuples d'Allemaigne, inauoiét du temps de Tacite, ni loix, eligion, ni fcience, ni forme de Repuque, \& maintenátils ne cedét à autres elcóques en bonne inftitution de toucholes, combien que du temps de ar les Germains, gens robutes \& belueux, viuoient feulemét de laict, froge, \&r chair, ne f̧̧achás que c'eltoit ni bled, ni de vin, ni de labourer, nicle ner, \& $a$ a celte heure, il n'y a pas vne nan quiles furpalie en toutes ces choVn de la Seree a prés tout ce difcours. dire, Ie croy vne chofe quant à moy, e l'excellence des vertus, \& la grádeur efprits, a efté toufiours vne, ì de Inie forte dans le contenu de ce mon, \& que leur femence a efié mife icy ant \& les hommes, \&z que le temps ne duit point d'autres efprits \& d'autres rtus, que celles qui font veuës aux L $;$ 


\section{IRENTIESME}

hommes de tout temps, \& que le ter. ne les empire ni amende, mais bien $q$ peut faire qu'elles paflent d'vn lieu I'autre, \& qu'vne natiō qui aura efté le palfé inciuile, faumage \& barbare, à peu puilfe changer fa fupidité, $\& b$ barie, en ciulitité, prudence, \& dexter: Le temps infruifant \& $\mathrm{informant} p$ riculierement l'efprit \& la raifon d chacun, \& tranfportant les grandes $v$. tus de paîs en païs. A quoy rien ne repliqué par ceux de la Seree, mais tc l'ayans approuué s'en allerent en ce opinion.

TRENTIESME SEREE.

Des Paunres ef des Mendians.

Efte Seree ne fut pas fi ioyeufe La precedente, à caule qu'aucu d'icelle, vn iour d'Hyuer qu'il faifo fort grand froid, en venans fouppe auoient trouué vn pauure malade, gu fi tout nud, couché de fon long f vn perron de boutique, ce quiles auo efmeus à fi grande pitié que durant

fouppe 
pper, \& encores aprés, ils s'eftoient nitrez plus triftes que de couftume: nbié qu'ils luy euffent affez largemét ribué de leurs biens, \& mis ordreà coucher, $f$ çachés bien que ce n'elt pas z de bailler le viure aux indigens, is qu'ils les faut veftir \& loger. Et :bahis que le Magiftrat ne contrainct riches, mefmement les gens d'Eglife, leur bailler leurs neceffitez : les $\mathrm{Ca}-$ ns difans que le bien d’Eglife fe doit ttre en trois parties, la premiere pour pauures, la feconde pour les pafteurs, ierce pour entretenir les baftimens de irs Eglifes, des holpitaux \& de leurs iifons. Les gĕs d'Eglife fe deuans conater du peu; cóme font les quatre Paarches de l'Orient, aufquels obeyffent as les Chreftiens du Leuant, qui n'ont e chacun deux cens ducats par an, enres quils ayent de grandes charges. Ir au Patriarche de Conftantinoble eit toute la Grece, Macedoine, la arace, Epire, \& tous ceux qui font fubits à ceft Empire, voire les Mofcoui-

s. Le fecond Patriarche, qui demenre Caire, a foubs luy l'Ezypte \& A rabie. L 4 . 


\section{T REN T IES M E}

Le tiers commande fur la Iúdee, $D_{a n}$ Barut \& Tripoli;\& tiét fon fiege en rufalem. Le quatriefme demcire en thioche, \& a puifrince fur les Grecs d Sirie. Sibien que la richieffe des Egli Occidentales ent ti mal difpenfee, eu gard à l'Eglife primititie, \& aux gra biens de maintenant qu'on ne peut of de la bouche la plus grand' part:

Au tomps pafféentiagge d'ar,

Croffe de buis, Enefane d'or:

En ce temps font autres les loix

Croje d'or, Ene grie de bois.

Les luifs encores qu'ils foient bannis leurs pais, pauures \& elpandus par to le monde, menans vine vie miferable, ne laiffent ils à s'aider l'vn l'autre, fibi qu' aे peine trouluerez vous vin Iuif $q$ mendie. Les Goths, peuple barbare, uoient accouftumé de brufler le logis a celuy qui ne vouloit loger les pauur eftrangers, eftimans celuy iuftement eft pricié de fa maifon, quila denie aux aut tres. Ceux qui ont efté en Turquie, fça uentbien que nous deurions mourir d honte, \& rougir autant de fois que nou voyons de pautires endurer \& la faim, \& 


$$
S E R E E \text {. }
$$

oid,gifans toute la nuict\& tout $\mathrm{HHy}-$ fur le paué, fimal velus qu'ils font, tant qu'il n'y a nulle comparaifon e noftre charité \& leui pieté, fi nous urdons à l'inftitution de leurs hofpi$x, \&$ aumofneries, àl'ordre qui y eft rué, \& au traicte ment que reçoiuét s pauures, forent Chreltiens ou Iuifs, nt riches ou paumres, tous y font re, mefmes que les Seigneurs, Bachats, imbalfadeurs, s'y logent, à caufe que sy eftes logez comme en vn Palais. les riches prennent leur portion bien que les pauures: les paffants. uans y fejourner troisiours \& nour$x$ hebergez. De Montagne recite que $x$ Sauuages furent amenez au Roy arles neufiefme, \& quils auoient. erceu qu'il y auoit parmy nous des nmes pleins, gorgez \& bien faouls outes fortes de commodité, \&z que uutres eftọient mendians àlcurs-pordefcharnez de faim \& de pauuretés trouuoient eftrange comme ces paus'neceffiteux poumoient fouffrir vne e iniuftice, quilils ne prinsét les riches gorge, ou miffent le feu à leurs mai-

$$
\text { L. } S
$$


IRE N T IES ME

fons. Ils font $\mathrm{fi}$ pitoyables que leur $\mathrm{C}$ paffion \& humanité ne s'eftend pas lement entr'eux, mais auffi ils onte miferation des beltes brutes, achep des oifeaux renfermez dans des ca? aufquels ils domnent liberté pour l'h neur de Dieu,comme ils baillent du\} aux chiens qui n'ont point de maift Cè que confirme de Montagne, dil n'y auoir pas long temps quil fe tro vn Turcà Venife(la ville la plas rich la Chreftienté) lequel rachepta tous oifeaux de leurs cajots, leur baillant bertépour l'amour de Dieu, \& de la tié que luy faifoient ces pauures pri niers parlans \& chantás, les Turcsa des aumofnes \& $r$ hof pitaux pour les ftes. Nous deuons, felon de Montag vin general deuoir non aux beftes fei ment, mais aux arbres mefmes \& plantes, \& comme il dit, nous deuon iuftice aux hommes, \& la grace \& be gnitéaux autres creatures, qui en peu eftre capables, $y$ ay ant quelque cóme entre elles \& nous, \& quelque obli tion mutuelle. On lit auffi que Py tha re eftoit fi pitoyable, que lon humar 
tendoit iufques aux beftes brutes: en ant les oifeleurs, apres auoir prins des eaux, de les laiffer aller, \& quand il fe controit entre les pefcheurs, il acheit les traits de leurs rets, $\&$ faifoit par es reietter tous les poiffons dedans la r. La plus grande iniure qu'vn Athen eut peu dire à fon voifin \& citoyen, it de luy reprocher, que iamais iln'et entré dans le temple de Mifericorauquel perfonne n'entroit s'il n'eitoit in \& fecourable,encores eltoit ce par miffó du Senat, qui iugeoit s'il eftoit Entre les Romains il y auoit vne loy dee inuiolablement; que nul n'eut faire fefte en public, s'il n'auoit pourauparauant à tous les pauures de fon artier \& voifnnage. Mefmes les Sorrs \& Sorcieres confeffent que celuy eft aumofnier \& mifericordieux, ne at eftre offencé de leurs fortilegẹs,enes que d'ailleurs il foit vicieux.Monir Bodin dit, que fi vn Sorcier demanl'aumofnè à vi qui a le moyen de la aner, \& il foit refuré,celuy qui n'aura $n$ baillé à ce pauure Sorcier, fera en ger d'eftre charmé, moyennant que L 6 
TREN I I ES M E celuy à qui on demande l'aumofne iç re que celuy qu'il efconduit foit forc Et fi eftoit auffi pour nous inciter a aumofniers \& charitables a tux paiu que la faincte Efcriture dit donnez ii ce,en lieu que nous difons, Donnez 1 mofne, comme eftant l'vne des ch qui iuftifie plus le mefchant. Et auff que nous donnons aux pauures, sapp des Giecs (comme on dit) Elecmoj] c'elt à dire, mifericorde, Agrape, qufi dire charíté \& dilection, encores abic d'huy les pauures nous prient de leut re charité. Voicy qu'vn grand en dit grands?

Alindigent monftre toy fecourable Iny faifant part de tes biens à foijon: Car Dien benit Fo accroift la maifon Qui a pitié du pauture miferable.

Las! que te fert tant d"or dedans la bon Au cabinet main riche veffement:

Dansles greniers tant d'orge o de froment Et de bon vin en ta caue ine fource?

Si cependant le pawne nud frifforne Deuant ton buyss o languiffant de faim - Pour tout en fin n'a qu' un morcedu de pain On severetra foins que rien on tuy donne. 


$$
\text { S E }{ }^{\top} \mathbf{R} \cdot \mathbf{E}: \text { : }
$$

Has tri, criel, le cour de telle forte oe mejprifer le paunire infortuné,

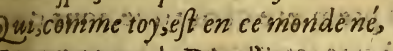
Et, cornine toy, de Dieu l'irnagê porte?

it à fin que les pauures de Grece fuffent ien toff fecourus, fans les faire attendte out vin ioúr à vne porte, commele plus ouuent nous faifons, ils portoient des loches allans par les rues, dont eftoient upellez Mithagiota, \& tout incontinent on leur enuoyoit l'aumofne, tăt ils crainoient ce que difoit Vlifle dans Homee, eftant en habit de pauture, Dy funt $m \tilde{e}=$ licorum vindices. Et combien que parl'Eangile, \& par Homere, la plus grande lemeure des pautures, \& $\alpha$ oùils eftoient e plus, c'eftoit à l'entree des portes: Is toutuons nous des nations, entre autres esCelres,qui ont eftéfi mifericordieufes $x$ pitoyables, qu'ils ne fermolent iamais la porte aux patures, 8 fileurpermettoyent d'entrer iufques à la table des conuives, \&z là ils demandoient de chacun l'aumofne, \& l'ayant receue, ils retournoient aux portes dont ils eftoient venús. Et à ce propos Nicolas dit en fon traicté des mours des, Gencils, que les.

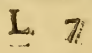




\section{T R E N T I ES M E}

Egyptiens n'eurent iamais de portes leurs logis, \& nous qui nous disốs Chr tiens, la premiere chofe que nous com mádons à nos feruiteurs, c'elt de ne lai fer approcher de nous pas vn pauur mais de les chaffer. Et dit auffi le mefin autheur, quanciennement il n'y auo point d'hoftelleries, parquoy les hoftes donnoient des prefens, \& pour fe rece gnoifte fe bailloient des marques cot pees en deux, qui fe rapportoient com mes nos tailles, \& telle marque s'app loit bospitalis tefera, \& en Grec Zeni (ainfi qu'on m'a faict à croire) comm qui diroit bopiralitatê, l'hofpitalité tenu par les anciens en grande reuerence, 8 eftimee faincte \& inuiolable, ne piu ne moins que la foy. Celte pitoyable ren contre de ce paurure fut caufe qu'vn del Seree, voyant la compagnie plus trift que de coufume, mit en doubte, $f_{1}$ pitié \& mifericorde auoit lieu en l'hom me fage : car, difoit-il, pitié \& compaf fion eft vne maladie de l'ame $\&$ de l'ef prit, de la mifere d'autruy, efmounan les pitoyables. Or les Stoïiens tiennen que l'homme fage n'eft iamais ef meu n 
oublé en fon efprit pour quelque choqu'il voye, ou qui luy arriue : cóment onc, difoit il, letoit efmeu \& fafché homme fage du mal d'autruy, puis que $u$ fien mefme il né s'en paffionne nulment? Parquoy il concluoit, felon les toyciens, qui tiemnent que ces efmoons viennent de nottre vouloir, qu'en homme fage ne pouuoit tomber pitié compafion, d'autant adiouftoit-il, ue qui eft prudent \& fage eft conftant, ui eft covftant il n'eft point troublé, qui 'eft point troublé il eft fans triftefle. Et ar ce à bonne raifon Socrate a reprins Iomere, qui feint Achilles, fils d'vne leeffe, efleué \& inftruict par le fage 'hiron, fe ietter par terre, \& de telle rte fe lamenter, qu'vne chetiue femne ne pourroit faire vn plus grad dueil. hales auffi à bon droit blafma Solon, vn es Sages de Grece, pour s'eftre monftré rop defefperé \& conftritté de la mort einte de fon fils, que Thales luy auoit it eftre mort, pour ef prouuer la conftantance de Solon, qu'on penfoit eftre des lus fages \& vertueux: cela nous demontrant qu'en ces chofes, les fages font les plus. 
T R E N TIES M E

plus fols, \& les plus tourmentez de pa fions \& triftelfes. Il s'en trouua vn aut de contraire opinion, tenant fort \& $\mathrm{fe}$ me que les fages n'eltoient hors de pa fion non plus queles autres: \& approt uant l'opinion des Peripatetiques, $q$ difent que les affections \& efinotion procedét de noftre nature, temoit qu'et tre le vice \& la vertu il y auoit des ch fes neutres \& moyennes, comme la m fericorde \& la pitié par lefquelles l'hom me fage peut eftre efmeu, troublé \& $p$ pa fionné. Les Platoniciens \& Peripatet ciens, difoit-il,n'oftent pas les affectio \& ne deffendent pas la ioye, ou la con miferation, mais temperent, \& les ioy \& les miferes: là où les Stoy ciés repro uent toutes les affections, \& approun leur apatbie, c'eft à dire n'eftre pointe meu rendans les hommes ftupides infenfibles, ne fentans rien de l'homm ce que reprent faind Auguftin; \& fain Hierofme : les Stoyciens voulans, ced fent-ils, ofter ce qui eft de nature \& na auec nous, \& qui n'eft pas volontair n’entédans pas qu'en oltans les vices d hommes, ils oftent auffi la vertu. Puis

Peripal 
ripateticien s'addreffant à celuy qui uftenoit que l'homme fage n'eftoit iaais efrieu ne paffionné plus à vne fois 'à l'autfe, luy va demander, s'il vouoit maintenir que ceux qui auoient uué ce pautire malade fur le paué, qui auoit efmetiz à pitié, ne fulferit-pas jes:Car ie fouftiés difoit-il, \& elt vray, e la pitié \& compafion peutefmouir lesfages, non pas commeles fems, qui de cómiferation \& pitié fe metincontinent à erier \& pleurè, \& qui paffionnent là où il ne faudroit pas, $\&$ r ưl'homme fage : \& prudent ne feroit rien troublé ne efmeu. Et mefries us voyons que la mifericorde caufee pouffee de l'imagination de voir foufrautruy, faict bien fouuent plus efuuoir \& changer la perfonne quil'igine, tant fage foit ellésque le patient if que l'on cognoint en ceux qui fe palint plus toft en voy ant faigner ou penvne playe, que le patient mefme. Il fouftenu par laduerfe partie, qui eit de l'opinion de Langius contre Lip. us, que pitié eftoit vne maladie \& vn d'vin efprit petit \& chetif; fuccombant 


\section{T R E N T I E S M E}

bant à la veuë du mal d'autruy; non $p$ difoit-il que ne foyons flechis \& efme à la douleur \& mal d'autruy, mais p aider, non pour fe douloir, permetic bien la mifericorde, \& non pas la co miferation, appellant mifericorde inclinatiō d'efprit, pour foulager la p. ureté ou la douleur d'autruy, \& ce mi ricordieux,encores qu'il ne pleure po \& ne foit efmeu, il confortera le mife ble à fon pouuoir, \& l'aidera liberalem \& fera plus benignement qu'il ne di \& baillera plus toft les mains que les roles au neceffiteux $8 \tau$ tombé:ioinct la pitié nous eft tant naturelle, que ce qui n'a pitié de ceux quail voit en adu fité, ne fe founiét point qu'il eft homn \& par confequent fubiect a toutes in mitez humaines, defquelles aucun ne peut dire exempt. Si elt-ce luy fut-il pliqué, que le pleurer de pitié n'eft po à blarmer, \& qu'il y auoit vn vieux ctum Grec, qui difoit, que les gés de bi $\&$ vertueux eftoient prompts \& fubie aux larmes, \& pleuroient facileme les larmes nairsátes aux yeux par la do leur du cour, car par la douleur fe fo 
as les pores, \& comprimants l'humeur iy eft enclos, il aduient que ceft huur s'efcoule dehors par les yeux. Mais ous diray, adioufta-il, ceix qui ont ié des paumes, pleurant ou ne pleuat pas,meritét d'eftre appellez pitoya$s, \&$ ne leur peut-on donner vn plus u nom, non plus qu'à ceux de Catane, quels ayans fauméleurs peres $\&$ meres feu, we peurent eftre honorez de plus ind honneur de leurs citoyens, que de nommer les pitoyables,eftant vn grád ófort aux affligez, de trouuer aucuns i ayent compaffion de leur mal.Quel'vin de la Seree s'interpofanten celte pute, va dire qu'il auoit veu des paufi bien haranguer, \& faifans fi bien calamiteux \& miferables, qu'il ne uoit fi graue Stöicien, qui n'eult par x efté incité à pitié \& compaffion, \& leur euft enlargy defes biens, encores il n'euft eu que cela , la neceffité leur unt enfeignéà vfer de cesartifices, \& rins cefte $R$ hetorique, nous eftans fi charitables, fi auaricieux, fi fubiects os biens, fi peu craignans $\&$ ay mans, , \& gardans fes commandemens qu'en 


\section{TRE N T I ES M E}

qu'encores ne peutuent ces paures mi rables, en monftrans leurs viceres \& yes, arracher vn pautire double rouge nos mains : eftans contraints, tant eft piez, cadauereux, chancreux \& desfi rez qu'ils forent, fe troutuer aux Egli à fin que la fainctetédu lieu incite \& guillonne ceux qui les voyent, ă don laumofne, comme la reuerence du te pleadmonyentoit les Platoniciês' \& St ciens de ne faire $\&$ dire aucune cho qui ne fuft vertueufe $\&$ digne da lieu ils eftoient, \& pour cefte caufe ne geoient gueres du paruis ou portique temple. Là où au temps paffé, on ñ' pas enduréles pauures, ainfi tombanis pieces fe prefenter en public, $y$ ayansi perfonnes deputees 'pour leur fubuter Ques'ils demandoient, c'eftoit affez dire, il me faudroit bien' du pain, rois bien befoin d'vne robbe. Tertul dit, nous baillons pius d'aumónes: defpendons plus à bailler par les rues pauures, que vous ne dependez en maifons : monftrant par la la charité premiers Chreftiens. Mais auiourd" lacharité eft morte fans heritier, la pi 


\section{$S E R E E$.}

aflee de cefte vie fans faire teltamét. ela auo it lieu, repliqua vn autre, veus iecle où nous fommes, \& la malice hommes pauures, tout le monde fe, it pauure, à fin de viure fans trauaila fon aife, \& fans foucy. Car encores la charité foit bien refroidie, \& que cun s'excufe fur les guerres ciuiles, fi aiffe-il de fe trouuer des persónes fai\& valides, qui mangent \& defrobent ien des malades \& des pautures. Et fi bien aduiler en cuidant fe comporcharitablement enuers les indigens, onner nourriture à la pareffe de pluis faineans, qui fe confians aux aunes, ne veulentrien faire, lefquels e ce qu'ils delaiffent leur meftier, ils ent encores les vrais pauures des entions qu'on leur feroit plus aduáufes. Mais pour efmounoir le peuplus grande pitié, difoit-il, deuinez ces gueux \& calins font? Ils contreles malades de fainct Iean, ayans la che pleine d'efcume:ce qu'ils font lement en mächant la racine d'herbe ulon, ou feront les demoniacles fe ans manoter:vous les iugerez hydropiques; 


\section{T'REN I IES ME}

piques, fe faifans foufler au cul : ils ferót iamais lans vne ia mbe gangren eftiomenee, (phacellee, fiftuleufe, cha creufe, qu'ils nomment vne iambe Dietl,accouftrans ainfi cefte iambe au vne ratte de bouf pofee deffus, remplie fang \& de laict. S'ils n'ont vne iambe, jouftoit-il, ils auront vin bras de pend lequel ils monftreront pour le leur, bien que cenx qui ne le verront le fen ront. Sils ne peutuent rien gaigner efta en vie, ils contreferont le mort, par qu'il y a des perfonnes qui ont plus pitié des morts que des viuants. Ce $q$ $i$ âpperceu vne fois paffant en vn cherr car en allant ie trouuay deux malotr qui demandoient l'aumofne aux päffal au retour, l'vn des deux eftoit eften fur la terre, qui faifoit fi bié le mort $\mathrm{q}$ tous les paffans y furent trompez : \& $f$ compaignon eftoit aupres de luy, $q$ amafloit les aumofnes pour le faire e terrer, fe difoit-il. A cefte caufe, pl fieurs ont voulu dire que les pauures 0 eftẻ appellez des Latins Mendici, àme tiendo, à caufe qu'ils mentent. Encor que ces gueux nous abufent, repliq 
lqu'vn, fi ne faut-il pas laiffer pour rimpolture, d'aider à ceux qui en ont oin, de peur que les bons n'endurent Ir les mauuais, n'eftant pas raifon que aute de peufoit chaftiee par la peine ous \& faut laiffer au Magiftrat à defurir \& punir les affrontemens de ces Atres \& maraux, Que s'ils eftoient it-il, auffi bien agencez comme i'en accouftrer vn, n'y a pas long temps,ils ndroient à fe moquer de Dieu \& monde, ce gueux de l'hottiere conint auoir faict l'hydropique plus de t ans, allant auec fa fuitte de ville en , interrogé comme il fe faifoit ainfi er, il refpondit que tous les matins compagnons, qui auoient partà la Ate, luy foufloient au cul, \& l'enfloiét ainfi qu'on faict vne veffie de por1 ,puis luy eftouppoient le fondemét des eltouppes poiflees \& gommees u'au foir eftans retirez, luy desbouient fon bourdóneau, \& que toute la $t$, il ne faifoit autre chofe que fou, cependant que ces compagnons de ardiers iouoient des doigts, \& que utres amaffoient des broutilles, tous

fe 


\section{TRE N TIES M}

fe fentás de la quefte, \& de ce qu'il atio amalfé, Le maifte de la maifon bien a fe de ce qu'on commençoit à onblier trifte rencontre qu'on auoit fáct en nant fouper chez lui, nous va conter qu ce iour melme il auoit troumé vn gued qui luy demanda l'aumofne, lequel fa foit fi bien le rompu, l'eftropiat, le bo teux, \& le manchot, \& conto urnant, bras \& les iambes de tel artifice $\&$ ind frie, quil penfale prendre pour vnal tre, encores que deux ou trois iours uant l'euft veu difpos \& droict : \& no contoit qu'ayant enuifagé ce pauure, luy difoit, \& mon amy,pourquoy vas ainfi? pourquoy reuire tu ainfi les bre quelle conuulfion t'a prins ? pourqu prens-tu tant de peine? T'ay-ie pas ve $n$ 'y a pas long temps, t'ayder auffíbien tes membres comme ie fay des miens: que ce gueux, ne le pouuát nier, luy auo refpondu, helas! monfieur, puis que vo voyez que ie trauaille tant à aller ain $\&$ contourner mes bras, tant plus deu vous eftre incité à me donner quelq chofe, \&z auroir pitié dè moy, veu la pe ne que ie prens. Lors ie ne me peu ten 
ire, \& de luy mettre de l'argent en fa $n$, quil ferra bien auec fa conuulfion. de la Seree venant à reprendre noftre e, luy va dire qu'il ne falloit pas baill'aumoline aux valides, gui ont le s. fain \& difpos pour trauailler , \& in leur baillant on les entretient en s impoftures \& mefchácetez, \& que etrr donnant ainfi aifément, cela les qquine, car celuy qui facile ment imc, fe rend plus hardy à demander. Ce pas la premiere fois, va refpondre le tre de la maifon, que i'ay efté reprins ailler où il ne falloit pas, car il me iient qu'vn de mes voifins me tanfa e que durant le cher temps, j'auois él'aumofue à vie ieune fille, encore lle entia la poche \& le bafton, me diqu'as-tu affaire de ba ller ré à ceite d'ulle? le t'. Ifocure qu' clle befongnemeux que ton re que moy. NefçaIt sil vouloit rire, on quicy, ie luy onds,iaimerois mieux baller à deux ois valides, en cores qu'ils n'en eurnu befo ng que d'en lailfier vn qui roit neceffité, pour le moins diforte ne refuferay iamais pauure qui me Liu.iij. 


\section{TRENTIES ME}

demandera du pain, tel qui foit : car luy n'elt pas homme qui denie du pair l'homme : que fi on trouue du pain à t re, en le baifant on le releue, parquoy Grecs foutent l'appeilent facerpanis: lévieux prouerbe Grec parlant des lins, \& de ceux qui mendient funs foing commande pour le moins de le ballier du pain, \& pour toutes aut viandes, des coups de poing, à fin de le faire lailfer cefte façon de viure fans th mailler, \& de les empef́cher de mang le pain des impotens \& malades, qui - peunérga gner leurvie. Mais ie re vo dois pas fuire, adioufta noftre hof comme fic vn Cardinal, lecuel sn voul chafrerles valides d'vn hof́fical, en cha fa aum les malades \& impotens \& voi comme il s'y porta. A Verfeilil ya fort bel hofpital \& de grand reuenu, d qual l'ceconome \& difpenfateur eft vn Cardinal, fort falché de n'en receuc pas grand profit, à caufe de la multitu des paunres la hofpiralez, pefez, \& nou ris. Ce Cardinal pour remedier à cel faic habiller vn fien feruiteur en Med cinj, "enuoyant à cefte Aumofnere po 
ter les malades, faifant femblant de vouloir guerir, bien inftruiat de fon iftre de ce qu'il deuoit faire. Les ayát s\& vifités, illeur va dire, qu'ily anoit moyen de les guerir tous, moyent qu'vn d'entr'eux fuft rofty tout vif, ue de la grefle qu'il rendoit les autres ent oingts \& engreffez par deux ou s matins, \& que fur fa vie 1ls feroiét sremis en bonne fanté \& difpofition. sauec grand ferment il leur promet etourner le lendemain, \& que coluy Ir qui arriueroit le fort, feroit routy t vif, \&r qu’ainfi anoit efté ordonné le Magittrat, \& par tous ceux de la . Ce fut affez dit, il n'eftoit 'quafi pas s de celte Maifon-Dieu, que tousles tans d'icelle, vont fonger comme ils rrosent fortir, non feulment hors aumofnerie, mais auffí de la ville, tát uoient grand peur, les vins de guerir tre contraints de trauailler, les aucraignás que le fort tombaft fur eux. voulez-vous plus. Ie vous affeure le lendemain que le Medecin rena à l'hofpital, il n'en trouua pas vin en y auoit beaucoup qui eftoient aM 2 
TRENTIESM E

litez, \& n'auoient bougé du lict il y auc plus d'vn an, eftans deffechez comn momies, ne reftans dans leurs corps des os enfilez enfemble. Si me voul efcouter, va dire vn autre, ie vous fer quafi vn mefme conte. Ily auoit en vi ville, commença-il à dire, fi grand nor bre de pauures malades, qu'ó ne les po uoit nourrir \& 2 entretenir, \& fi craigno on bien fort qu'ils ne milient la peite ce lieu-là.Le Conléil de la ville affemb faict amener deuant eux tous les mal des \& impotens, \& les faict vifiter pi leurs Miedecins \& Chirurgiens, lefyue dirent à ces pauures malades que jama ne gueriroient s'ils ne changeoient d'ai \& que l'air de cele ville n'eftoir pas bo mais tout contraire à leur fanté, leur rı monfrant qu'ily auoit des maladies ql ne fe guerifient iamais en vn païs,ou $b_{\text {i }}$ en vin autre, comme à Rome on ne pe guerir du mal de iambe, \&à Naplesd mal de tefte. Parquoy fut ordonné, por leurgrandbien, quils fortiroient de 1 ville, pour ioüir d'vn meilleur air, \& plu fain. Mais le bon fut d'vn de la ville, le quel fçachát qu'vn des malades, à qu 
faifoit changer d'air, auoit des efcus ufus en fa robbe(tellement Petacee \& (chiree qu'on l'eut prins pour vn pree de Proferpine ) soffre de luy bailler e robbe toute neufue, foubs ombie de ié \& d'aumofne, à fin d'empoigner cevieille robbe, qu'il difoit vouloir vn a faire rabiller, pour la bailler à vn au- Ce pauure prie le Magiftrat de n'ee poinct contrainct de prendre cefte be neufue, \& laiffer la fienne, qu'ily oit d'autres pauures qui en auoient is grand befoing que luy, qu'il auoir yen d'auoir vne autre robbe, parce ion luy auoit dit qu'il y auoit vn Corlier qui vouloit laifler fon habit, quil oit fi foible que les coufures d'vne bbe neufueluy feroient mal. Ce bon mofnier affeuroit le Magintrat que ce uure ne vouloit prendre vn bon ha,a fin de gaigner plus d'argent, \& efounoir d'autant plus le peuple à luy nner, le voyant endurer fi grand froid ce mefchant habillement. La ville ne achant où tendoit la charité de ce ciyen, eftoit bien empefchee, encores ivn de la ville pour la decifion de ce* M 3 


\section{T R E N T I E S M Z}

fte caufe euf mis en auant ce qui fe tro ue en Xenophon, qui eft affez commu C'eft, qu'Altiages demanda vn iour Cyrus conte de fa derniere leçon, lequ refpond quil y auoit vn grand garç en leur efcole, qui auoit vn petit fay qu'il doma à vin de les compagnons plus petice taille que luy, \&z luy of a fo faye, qui eftoit plus grand que lefie Mon precepteur, difoit Cyrus, mayat faict iuge de ce different, ie iugeay qu l'vn \& l'autre fembloit mieux eltre a commodé en ce point. Surquoy mo maifire me remóftra auoir mal iugé, ć iauois confideré la bien-feance, \& no pas la iuftice, à laquelle premieremer falloit auoir efgard. Laiflant ce ptope indecis, par cequion ne voit gueres le pauures refufer vne chole qu'illeur el necellaire, on fe va metre à dire que le pauures encores qu'ils trouuent à man ger \& à boire, endurent beaucoup par vermine qui les mange, pout ne mue pint d'habillemens, quelqu'vn de la Se ree nous contát que ces calins ne laifsét pour eftre tous coufus de pouils de rir \& de fe moquer, comme fit vn ces ion paflez: 
fez, lequel mettant la main a fon colva dire,

O mon Dieu que ic fris bewreux, Penfant prendre un ponil, ieriprens deux: vous prie, vadire mefler Panthalon, croire que fi voulez bailler dulinge à s pautures, qu'il n'y a rien meilleur que leur faire des chemifes qui foient de 1, pour les garentir de celte vermine de uils. Voyant qu'on nele vouloit pas oire, il va dire que Pline affeuroit que lin n'engendroit point de pouils, \& u'il ne parloit iamais fine Plinio, Piztarso, Platone, e Varrone, ne faifant iamais s ronde que fur leur mot de guet. Dy tti as luy repliqua vne feffe-tondue que th e dis riêfi n'as le pot \& le verre au nez: orsil va refpondre, qu'il ne faifoit pas omme De Montagne, qui dit qu'il n'alogue point le plus foument fes autheurs ùil prend ce qu'il dit, afin que fes rereneurs s'efchaudent, \& que le penfans eprendre, ils reprenent Platon, ou Aritote, ou quelque autre bon Autheur. Mais quand à moy, difoit-il, ie ne veux ooint que perfonne s'efchaude, \& auffi e ne veux point me brufler s'il m'ert

M 4 


\section{T RE N T IES ME}

pofible, \& fuis bien content qu'on ne prenne à moy de ce que ie mets en auá parquoy ie nomme toufiours mes al thcurs, à fin que s'ily a de la faute en - qu'ils ont efcrit, qu'on s'adreffe à eux, non pas à moy, qui ne le recite qu'apr :eux. Retournans a la mifere des pauure quelqu'vn de la Seree commença à dir ie melbahis cóme les pauures, mefme les plus miferables \& cadauereux, crat gnent tant à mourir, veu le mal qu'il endurent, là où pour fortir hors de tou tes miferes, ils deuroiét pluftoft fouhait ter la inort que la vie, \& comme dit vr Poëte,celuy la n'eft iamais miferable,qu ne craint point de mourir, \& comme di vn autre, la inort eit le repos des maux, \&z la fin des trauaux, ioinct l'efperance affeuree que doiuent auoir les pauures d'eftre bien heureux apres leur mort, sils prennent leurs afflictions $\&$ leur pauureté en patience, \& toutesfois its ont auffi grand peurde mourir que les plustiches, $\&$ bien fortunez. Voila de belles remonfrances, fut-1l repliqué,que plufieurs aiment mieux faire aux pauures perfecutez de tát de pauuretez, que 
donner vn double rouge. Mais, di-il,ils ne fçauent pas qu'iln'y a chofe pefante que la pauureté, \& qu'il eat plus aifé de la loür que de l'endu\& qu'en matiere d'aumo?ne, il faut ner la bouche, \& ouurir la bourfe, cun excufant bien, ce dit Seneque, laignant celuy qui elt appauury fans. 1 y ait de fa faute, mais nul ne luy ne fecours. Toutefois, adiouttoit-il, ainte que ie voy qu'ont ces pauures. erables de mourir, maffeure qu'ils tt pas tant de mal commel'ont pourpenfer, combien qu'ils deuffent plufouhaiter de mourir que de viure, dieux n'ayans rien donné de meilaux hommes que la vie brefue, fi $s$ regardós à ce qui eft ef crit dans les. tes, qu'Agamedes \& Triphonius aauoir edifié le téple de Pithus Apolils luy firent oraifon que for plaifir de leur dóner la meilleure chofe qui ffe aduenir à l'homme: Leur oraifon e, la mort les faifit en s'endormant. Et hime dit vn Poëte:

que les Dienx ant donné diuers cours, rs miferable, aux babitans du monde:

M S. 


\section{TRE N T IESME}

Car foièt leurs iours logs moyens ou fort con Rien que mifere en leur vie il n'abonde. Et ailleurs, 2 uicongue foit en ce monde venu. Ou raifonnable, on brutal animal, Deuant qu'il foit à fa fin paruenu: Il eft certain quil n' aura rien que mal. Dict en outre ce mefine Poëte de l'E d'Amphiaraus.

Extreme ampour luy fortoit Iupiter. Et Appollo l'airzoit autont ous plus: Que firent-ils,pouit versluy s'acguiter De ceft amour? ils fixerni an furplus (Etde bient' bomme eff fonnent forclus). Quien ces bas lienx brefue fut fa demeure. Et parcela fans dorbbteie conclus, Que nul naybien, in qques à ce gril mneure: En vn autre lieu il dit auffi: Plenrer peut bien celuy qui vient à naiffre, $V$ eu que toufours in mifere il doit effre. Homere appeile auffi en toutes occafi les hommes miferables, lequel imité Menandre, dít, qu'il fuffit pour nom malheur,d'eftre homme. Le mefmeH mere en vn autre lieu, dit ainfi: Ent rousles animax terreftres, aquatiqu \&s volatiles, il n'en y a point de fi mifer 
que l'homme. Menandre dit quelia leur \&zla vie font parents. Plaute dit 1 eft beaucoup meilleur d'auoir vefcu deviure, Silenus \& Pline, auec le uerbe Latin, \& beaucoup des anciens ent que c'et vn grand bien de ne naipoint.Que les pauures, adiouftoit-il cores n'ayent pas tát de mal que nous mons, \& plus que les autres: L'expence nous apprend que nous nous peris d'impatience, les maux ayans leur , \& leurs bornes, il leur faut donner lage, \& s'arreftans moins chez ceux iles laiffent faire, laifsós faire à natuelle entéd mieux fes affaires que nous. ais vn tel en mourut, fi ferez-vous bie us, finon de ce mal, d'vn autre, \& comnd'autres qui auoient trois Medecins ar colté. Il faut fouffrir doucement loix de notre condition, nous foms pour affoiblir, pour mourir, pour re malades en defpit de toute medeciC'elt la premiere leçon que les Mexins font à leurs enfans : Enfans, difentle faluant au partir du ventre des me, tu es venu au monde pour endurer, dure, fouffre, \&z rais-roy. Et puis cof 


\section{TRE N TIES M E}

- iniuftice de fe douloir qu'il foit aduen quelqu'vn ce que peut aduenir à chac il faut apprendre à fouffrir ce quion peut euiter.

Premierement, le pauure tant mifer ble foit-il,eft femblable la moitié du té auriche, c'eft quand il dort, car nele che,ne le pauure, quand ils dorment, 1 font rien : or fans action il n'y a felici ne mifere : Secódement, le malheur n't pas toufiours à la porte des pauures. miferables: car comme dit quelqu'vn,

Il n'eft malkeur, douleur, ne mal i f ferme,

Q wi quelque iour ne prenne fin of terme.

Que fi la douleur eft grande, difo. Epicure, elle fera brefue, fi elle ent longu elle ne fera pas grande. Plus les pauur ne pouuans mourir de faim, la poifon n leur peut nuire, pource qu'ils mangen l'oignon \& l'efchalote auant le repa: d'auantage, les pauures ne font poin fubjects à vne infinité de maladies, (qu tourmentent les riches:) pour les diete qu'ils font fans ordonnance de Mede cin. Et ne s'elt-il pas trouué, adioufta il encores, des perfonnes qui ont eftabl! leur foumerain bien à viure fans gloire, \& 
ogneus, à eftre pauures, à def prifer les effes, à aller par le monde de miifon naifon cherchans du pain, à aller defuffez \& nuds, à dormir dans des tonux , a fe chaufer au Soleil, eftimans fe indifferente d'auoir du bien ou de $n$ auoir point:Soyez affeurez,difoit-i $l_{\text {, }}$ il y a des incommoditez auffi bien en heffe qu' en pauureté, \& que tout enit a fon enuers, \& qu'on faict autant mal d'arracher le poil à celuy qui a uxcoup de cheueux, comme on faict à qui n'en a gueres. Plus, ce qui aide pauures à porter le mal, c'eft que ucoup d'entr'eux ont accouftumé dés Ir ieuneffe à eftre fouffreteux, \& auoir mal, \& celuy eft bien heureux, difoit nis l'ancien, qui a apprins désfa ieufle à eftre malheureux, \& fouffreteux, qui a prins naiffáce entre la pauureté, eft efleué entre les miferes. Les mifede ce monde eftás comme le feu, qui, s qu'il eft plus ardent, affine d'auantal'or qui brufle,ainli tandis que l'homendure plus de míleres, d'autant plus e fait parfaict, Mais, par ce que ie voy $e_{2}$ adiouftoit-il, que perfonne ne m'en; M $\geqslant$ 
TRE N T I E M E

croira, \& encores moins voudra eflay la pauureté, fi eit-ce que les pauures ront plus grade delectation que non les riches, fi d'auéture il leur arriue qu que bien, la volupté \& delectation elta en quelque fens, \& tout sés elt auec $m$ tation, \& la mutation eft en chofes cc traires, or la mutation eft ou du mal bien, \& ceci eft la ioye, ou du bien en m $\&$ cecy eit la trifteffe,doncques pour $\mathrm{f}$ re la volupté \& delectation, il eft nec faire que le mal foit propofé, \& tant $p$ le mal eft grand, tant plus le plaifir $\int$ grand venane apres le mal: Mefmes en trifteffe ily a quelque allege de plaifir, peintres auffi tiennent que les mouu mens \& plis de vifage, qui feruent at pleurs, feruent auffi au rire, l'extremi du rire auffi fe meflant aux larmes. Pe fez-vous, difoit-il encore, le plaifir qu' eules paures qui font deuenus rich durant nos guerres ciuiles, \& qu'elle tr Ateffe ont enduré les riches eftans deut nus pauures? Quelqu'autre de la Sere va repliquer, que les pauures n'eftoier pas fimiferables qu'on les faifoit, parc difoit-il, qu'ils ne craignết point à fe ma

ries 
er, \& à faire force enfans: ce qu'ils ne roient pas s'ils penfoient que leurs enns fuffent fi mal-heureux qu'on eftime s pauures. Vous ne fcauez, fut-il repli1é, pourquoy les paures font $f i$ hardis e marier, \& ne fe foucient d'auoir \& de ire beaucoup d'enfans? C'eft qu'ils fçaent bien qu'ils ne les nourriront pas, \&2 ur remedier àcela, il y a vn païs où le ambre d'enfans eft prefcript felon les acultez. Nous trounons en Herodote, u'il n'eftoit permis aux perfonnage de etite qualitéde fe marier, \& que par les oix eftablies par- Solon aux Atheniens, toit prefcript la forme de mariages, aus enu peuple de volonté, \& aux nobles, $z$ autres tenans rang en la Republique, e neceffité. Auffi que c'elt vne grande lie de fe marier auát qu’auoir fongé le noyen de nourrir \& entretenir fes enans \& fa famille: car nous troumós dans jenefe, que Dieu ne bailla point de femdeà Adam, infques à ce qu'il euft impoéle nom à toutes les bettes, \& mifes en fa roffeffion. Vne chofe, difort il, re onfore les pauures \& miferables, c'eft qu'il ny If infortuné,ne fi maladif \& impotent, qui 
TRE N T I S M E

qui n'en trouue vn plus mal-heureu plus paure, plus perfecuté de mal qi luy, tellement quil fe repute heuret auprés de ceux cy, ne fçachant pas cet qui fe contriftent tant de leurs fortune $\&$ fe penfent des plus mal heureux, mal des autres. Et n'y a rien qui plus for lage les affligez; que penfer au mal d'al truy, eftant vn grand reconfort aux che fes triftes, de confiderer les infortun des autres : \& comme difoit Democrit Si tu veux euiter la trifteffe de ta mife re, contemple la vie des affligez, \& par $]$ comparaifon d'icelle auec la tienne, $t$ verras auoir occafion de t'eftimer bier heureux $\&$ cóme dit le gentil Alamann:

Dewx vrais conforts'soffrent aux mal-ben reux,

L'vn du paffé auoir la fouren ance:

$L^{s}$ autre eft, de voir plus grande la fouffräa $D^{\prime}$ 'autre, quis foit plius qui icenx. fonffretenx Et cela a efté caufe, difoit-il, qu'aucun ont voulu dire, que fi tous les maux \& fa cheries du monde eftoient enfemble et. vin monceau, pour eftre egallement departies, qu'il n'y a celuy qui ne reprint fon mal, pour n'auoir part en l'autruy 
$S E R E E$.

tt le monde gouuerné de telle forte le mal eft compenfé auec le bien, \& irty à vn chacun felon fa charge, par te \& efgalle proportion.Mais ce qui s gatte, c'eft que le naturel de l'homeit toufiours enclin à regarder plua fon mal quà fon bien, lequel facient il oublie, \& au cótraire, elt própt nfiderer le bien appatent d'autruy, fonger au mal caché qu'il ne veoit: ue dit mófieur Pybrac en cefte forte: Toftre heur pour grand quill foit nous femble moindre.

es feps d'autruy portent plus de raifins. Lais quant aux manx que fouffrent no,s voifins,

eft moins que rië, ils ont tort de s'en plainsdre.

pource, commença à dire vn autre, pour adoucir les peines iamais ne quent Orateurs:efcoutez les raifons ntences que ie voudrois que tous les ires \& infortunez euffent bié imprisen leurs memoires. La premiere, Ine fe faut point facher des chafes nous aduiennent, lefquelles ne $f_{e}$ dent euiter par aucun confeil \& fageffe, 


\section{TRE N T IES ME}

gelle, car es maux où il n'y a point mede, le meilleur elt de ne les point $c$ cher:I ia feconde elt, que nous deuon prendre parce qui arriue à plufreurs: rien ne nous furprend de nouneau, \& ne foit commun à la códition huma Tiercement, qu'il ne fe faut contrift ce qui arriue à tout le monde, car fe. uenant de la Loy commune à tous', doit aleger le mal.Et croy, difoit-il, la plas grande mifere de toutes, eft poutuoir porter la milere, la mifere dant volontiers auec ceux quil la not flent, difoit Bias: $\&$ comme difoit I gene,iln'y a que ceux qui font paul maugré eux ,qui deuffent auoir hont l'eftre : car celuy qui fe comporte auec la pauureté, ce dit Seneque, el che, celuy qui a peu n'efát pauure, $n$ celuy qui defire d'atantage. Si dit-on munement, va repliquer vn de la Ser qu'en pauureté n'y a point de fiance Laërce dit, les Spartiates auoir toufio eftimé les pauures eftre mefchans, $\mathrm{Cl}$ dian appellant la pauureté inique, \& $\mathrm{T}$ gile deshonnefte, la pauureté eftant $m$ uaifegardienne de pudicité. Encores 
d'huy, difoit-il, appellons nous ceux i nous voulons mal, \& penfons iniumarauts, coquins, beliftres, comme voulans reprocher qu'ils font mefis \&z lartons, \& qu'on ne fe fie point ux, \& qu'on a en haine la pauureté, ce qu'elle occafionne plutieurs à s'efra droict chemin, que quand nous cós quelque malediction à aucun, \& voulons mal, nous luy defirons fur la paurureté, ce que vertez par ce trin,

prie à Dien quil vous doint paunretés Iyuer fans fen, vieilleffe fans maifon, 'renier fans blé en l' arriere faifon, 'aue fans vin tout le long de l'Efté. quiont telmoigné les Anciens, qui as paures n'ont plus voulu viure, \& me dit Theognis,

our paunreté fuir \& eniter,

in pleine mer fe faut precipiter. $A$

Medee d'Euripide chante ces vers: as! ie prewoy les maux que pauureté Meferafaire outre mavolonté.

franc-à-tripe ayant bien noté toutce auoit efté dit de la pauureté, va comncer a dire:Cela me fafche tant d'eltre ellé pour ces beaux noms, maraut, 


\section{TRENTIESME}

coquin,beliftre,grăd colin, que pour uoir fi $i$ 'eltois riche ou pauure, i ay ve tout mon bien, \& $z$ maintènăt ie f̧aur on me doit iniurier, de ces iniures

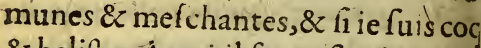
\& belifre. A qui il fut refpódu, que ureté n'eftoit point vice, \& que comb que ce ne foit pas vertuaufl, fi fau plus tolt craindre ceux qui craign pauureté,que les pauures, plus de m fe failtins pour la richelfe que pou pauureté, \& comme dit Theognis, be coupplus de gens font peris d'eftre faouls que de faim, les contentions iniures ne naiffans pas communem à caufe des chofes necelfaires, defqu les aucuns ont befoin, mais bien pour fuperflues, où noftre appetit proced vne infinité. D'auantage, il fut adiou que les pauures ont quelque efpoir d ftre riches, \& que beaucoup ont eu en: commandation la pauureté par ce qu' le rend les perfonues fi vigilantes $\& i$ duftrieufes qu'elles peuuent deuenir : ches, fi elles trouuent des gens $q$ leur aident, moyennant que ces pauur à qui on aide, ne foient de ceux qui a 
is ont eu quelque moyen', \& l'ont. endu, car aydant à ceux-là, vous feriez pluftoft pauure en leur bail, que de les rendre riches, d'autant celuy qui a defpendu le fien autretqu'il ne falloit, n'employera iamais ce qu'on luy donne, ou prefte, \& n'eft Et comme dit Seneque, de peur d'eauure, il faut mefnager de bonne e,car l'efpargne qui com mence par nd,eft tardiue, par ce que non feuletle peu.mais encore le pire demeure és de la lie. A ce propos Socrates adeftoit IIfchines, qui eftoit pauure, empruntaft de foy-merme, en failuy difoit-il, moindre defpenfe. La imonie fut fi gráde aux anciens, que on le vieux vendit fon cheual de fer, pour efpargner l'argent qu'il euft ¿éa le ramener par mer en Italie, il intoit de n'auoir iamais eu de robbe euft coufté plus de dix e fcus, ny auoir oyé au marché plus de dix fols pour our. Il ne fut taxéa Tyberius Gract ; allant en commiffion pour la chofe liquée, que cing fols \& demy, eftant le premier des Romains. Le plus grand 


\section{TRE.N T I E S M}

grand mal qu'ait pauureté, va dire vn tre de la Seree, c'eft que les pauures toufiours reboutez \& moquez, \& qu neles conuies gueres és banquets, aux nopces, \& fi ne trouuent iamai parés ne d'amis, d'autant dit Menanu que le riche penfe que ce parent pau luy doit demander quelque chofe, nul ne confeffera celuy qui a affaire d" de luy appartenir aicunement. C'elt de chofeque cela, fut-il repliqué, \& faut point auoir honte de confeffer pauureté, mais bien eft reprochable ne fe mettre en effort de l'euiter, diff Thucidide. Que les pauures adioufto il, foient fibie ts à beaucoup de mifer vous verrez que s'ils ont vn mefcha logis, ils auront encores vn plus melch lit : ils n'ont iamais repos en leur vie, ne ferót auiourd'huy où ils eftoiét hit ny deuant où ils eftoient à ce iour, s' ont des chauffes; elles feront repetacee ouil les faudra eflargir eftans trop eftro ctes, ou il les fautra a ccourcir eftás tro longues, ou clies, feront courtes, \& contuendra allonger, ils n'ont iamais e tierement àdsfner, quand il y a du vit 


\section{$S$ E R E E:}

aura point de pain, quand ily aura tage, il n' y aura point de chair, quád. it vn faye, ils n'ont point de man, quand ils auront vn bonnet,ou vn eau,ils n'auront point de fouliers, \& id ils ont des chauffes ils n'auront $t$ d'efguillettes. Auec tout cela, les ires ne peutuent trouuer de logis, car la peur qu'on a d'eftre mal payé des ges, on adioufte foy à vn prouerbe, lit, qu’ il ne fait pas bó auoir vn voiop pauure ne trop riche. Et ie croy ceeft la caufe pourquoi Diogenes hait dăs vn tonneau,en lieu de maifon, ouuant trouuer de logis, eftant la. grande pauureté \& incommodité Centit iamais, n'en ayant gueres end'autre, demandant ce dequoy il taffaire de telle grace \& hardieffe, n'eftoit pas founent refufé. A vne il difoit, ie vous prie me diftribucr os biens, fi auez accouftumé de bailuelque chofe, finon commencez à A l'autre fois, fi quelqu'vn cótêtoit re luy de ce quil eftoit fain \& valiluy difoit, ie vous prie premieremét lonner, \& puis nous en difputerons. 


\section{T R E N IIES M E}

Il demandoit deux fois autant à vn $p$ digue, \& qui s'en alloit pauure, qu'à bon mefnager \& riche, parce quil ef roit à en demander \& en anoir enco duriche, là où il n’efperoit iamais r recenoirde celuy qui s'en alloit paui Vin grand Seigneur luy voulant bai vngrád don, luy demanda s'il feroit ho me de bren, s'il lui donnoit quel que fe, il refpond qu'ouy, encores qu'il ne donnalt rien. Et quand il voyoit qu demandant peu,aucuns luy promerto beaucoup, il les laiffoit là, \& difoit 9 le promettre beaucoup à qui peu dema de, eftoit vne efpece de refus. De pe d'eftre efmeu \& faché fi on l'efcond foit, il s' accouftumcit à demander à ftatues. S'il rencontroit vn homme ric \& mefchant, il neluy demandoit iam: rien, difant, Si toufiours il a efté larr du bien d'autruy, quelle ef perance y a quill donne du fien ? Voyant qu'on bai loit pluftoft l'aufmone aux boiteux , bo gnes, aueugles \& eftropiats, qu' aux $\mathrm{Ph}$ lofophes, \& gens de fçauoir, difoit ql c'eftoit quils craignoient pluftoft deu nir boiteux \& maleficiez que Philof 


$$
\text { S E R E E: }
$$

\& f çauans. Quand on luy remontla peine de fa pauureté, $\&$ de tous utres compagnons de Philofophes, u'il pouuoit fe mettre à fon aife, il it que la boutique du Medecin eltoit hole de Philofophie, où l'on accoupour la fanté,non pour la volupté \& ir. A propos que les Philolophes \& ans le plus fouuent ne font pas les riches, quelqu'vn va conter la refe que fit vn artifan à vn homme de e, qui demandoit l'aumofne, touis fe vantát eftre mailtre és fept arts aux , luy refpondant ceit artifan, Et , ie fccay plas que vous, car auec yn art ie nourris moy, ma feme, \& mes s, là où auec les fept arts tu ne te fçau nourrir feulement. Ces vieux cótes mmurs, \& tant de fois redits, furét e que chacú fe vouloit retirer, n'eußt juvin de la Seree nous va dire que la ureté le plas fouuent venoit d'eftre ime de bien, \& qu’à celte caufe qu'elgeroit pluftoit chez les gens de bien, chez les mefchans \& riches : carles hans \& richesl'eftiment mauuaife, nefe veut mefler ny auoir affaire Liu. iij. 
TRENTIES M E

auec eux. Et pour preuue de ce qu' foit, il nous mettoiten auát, \& deuă yeux,plufieurs pauures auoir eftégen bien \& grä̀ds perfonnages : cóme Epa nondas, quifut mis en fepulture du blic, auffi biě que Lucius Valerius Pu cola. Il recita qu'il falloir que les $A$ nie s haillaffent vne robe \& des fouli Lemachus, toutesfois \& quátes qui i. firfoient Enpereur \& conducteur c mee, \& que Paulus Emilus n'enft pas quoy rédre le dot à ra femme. Et qui difoit-1, que les mefchans font riche les gens de bien pauures? Sinon qui monde eft renuerfé, \& que les vertu font debontez, \& les vicieux auan Parquoy wn Philofophe difoit, que devoit renaifre, il choifiroit pluftoft toutautre efpece d'animal qu'hom fçachant que l'homme feul entre tout qui a vie, eit iniuftement recogneu \& worifé, entát qu'vn bon chetral eft mı penfé qu'vn pire, vn bon chien plus pi que celuy qui ne vaut gueres, qu'vn c eflant genereux eft plus eftimé que coiiard, \& mieux nourry, là où entre hó mes, il ne fert prefques de riers d'et 
Ezrextueux; d'autant que les vicieux alviuans font plus efrimez que les s. Si eft-ce, repliqua vin autre, que stroutuos que les Romains auec leurs f́eurs, mettoiét hors l'ordre \& qualiSenateurs, ceux qui deuenoiét pau, \& que pour tenir l'Eftat de Sena, il falloit auoir vaillát trois mille efcouronne, \& que ceux de Chartage, Imettoient en leurs Magiftratsles gés ien, s'ils n'eftoient anec cela riches, utuns impofible qu'vn pautre peuft rcer fon office fans corruption. Celuy parloit touliours pour la pauureté,ne a pour tout cela à dire, que les Rons n'auoient pas la pauureté en fi nd meépris que lon penfe, ce qui eft à prouuer, dı́oit-il, par Scipio Năfijui demandant l'Edilité, \& prenant la in d'vn ruftique, qui auoit voix aux nices, \& la trounát fort rude, luy dedasill cheminoit des mains. Ce qu'édu \& rceu de tout le peuple Romain, uy refufal'Edilité,toutes les Tributs ns prins en maunaife part, qu'on leur rochaft la pauureté. Puis pour recomndation de la pauuretéil adiourta ces N 2 
T R E T I E S M E

vers rraduits de Palingene par vn ex lent perfonnage de ce temps.

Obonne paunreté prefent des cieux ven Von encores affez bien des bommes recogi La garde des vertus, de chaftetél'amie, Lefrein des voluptez, l'entretien de la vie Tumefprifes du fort les accidens diuers, La rage de la mer, des vents, ei des Hyue Iilunt ton petit train, fans que deffus les or Tis findes trop auant les aby mes profondes Vufege Democrite, on fage Anaxagor Tuss rencmez au möde, ¿ mille autres en Mespiferent iadis l'or,l'argent, or les bien. Comine eftans de tous manx la canfe of meyens:

Pourguoy? Inon d'autät qu'ils auoient $\operatorname{cog} n$ fance

Que ce n'eft le vray bien, veu que da iouiffa Broitille lentendement de foucis or trawat Et fait l'böne abifmer en wn goifre de mat D. fire donc fans plus autant qu'ilefi bejoing Pour maintenir ta vie, é ne va point p loing.

Mais four tout cela, ni par rime, nip raifon, on ne peuit retenir la compagn cui fe retira en diligence, cóme voula fǚla paunreté. 
RENTE-V NIES ME SEREE.

\section{Des Ricbes of des awaricieux.}

A precedente Seree, où auoit efté torlé des pauures, ne fut point tant e de difcourir des riches (bien quie $x$ contraires mis l'vn prés de l'autre $f_{e}$ oiffent mieux ) que la richeffe \& heté d'vn de nos Serees, qui nous loit ce foir à foupper. Ce quail faifoit tefois le plus tard quil poutoit, atdat des viures de fes maifons, ou bien ceux à qui il auoit baillé de l'argent iage, luy euffent faict quelque pre, ou qua ${ }^{2}$ l eut veu le gibbier à bon ché, qui eft quand il commence à der. Et lors à fin que tout paffat pour I conuioit tant de gens de toutes forqu'on ne poutuoit commodément fe yer a la table, \& fi ceux qui eftoienz $n$ bout, ne pouuoient entendre ceux parloient à l'autre, tellement qu'il it que l'vn dift à l'autre ce que l'audifoit, comme à la guerre, ou en va ire : ce qui eft contre les preceptes de carçue. Vous affeurant qu'il n'affem$\mathrm{N}_{3}$ 


\section{TK N T E-V N I ES M E}

bloit point tant de perfonnes pour m frer fa richeffe (eftimant qu'elle fer fans honneur fi elle n'anoit beaucoup refmoins, cổme la Tragedie de plitife fpectateurs)qu'à cellefin de nefaire g res de barquerz; \& pour celte canfe mettoit fes parents \& a mis; \& ceux autresfois l'auioient conuié, \& ceux Serees,en mefme robe:Auec toút cela pis encore eftoit, qu'il nous traitoit fi iniliere ment, que fo melmes Epaming das y euft efté, il ne s'en fuft pas allé $f^{2}$ fouper : comme il fit vine fois de chez fien amy, quand il vit l'appareil plusgr que fes facultés. Parquoi ceux dela Ser ne fe pouboient tenir debailler à nof holte quelque attainte, toutefois en ri A vne fois on luy difoit, mó hofte, ie cr que vous eftes Medecin, car vous no traictez comme on faict les malades. $T$ autre loitant ce banquet, affeuroit qu' pounoit dire de ce cóuy comme de ce de Platon, qu'on s'en fentoit encores lendemain, \& qu'on le pounoit appell le fouper des dieux, comme fait Horac Vn tiers difoit, que noftre holte voulc obeïrà la Lcy, qui defendoi te ferm 
ortes quadon prenoit fon repas, $n^{\prime} y$ nt rien contre les Loix fumptuaires, reigloiét l'excez des conuiues \& báts. Vn qui anoit plus grande enuje de dre que de ruer,ayant veu la Demonanie, nous va dire, que noftre hofte it pire que les forciers, eftant pour le ins la table des forciers bien garnie de utes fortes de viădes bien exquifes, \& rrande quantité, toutesfois qu'ettans is de leur table, qu'on ne laiffoit tout ontinét d'auoir auffi grand faim qu'a tree, mais à ce băquet, nous difoiteil, s n'auez quafi rien fur table, pour dó, pour le moins le plaifr que ceux qui pent chez les lorciers ont en man$t, \&$ ne fçauriez appeller ce fouper va gnifique báquet, queles Latins appelt Cana dubia, quand il y a tár de vianqu'on ne fçait laquelle prendre la miere pour manger:mais c'eft bien na dubia, ainfi que le pren Henryienne:car nous ne fçauós fi nous auós uppé ou non. Et voicy fes vers, que i'ay $s$ en Latin,

nuinis dubiam dico te apponere canass Pofthume, fed dubiam nomino more nowo. N 4 
TRENTE-V N I ESM E

Nonetenim dubia eft coena, vt fuit illa $T_{e}$

2)um dubitat frimiz quern velit effec Sed quoniam banc dubitat quifquis con. abiuit,

Verè an per formmum fit dota coena tibi Vn Franc-à-tripe de noftre Seree, voy qu'ó defferuoit, va dire à l'oreille du proche de luy, qu'il ne retourneroit de vie fouper la dedás, Celtuy-cy luy ay: demandé, pourquoy? parce, refpondit que les Graces ne font gueres loing Benedicite. Illuy replique, qu'il n'y au rien pire pour la fanté que de tenirlóg table, ni qui engendre plus de maladi a caufe que ce que vo" auez prins du c mencement du repas eft quafi diger quand long temps apres vous en pren d'autre,parquoy ces viandes prenans uerfes cócoctions, ne faut s'efmerueill fi elles nuifent à ceux qui tiennét long table,à caufe du difcord. Puis il va adio fter, que noltre holte auoit eu foucy noltre fanté,ne nous ayăt baillé des vial des fi exquifes \& rares, ni de beauceu dé fortes, \& que toufiours les pl: fimple viandes, \& qui coultent lemoins, font it plus falubres au corps, \& aufi qu'il 
it rien pire que de manger de beaup de fortes de viandes, la diuerfité des ides tourmentant l'eftomach, \& emchant la cócoction, l'vne viande eftát le à digerer, \& l'autre difficile. Ie me ttois bien, commença à dire vn autre, eftoit à ce foupper, que nows ferions I traictez, ne voyant point de fel fur la le, prenant de là augure que le banetne feroit gueresmagnifique, ni opt:$t$, mais infortuné,eftant l'opinion des ciens, \& fi eft bien encures la noftre, la table qui eft fans fel, eftprofane \& lheureufe, \& vn vray banquet de dia$s, \&$ de forciers. A ceite caufe la preere chofe que les feruans mettent fur table, apres la nappe, doit eftre la faliegarnie de fel noir, fi celt pourles Prin\& grands Seigneurs, le fel blanc reant plus aifément le venin que le ir. Que la table ne doiue eftre fans fel, vieux prouerbe le monftre biens, quand it, Ornnis men. a male ponitur abjgave fale. ais,repliqua vn de la Seree, commente -ce que la table fans fel eft eftimee inrtunee, veu que les preftres Egyptiens oiét la mer en abominatió, \& l'yn des:

N S : 
TRENTE-VNIESME poincts qu'on leur deftendoit en les riant, c'eftoit de n'vfer iamais de fel table? Et pour cela, les preftres Egypt ne faluoiétiamais les pilotes, \&z gens marine, ce dit Plutarifue, à caufe qu eftoient ordinarement fur la iner, do eft faict le fel. Et c'eft auff, adiouftoit la principale raisó pourquoy ces preft abominoient le poiflon, de forte quandils vouloiêt efcrire le hayr, \&z bominer, ils peignoyét vn poiffon, col me en la ville de $S_{a y}$, à l'entree du te ple de Minerue, il y auoit peint vn pe enfát, vn vieillard, \& puis vn efparuic \& tout ioignant vn poiffon, \& à la fun ' cheual de riuiere,qui fignifioit \&r voulc dire fous ces figures, ce dict Plutarqu $O$ arriuans, \& partans, ieunes $\&$ vieu Dieu hait toute violéte iniultice, repr fentans Dieu par l'efparuier, parle po: fon eftant nourry en la mer lalee, has ne \& abomination, \& par le cheualc riuiere, toute impudence de mal fair d'autant que l'on tient qu'il tue fon $p$ re, \& puis fe melle par force auec fa me re. Le propos du fel acheué, celuy me: me qui auoit faict l'augure, va recite 
vers qu'on dit eftre de fainct Gelais: Du Chatelus donne a difner

$A$ fix pour moins d'vn carolus:

Et lacquelot donne à foupper

A dix pour moins que Chatclus:

De ces banquets fi diffolus

I'en reniera creux comme on fallot,

Si ie ne Juis chez Chatelus

Ne me cercbez chez Iagrelot.

át recité ces vers, il nous va dire quo'il recŏpenferoit bien fur le deffert : mais yăt qu'il n'y auoit que du fromage, \& ion fe riott de luy, ne laiffa à fe mettre in manger à bon efciét, \& difoit qu'il oit trefbon, \& que l'efcole de Salerne oit yeritable, quand elle dit, Cafonsille nus, guem dat anara manus. Puis nous va re, \&z que fçauez-vo' fi notre hofe ne mótrera point plus liberal à nous dòrquelques beaux presés queles Latins pelloient Apophoreta: quád nous fortiins du banquet, quiln'a efte en nous illant à fouper, \&x que l'vn recompenra l'autre. A quoy il fut refponda, qu'il failloir point siy attédre, \& que par cy atuant il les auoit toufiours traictez en ite forte, \& encore pis,plufieurs fois les N 6 
TRE N TE-V N IES M E ayrans conuiez à difirer, contre toute co tume des Serees, faifant cela pour bea coupde raifons. Premierement, pour $n$ uoir pas tant de gens à fes conuis, par qu'on n'a pas mis fin fi tolt à fes affaires qu'on et plus libre au foir. Secondem à fin que les fémes n'y vinfsét point, $f_{c ̧}$ chantbien qu'elles ne pourroient eftre toft preftes, \& atiffees pout le difner, pour cefte caufe les Sybarites conuioie les femmes aux bäquets quatre ou cin mois deuăt. Tiercemét, il les auoit beat coup de fois cóniez pluftoft à difner qu fouper, pour ef pargner tant la chandel. que le bois, qu'il faut l'Hyuer au foupe Quartemet, qu'on fert plus de fortes viandes aufouper qu'on ne faict au di ner, \& qu'on tiét plus longue table, efta lors exempts de toutes affaires. Encore me fouviêt, adiouftoit-il, quâ â l'vn de fe difners les viandes eftoient fimal cuites qu'vn de la Seree va dire à noftre hofte Ie croy que nous auions efté conuiez : foupper, comme c'eft noftre couftume parce qu'v vn iour vous me dictes, le vou: veux convierà fouper vn de ces matins. Maisic me doutay bien, difoit-ily enco. 
, que les viandes auoient efté feruies ficrues, tant pour éfpargner le bois, à fin qu'on n'en mangeaft pas tant. is vir de ceux qui auoiêt efté conuiez, auoit efté en Turquie, repliqua que euft efté au grand Caire, fon hofte euft rien gaigné : car,difoit-il, i'euffe ns cefte chair mal cuite, \& en fortant lement en la ruë, $i$ 'euffe trouué qui t tincontinant me l'euft faict cuire, $y$ it en ce lieu-là enuiron de douze milcuifiniers, lefquels allans par la ville rtent de petits fouyers fur leur tefte, i en payant fontcuire \& accouftent s viandes, \& ce a faute de bois qu'ont ux du Caire. Oubien ie feray comme Anciens, qui fe faifoiét feruir la viáfur des fouyers, qui fe portoiét fur la ble, \& auoient des cuifines portatiues, ins lefquelles tout le feruice fe trainoit tres eux, \& laiffoient cuire les viandes nt qu'illeur plaifoit, pour les manger utes chaudes. Vn autre de la Seree, reenant à noftre hofte, nous va dire qu'il s auoit traictez comme le diable (à qui ont tous les auaricieux ) fit vne fois $\mathrm{fa}_{\mathrm{a}}$ sere, à qui il ne bailla que d'vne vieille: 
TRE N T E-VNIES M E

oye, $\&$ d'vin cochō fans moutarde. Qu qu'vn qui tenoit de la complexion de fre holte le defendant va dire, que deux mots pouvoient eitre appellez $v$ des des dieux, comme Neron loïoit champignons, les nommans en Prouer Grec, la viande des dieux, parce qu' iceux il auoit empoifonné fon predece feur Claudius, EmpereurRomain. Et q fi nous voulós adiounter foy à Lápridiu nous trouuerons que l'Empereur Seu rus bailloit bien des oyes aux feftins $\mathrm{d}$ Saturnales, comme auiourd'huy not faifons à la fainct Martin, \& que Socr: te en Xenophon dit qu'il faut fuir viandes qui prouoquent ceux qui nor point de faim à les, manger, \& les vir qui incitent à boire ceux encores qu'i n'ayét nulle foif. Puis no difoit, approu mant le banquet de noftre holte, que n'e Itions pas mal à ce fouper, fi nous regar dons à la Loy du Conful Fannius, qui or dóna que nul des Rom ins 'n'euft à met treà chafque repas autre oifeau qu'vne poulle, eincores falloit.il qu'elle n'euf? elté engrailfee, \& que les báquets fuperAus eltoient aufl bien à reprendre que

ceux- 
$x$-là, où il n'y arien trop. Abraham oit que grand Roy \& riche; toutessilpianoit à fa table d'ordinaire; que pain, du bëurre, \& du laict ponr fe arrir. Sil fäifoitquelque fettin, mefaux Angess; il y adiouftoit du gafteau urtoutes delices, \& quelquésfois yne ece du plus gras veau de $f a$ bergerie. oftre franc-à-tripe lors luy va refpone, qu'il vaudroir mieux eftre taxéenla fpéce \& fuperfluité de viures, que d'en oir peu ce qusil montra par le feftio ie fit IefusChrift,oû il y refta beaucoup viures apres que tous furent raffafiez. auffi difoit-il,que les anciés ont prins ur vn mauuais prefage, \& grand malur, quand on leuoit les tables vuides, qu'il n'y auoit rié deflus, les Romains ulans que ce qui demeuroit du banuet fult pour les feruiteurs : cela fe faint par vne accouftumance d'humanité auers eux, les feruiteurs Romains penins qu'en mangeant du relief de leurs raiftres, eftre par cela compagnons e table auec leurs feigneurs, fi bien u'il fe trouue des maiftres, léqquels our fe faire aimer de leurs gens, baillent 
T R E N T E-V N I E S M E

lent à leurs feruiteurs de ce quileur ferui fur table, fans qu'ils attendent reliques \& reftes, mefmes Lampridi dit qu'Alexádre, Seuere Empereur, ba loit de fa main à ceux qui le feruoient: difner \& fouper, du pain, diu vin, de chair,\& de ce qui eftoit ferui fur $f a t a b$. Ce que confirme Plutarque, quarid ild queles Roys de Perfe faifoient liuraif des viures qu'on leur leruoit à leur tabl non feulement à leurs amis, aux gardi \& capitaines,ains vouloient que le mas ger mefmes des Efclaues, voire des chiá fuft feruy fur table, puis leur fuft diftr bué, voulát que tous ceux dont ils fe fer uoient, fuffent, autant qu'il eftoit poffi ble, leurs commenfaux, \& vefcuffent d leur maisó, les plus fauuages beftes s'ap. priuoifans en leur domnant à manger Xenophon parlant du petit Cyrus, di qu'il a efté le plus digne de commander : la monarchie des Perfes, \& qu'il auoit de couftume toutes les fois qu'il trouuoit vne viande bonne \& d'appetit, d'en enuoyer vne partie à fes amis.Ie me doute, va repliquer quelqu'vn, que ceux qui diftribuent aux gens de leurmaifon des

viandes. 


\section{S E R E E:}

ndes qu'on leur a feruy fur leur table, font de peur des Parafites, qui mangét efte des tables, cemme nous trouuons Plaute : parquoy, en toute forte, il eft $t$ bon que les tables foient bien gares, \& qu'il en y ait toufiours de reite, ur donner à entendre qu'il faut garr quelque chofe de ce que nous auons prefent,pour l'aduenir, \& fe fouuenir iourd'huy de demain: \& quauffi on fme, auec Plutarque, la table d'Achil, qui eftoit toufiours vuide \& affamee, dit Homere , \& ledit Plutarque dit à propos, que Lucius auoit ouy dire à fa ere, que la table eltoit chofe facree \& inote, \& qu'il n'y auoit rié de facré qui uft eftre vuide. Et fi les tables n'eftoiét en garnies,adiouftoit-il,cóment pourons nous traicter les gens \& les feruiurs de ceux qui nous viénent voir: Car ous auons vne couftume en Fráce, que uand il arriue vn gentil-homme en nos aifons, d'eftre outre mefure ententifs a ouruoir que fes feruiteurs foient bien caictez, \& cecy,ou pour cótraincte, que omme moins fages \& difcrets, \& plus ifficiles, ils ne facent de mauuais rapports. 
IR E N T E-VN I E S M E ports de nous là où nous fçauós bien $q$ les mailtres fe contenteröt çe peu, \& tout ce que ferós en leur endroit,ou q nous fçauons que les feruiteurs natur lemét font addonez à trop parler \& no lestraictons ainfi bien, plus en intenti qu'ils publient noftre courtoifie, que peur que nous ayons qu'ils blafinent Atre chicheté \& taquinerie, ou bien qu noltre amirié n'elt poinct entiere ny a greable au maiftre, fi elle ne s'eltend is ques à fes feruiteurs, \& vous fçauez er cor, qu'il y a des maiftres fi tendres doux à leurs gens, qu'ils aimeroiér mieu la commodité \& $\&$ aife de leurs feruiteurs que la leur propre. Reuenás toufromus noltre feltin, wne felle-tondue va parle ainf ? Ie fçay bien que ie feray quandi me faudra aller à ces conuis de Chatelu. \& Iaquelot, c'ett que ie fouperay auant que d'yaller. On luy repliqua que ceux des Serees ne le troumeroient pas bon, \& qu'il en feroit repruns auffi bien que ceux qui alloiêt aux feftins publiques(queles Grecs appelloient Syfitia, ce mot deno. eant la grande frugalité qu'ils y gardoiét \& les Lacins Sodalitates) le ventre plein, eltant 
nt deffendu de fé troutuer à ces conapres eftre raffalié, pour autant que \& qư ne mangeoient là, \& ne bellent auec les autres, eftoient accufez gourmandife, \& de ne fe contenter nt de ce qu'on feruoit au commun. uez vous dóncbien que ie feray, va il pondre, c'eft que quand ie feray de reir de' ces affamez banquets, dont on ient creux comme vne laterne, ie fouay chez moy, ou bien des que les nutes feront feruies en ces maigres fe1s, ie dommenceray àmanger des preers, les viandes tant chaudes foient es, m'eftant accouftumé à me laurer les ains, la bouche, \& la gorge, d'eau chatià fin de manger pendant que ceux du nuin'y ofent feulement toucher. Lors luy fut repliqué, Donnez vous garde il ne vous aduienne comme il fit à vn igneur eltant à la table d’vin Prince, leiel mit en fa bouche vn morceau fi aud; qu'il fut contrainet de le rendre, ais en le remettant fut fon affiette, il trire le Prince, \& tous les affiltans, en y difant, Pardieu, monfieur, vn fot fe uf bruflé. Les tables de noftre Chate- 


\section{TRE N TE-V NIES ME}

Lus leuees, vn de la Seree, que nous no mions le mauuais riche, de toute au complexion que noftre holte, commes à blafmer les richeffes, \& cóme s'ill H $^{*}$ voulu prefcher $\&$ admonelter, va di apres Socrate, qu'on deuoit faire cor des richeffes, fi elles eftoient conio ctes auec la ioye,mais qu'elles en elto totalement efloignees: car files rich difoit-il, fe veulent feruir d'icelles, fe corrompent par trop.grande volupt s'ils les veulent garder, le foing les ron \& mine au dedans, \& s'ils en defirent a querir, ils deuiennentmefchans \& ma heureux. Puis il adioufta, que l'auaric rendoit l'homme paunre toute fa vie, fin qu'il fe peut trouuer riche feulemen à la mort, tellement que fi on veut ma à vn auaricieux, il ne luy faut que de firer longue vie, car craignant de tombe en pauureté, il vit pauurement toute $\int_{a}$ vie. Puis il difoit, que celuy qui veut de. uenir riche, deuoit mettre peine non d'accroiftre \& augméter fa richeffe, ains de diminuer fa conuoitife d'auoir, pourautant que celuy qui ne met point de bornes à fa cupidité, eft toufiours pauure 
ndigent, \& $q$ qui appete peu, ne peut ir faute de beaucoup, celuy appront plus pres de Dieu,qui fe palfe de , Dieu n'ayăt affaire d’aucune chole. tre, il difoit que durát l'antique Roon n'affignoit à vn homme que deux es de terre, vn arpent contenant auqu'vn ioug de boufs peut labourer en our, qui peut cótenir deux cens quate pieds, mais que l'auarice croiffant, at par apres permis de tenir iufques q arpés, \& que depuis le populaire n'é woit auoir que fept. A infi, adiouftoitous voyez bien que la Loy a bié prefaux fages \& gens de bien la quantité oiens qui leur eft fuffifante:mais quăt fols \& mefchans,ie leur diray, apres tarque, que la Lune,vn téps fut, pria nere de luy faire vn petit furcot, qui ioignift bien au corps, Et comment il polfible, refpondit fa mere, que i'en e vn qui te ioigne bien, veu que ie te tantolt toute pleine, puis apres en iffát, \& vne autrefois en decours?c'elt ire, qu'on ne fcauroit diffinir mefure cune certaine de biens àvn fol, \& à vicieux, à caufe de fes diuerfes cupiditez. 
4. TRENTE-VN\ESME ditez. Et quant à moy, difort ce mau riche,ie tiếs encores les pauures plus ciles a contenter que les riches, car f pauure a faim, ou foif, ou froid, fiv le faictes inanger ou boire plus qu'il veut, fi yous luy donnez trop d'hab mens fur luy, il s'en fachera, mais l'ho meriche n'aiamais trop, n'ayant to fa vie allez d'eau pour affouuir fon dropifie, \& comme dit Plutarque, ce n pas l'habillement qui donne la chaleu I'homme, mais feulement qui arrefte cótient au dedans la chaleur qué l'hor meréd de foy-mefmes, empefchát qu'i le ne fe ref ande parmy l'air,aufi, difo il, pour eftre enuironné de richeffes, ne vit pasplus heureux,ny content, $f$, l'interieur de l'ame ne procede la ioye, le repos, cela n'eltant bien qui n'a poi: de fin, \& qui ef commencement du dt fir d'auoir Noltre holte, à quiil femblo. que ce mauuais riche parlait de luy, $v$ repliquer des chofe aufí fingulieres qu' en auoit dictes de communes, commen çăt en cefte forte, Si elt-ce q̄ le defrr d'en richir nous elt autăt naturel, que celtuy là de viure, car comme dit vo Venitien 
ature ayant pourueu les beftes brutes hofes appartenantes à leurs vies, elle leré en l'homme pauure, nud \& fubà phifieurs neceffitez; le defir des rifles, luy dónant l'efprit \& l'induftrie $r$ les acquerir, à fin quil peuf auec vnique inftrumét, fe pourchaffer les fes qui luy feroient neceffaires, non ement pour viure, comme les auariix font, mais à viure humainement, ievenát plus aggreable par les richefqui fuppleêt à toutes neceffitez.Qu'ó de atoir desbiens, difoit noftre hofte, ton puiffe retirer quelque moyen de reoutre ce que la nature nous enfeiencores le peut on veoir, ce dit mefFrancifque Lotin, en toutes les anciéRepubliques, lefquelles on faict tout oir de femondre leurs citoyens a en ir, \& y pourueurent de faict par la e de la loy, ordónans qu'aucun ne fuft eu ne admis au gouuernemét de la ciil n'auoit autant de biens qu'il eftoit uis pour eftre enrollé \& efcrit au liure cés, \& fuiuát cefte for me, les citoyens mains croiffoient en biens \& en cés. maunais riche, qui blafmoit l'auarice, 


\section{T RE N T E. V N IES ME}

$c e$, va refpondre ainf, Nous ne fo mes pas au temps, Dieu mercy,qu'il queftion de tant louër les richelles, $p$ doubte qu'on ait qu'elles viennét en d pris, car vrayement ceux-la font trop muns, qui feles font leurvray idole, quelle affection certainement eft eng dree,non pas d'vn defir naturel,mais defordonné appetit, auquel nulle rich fe n'elt fuffifante de fatisfaire, parce $q$ tout ainfi que la nature fe cótente qua acquiere peu de chofes, \& faciles; mefines, nos vaines volontez noustic nent toufiours pauures \& neceffiteux, pendant que vainement nous formo diuerfes neceffités, par lefquelles il no femble quauons affaire prefque de ch fes infinies, qui eft caufe de nous expol librement à la mer, \&zà tous perils, neă moins que les pauures viuent auffi bit que les riches, \& Ies riches meurét con me les pauures, mais à plufieurs pauur la vie eft plus ioyeufe, \& la mort moir amere, qu'à beaucoup de riches, la pal ureté ayant ce feulbien par deffus lar cheffe, qu'elle n'a foucy de rien, le Poët Theognis eftant de bas \& larche coura 


\section{quand il dit:}

\section{Pour paunuretéf fuyr \& eniter}

En pleine mer fe faut precipiter.

efi aucun, adiouftoit-il, fe contente on auarice, il fe contente, parce qu'il experimété autre contentement, cól'oifeau qui a efté nourry \& elléué en ige, lequel ne fçait voler quand on le dehors. Et le malheur encores eft, nous fommes plus auaricieux lors nous ne pounons vfer de nos richefqui eft en la vieiliefie, \& la caufe en mon aduis, parce que les gens vieux uent beaucoup de fois auoir enduré, peur que le bien leur defaille, ou biế denenans timi des \& craintifs, ont le froid, \& muans de complexion, font me fi vn hoome tant moins il auroit re de chemin, de tant plus il fe fourit de viures ou d’argét pour parfaire royage, $f$ bien que vous verrez ces $x$ atuaricieux garder leurs biés comItás à eux, en chaffant les coqs com'Euclio de Plaute, mais ils n'en ofent , comme s'il appartenoient à dau\& qu'ils ne fuffent pas à eux, l'auacontraignát l'auaricicux d'acquerir Liu.iij. 


\section{TRE N T E-V N I ES ME}

dés biens auec peine \& trauail, \& luy fendant d'en iouir, \& luy en oftant l'v ge,elle le prutue de tout bien, car ce qui nous fert ne peut eitre appellé bicn,p noftre regard. Ce que les Grecs ont tr bien entẻdu,appellás en leur langue to les biens temporels, vfages, pour figni qu'vn bien ne doit point eftre reputé finon feulement qu'il fert \& qu'on vfe. Gardant auec grand foin ce qu' gaigné auec fueur, \& qu'il conuient fer auec douleur, femblant à $\mathrm{l}_{a}$ fem grolfe, prenát grand plaifir à amaffer threfors, puis il a grand' farcherie qu illes faut mettre dehors, $\&$ comme di Poëte Satyrique:

De viure en pauuretéa à fin de mourir ric A la fin nofte mautais riche, ayant monnefté noftre hofte, \& le fien, par $r$ fon, luy veut remontrer par rime à fi l'auarice, par des vers de Ronfard, ql recita ainfi,

Quand tutiendrois des Arabes beureux, Uii des Indes les thre fors plantureux, Viire or des Rois a' Affyrie la pornpe, Ti n'es point riche, \& ton argent te trompe. Ie parle à toy qui erres. 
Apres lor par les terres, Pris d'elles i'ennuyant

La voile au majt tu guindes,

Et voles iuggues aux Indes

Lapaunreté fuyant.

foin meurtrier pourtant ne laiffe pas

uccompagner tes miferables pas,

nque par toy mainte grand nef charger

lingots d'or fende la mer Egee.

Le foing qui te tourmente

Suit le bien gui sangmente.

juidant de çà de la

army les caux ta peine,

Ouimoins de biens eft pleine

Quant plus de bien ell'a.

teu de rente on vit bonneftement,

uray threforeft le contentemcnt,

$n$ les gräds buens, qui n'attrainèt qu'enuie

is, non pas biens, mais malbeurs de la vie.

ron mal eft incurable;

Anare miferable:

ar le foing d'acquerir,

ui fans repos t'enflarne,

ingarde que ton ame

Ve fe puiffe guarir.

onfard en vn autre lieu:

aut-iltant gu'on $\int$ greue

O 2 
T RE N T E-V N I ES ME

D'amajer of dauoir:

Matin le iour felcue

Pour mourirfur le foir.

Puis vareciter vn quatrain de monfe de Pybrac,où il dit ạin 1 :

De peu de biens nature fe contente, Et pen fufit pour visure honnsftement: L'Jomme cnncmy de fon contcntement Plus a, co pius pour auoir fe tourmente. Er nes'en eft trouué, adiouta-il encor qu'vn ou deux qui-en ayét eu plus qu' ne demandoient, à fçauoir Mydas, \& Romain Aquilius. Vn autre de la Ser voulát fouliger ce mauuais riche, qui ausit tant conté, nous va reciter ce $q$ eftoir arriué entre deux de les voifur dont l'vn eftoit riche \& $c$ chiche, \& l'aut n'eftoit ne riche ne chiche. Or ces de fe rencontrans à la poiffonnerie (n'y ay lieu où l'on cognoiffe mieux les auar cieux de ceux qui ne le font point ) les che auaricieux voyát que fon voifin, $q$ n'eitoit pas de beaucoup fi plein de bie que luy, ne laiffoit pour la cherté d'ach pter du poifsó, ne $f$ e peu tenir de lui.dir Optimn vectigal parcimonia, \& que la fri dife \& gourmandife, auec grande defp 
, appauurilfoient bien les maifons, \& il falloit bien noter la refponfe que fit gentil-höme à vn Roy dé France, leel contéplant la maifon d'vn fien inaied'hoftel, \& le Roy luy difant que la ifine luy fembloit bien petite \& eftroià la proportion du logis, le maiftre ioftel luy auoit refpondu, que la petite ifine auoit fait grande la maifon. Lors uy qui auoit achepté le poiffon bien er, demanda à cefte chiche face, qu'on pelloit Chie-froidure, fi la darne de gre ne couftoit que cing fols, nel'aepterois-tu pas? Ay ant refpódu qu’oui, uy va dire, ie ne fuis dőc pas plus friăd etoy : mais c'eft que tu es plus auariux, \& aimes mieux l'argent que moy. côte acheué, chacun comméçà à coler tous les vieux contes qu'on trouue $s$ auaricieux, a fin que noftre hofte fe rrigeaft, \& nous traitaft vne autre fois eux.Le premier fut d'vn autaricieux \& rrier, qui s'eftant pendude ce que le deftoit amendé, voulut faire payer la Ide à celuy qui l'auoit coupee, pour lui uer la vie, fe voulant rependre fi vne tre corde ned luy euft rien couféé, pen- 


\section{TRE N T E-VNIESM E}

fant vne autrefois mourir à meille marché. Le fecond, d'vn auaricieux miferable, que venát à guerir d'vne lo gue maladie, \& voyant que fon Mede cin, \& fes medecines payees, il né lu reftoit rié, il aima mieux fe laiffer mou vir, que de viure pauure. Le tiers cont fut de Craflus, le plus riche de Rome duquelle bien fut êti mé par les Céfeur fix millions d'ef cus couronne, qui pleur vne lamproye, laquelle eftoit morte es fon viuier ougardoier, Le quart fut $\mathrm{d}$ celuy qui mourut de defpit d'auoir tro achepté fon fepulchre. Le quint, de deu voifins bien riches, qui s'accufoiét de $\mathrm{cr}$ qu'ils efto:ent les plus fachez, l'vn repro chant à l'autre qu'il védoit fes vieux fou. liers, \& ce vendeur luy repliquoit, Et roy tu les acheptes, parce quie les fouliers de velours deuiennent de fatin, quand ils font vieux \& pelez. Le fixiefme fut d'vn Romain, nómé Caffius Licinius, fi miferable que cótuaincu de plufieurs crimes, qui toutefois ne meritoiét que confícation de fes biens, s'eftrangla en la prifon (n'ayát iamais fait rien de bon que cela) à fin de fauuer fes biés à fes enfans, eftát 


\section{$S$ s $R E$ E.}

irt auát que la fentéce fůt prononcee tre luy, ne lemblant pas ceftuy-cy à ix qui donnent eftás malades tout ce ils peuuent,ce qu'sls ne feroient eftás ns, \& me femble que lors ils font larTe du bie d'autruy, \& non pas du leur, its dónent ce dont ils ne peuuent plus Ceruir. Le feptiefme fut d'vn is auariux qu'il ne voulut iamais payer ceux $i$ auoient enterré fa femme; \& quand Curé, les coultres, \& le foffoyeurluy mandoient de l'argent pour l'enterrailleur difoit, en fe fafchant, Voulez us auoir le corps \& les biens : Le hriifme fut d'vn qui mourát s'infitua foy fme heritier de tous fes biens. Le nellfme, d'vn fi extremement auaricieux iitne faifoit iamais fes cheueux, ne fa rbe, qu'au defcroift de la L une, tenant ur certain que la barbe \& les cheuevux upez an defcroifsát de laLune, fecroifne bié tard, \& fi auec cela ceux qui font uper leurs cheueux à la fin de la Lune; viennét chauues, ceq eftoit caufe qu' il payoit les barbiers que pour la moitié. ue fi on difoit à ceft auare, que ceftoit : ande chofe, \& qui couftoit peu d’argét

O 4 


\section{TRE N T E-V NIES ME}

à fe tondre, \& à deffaire fa barbe, il difo que Clenard auoit mis au chapitre $c$ defpéfe, pour faire fa barbe en Portuga quinze ducats par an. Le dixiefine $f_{i}$ d"vn marchand, lequel vendant de bo vin, alloit cercher par tout du vin-aigr $\&$ duvin eluenté pour fon difner, \& f 0 feruiteur eltant interrogé que fon mai fre faifoit, refpond, mon mailtre ayan beaucoup de bien, cerche du mal. L'on ziefme fut d'ü riche taquin,quide nuic fut trouuébrullant fes pourceaux:car le voifins, voyans fi grand flamme par le feneftres de fa maifon,vöt crier au feu, \& rompans la porte, \& eftans entrez,trouuent ce tacroux qui brunloit fes pourceaux en fa cheminee, de peur d'en bail ler des rillees. Le dernier fut d'vn vfurier lequel auoit des prefcheurs à gages pour blafiner les vfures \& les vfuriers, à fin d'eftre feul de fon meftier, \& quád quelques vris qui n'eftoient pas cautionnez luy demandoient de l'argent à loüage, il leur difoit, Les bons menagers \&.gens de bien n'empruntent point à vfüre;mais ils liny refpondoient, lesgens de bien n'en preftét point auffi. Le mauuais riche pre- 


$$
S \text { E R E R. T }
$$

la parole, apres s'eltre teu vu long s, va dire que puis que les vfures: ét permifes, \& quion fourniffoit les icieux \& . vfuriers, qu'on monteroit iufques a plus haut point, quelques eratiós\& defences que les Edicts de. Rois en puiflent faire pour les corri$x$ que prefter à vfure eftoit biè diffe-es inaurs de nos predeceffeurs Frá, qui eftoient fi efloignez de ces vfuquilis preftoient à leurs amis à renin l'autre monde, ce dit Textor, fenles François deflors que les ames ent immortelles. Et les Egyptiens ndils auoient affaire d'atgent, bail:en gage les corps morts de leurspas, comme affeure Herodote, \& aprés: Diodore. Puis noftre mauuais riche mant ce meftier iuré, dont il y a peu uaiftres, va adioufter. la difference de vfures auec cellesides anciens : car eles Grecs \& les Romains, difoittoit vne loy, qui defédoitl'vfure pliss. t que d'vn denier pour cét par an , \& pelloient vnciaire, \& l'vefurier qui ti, plus de profit, eftoit códamnéà ren, le guadruple, les Romains eftimans

O s, 
7) T R E N T E-V N I ES M E

l'vfurier plus mefchát que le larron, n'eftoit tenu qu'au double, difoit $\mathrm{C}$ Et encor cefte loy depusis fut reduite. tre les Romains à deny denier pour c \&r peu apres I'v fure fut entieremét int dicte par la Loy Genuitia, pour lesfe tions quiarriuoient du mefpris des $L$ vfuraires. Il fut refpóduà ce mauuais che,par vn qui eftoit maiftre iuré en eftat, \& qui fuiuoit l'erreur d'Accurle Centefima vfura, eftoient dites ainifi, de que par chacun mois le cétiefme del efoit payé par le debteur au crearci qui venoit à douze pour sent par an cela s'appelloit la centiefine vfure, fe payoit toutes les. Calendes de chac mois. Si me cófefferez-vous, repliqua mautuais riche, que les vfures ont qu roufionrs efté odieufes, dómages en $\mathrm{x}$ Republique, qui rongent le debteur is ques aux os, pourcelte caufe les Hebrie appellér l'v fure morfare, \& les Gnofier ce dit Plutarqque, pour les authorife aupient de couftume que ceux qui pr noient de l'argent à v fure, le rauiffoie a force, r'en ofans faire contract, à th que fis les debteurs venoient aे renier 
te, \& à vouloir fruftrer l'v furier de sö ent, il peuft agir de volerie contr'eux, u'ils fuflent par ce moyen punis daage.Puis ce rnauuais riche va direque Chreftiens eftoient plus mefchans \& eux que les Iuifs, qui ont le bruit d'eles plus grands vfuriers du monde. ulels encore auiourd'huy ne preftent nt à vfure à ceux de leur Loy \& Reli-

n. Tous ceux de la Seree furent d'a auis laiffer ce meftier iuré, \&z reuenir enes aux cótes des riches \& auaricieux, r'autres, ils vont conter d'vn grand \& ae Seigneur, qui prenoit fort grand ifir àvn plaifant homme, lequel efant ure va dire à ce mófieur:le m'efbahis tu ne me dónes quelque chofe, puis e ie te baille tant de palfe-temps? Ceft are n'euft point de hóte de luy refponSi ce paffe-temps que tu me donnes courtoit quelque chofe, ce ne me fet plus ne plaifir ne recreation, fans cóerer, quoutre la pauuretéde cefuy-cy fa gaillardife, que le plaifr doit eftre imé plus grand de celuy qui dóne, que celuy qui reçoit le don, dautant qu' il able que celuy-là qui baille fe doiue O 6 
TRE NTE-V NIES M E: pluftoft refiouir de fon operation $v$ tueufe, que l'autre qui iouit feuleme de la vertud'autruy. Que fila force donner eftoit bien entendue, qui eft ae ure de vertu, auffi feroit elle plus del ctable que n'eft le receuroir, d'où proce que nous aimons mieux les perfonn aufquelles nous auós faict du bien, quie les ne nous aimét. Il fut dit que ce mo fieur ne prenoit iamais feruiteur quin fuft bien en ordte, que fi ie les habile, foit-il,ils me laifferont, faites nrieux; lu dit quelqu’inn; accoufté les, \& puis l enuoyez, ainfils ne vous laifferont pa Ieles traicte fibien, refpondit-il, qu'i s'en vont d'eux mef́mes, ainf ie ne baill jamais congéà mes:éruiteurs. Et a la ve rité, va direlors vn dela Seree, les Fran çois.font mal feruis, à caufe des ferui teurs qui font $f$ corrópus qu'à tous pro pos ils changent de maiftre, s'enfuyan dés que les aurez veftus:parquoine vous efmerueillez fi plufieurs maiftres ont des feruiteurs apres eux auec la deuife de pautreté, c eft à dire, portans l'vne iambe nuë, \& l'autre chauffee. Et aufi que le plus founét, adioultoit-il, les maiftre sót 
hiches que les feruiteurs ne les veu$t$ feruir finon auec conditions certai-. iparquoy vin de nos voifins en prenát. feruiteur luy promet quil ne boiroit nt d'eau en fa maisó sil ne vouloit.Le. iftre ne luy voulát bailler du vin pour re, il interpretoit la condition pour ;\& le valet au contraire: Ce propos fion entre en difpute s'il n'eft pas meilr d'eftre fage \& fçauant que riche, nohofte fourtenant qu'on voit les fages çauans frequenter \& cercher plius les. ifons des riches, que les riclies celles fages \& fçauans, \& a ce propos allea ceft Epigramme:

Dy moy, amy, que vaut-ilmieux auoir uccoup de biens, gu beaucoup de (çanoir?

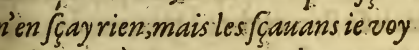

rela cour à ceux gui ont dequoy.

efte caufe on demanda à noftre hofte. n'aimeroit pas mieux eftre le Medeque le malade, ay át dit qu'ouy, on luy: dire, \&z toutesfois nous voyós les Me ins aller plus fouuét.chez les malades e chez les.fains. Et auffi queles fages, ans communément: pauures, fçauent: quoy il ont befoin, \& le cerchent chez

Q) 7 : 


\section{TRENTE-V NIESA}

les riches,\&les riches ne fçachăs ce qu leur faut, ne le cerchét point. St voyon no', repliqua noftre holte, les braues hi mes, fçauans \& fages auoir approchéd. riches Princes:coome Ariftote qui a vef́ quafi continuellement auprés d'Alexar dre, Plató auec Denis, Seneque auec $N_{t}$ ron.Il luy fut refpondu que la recôpen! des richeffes r'auoit point efmeu tor ces grands perfonnages à fuiuir ces Prir ces, mais que ceftoit vn defir de les.in ftruire à bónes mocurs, def quels le falu du peuple defpend. Encore feroit-il bor: va dire noftre hofte, à ces tant fages qu vous voudrez, d'a maffer des biens, toute fois auec höneftes moyés, \& par le may d'iceux fe deliurer foy, \& fa pofterité, di la feruitude des riches, pour viure en li berté, \& pour cefte caufe Plutarque poft pofe Ariftide à Marcus Cato, la fortune accompagnant fa vertu. Cela feroit bon. repliqua quelqu'vn, fila plufpart des ri. cheffes ne procedoit point des vices, les bons \& les riches ne mangeăs gueres en vne mefrne efcuelle, nos yeux ne pouuăs regarder tout à la fois le ciel \& la terre, la richeffe \& de vice n'eftans gueres l'yn 
s lautre. Ce qui eft confirmé par le uerbe commun, qui dit, que le riche il eft mefchant $9 u$ heritier du mefit, \& par ce que dit Menandre, l'homdroict \& bon ne peut foudainement, efaict riche, \& par ces deux vers:

o vitis quod dinitive cumplatur apertü oft. Vomen iders quitis dinitifgue datum.

ffi,adiouftoit-il,que Plató dit,qu' il ne seut faire que l'homme foit vrayemét n \& grandemet riche tout enfemble, arát toutesfois le riche du chiche, diat que le chiche quelquesfois n'elt pas ichant, mais iamaisbon. Et aduient mmunenjent que les richeffes tombét tre les mains des plus fols \& mefchàs, qu'elles font comme le rume, qui tótoufrours fur les parties plus debiles. ce propos, ie voudrois fcauoir, difoitpourquoy les hommes mefchás eftoiét our la plu(part, pluftot riches que les ns de bié.ll fut dit, laiffant la folution Ariftote, \& fuinant l'Anaerife, que c'eit à caufe que les mefchans eftoiét fort genieux, ayans vne forte imagination ur tromper en acheprant \& vendant, achant amaffer le bien, \& comme il en faut 
TR E N T E - V N I ES M E

faut auoir, mais les bons ont faute d'im: gination,plufieurs defquelsvoulans in ter les mauuais, en fin fe font trouue courts. Il fut aufiadiounté, quill y auo des gens fí mefchăs, qui ne faifoiêt poir de confcience d'en prédre où ils entrou uoient, difans que le bien \& l'auoir de c monde auoit tant de fois efté defrobt qu'il n'auoit plus de vray maiftre, ain eftoit au premier occupant. Soyentve nues les richeffes dont vous voudrez, $v$. repliquer noftre hofte, tenant toufiour le party des fiens, fiappellera-onpluftol les riches en fa maifon queles paures tant gens de bien foiét-ils, \& fil les riche feront pluftoft admis aux Magiftrats, tă vicieux foient-ils, que les pauures, tan vertueux puifent-ils eftre. Ne feroit-ct point, luy fut-il refpondiu, par ce que le: riches femblent auoir ce pourquoy les hömes font inuitez à mal faire; ou pource que les riches femblët tenir le lieu des vertueux. Quel'que autre de la Seree ayát veu l'hiftoire de l'Amerique, nous va faire vn cóte, à propos del'auarice infatiable des hommes, d'vn A mexiquain, qui demanda à va marchand Francois, eftant $\therefore$. $A$ and 
au Brefil de pardelà, cóme il femeten fi grand danger de paffer la mer: : aller querir de ce bois, \& autre chandife. Le marchand luy refpond, ceftoit pour deuenir riche, \& amafes biens. Mais quand tu feras riche, qua ce fautuage,nemourras tu point. ray bien, luy refpond le marchand çois, auffi bien que les autres. l'Aiquain luy demanda de rechef. Et advous ferez mort,à qui fera tout le. que vous laifferez ? A mes enfans, ond le marchand, fi $i^{2}$ en ay, finond plus proches. Vrayement, dit lors eillard de Topináboul, A cefte heur gnois que vous autres Mayr, (c'elt eFrançois) eltes de grands fols, Car. faut-il tant trauailler à paffer la , fur laquelle (comme vous nous dit)la plufpart des voftres font peris amaffer des richelfes, ou à vos en-? ou à ceux qui furuiuent apres vous erre, luy difoit-il qui vous a nourris, -elle pas affez fuffifante pour les. rrir? Nous auós des enfans \& paréts, uels hous aimós, comme vouts voiez: sparce que nous nous afteurons que apres. 
TREN T E-V N I ES M E aprés noltre mort; 12 terre, qui no nourris, les nourrira, sás nous en fou autrement, nous nous repoforis fur c Voila comme cefte nation, difuit ce qui auoit faict le cóte, fe moque de qui en danger de leurvie paffent la pour s'enrichir, les Ameriquains at buás plus à la nature, \& à la fertilitéd terre, que nous ne faifons à la puiffar \& prouidence de Dieu. Et puis nous nommons Barbares, rudes, \& fauuag mais ce $n^{\prime}$ eft pour autre chofe, finon 0 Barbar fignifie defert, \& ne font pa barbares que nous, qui eftimás que pa uretéfoit le dernier \& plus grand mal l'homme, ne poutuons auojr le cour la laiffer à nos enfans, penfans que foit vn tref-grád \& fafcheux mal. Que ces Ameriquains poutoient voir tout les autres entreprinfes vaines que no faifons de pardeça, ils nous eftimnroie bien encores plus fols. Et vrayement, a joutoit-il, ils auoient aufi grande occ fron de fe moquer de nous, que no auós à rire des petits enfás, lefquels au vne grande diligence \& peine baftilfer des maifonnettes de tuiles \& de paill ne -1 
$S$ E R E E.

ous faifons des chofes auffi ridica'eux, \& comme dit quelqu'vn, ,. ous rivns du foucy de nospetis enfans. wand ils font des chafteaux, of baftiffent depaille:

are ists

! que faictes vous mienx, voas quiperdez vos ans Itoute vanité, Jaks rien faire qui vaille? Ameriquains \& Toupinanbouls, diencores celuy qui auoit faict le cóte uffi gráde occafion de rire de nous, nous auons d'eftimer fols ceux que Gounerneurs attachent d'vu neud: ille, ou d'vn fimple filet, \& neanns demeurér fans bouger de là, comils fuffent garrotez auec des fers, oul intraties; tant eft femblable leur foce dit Lipfius, à noftre erreur, qui mes par vn lien friuole de richelfe ints a l'auarice \& conuoitife. Que fit voulez veoir les mal-heurs que l'ace 8 la cónoitife de l'or ont apporté oftre temps, lifez ce qua efcrit l'Eque de Cafas, lequel faict eftat de: rt millions de pauures creatures mibles des Cánibales mortes par l'aua\& tyrannie infuportable de l'Efpagnol, 
T RE N T E-V N IES M E gnol, l'or \& la richeffe de leur terre leur propre mal :Mais par permaiffior uine, les Elpagnols qui premier les af lirent, n'en eurent gueres meilleur $n$ ché, tant par la mer qui les a englou que par la famine qu'ils ont enduré, pour auoir feruy de viande à ces Sau ges. Et outre tout cela, l'Efpagnol sō extreme auarice, déloiauté, \& cru té, a laillé à la pofteritéle nơ de Chrèt odieux à tous les peuples de ce noutu mande. Vnefeffe-tondue lairfantl'a rice des Efpagnols, \& fe remettant fur noftre; nous va dire; Ie ne vous conter point l'auarice d'vn raquin \& racro (lequel a voulu fairéferuirà fon aua ce vne difcipline anciéne del'Eglife la rencontre n'eltoit auff fententie que plaifante. Ce vilain icy, qui n'auc que le gain deuant les yeux va faire $p$ blier à fa parroilfe vne excommáge po desnaueaux qu'il difoit lui auoir efté de robez, mais à la fin, il fe trouna que femme, quiles mangeoit tous les iour toutes les nuicts ne faifoit que peter veffir, sás le dire, \&z plus quie de couftum Le mary qui eut bon nez, s'alleura qu 


\section{S E R E E:}

,it fa femme, qui auoit mangé fes eaux:Sus cela, le mary voyát qu'il en roit fortir du bruit \& de la noife,s'é au Curé, \& en entrant en l'Eglife, a crier, Monfieur le Curé,ne palfez

$t$ plus outreà publier l'excommanmes naueaux, car pour le feur i'en nty du vent. Celuy qui auoit faist ce $e$, voyant qu'on en rioit pas trop, a faire vn auffi pitcyable d'vn autre icieux, lequel il commença ainfi:ll y adis, comme i'ay ouy dire, vn pere Té de fa maifon par fon proprefils, rce qu'il difoit que fon pere luy defdoit trop, dont ce pere fut contraint en aller à l'hoftel-Dieu. Deuant la eduquel cóme il veid vn iour fon fils $\mathrm{er}$, le pria que pour l'amour de Diel, y pleuft enuoyer deux linceux pour coucher. Le fils men de compaffion, cores qu'il fe fuit fenty heureux s'il peu dire, Noftre Peregui esés (icux) manda dés qu'il fut chez foy à vn petit fils, de porter à fon grand pere $x$ linceux àl'hofpital.Ce petit galand uy en porte que l'vn, Dequoy à fon our eftant reprins par fon pere, il luy dits 


\section{RE N TE-V NIES M E}

dit, I'ay gardé l'autre pour le vous dô mais q́ foyez àl'hofpital, oftant parv à voltre vieillefre. Ce mauuais hom difoit celuy qui faifoit le conte, enc qu'il fult bien riche $\&$ auare, fi penfa luy-mefme qu'il pourroit bien deus pauure, \& qui il feroit polfible mefuré fes enfans à la mefme mefure qu'il au mefuré fon pere, luy fouuenant que fils eftant petit, \& monté derriere luy croupe, luy auoit dit, mon pere, Mais vous foyez mort, ne cheuaucheray pas alors en felle? Ceux de la Seree fe metrre plus que iamais à faire des con des auaricieux, entre les autres vin va re, que Valere le grand auoit efcrit d' auare, lequel eftát en la ville de Cafil anfegee par Hannibal, prefera l'efpoir gain à fa propre vie, car il aima mie vendre vn rat, qu'il auoit prins, deux $\mathrm{c}$ deniers Romains, que d'en raffafier faim, dont il mourut bien toft apres, l'achepteur, plus fage que luy, fauua vie par celte viande, ne fongeant qu'a prefent, car en tout l'eltat du monde, 0 ne iouit que du prefent, attendu que 1 paffé n'eft plus, \& celuy qui eft à veni 
pas encores. Il n'y euft que le védeur epliquer vn autre de la compagnie, nourut, mais Leon d'A frique eftoit en vne grande necolfité d'eau, tant le deur que l'achepteur moururent, diqu'aux deferts d'Arabie il fe trouua beau en la plaine d'Azra, qui porte hoignage en grådes \& groffes lettres, in marchand achepta d'vn voiturier coupe d'eau, dix mil ducats, \& neátins que tant l'achepteur que le venr moururent de foif.Iouian Pontain, irequelqu'vn, raconte vne hiftoire fante d'vn Cardinal, nómé Angelot, sel fut bien chaftié de fon auarice. Ce dinal, cóme dit Pontain, auoit celte fume, que quand les parefreniers ient donnéle foir lauoine à fes che$x$, il defcendoit par vne fauffe porte eftable, tout feul, \& fans lumiere, \& coboit leur auoine, pour la rapporter n grenier, dont il auoit la clef. Et tát tinua, qu'vn de fes parefreniers, ne chát qui cltoit ce larrou, fe cacha dás able, \& attrappant fon maiftre fur le t fans le cognoiftre, luy donna tant de us de fourche, qu'il le fallut rempor-

ter 


\section{TRENTE-V N I E S E}

ter demy mort,eftant bien puny de quinerie:comme auffi fut vn pauure ré de fon auarice, lequel lan Moria, de Milan,chaltiabien iuftemét,mais t cruellement, pour auoir refuféle m Itere de fon office pour l'enterrage mort:pour ce que fa vefue n'auoit quoy luy payer les frais des funerail Car le Duc allant luy-merme au con du deffunct, fit prendre \& lier le pre auec le corps mort, \& inettre tous de en vne melme folle.Pontain recite au adiouftoit-il, que le Pape Martin,eftoi auaricieux, qu'il auoit accoultuméd fteindre les cierges quion laifloit bruf route la nuités Eglifes. Et difoit ce Pap quand on le reprenoit de fi petite efp gne, qu'iln'y auoit point de plus gra móceau q́ celuy qui fe faifoit peu à p \& foument, \& que ce n'eftoit que fatro bole dece quife dit, qu'autant chie bouf que mille moucherons, par ce qu y a plus de moucherons que de bouf Vn autre auffi a efcrit la refponfe que vin pauure Cordelier au Pape Sixte qua triefme, qui du melme ordre eftoit pa denu à fi grande dignité. Lequel Rppe 
monftrant fes grandes richeffes, dià ce pauture frere mineur, ie ne puis dire comme fainct Pierre, ie n'aj or rgent: Non vrayement, refpoud le delier,ni ne pouuez pas dire auffi cóluy aux impotens \& paralytiques, ez-vous \& marchez. Vous oubliez, lire va de la Seree a celuy qui eftoit sles contes des auaricieux de recieque voftre mefme Pontain a efcrit bidier Iulian Empereur, lequel fut biect à ef pargner, que d'vir cochon eurault il en faifoit quatre repas, \& y en feruoit-on qu'vise piece à chadifner \& fouper. Quand les contes uaricieux \& taquins furét acheuez un fe leue de table; \& dirent entrequ'on ne voudroit plus difner ne er là derlans, fans apporter dequoy ger, encores qu'on fuft conuié vin deuant, \& que ce conuy, que le's sappellent symbolum, è è fportula, Lațins Collesta (dont eft venuë noollation ) où chacun-apporte fa porleur plaifoit plus, \& felon Hefioplus libre, plus hónnefte \& fainet, nt à entretenir l'amour, l'amitić \& Liu. ijj. 
TRENTE-V NIESME

l'egalité entre les perfonues bien nees liberales ; que le banquet magnifiq que les Latins appellent Coema recta, eltapprefté aux defpés de celluy quic uie, \& par ces feftins font appellez Grecs Afgrmboli, ou chacun a fon ef franc, que les parafites fuiuent, lefqu fentent plis leirrs perfonnes ferues $\mathrm{C}$ franches, ne feruans ces banquets $q$ faire des amis de table. Puis les conui entr'eux mefmes, vont dire que les'] rafites ne gaigneroient rien de venit: reliques de ce banquet, \& auffi qu'il faudroit point brufer les teftes, com faifoient les anciés en vn facrifice qu appelloiêt Proternia, ou les ietter en le cornme fit Sylla les reliques qui dem rerent du contiy qu'rl fit au peuple, lesbailler aux chiens, comme faifoit peuple, ce dit Atheneus, ou les cout de terre, ce que pratiquoient les Bor fiês,ce dit Miletus, ou les laiffer aux̌c neilles, corrme font les preltres de $\mathrm{C}_{z}$ cuts, qui leur ßónenent tout ce qui refte la table du Roy, fr nous voulons cro Ludouicus Romanus. Ils dirent enco en fortant de table, qui en ce banquet 
uoit point contreuenu au fy mbole de thagore; qui dit, N'amaffe point ce qui oit de la table, que les Grecs \& Latins ellent Analecta, eftant defendu aux ciens d'a maffer les miettes de pain, \& res chofes, qui tóboient fous la table, ns ces reftes confacrees aux morts; Imes qu'ily a des peuples, lequels par grande fuperftition iettent deffous able de chique chofe qui en feruie, r les ames de ceux qui in'ont ne paréts mis quiles reçoiuent en leurs bants. Vn de la Seree qui approchoit de omplexion de noftre holte, oyant ces ours, nous va dire, Vo' leriez efmerlez de la fafcherie \& de l'ennuy qui tà l'hóme pour caufe de fa nourri" la volupté du manger durant peu emps au corps de l'homme, l'occupa\& follicitude de les apprefter eftant ue de peine, \& comme dit Plutarnous deuons prendre la nourriture me vne medecine pour guerir de la , non comme plaifir aggreable, mais fiaire à la nature: \& auffi tous ceux soiuent \& mangent, \& fe nourrifdifent qu'ils fe penfent \& traicient. 


\section{TRENTE-V NIES M E}

Et à ce propos loiiant le banquet noltre hofte, qui eftoit fans fuperflui nous va alleguer des vers du plaifir gentil-homme champeftre, ou il ya, Et pour plaifir, il afferrble

Ses meilleurs voifins d'alentour 2 ui arnaffent leur mente en femble, Et cornme bon à chacun femble Sevont vifuter tour à tour. Pour eux à la ville il m'enuoye Cercher du plus cxguis gibier, Mais princment illesfelloye D'vn cochon, d'un chapon, d'vne oye, Et des pigeons du colombier. Là ne e parle que de rire,

Et de goffer en liberté, On n'y oit point d'autruy mefdire, Onn'y veult à perfonne nuyre $\dot{N} y$ d'effect, ny de volonté. Leur repas ef libre of modefte $D$ 'bcrbes \& de fricts m: fangé, N'engendrant un boguet molefte, Quivolontiers anx banquets refte Aprés quelon a trop mangé. Aufji ne leurfault-il point fa' $r$. Tant de depens en Medecin, Ny en drogue d'A poticaire: 


\section{S E R E E.}

165

Auffi perfunne à leur affuire Nevient esfier le baffin. orés que celtuy-cy eut fouftenu noltre ote en railon $\&$ en rime, ayant prins ngéde la compagrie, on fe mit a parler luy,vn de la Seree ayát remarqué, que ut le temps qu'ilauoit parléa novis, il oit eu les doigts ferrez contre la main, is iamais les eftendre; \& que par les faes lettres hieroglyphiques des Egyens, la main feneftre ferrant les dojgts, oit vne marque d'auarice, cóme auoir main ouuerte figne de liberalité : \& à ce propos Diogene difoit, qu'il ne lloit pas bailler les mains pliees aux is. Et difoit outre qu'il elloit frauariux, quil ne fe pouuoit contenir de haiter des ticheffes, ce qu'il monen faifant vn Epitaphe, où il y atroit fi:

Cy gift è fe repise en fomme

Le fen Ercfque de Luçon,

Qusi d'or avioit une grand' fomme,

Pluft an bon Dien que ie l'euffon.

is adiouftoit, que plufieurs fois il it trouné ce deffenfeur de noftre hoeftant feul,parlătà luy-méme, \& qque 
c'efoit vn argument vrgent d'eltre au re, \& fubiect aux biens, que de parlen foy-mermes, \& qu'vne fois luy aya demandé à qui il partoit, m'ayant is pondu quil parluit à foy-merme, ie l, dy, Garde toy de parler a vn auricie \& muuais homme. Vous cognoift anfi, adiouta vn autre auaricieux à fo couteau, car il n'aura iamais de coufte gui coupe bien, ne le faifant aiguifer peur qu'il fe gafte par trop, là où lebo compagnon ne fcauroit durer fi lefie ne coupe comme feu, fans auoir elgat ail durera long temps, ou non. Vn Fran -tripe voyant quón fe vouloit retire appellant noltre hofte, luy va dire qu n'auoit pas yardé la couftume des Anci qu'on practique encores auiourd'huy e Angleterre, lefquels, le banquet finj aprés auoir baillé à lauer les mains, a portoiét vn calice plein de vin, \& difoie Cape hanc fanitatis metaniptridem: voular proutuer par bonnes raifons tant nature les que medicinales qu'il eftoit fort bor \& mefme feruoit à la ranté, de finir 'e r pas par boire,nonobitant le commin qi dit, Sis tibi poffremus sëper in ore cibus. Pui 
va demander, s'il ne s'eftoit point aprceu que plufieurs conuy n'anoient int beu en mangeant, non point voutit imiter les Orientaux, lefquels ne iuent iamais iufques à ce qu'ils ayent ins leur refection, mais gue c'eftoit le voyant l'appareil de ce banquet fi aigre, ils nauoient pas eu le loifr de ire, ayant peur quen demádant à boi, mettre de l'eau dans le vin, à rendre verre, de ne trouuer plus rien que már aprés auoir beu. Noftre holte le preant à rire, \&r entédant bien que vouloit re tout ceftaduát-ieu, cómandia qu'on laft tirer du vin. Le vin venu, nolte tanc à-tripe nous prouoque à boire, én ous difant, imitant les Anciens, Viuós, faut mourir ; combié qu'à tous ne plaiit cefte façon de conuier ainfi à boire. Joltre holte ay ant beu, noftre Drolle luy a demander fi en beuuant on remuoit $l_{2}$ angue, luy n'en fçachant rien, aucuns dioient à leur aduis que $\hat{1}$, \& pour s'en feurer demandoient du vin, les autres uroient que non, \& pour en eftre plus ufeurez, beumoient deux ou trois fois encores. Noltre holte voyant que fon vin 
TRENTH-V N I ES M E s'en alloit,fans refolution fi en beuuát remuoit la langue ou non, fe contraria les vns aux aucres, \& la plus grand' pa demandans à boirc incelfamment po en fcauoir la verité, leur va dire, que doubte fe refoudroit mieux en partic lier, \& que l'ellay s'é feroit mieux \& pl afleurément chacun en fa maifon, gu' if grand bruit \& tumulte, \& qu'àla pr chaine Seree chacun en pourroit appor ter fon opinion, \& tous enfemble, \& à pluralitédes voix, on en feroit vnaxio me, \& reigle alleuree. Ce Franc-à-trip Içachantbien la maladie, aprés auoir mi le verre a la bouche, bailla le refte augar çon qui leur mettoit à boire, le priant d boire ce qui reftoit de vin. Mais le garç tout honteux n'en voulant rien faire, $c$ Franc-à-tripe s'addrelíant à nous, va dite, que c'eftoit vne chofe fort antique \& bonne, \& que les Anciens ont penfé religieufe 8 r faincte, fi nous croyons Athe nee, que de bailler à la fin du cóuy à ceux qui auoient donnéà boire, tout ce quien reltoit. Puis s'appiochant de fon holte, luy va dire, comme fit Augulte a vn de fes amis qui lity auoit faict vn banquet frugal, 
gal, Te ne penfois pas t'eftre fi familier

- Vne Feffe-tonduë voulant prendre gé de la compagnie, nous va dire que oanquet de Varus, encores qu'il n'y gueres de viures pour contenter le tre, eftoit bien autre que celtury-cy: pour le moins il eftoit magnifique de re, de vaiffelle d'argent, de tapifleries, tutres chofes pour refiouir \& repailes y cux, mais qu'en ceftuy-cy il n'y it rien ne pour le ventre, ne pour les ix. Quand noftre hofte veid qu'on fe quoit de luy en fa prefence, en beu:on vin, va faire comme vn nouueau rié , à qui la fefte duroit trop, pour nneftement nous bailler conge, car fur eure il faict mettre vn chauderon au fur le feu, atrec de bonnes herbes, la mefme chambre où ils eftoient, \&r auffi toft que l'eau fut chaude, il cria utement, comme fit le nouuean ma, Qui n'aura icy aucun affaire, qu'il naille, car ie me veux laner les pieds. auec ce beau congé \& honefte propos, Atre hofte rompir la fefte, \& renuoya compagnie.

$$
\text { P s }
$$




\section{TR. E N T E-DE V X I E S M E}

TR-EN TE-DEVXIESME $S$ E R E E.

Dela Mufigue, \&o desioücurs a'instrumens.

Efte Seree deuoit eftre gaillarde 1. 1 belle, fi elle euft continué com le commencement, mais vn de noftre pagnie fut preffé fe retirer à caufe quelque mariage qu'il vouloit faire lendemain, qui fue l'occafion que pr mes ce fujet à propos fur celuy que no difoit le noftre: qui s'enqueroit de qu ques bons ioïeurs d'inftrumens pour $f$ reles nopces, ce que nous propofant, chacun de nous tuy en enfeignoit, qu'vntel demeuroit en tel lieu, vn a tre en tel autre, qu'ils eftoient les me leurs muficiens. Aucuns de nous vo loient blafmerla dance, iz les autres voulo ens loner, ainfi diuerfement:il eut vin qui nous va dire, quasil anoit ve vn homune marié qui fortoit hors defo fens quand il oyoit le fon des infrumes qui faifoient danfer, aufa bien que lo dist que les Tigres deuiennent enragez 
e defmembrent au fon du Tabourin, pauure mary péfant qu'il n'y euft rien fit pluftort fortic \& a pparoir les corquela dance, \&les mouucmens.; Et fera hors de propos (difoit-il) fi ie is dy vn Echo dela dance:

2uireguiert fort \&o mefure \& cadance?

Dance. Quifaict founent anx nopces refidance?

Dance.

Qui faict encorles filles en abondance?

Dance.

Quifoict faulter fols par outrecnidance?

Dance.

2uiceftle grand ennemy de prudence?

Dance.

Quimet aux frons cornes powr enio ence? I

Dance.

Quifaict les biens tomber en decance?

Dance.

e propos vn va dire que qui ne prend uf à la mufique, qu'il a les efprits difdans \& qu'il n'aime point les fcienneles.Mufes, car Mufica, eft dicte Mufir, les Mufes eftant inuentrices de mufique. Nous lifons (difoit-il enres) qu'vne bande de ieunes folaftres 
TREN TEADEVXIESM E aprés auoir beu, s'en allerent par la le auec infrumens de mufique, la eftans incitez d'vne fiction d'allarr que fonnerent les iouieurs d'infrume siefforcerent à rompre la porte du lo d'vne honnelte femme, quoy voy: Pythagoras, aduertit ces iouicurs de fo ner plus lentement, \& retarder la $n$ fure, ce que quand ils eurent faict fureur de ces ieunes gens fut foud: amortie, à raifon quela tardité de 13 fure leur effemina \& remollit tout cœur. Que la mulique n'effemine hommes (dit vn autre) cela eft confirt par Soliman, à qui le grand Roy Fra çois enuoya des chantres \& ioüet d'inftumens, des meilleurs de Franc aufquels il print grand plaifir : mais $S$ lyman voyant tout le petple accou pour les ouyr, \& vouloient apprend ceft art, renuoya tous les chantres, mit au feu tous leurs inftrumens, peur deffeminer par la mufique, le col rage de fes fubiects, qui n'vfent mefm és nopces que d'intrumens qui ferue à la guerre. Il y eut vn Drolle qui not va dire, qu'vn iour vne femme de iotier 
inftrumens, ce falcha fort contre vn ii alloit ioiier auec fon mary, lequel ppelloit toufiours Sire, \& luy fe faiit appeller Monfieur, vn Franc-à-tri, demandant à ce Drolle ; pourquoy : mot de Sire , n'eft plus en vfage, ce rolle luy dit: le croy que c'eft à caufe te les femmes ne font plus ouyr leurs aris veffir. Par-Dieu, refpond ce Franctripe, ic fuis donc Monfieur, car ie ouy iamais ma femme veffir: mais ie $y$ bien founent fenty. Ce Drolle dit icores que fi on veut que les femmes crient point, quil les faut toufiours ire danfer, pour les rendre effeminees, nis que cela y fert tát,\& qu'ils'eftoit loau prés d'vn iouëur d'inftrumér, pour nufer la fienne qu'il en auoit meilleur mps. A ce propos va dire vn autre, qu' il oudroit donc qu'il y euft des ioiieurs intrumens par tout pour amufer les mmes, \& la fienne aufi, qu'il auroit iffi bon temps que luy, \& qu'elle eftoit manuaife qu'il n'en pounoir venir à out, fuiuant le quadrain qui vient fi ien à propos, \& qu'il aimeroit autant le u en fa grange, que fa femme en feus 
TRE N T E-DEV XIESM comme le quadrain le dit:

- Femme fafchee en a maifon

- Eft reffernbtant an fectifon Quefi au feu vous le mettez. Il bruflera de tous coftez.

Vn autre de la Seree, va dire que l'a monie de la mufique eft belle pour at paifer les plus fafchez: mais qu'il a ou dire, que fi vn homme porte fur foy 1 cour d'vn caille mafle, \& la femme d'v ne femelle, qu'ils n'auront aucun cour roux enfemble, fi on veut croire Mizal. dus, vn autre Drolle va dire, qu'il 1 trouue des femmes gui ioüent auffi bie des inftruments que les hommes, (ied de mufique ) \& qu'il y en a que fil leur maris vont fouftler d'vn colté, ils ioïen del'autre. Vn de lasiseree reprenant propos difoit qu'il eftoit bon d'vfer de. armonies facrees \& fainctes, tant aur maifons qu'aux Eglifes, principalement \& que la mufique chalfe les mauuai efprits, comme Dauid auoit faict aue fa Cythare, refrenant l'efprit malin de Saul. Les femmes des joucururs d'infru. nens (dit vn autre Drolle ) il s'en trour 
d'auffi gaillardes que nul autre, \& efmes qui ne ioüent pas des inftruens de leurs maris, mais du leur bien prement, de façon qu'ils en amenent en meilleure pratique à leurs maifons, qui font mieux la court à leurs ef cors que leurs maris, ie vous affeure reiqua vn autre, il elt bien vray ce que us dictes, car iay veu vn efcolier ii eftoit entretenu par la femme de on maifte, \& luy faifoit tellement mour qu'il ne fe pouuoit deffaire elle, tandis que fa bourfe eftoit garnie, ii fut caufe à la fin de la ruine de ce une homme, \& tandis qu'ils eftoient ces bonnes fortunes, elle fe donnoit en dubranfle du loup, excogitant tout qu'elle pounoit pour fe donner plaiauec fon efcollier, qui au lieu de faides poëfies, elle luy en recoumroir s plus excellentes quelle pouwoit, par autres Sieurs qui la cognoiffoient auffi en que for efcolier, qui y penfoit tre vnique. Il y en a, dit wn autre, qui our s'elmouuoir cherchent des chos propres à les efguillonner, quand font pres de leurs maiftreffes, auft bien 
TRE N T E-DEVXIESME bien que la femme que difons. Vn la Seree nous va conter, vn bon to qui fut fait en un bal qui fe filt chez de leur voifins, auquel bal plufieu voifines $y$ eftoyent allees pour danfe Au foir quelque vns de leurs maris s: uiferent de s'abiller en mafque, poi cófiderer quelle belle dance leurs fen mes faifoient, \& eftans lefdites mafqu entrees au logis de la dance, chacu d'eux prend fa femme, pour dáfer, far qu'elles fçeuffét que ce futt leurs mari \& aprés qu'ils eurent vn peu danfé, y eut vn de la mafcarade qui meine femme derriere vne des tapifferies $c$ la chambre, pour heberger fadite fen me, laquelle ne fe fift gueres prier, qu' ne s'accommodaffent à l'apointemen \& y firent ce que vous feauez qu'ils pouuoient faire : Aprés que le mafqu eut faict d'elle, il la fort dehors de des riere cefte tapifferie voulant s'enallet Or elle defirant recognoiftre ceft hom mequi l'auoit $f i$ bien fait branler dou blement, elle va iufques fur la montee pour tafcher à remarquer ledit fup pliant, luy qui ne penfoit pas qu'elle fuiuit 


$$
S \text { E R E E. }
$$

ailt, deffaict fon mafque pour efluici vifage, ayant fort chaud, ce qui fut fe qu'elle vit que c'eftoit fon mary, elle luy va dire : Par ma foy fi i'eulonfé que fceult efté vous, ie vous es bien empefché de faire cela icy, vous euffe faict attendre que vous liez eftéà la maifon, voila pas vne e refolution de femme ? qui ne fe rmentoit pas dauantage de cefte orife de fon mary, \&zvous laiffe à fer qui eftoit au Gemini ouau $\mathrm{Ca}_{\text {- }}$ orne, du mary ou de la femme. Vn e de la feree nous en va dire vn auqui n'eltoit moins gaillard que cecy lequel (dit.il) il auoit ouy faire apte il y auoit long temps, d'vn quiqui gouuernoit la femme de fon in, \& l'alloit voir fi fouuent quà la e mary s'en apperceut, \& pour bien outurir la verité du faict, il fift femt vn iour d'aller aux champs, eitant cord auec fa chambriere, que file int venoit qu'elle luy ouurift la poru deuant du logis, pour les pou- furprendre : ce qui fut fait fi aे os, que celt homme eltant fur les mon 
TREN TE-D E V X I ES ME

montees, commerça à parler haut dire,ouure l'huis de la chambre ma f me, ie n'ay efté gueres loin, le gal qui eltoit couchéauec ladite Dume, bien eltonné, \& dit que feray-ie, $c$ femme lors luy va dire, mettez vous ce coffre, il ne vous cherchera pas mais ayát oubliéà mettre les habits a au coffre, ceft homme entrant dan chambre les aduife, \& $<$ dit, O ho voil habits du voifin, par la mort bieui feans, eft-il venu voir ma femme, auray tout à celt heure la raifon,ce $q$ fit, car il enuoya querir la femme de dit voifin qui entoit dans le coffre, qu vint parler à luy tout prefentement quec'eltoitpour vn affaire d'import celte femme incótinét s'en vint le tr uer, penfant que ce fuit pour fon pro mais elle trouua celt homme en la cha bre, qui eltoit è furie, \& qui tenoit poignard, \& la prend par la main,luy fant, ma voifine, faut que vous fçach que voltre mary m'a faict vn tel tour que i'en veux auoir ma raifon, il eft d ce coffre là enfermé, \&zêtoit couché at ma femme quad ie fuis reuenu des ch 
ut que tout à cefte heure que ie vous fie autăt, ou autrenaét, par la mort, le fang (difoit-il)furieufement, il ne urra iamais que de ma main, \& tout à heure, cefte féme pour tout cela ny bit pas códefcendre, \& difoit quant e qu'elle n'en feroit rien. $\mathrm{O}$, par la t bieu (dit-il) c'eft donc à ce coup Ine mágera plus de pain. Ce quoyăt aure prifonnier crià à fa femme; \& dit:Hé!ma femme,aye pitié de moy! ne moy la vie! quoy? (dit-elle) fatut ce ie faffe cela? c'elt vne grand honte, ue difant elle fe lailfa aller à fon dit in, quila renuerfa fur le mefme cofz en prend par ce moyen la raifon. te cour placé en meilleur lieu que re zani cornetto, qui auoit fait coiftre à fon compagnon que la tapifeftoit propre à $\mathrm{fa}$ femme, auec le fon inftrumés, \& qu'elle n'auoit pas l'efdifcordát, ayant autres fois aprins $l a$ fique, noftre faifeur de nopces no 9 fit effus celfer nos difcours, eftant prefe fe retirer, pour les affaires qu'il detauoir le lendemain. 
TRENTETROISIESME $S E R E E$.

$$
\text { Desgens d'Eglife. }
$$

कैo Es gens d'Eglife, craignans Di D. paffionnez, lefquels defirent vne bor \& faincte reformation felon les fair Canons, ne trouueront iamais mauu d'eltre admonneltez, à fin qu'ils foyét citez de fe corriger s'il y a quelque $c$. fe en eux à reprendre, pour fe don garde de ne faire \& $z$ ne dire rien, qui foit bon \& fainct, principalement a veuë du peuple, qui regarde toufio plus à ce que font leurs fuperieurs (1 quels ils doiuent enfuiure) que non à ce qu'ils difent, \& qu'ils font ten de faire, les hommes croyans mieux a yeux qu'aux aureilles, la voye des prece tes, ce dit Seneque, eftant longue, \& c le des exemples eltant bien plus court $\&$ ayant plus d'efficace, eftant plus ai de dire que de faire, la vie prefchal mieux que la parole, eftant chofe bien reprendre de faire comme le mauua muficiel 
cien, qui chante l'vn anecla bou, \& fonne l'autre auec l'inftrument. ource que les citoyens, comme a $t$ Rodian, ne font que les finges de i fuperieurs, cenx qui ont charge de - fe doiuent bien garder de cómettre ques offenfes, les fautes des grands s plus grandes, pour auoir trop d'iteurs, comme l'a tres-bien dit vn e:

autant plus que celuy quifaut, or qui mesprend.

voit en grand bonneur, of en dignité baute.

autant plus chacun voit of remarque fafaute.

ue l'intention de ceux de la Serce, parlerent des gens d'Eglife, n'ayt t efté de detracter de perfonne, vn efraftique, homme de bien \& docte, y eftoit, \& s'y trouuoit bien fouuent, efmoigneroit ( $s^{\prime}$ il eltoit en vie) de ce qui fut dit encelte Seree, \& à le occafion. Or fçachant que l'ignoe \& mautuaife vie du miniltre ne e point la doctrine, chacun necraiit de faire fon compte, mefme notre 
TRENTE-TROIS IES ME noltre Beneficier faifoit le fien en rang, non pas fans rire le premier, a bien de fon compte que de celuy des

- tres, finó il defendoit fon party le mi qu'il pouuoit, comme il eftoit tenu. qu'il fit du commencement de la Set voyant quion faifoit vn compte $d$ Euefque Portatif, qu'ils appellent, quel fut prins pour vn meneftrier iouëur d'infrumens, pour auoir les doi pleyans de pierres precieufes, \& pr auoir deuant luy fon homme qui $p$ toiten vn eftuy fa croce, quifaifoit ger que c'eftoit des infrumens dont $s$ ajdoit. Et pour excufer ceux qui auo prins celt Euefque pourvn meneltrier qu'il n'eltoit pas ce qu'ón euft peu pe fer, Pline fut allegué, qui ditqu'vn menias de Thebes, foutuerain jouëur flutes, portoit ordinairement de fo belles pierreries, \& que ca fut luy ? amena la coufume, que les meneftrie tels que luy, fuffent eftimez felon pierreries qu'ils portoient, $\varepsilon z$ defaid adioute Pline, Diony fodorus, qui au efoit grand ioüeur de fluftes, envfac : : melme 
ine, pour ne fembler moindre que nias, \& que Nicomachus, qui de mps auoit grand bruit entre les meiers, portoit auffi force anneaux \& eries. Et puis fut dit, que ces exemdeuoientbien faire celfer le caquet x qui font tant des gros, à caufe de pierreries \& bagues, veu qu'anciéent on remarquoit les bons ioueurs trumens à cela, \& par ce moyen ditraufli, que les Ecclefraftiques, deau feruice de Dieu, ne deuoient en n du monde porter des anneaux $\&$. ierres preciecifes en leurs doigts, nó que le Flamen Dial à Rome, mefu'on troulue vn Synode tenu à $\mathrm{Aix}$ rappelle, en Allemagne, que fit teouys debonnaire, parlequel fut deque deffenfes eftoient faictes à tous ques \& Ecclefialtiques de porter ts fomptueux, \& de mettre en leurs ts aucunes pierres precieufes. Le noine \& homme d'Eglife pour four ceux de fa vocation, \& 2 de fon eftat, va dire, que ceux de fon ordre ne oient pas.fans caule des anneaux, \& que 
TRENTE-IRO IS I ES M E que l'áneau en la faincte ef criture ef la figure de la foy, \& que du temp Charlemagne, \& bien trois cens aprés, durant le temps de trois cens $E_{1}$ ques, les Roys bailloient les Euefchei les Abbayes,par vne verge $\&$ anneau figne de dignité \& $x$ preeminence, les $h$ norans \& approuuans par là , comme Romains par l'anneall portoient tefn gnage de la vertu des leurs. Et auffi, di. noftre homme d'Eglife, les ancien: portoient pas l'anneau pour orneme mais pour figner \& feeller, n'eftant mis d'en auoir plus d'vn, qu'ils portoi au doigt libre, defigné feulement pa: foy comprife au cachet, anciennem chacun faifoit grauer les pierres ench fees és anneaux pour cacheter lettr coffres, le vin , \& les armoiries: Cicer difant que fa mere en vfoit ainfi, \& c c pourquoy le Poëte dit, le cognois la tre à la pierre fidelle, c'eft à dire,à la fig re grauee en la pierre de l'anneau, ie gnois le cachet. Que fi par aprés, adic ftoit noftre Chanoine, les gens d'Egli ont adiouftéàleuirs anneaux \& cach des pierres.precieufes, qui font de diue 
ouleurs, à caure qu' elles font engen$s$ de diuerfes exhalations, c'eft pour onftrer que les perfonnes deftinees lement au feruice de Dieu, \&z de fon (e, doiuent luire entre les hommes ertu \& fçauoir, comme les pierres iaufes reluifent \& font belles par is toutes chofes, \& principalement uefques, qui auffi les portent aux ts les plus eninens, qui font les deux prés du poulce,parce qu'en l'ancienglife, les Euefques deprimans lesaudoigts,en tenás ces deux tous droits, fioiét qu' ils vouloient parler au peucomme il fe troute en Fulgentius. ncores auiourd'huy, difoit-il, les ques font ainfi pourtraits, \& peints, tant qu'en cefte forte, le temps paffé, arloiêt au peuple, \& le beniffoiêt en eu que les Latins appelloient Saluinm, \& les Grecs (à ce qu'on m'a dit) asticon, \& mefines ence temps, dinoftre Chanoine, les Enefques auec efte, \& les deux doigts tendus, bent bien le peuple, mais ils ne parpas foutuent à luy. Dauantage, qui ait, pout fuiuoit-il, que les pierres Liu. iij.

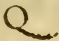


TRE N TE-TRO ISIES M E precieufes ont beaucoup de proprie \&zvertus occultes des Aftres, felon M filius, qui recreent par vne vertu lat te,nos efprits, \& aident à noftre coi \& chafrent les maladies? Ce qui fe fa par noftre chaleur naturelle, laquelle cite en les portant, leur vertu cachee, la communique au cour, au ceruea aux yeux \& 2 à tous nos membres, efta vne impudence extreme de vouloir porter toutes chofes à des qualitez $m$ nifertes, eltant du tout impoffible de dre raifon de tous les fecrets de natur \& celte ignoráce eft caule que le peup qui ne fcait rien, reprend ceux qui po rent ces pierres precieufes, comme v1 chofe fentant pluttort quelque fuperflu té \& orgueil, qu'aucune faincteté, hol neur \& vrilité, arguant les Ecclefiaft ques de les porter par bombance, \& fol oftentation,\& gloire. Et fe peut-on plais dre de ceux-là qui font caufe quion di fame vne chofe fi rare, fi belle, \& fi ex quife qu'vne pierre precieufè, comme vn iour Arifippus, lequel ayant prins v jour grand plaifir à vn certain onguen radire, Malheur foit aux effeminez, 8 lalcifs 
ifs qui ont diffamé \& polluẻ vne chobelle, fi bonne, fi plaifante \& agble. Et penfe, quant a moy, difoit re Ecclefraftique, qui aimoit fort ierreries, \& en portoit ordinaireten fes anneaux, que les gens d'E. portent l'Amethyfte, pource qu'elnd fobre celay quil la porte, comme en a le,nom, refiftant à l'ebrieté, ant que celte pierre attire les va$s$ du vin à foy, lefquelles autrement bleroient le cerueau, ce qui feroit rand fcandale a la profeffion des Ecitiques. Aurfi on dit, que l'Ameengendre les fonges, \& que ceux eulent deniner par les fonges, la ent, fe nommans en Hebriet Choinod eft fomniare. Les gens d'Eglife pas aufil le diamant en leurs doigts caufe, difoit nofre Chanoine, car mant denote ta conftance $\&$ ver e les pafteurs doiuent auoir en la on Chreftienne, laquelie doit furer \& endurer toutes perfecutions Dieu, comme le diamant refifte à e, au cizeau,au marteau, \& au feu, ne dureté merueilleufe, \&z grande

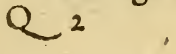


IRENTE-IROISIESME

folidité,ne cedant le diamant qu'au fa de bouc, comme fainct Cyprian le monfre, qu'aufî les nations les plus b bares \& $z$ vaillantes n'ont peu eftre ado cies $\&$ amolies que par le fang de lef Chrif. Et aufri adiountoit noftre Ecclel ítique, on porte le diamát, pource qu' cefte proprieté en foy, de garentir cour de celuy quile porte de toute pe \& frayeur, l'incitant de refinter aux werfes de fortune, auec cela, il fe ternif s'amolliit, fi on approche prés de luy venin, auquel les Preftres, entr'autres, fort fubiects, empefchant aufli tous fo tileges \& enchantemens, les incubes fuccubes : Cardan difant auoir eflay que le diamant lié au bras feneftre, touchant la chair, emperchoit les cra res nocturnes, fi c'eft vn bon diamas lequel fe cognoift, fi par fa prefence pierre quion nomme Aymant perd vertu \& puiflance, efrant le vray diam ennemy mortel de l'Aymant, ce qu'o efprouné à leur perte beaucoup de ma niers, qui portoient le diamant en let doigts, ce qu'aucuns tout esfors ne ve lent croire. On dit auff adiouftoit noft

Eccle 
clefiaftique, que $f_{1}$ vous frottez vn nict ou vne efpee de la pouldre de diaant, que facilement ils tranfperceront utes armures, \& que pour cela \& $f_{a}$ auté \& vertu, le grand Roy François hepta vn diamant foixante douze mil cus trebuchans:Pline efcriuant, que de ntéps le diamat ne fe trounoit qu'aux binets des Princes, encores rarement, mbien que par les efcrits de Zacharie Ezechiel il en foit faict mention. Toufois qu'aucuns ayent dit que le diamát it veneneux beu en pouldre, ou par fon treme frigidité, ou par la violéte crofió 'il fait aux boyaux, \& que nonobitant dureté , folidité \& vertu, qu'il s'eft ouué des hömes, lefquels ayant apperu vn diamant entre les mains d'vn ladaire, \& l'ayant contemplé fixement, ent rompre ce diamant, tout fur theten plufieurs pieces, tant ils auoient syeux pleins d'vn puifsat charme. NoEcclefialtique continuant fon preier propos, qui eftoit de defendre les ens d'Eglife, qui portoient des anneaux arnis de pierres exquifes, va dire gu'ils ment à porter la Hyacinthe, à caufe

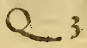


TREN T E-TR O ISIES ME qu'elle empefche celuy là qui la po des ef́clats du tonnerre, \& qu'il a efté ferué que là où le foudre elt frequen ne tue iamais ceux qui l'ont en le doigts: Albert difant, qui'elle faict at dormir, \& on dit que le foudre n'offer point ceux qui dormét, mefmes Sera affure les hommes eftre hors du peril tonnerre, s'ils portent feulement la re où fera la graueure de la hyacint Les gens d'Eglife,adiouftoit noltre Ecc fiaftique, ne portent pas fans caufe Chry folite, quaucuns appellent Topar parce quelle reprime la paillardife p fa frigidité, que fur tout les Preftres de uent euiter : $\&$ auffi on dit que mife $f$ la langue du fieureux, elle le defaltere, oftanche le fang des playes par fa friq dité. Il nous alfeuroit auffi qu'ils me toient l'efcarboucle en leurs anneau. qui tient le premierlieu en cefte efpec de pierreries, \& le Balais qui va aprés, le Rubis qui tiét le dernier lieut, pourat tant qu'ils refirent à l'air corrompu, à pefte, à la poifon, \& à la melancholie : voila pourquoy (nous difoit-il) les meds cins qui frequentent les lieux peftiferez \& plein 
pleins de mauuaisair, portent toufirs des anneaux garnis de ces pierres. fcarboucle, adiouftoit-il, eftant ainfi pellédes anciens, à caufe de la fplenur que elle a auec le charbon embrafé, ant aufli nommé Apyros, pource qu'elpeft iamais confommee du feu.Ils porit, difoit encore noftre Chanoine, la doine \& la Carchedoine, pource que rtees elles feruent à la chafteté, qui eft en feante aux Preftres. Que s'ils portêt belle \& plaifante Emeraude, en Latin pellee Smaragdus, c'eft pour recreer ha uë des Ecclefialtiques, laquelle fe diinuë par leur continuel eftude, eftant tre toutes les pierres precieufes, celqui plus refiouït la veuè, \& recree les ux, tellement que fi elle eft creufe ou atte, vous yous y pourrez mirer come en vn criftal, \& auffi pour monftrer ur chafteté, l'Emeraude eftant fi faine \&zchafte, que par fa viue, conftan, \& claire verdeur, elle eft indice de idicité \& virginité, fe mettant en pies \& brifant, fi elle attouche les pailrds, \& paillardes, \& mefmement l'acte Venerien, comme ayant honte

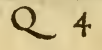


TRENTE-TROISIES ME d'efre entre les mains des impudigi eftant la plus tendre pierre \& la plus gile de toutes les autres, à caufe de humidité, qui êt fi tenue qué par c leur elle fe caffe, la chofe humide fois chauffee s'euaporant facilement air, \& en occupant plus de place, il n de merueilles fi elle fe met en pieces, quoy eftát molle, elle eft fubiecte à be coupd'inconueniens. Que l'emerau. adiouftoit noftre Ecclefiaftique, foit an de chalteté, il fe trouue aux hiftoires Hongric, que leur Roy, eftant couc auec fa femme, ayăt vne belle Emerau en fon doigt, fut eltoné qu'elle febrifa plufieurs pieces. Et par ce, ie ne $\mathrm{pt}$ croire, difoit-il, ce que dit Orpheus liure des Pierres, \& $x$ ce qu'à efcrit Pli au dernier liure, que l'Emeraude ait ve ru tractiue \& confortatiue du memb naturel, parce qu'elle auroit deux pr prietez \& vertus contraires, mais ie per ferois bien eftre vray ce que dit Arift re, qu'attachee à la telte de ceux qui or le mal caduc, qu'elle les foutage par 1 vertuocculte, \& qu'elle profite, felo. Diofcoude, aux lepreux, puluerifee, 8 
uë, que fi elle eft mife, ce dit Sauanola, fur la cuiffe de la femme qui eft en d'enfant, elle foulagera l'enfanteent. Que fi vous voulez fçauoir fil' l'Earaude eft bonne \&z naïfue, il ne faut e la prefenter au crapaut, car fi elle it point artificielle $\&$ contrefaicte, il a incontinant aueuglé, combien que autres l'efpreuuent à la pierre de tou. e; dicte Lydia en Latin, y delaiffant e macule d'airain. Il fe crouue que le y d'Angleterre Edoiiart donna à Erafevne Emeraude, ayant receu vn liure luy, qui fut eftimee aprés fa mort trois lle ef cus. Les Ecclefialtiques aumi,ad.iftoit noltre Chanoine, prenent plaifir uoir les doigts parez du Saphir, parqu'il reprefente le Ciel azuré, duquel ont les clefs, \& fi, aprés l'Emeraude, il. a pierre plus plaisáte à la veuë,\& quii guife \& conforte plus, reprimant, feGalien, les excremens des yeux, arichant le fang par fa frigidité, latelle le rend aftringét, ce dit Auicenne, bien que le Saphir mis fur la lanie, defaltere par fa frigidité. Et fi Arult de Ville-neufue, grand Philofo-

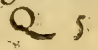


T R E T E-T R O IS IES M. E phe, \& expert Medecin, dit que le Sap eft vne pierre tres-dure, belle à l'œil, creant la veuë, reffemblant la coul du Ciel tres-ferain, rendant l'horn fort contant, chafte, doux \& hum faifant obtenir par fa vertu, la grace hommes, \& mefmes des Rois \& Prin \& pource eft dicte des anciens, pie faincte $\&$ facree, croilfant en grand bre au fablon du Medois, \& del'Inde Ifidore dit que le Saphir repercute mauuais air de celuy qui le porte en $t$ peftilentieux \& \& qu'il en y a de coul rouge, \& de couleur d'azur, \& que ce qui eft de conleur d'azur, comme fo tous les Saphirs que nous auors auio d'huy, sappelle Saphir mane: Not homme d'Eglife, difoit en continuar defendre ceux de fon ordre, quils $p$ roient la Turquoife (encores qu'elle foit diaphane \& tranf(perante ) pai que portee fur foy, \& qu'on tombe, le eft eftimee recenoir tout le coup, rompant er pieces, l'homme demeura fain \& fauue, que ficeluy qui la porte uient malade ou en langueur, cefte pier muera de couleur, \& fi deuendra ble 
e, mais reuenant en fanté, vous la ver$z$ reprendre fa naifue couleur $\&$ beauQue fil'Onix eft pendu au col,ou pozen bague, il refrenera la paillardife: pour cefte caufe les Indiens en po:nt par tout, \& difent qu'en cefte pieron cognoift ceux qui font lubriques, atcoup de bons autheurs ayans efcrit il n'y a gueres de pierre, que les Lais appellent Gemma, qui n'endure angement, fi celuy, ou celle, qui la rte eft lubrique, \& incontinent: fi en que les paillards, adulteres, \& inceeux, \& aut:es impudiques, ne portent: nais les pierres de leurs anneaux, net, claires, \& belles, mais au contraire, ates obfcures \& fumeufes, eftans vies par vne vapeur orde, fale, \& veneufe, procedant de l'haleine \& exala. in tant de l'homme que de la femme: qui a efté caufe, que les maris les plus urfez, entendans les fecrets de $\mathrm{Na-}$ e, \& auffi les femmes les plans doctes prit ont defintéde porter des pierres, les femmes ayans defcoupert l'imdicité de leurs maris, \& les maris $l_{a}$ Ullardife deleurs femmes, en regardante

Q 6 . 
TRENTE-TRO ISIESME les pierres de leurs anneaux, \& les yans obfcures \& fales: cequi fe peut 1 re, tout ainfi que les femmes ayans 1 cataminy peuuent obfufquer \& efblo La clarté du mirotier. Quelqu'autre d Seree va dire à noftre Ecclefiafti que $q$ ne doutoit plus déla proprieté, \& ve des pierres, depuis quilauoit experin té qu'en Efcoffe il y a vne pierre, laque ayant demeuré fur la paille elle l'allu. \&zlanflamme, \& que la pierre nomm Aftriotes, diftincte de macules cédrees grifes, fe moune de foy-mefme dedan: vin-aigre, \& dans le vin , \& ce à caufe fon humeur fubtil, qui eft cớuerty en peur par la force durvin-aigre: parqu celte vapeur cerchant à fortir, \& ne trouuant, elle pouffe facilement çà \& cefte pierre qui eft legere. Et ce qui n incité à vous rendre la raifon de ce magie naturelle, c'elt pour fe döner de d'aucuns quifontbien leur profit locculte proprieté de cefte pierre, cốr anffi faifoit Orphee, forcier \& enchăte excellét, qui vfoit d'vne pierre nor mee Siderite, de laquelle il v foit de nui a chandelle, \& falloit que celoy $q$ 
uloit fçauoir quelque chofe par cefte tte de diuination, fut bien purifié, \& it le vifage voilé, \& \& lors il sétoit moutit cefte pierre quand on en approchoit feu, qui luy donnoit telles refponfes sil demandoit. Et poffible, adiouftoitque la pierre Siderite, dont nous parlós, moutue naturellement au feu, comme

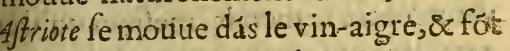
roire à ceux qui regardent remuer ces erres, que quelque efprit parle à etzx, inuand nous ne pouuons rendre raiin de quelque chofe, \& que la Nature. peut cognoiftre, tout incontinent us ingeons $y$ auoir en cela quelque uinite, ou quelque miftere, occulte, ont on ne peut rendre raifon, comme 1 l'anneau de Gyges Roy des Lidiens, uquel y auoit vne pierre, qui auoit telle ertu que tournee vers luy, il voyoit out ce qu' il vouloit, fans eftre veu. Mais ue direz-vous, repliqua vin de la Seree, es gens d'Eglife, qui portent des anneux aufquels il y a des images grauees, clefquelles ils confacrent, en opinion es'en poutoir feruir en quelques ma ies? Car i’ay leu qu'vn anneau, en ls. 
TRENTE-TROISIESME chaffe duquel y auroit vne Agathe, eltoit peint Hercules fuffoquát vn Lio feruoit pour guerir les coliques paffion \& que du temps de faind Chryfoftom il y auoit des Chreltiens fuperftitieu qui portoiét vn anneau, où eftoit grail l'effigie du grand Alexadre, efimans qu relle effigie les faifoit heureux, \& bie venus'entre le monde, mefmes qu'il en a quiles confacrent par mots facrez. que reprouuent Gregoire troikefm Gelafrus, \& le Concile Laodicenfe, disá que ces preferuatifs \& phylacteres fon du diable, \& des demons, les Iuifs auf bien que les Payens, ayans creu qu les demons, Empufes, Lares, Larnes Idoles nocturnes,Lutius,Lemures, Phá tofmes, eftoient chaflez par la vertu d quelques pierres, le poëte Dionyfiu. appellant la pierre Iafpe, ennemie des de. mons, Thrafillus efcriuát auffi qu'au $\mathrm{Ni}$ il fe trouue vne pierre, qui elt fort bonne pour guerir ceux qui font vexez par les mauuaix efprits, \& $\&$ quaufi tolt qu'on Ia leur met au nez, que le diable fort: les Mages Chaldeans, fectateurs de Zoroaltes,ayant faict aulfi grand cas d'vne

pierre: 
rre qu'ils nommoyét Mmnefiris,qu'ils ent chafler les Demons terreftres, es auoir dit quelques parolles chares. Noftre Ecclefiaftique pour louër tantage les pierres precieufes, qu'il noit fur toutes chofes, principalemét les qui font diaphanes $\&$ tranfparan, nous va dire qu'il n'y auoit rien en monde qui fut fibeau, ne qui pleuft $t \grave{a}$ la veuë, que ce que les Latins aplent Gemma, les yeux fe delectans de fes claires, nettes, \& belles, la beaule la chofe eftant vne proportion auec couleur conuenable:fi bien que tout fi que les yeux corporels prenent ifir à la beauté corporelle, \& à la luere fenfible, en cas pareil les yeux de prit prennent fort grand plaifir en $r$ lumiere, qui eft la raifon, \& en leur uté, qui eft la vertu? à cefte occafion oit-il, Platon a efcrit que fi nous pouins auffi bien veoir des yeux de l'er$t$ la beauté des vertus, conme nous yons des yeux du corps la beauté correlle de quelque chofe, \& fur tout de elque pierre precieufe, que l'amour i nous enthmmeroit à beauté \& 


\section{TRENTE-TROISIESME}

vertu, feroit incroyable $\&$ tref-ard Que fi les pierres, adiouttoit-il encor euffent efté fans vertu \& efficace, M fe n'eult pas commandé fi expreffém de mettre à l'acouftrement du Ponti quon appelloit $R$ ationale, douze piert \& les Ábiffins \& Ethyopiens n'euf pas faict porter le nom à leurs Roys pierres precicufes, que les Latins app lent Germa, nommans leurs Roys B lugian, que nous nommons(corromp le mot) Pretegian, ce mot de Bellugi fignifiant, en leur langage, vne pie qửon ne peut eftimer, ce peuple là vo lát inferer leur Roy exceller tous les a tres Roys, comme celte pierre exce toutes les autres. Ce que veut prete dre le grand Seigneur de Turquie, quel s'eitime paí deffus tous les gneurs du monde, comme ila vnd mant, qu'il porte à fon turban, qui eft demefuré qu'il excede de beaucoup carats tous les autres de la terre. Que on me dit, difoit noftre Chanoine, qu les pierres du jourd'huy n'ont pas tel vertu \& proprieté qu'anciennement, des affeureray qu'elles font donc adu 
ees, falfifiees, \& contrefaicies de telle te qu'on y peut efre trompé, mefs que notis trounous que la femme n Empereur en achepta de verre, ce Coelius, Cardan auffi difantque les liens appellent le François lourdaut, i fe laifle tromper, achetant de luy des rres artificielles, les bónes fe cognoifs par la veuë., par la lime, \& par l'atchement, les bonnes pierres eftans s legeres $\&$ froides que les faufles, les illeures eftans mifes fur la langue us plus de froideur que les autres. is noftre Ecclefialtique nous va conqu'il fe troumoit par efcrit, que mens fixiefme perdit vn Carboude la valeur de fix mille efcus, de la Ir d'vne muraille qui tomba à Lyon couronnement de ce Pape, dont le $c$ de Bretagne, \& plufieurs autres ururent, le Roy Philippes en eftant fé, \& que Pyrrhus anoit vne Agathe, lans laquelle on pouuoit voir \& difner les neuf Mufes par leurs fignes, fibien qu'A pollon auec fa lire, non art, mais par nature. Ie me fuis foutefbahi, repliqua vn de la Seree, vetr 
TRENTE-TROISIESME la beauté, la fplendeur, la clairté,la vi \& proprieté des pierres precieufes, $\mathrm{Cl}$ meles anciens ont faict fi grandca. leurs perles. \& vnions, qui ne font $x$ lement diaphanes \& 2 tranfparents, n'ớt aucune vertu \& proprieté, lefyl les toutesfois n'ōt laiffé d'eltre en fig prix \& eftime, que les heritiers auoi droict de retraicts sils fe vendoient, $c c$ me fi c'eult efté vn heritage, \& eltoi eftimez immeubles, s'en eftant trol qui pefoiét vne once. Et pour confirr l'excellence de la perle, Pline dit qu' ciennement c'eftoit le plus precieux. yau de nacure, encores difons nous commun prouerbe d'vn homme illuft ou d'vne chofe belle par excellence, $c$ vne perle, le grand Nagus, feigneur cinquante Prouinces, mettant en titre d'honneur, Iohan Belul, qui el dire, perle precieufe, \& fi trouuons $q$ Cleopatra auoit deux perles du pois $\mathrm{d}$ ne once, qui furent eftimees cinq ce mille efcus. Et Budee dit en fon Epiton de Affe, que Pline recite auoir veuv Dame de Rome, non point en vn 1 lennel banquet, laquelle auoit autrefo eu a mary Caligula Empereur qui s'a 
oit Lollie Pauline, qui auoit le chefs orge, le fein, \& les mains couuertes orles \& emeraudes, ioinctes enfem\& entrelaffees, qui valoyent vn mid'efcus couronnés, luy eftans efuës par fucceffion. Mais auiouryy à caufe de l'abondance des per, \& qu'elles ne font pas fi belles uyfantes que les pierres precieufes, s ne font pas en figrand credit, ne fi res comme autrefois, ayant en vne nque efté mife vne perle qui pefoit aie once, enrichie de cing groffes per, \& neantmoins tout le benefice ne eltimé que treze cens efcus. Que les res precieufes diaphanes ayent plus ertu que les perles \& $x$ vnions, nous le ons encores de ce temps, car fi les fés'apperçoiuent que leurs enfans fe uent fubitement mal, elles n'ont at recours aux perles, mais parfumás cens leurs fils, elles leur pendent au quelques pierres precieufes, comme ayacinthe, vn Saphir, vn Efcarbouce qu'elles font comme vn fouuerain ede contre le charme, l'aiant apprins emocrite Abderite, 2 lequel voit fou-

uent. 
TRENIE-TROISIESM E uent de la pierre Catochitis, en la $p$ ou la monftrant, à fin de fe garde charmes \& enforcelemens. Encores ces pierres nous euflent faict chope mis hors du chemin, fi fufmes-nou dreffez par vin de la Seree, qui nous mit en noltre premier propos, qui de parler des gens d'Eglife, qui ' conta ce qui eftoit arriué à vn Card C'eft que ce Cardinal eftant mont vne mule, \& cheuauchant auec le Louis vnziefme, rencontra, des Co liers fur le chemin, qui alloient à vn pitre general de leur ordre, Ce Card voyant ces freres mineurs montez des afnes, comme alors ils auoien couftume, leur demande, où vont les nes, beaux -peres, où vont les afnes? Iuy refpondirent, fur les mules:Mon gneur, furles mules. Le Roy voyant fon Cardinal eftoit demeuré muet ce me vn poiffon, luy va dire, qu'il ni falloit iamais moquer de ce qu'on eft taché. Vous me faictes fouuenir, vad vin áutre d'vn Euefque, à propos d'afn qui auoit auffi vne mule bien accouft: \& enharnachee de velours rouge $c$ 
fi, combien que fes parens $\&$ amis remonfroient que l'equipage de fa n'eltoit pasdecent, d'autant qu'il auoit pas long temps que la mere de Euefque eltoit morte, luy remôfrăăt puis que fa mere eltoit morte, qu'il jit que fa mule fult paree de noir, $i$ bien que luy. Aufquels noftre Euefrefpondit, il feroit bien raifonnaque ma mule portaft le dueil, fi $f_{a}$ e eftoit morte, mais n'eftant pas morourquoy eft-ce que fa fille fera habilde noir? On ne pounoit(adionftoit-il) e accroire à ceft Euefque, que fa mueuft porter le dueil, la inere de fa muftantencore en vie. Noftre Ecclefiauelors nous va conter, quallant en tation, \& eftant en vne paroiffe, il anda à vn des paroiffiens : viença, a amy, qui eft Curéde ce lieu, \& que aroiffien luy auoit refpondu, c'eft vn tif Gentil-homme.Puis luy ayant deadé, la cure eft elle bonne? Le paroifluy auoit dit: Elle eft meilleure que uré. Difent-ils aumoins la meffe? Ils lifent plus qu'on ne'veut, luy refponce villageois de cefte paroifle (adionftoit 
TRENTE-TROIES M E Atoit noftre Ecclefiaftique (Nous $n$ tranfportafmes à la vifitation d'vne baye, qui eltoit à la verité bien mal tretenuë, \& fort ruinee, \& quand dit à cę- Abbé en vifitant ce Monafte vous n'entretenez pas bien voltre baye, elle eft toute ruinee, cełt Abbé auoit refpondu: Monfieur, ie n'ay fait les brefches, mais ie vous affeure $\mathrm{g}$ ie les entretiendray bien. Le vieil cor pte (lequel pourtát iamais n'enuieillir fut mis en auant, du Ruftic qui repliq à l'Archeuefque. Si le diable emporte Comte, que deuiendra l'Archeuefque: qu'euft dit aufiourd'huy le Ruftic, s euft veu aller les gens d'Eglife à la gue re ? Les Anciens n'ayans iamais voul que le Pontife \& l'Euefque euffent la lä gue, ny la main, nela veuë, ne l'aureil le maculee de fang humain, parquoy leu eftoit defendu de pourfuiure accufatió capitales, d'en eftre iuges, d'y affifter d'aller en guerre, traitter la partied, chirurgie (porte le Concile de Latran qui vfe de cauteres \& d'incifions, \& qui eft en Aule Gelle \& Plutarque, de toucher fer, ny venir en vn campou armee prefte à combatre:Pacatus appellant 


\section{$S^{\prime} E R E E$.}

quifouftenoient Itachius Euefque ncontre de Prifcillianus, Satsllites non iftites. Et puis il va foumenir à vn aule la rencontre que fit le Roy Louys efme à ceux qui vouloiét annoncer uefque leur parent, le Roy s'enqued'vn homme fçauant, \& de lettres, l'enuoyer Ambalfadeur à Venize. quand le Roy leur eut demádé quel me c'eltoit, ils vont refpondre, Sire, Euerque de tel lieu, Abbé d'vne Abbaye, Seigneur de telle place, n de telle feigneurie. Le Roy ende ces longs tiltres, leur va dire, il y a tant de tiltres, il y a bien peu tres. Le Roy voulant dire, que tant ily a de tiltres, tant moins il y a de. es. Vn franc-à-tripe, prenant la pava dire : Celuy que fçauez, qui a u fon Abbaye, doit donc auoir beaudelettres, n'ayant pas vn tiltre, \& diray autre chofe, finon que le trouvin iour en vne chambre haute, où il it bien fort, ie luy dy : Monfieur, feriez mieux à bas. Entendant ce voulois dire, il me va refpondre, auoit vn bon benefice, qui valoit bien 
TRENTE-TROISIES ME bien fon Abbaye, c'eltoit vn benefice ventre, qu'il ne bailleroit pas pour ci cens fois autant, encores qu'il n'euft tiltre ne benefice. Mais adionfa-il vous feray vn petit compted'vnau Abbé, qui auoir tant de tiltres qu'il poumoit auoir beaucoup de lettres, car jour cebeneficier prenant poffeffion benefice, on commença à dire en lifa ces qualitez \& tiltres, Abbas fancti, \& Abbas, \&c. Et lors vin des affiftás va cri Hé! vertu-Dieu que de bafts pour vn me, ie croy que c'eft vn afne à tousba Cetx de la Seree voulans rire \& dut $\&$ de l'afne, furent empefchez par Drolle, lequel nous compta que cem me Abbé ay ant bonne enuie de pouru fon Abbaye d'vin Aumofnier, au lieu celuy qui eftoit decedé, demandaà moynes où il pourroit trouuer entre fols de moynes vn bon Aumofnier, qu vin fecond frere lean des Entameures 1 va refpódre:Et pourquoy ne trouucre vous entre ces fols de moynes vn be Aumofnier, auffi bien que nous ano troulué vn bon Abbé entre ces fols moines? Ce fut à Mófieur l'Abbé, qu'i 
u d'entr'eux : de recognoiftre que reftre Abbé, il n'eftoit pas plus fage les autres. Vous the faites foumenir, lire vn autre, du Pape Iules de Minic, donna le chappeau de Cardinal à vin ne enfant ( qui à cefte caufe fut nomCardinalin ) lequel eftoit fi ieune il n'y auoit pas log temps qu'il caffoit ores fa coque pour efclorre; Fans eftre maifon, ne d'efprit, ne de fçauoir, f, n'ayant rien-en luy qui meritaft le ppeau. Les Cardinaux ne trouuans bon cela, dirent au Pape, que tout ce eftoit requis pour efte mis en telle grande dignité, manquoit en ce Caralin. Le Pape lors leur replique: Et is autres, queile fageffe, quelle vertu, 1 f̧̣anoir,quelle bonté \& efprit, bref, mez-vous trouté en moy pour ma$r$ fait Pape ? Les Cardinaux lors fe nás au bout du nez, ne parlerent plus Cardinalin. Laiffant le Pape \& fon dinalin, ils fe remettent encores à - Abbé, \& vont compter que durant trăds iours derniers tenusàPoi ctiers; Abbé euit affaire à Meffieurs du lement, pour quelque procez qu'il Liu. iij. $\mathrm{R}$ 
TRENTE-TROISIESME auoit pardeuát eux. Or eltant bien fu \& habillé en Prelat,lesHuifiers luy v lét bailler place, \& tout fur l'heure $M$ fieur le Prefident fe leue pour aller Confeil, \& les Confeilliers auffi. Lors Itre Abbé penfant qu'ils le leuaffent $p$ luy faire honneur \& place, leur vac tout haut, Meffieurs, ne bougez sil plaif de vos places, ie feray bien icy, a affez de place pour moy. Meffieur. printent à rire, $\&$ jugerent que celt bén'anoit pas beaucoup hátéla plaide rie; \& ne l'en eftimerent pas moins : ftant gueres beau de voir vn hommed glife eftre grád chiquaneur, \& ne bou! du Palais. Il n'y auoit perfonne ence Seree, qui n'euft des comptes à faire r Miniftres de l'Eglife, à l'imitation s prefcheurs, qui font leurs comptes or nairesde la nonchaläce \& $\&$ du peu de fí noir de la plus part de nos Ecclefial ques, \&rce le plus foument, pour n'eft veu tels, mais ce qui eft trouué bon general, ne fe trounc pas bon aucunefc en particulier, ce qui les faifoit taire, aufinquela reuerence $\&$ honneur, $q$ ceux de la Sarce portoient à noftre $\mathrm{Ch}$ 
SE R E E. TY: T IS

ine; les rendoit muets, de peur de luy plaire.Dequoy nofte. Chanoine s'apceuant, \& pour nous inciter à paraeuer la Seree du fubiect encommencé, faire luy mefme deux outrois comis de quelques Ecclefiaftiques; Mefurs, commença-il à dire, vous ne voús ndaliferez point fi nous defcoutitons elques ignorances \& maluerfations gens d'Eglife, li vous confiderez queldifference il y a des Ecclefiaftiques de temps à ceux du temps palfé, s'eftant uué en I'Eglife primitiue plufieurs fonnes de grande faincteté, qui n'ont ulu eftre Preftres, ne fe fians en leur nfcience pour vn fi grand miftere tel ieft ceftuy-cy, \& fe font couppez les igts pour eftre plus affeurez de n'eftre int Preftres. Le premier de mes comes (difoit-il) c'eft d'vn Ecclefiaftique, i demanda à vn Predicateur qui auoit efché tout le Carefrne, quelle matiere uioit traittee en iceluy, lequel lui ayãt pondu qu'il auoit interpreté Genefe, thōme d'Eg life luy va dire: Voila quii bien, Dieu vous face la grace de conrtir ces mefchans heretiques. Lefe-

R 2 
TRE N TE-TROISIES ME cond compte que fit noftre Chanoin fut du mefme Ecclefiaftique, lequel yát vn tableau du Decalogue,où on pe conmunement Moyfe auec vne gran barbe grife, \& au delious Exod. xx. e inant qu'Exod. fut le nom, \& que xx. la remarque de fon aage, va reprendre peintre d'auoir porirtraict Exod.fi vieu nayant encores que vingtans. Le tie compre fut du mefme Ecclefraftique, quelvoulát baftir à vn fien benefice, alla chez vn Libraire pour auoir des ures d'Architecture, qui luy apporta petit liuret, inciculé. Fiundamentum Log ces, l'ayant veu, il va direau Libraire,au. fçauant que luy, que c'eftoit ce qu'il di mandoit, \& que le principal d'vn log eftoit le fondement. Or ayant enuie d': uoir d'autres liures d'architecture, q! apprenent à baftir, regarde où eftoit in primé ce liure sà fin d’en acheter, traitar demefme matiere. Voyant que ceftoit Paris Apudgeminas cyppas demande a fo Libraire quelle enfeigne c'eitoit, pour trouuer à Paris, mais né le fçachant, v1 Regent de college le va affeurer, qu -.) 3 
udgeminas cyppas, váloit autantà dire bon François, que $f_{1}$ on difoit, Aux ix boules. Lors cebsneficier va refdre, Ie le croy bien, car quád on veur uler, \& ioiier à la longue boule, auant e la iecter, on fait cing ou fix pas. Le gent ne fe poumant tenir de rire de la tilité da celt Abbé,l'accompagne iufes à fa maifon, où par les chemins il ife vn beau logis tout neuf, demandant maittre maçon, apres l'auoir vifité dens \& dehors, fi cefte maifon auoit efté cte en la ville, \& qu'il en voudroit a auoir vne pareille. Ce dernier com- acheué, vn entre les autres, ayant fé rire ceux quine fcauoiét point cerencontre, fi la maifón eftoit faicte en Ate ville, commença à nous demanr, fivn Curé fit bien de ne vouloir pas jerpour la fantéd'vn fien parroiflien, ii lauoit enuoyé querir pour prier ieu qu'ille remitt en fanté? Car le Culuy ayant demádé en quel tếps il eitoit eilleur Chreftien, ou en fanté, ou en aladie, 8 le malade luy aiant refpondu 1e c'eftoit quand Dieu le vifitoit. Il ut donc mieux, repliqua fon Curé,que R 3 
TRENTE-T ROISIESM tu demeures $\operatorname{ainf} i$, a fin que tu fois $p$ homme de bien. Puis nous va compt comine vn Predicateur ces iours paft fut appoirctépar ceux d'vne ville, àce efcus,pour y prefcher tout le Carelime, que tout le peuple du commencement contentoit fort bien de fes fermons, eft f̧auant \& eloquent ce qui fe peut. $M$ atiec le temps on sapperceut que fav ne refpondoit point à $f_{a}$ doctrine, $\&$ à qu'il prefchoit, \& que ce font deux ch hes de dire, 8 de faire. A cefte caufe ville deputa quelques vns, pour remor frer à ce l'redicateur, , le fcandale qu' faifoit de ne viure comme il enfeignoil \& que fa vie fajfoit beaucoup plus d mal \& de fcandale que celle d'vne pet fonne privee:car combien, luy difoien les deptrez de la ville, quenuers Dieule vices ne foient point plus grands aux pa Ateurs \& miniftres del'Eglife, qu'aux aut tres : fi eft ce que leur office \& dignité faict que leurs pechez font plus f canda. leux, manifeftes \& remarquez, qu'aux perfonnes priuees, auffi qu'il eft plus aife de tire que de faire, \& que la vie deuoit prefcher la premiere, attirant plus de monde 


\section{S E R E E.}

de à bien viure que la doctrine, comle chef de guerre, qui accompagne parolles auec l'effect, efmeut plus les dats à bien faire. Ce Prefcheur, ayant out entendu par les commis dela vil\& comme ils fe contentoient fort n defes predications, mais non pas de actions \& de fa vie, leur va dire, Vous dónez cent efcus pour vous prefcher admonnefter, mais fi vous men donez deux fois autant, ie ne ferois pas ce e ie vous dis \& prefche.Lors ces depu? noterent bien ce que dit Lacide Phiophe, qu'autremét viuons-nous en la ifon, que nous ne difputós aux efcho, arreftans entr'eux qu'à l'aduenir ils oient foucieux de fe pouruoir d'vn efcheur qui auroit la vie conioincte iecla doctrine \& le fçauoir. Vne feffendue, alors va dire à ceux de la Seree: efpargnons pas ces prefcheurs, auffi en mefdifent-ils, \& parlent de tout le óde, \&z qui aimeroit,difoit-il,ceux qui prennent \& blafment nos actions? Nore Chanoine, pour monitrer qu'il ne ouuoit pas bon, ne la vie ne l'ignorand'aucuns de fon eftat, nous va reciter 
nne Occidétale fe fert du Latin, comles Chreftiens Orientaux du Syrien, Abiffins \& Ethyopiens du Caldaiie, les Iuifs de l'Hebrieu, les Mathemaues de l'Arabique. A propos va replier vn de la Seree, que tous les gens d'Efe n'entendent pas le Latin, \& qu'il rouue de grands cleres en Frarçois, inefont quafnes en Latin, efcoutez il arriua du temps que les Polonois adreat en France, cu paftants leur che$n$ pour aller en Cour, vont faire la rerence à vn Prelar, auec vne petite hague Latine, car ils ne fçauoient point rlei François. Ce monfieur le Prelat ne ar dit rien : mais feulement leur fai at ne de la telte \&r des mains. Parquoy ant reprius de fes gens de ce qu'il ne ir auoit rien dit ne refpondu, jeurva : Sçauez-vous pas bien que ie ne rle ni n'entens le lingage Polonois? irs fes feruiteurs repliquerent àleur aifte ; Comment, Montieur, ces Ponois parloient Latin. Que ne me le fiez-vous? leurva dire ce Prelat, i’eufrefpondu de mefme, Vn de la Seree, raignant que de force de rire noftre. R. S: 
TREN TE.TROISIESME

Chanoine nevint à mourit, lailfant gnorance des gens d'Eglife, lefquels vo diriez auoir fait vou d'ignorance co me de chalteté, nous va reciter le bon z le du Curé de fa parroiffe, encores qu ne foit des plus fçauans, lequel il va de crire ainfi. Il n'y a celuy d'entre nous, $q$ n'ait ouy chanter la paffion le iour Védredy faince, là où tous ceux qui ch tent la paffion difent d'vne voix balfe douce ce que dit Iefus Chrift aux Iui \& ce que dirent les Inifs, eft chanté bi plus haut par le Preftre ou Biacre, poi demonitrer que la parolle de Diena humble, douce, fimple, \& veritable, quelle ne demande aucune vehemen pour fon approbation, Mais le Curér nof re parroille, difoit-il, fait tout le co: traite, \& quand on luy demanda, pou quoy enchátant la paffion, il faifoit nt ftre Seigneur parler plus haut que li Iuifs, au contraire de toutes les autr parroilfes, il refpond, que quelque pas où il feroit, il n'endureroit iamais quiv autre parlaft plus haut que fon maittr Ayant acheué ce conte, celiy quil? uoit fait, va adioufter que le bon zel 
a bonne vie de ce Ciré, ne peut emcher fesparroiffiens de rire durant la Ife, à vn iour de Dimanche qu'il pronoit des bancs à fon profne : \& voicy ment. Vn pere, difoit-il, ayant pro\& fiancé fa fille à vn de fes voifins, efcrire à vn clerc de village, à fin aire proda mer les bancs à fa parroifAariage eft accordé entre Pierre Boif\& la fille de cheznous, tous deux roiffiens de ceans, \&c. Le Curé à qui auoit apporté le breuet durát fa Mefe prenant le va lire cóme on luy auoit orté, \& comme il le trouua ef crit en memoire, Mariage eit accordé entre rre Boiffon, \& lit fille de chez nous. qui fit rire tous les parroifiens, \&c uré auffi, quileurr va dire que quand aroit des filles à marier, qu'il ne parit pas fi haut. Voila comment les nmes, difoit celuy qui auoit fait le? tte, doiuent bien regarder à ce qu'ils ent, principalement en public, parjue le peuple eftant enclin à fe mocor \& rire d'autruy, bien fouuentinorete leur dire en mauuaife part, enes qu'ils n'y penfent pas. Ie vous R 6 
TRENTE-IROISIESM E prie, vadire vir autre, d'entendre refponce que fit vin Curé à vn Genti hóme fon parroiffien, lequel accufo fon Pafteur de n'eitre pas beaucoupd uotieux. Car vn iour ce Gentil-hon me prie fon Curé de lay dire vne Me fe à fon intention. Or il arriua qu'v autre Preftre commença à dire fa $\mathrm{Mel}$ en mefme ternps que le Curé : mais Curé qui chantoit pour le Gentil-hon me, eut deux fois pluftoft faict \& : cheué fa Meffe que luy, dont le genti homme s'en fcandalifant, va dire a Curé qu'il nauoit pas figrande deuotio qque l'autre Preftre, qui n'eltoit encort gu’à la moitié de fa Meffe. Le Curé , lor lity va refpondre, Ie le croy bien, mor fieur, mais fçauez-vous pasbien quel. cheuaux vont pluftolt que les afnes? Li Ecclefiaftiques, repliqua lors vn de la $S_{i}$ ree, \& principalement les prefcheus font le plus fouuent contraints de dir \& controunerquelques fornettes, tar pour anoir des auditeurs', que pour le ef mounoir à leur donner quelque che fe, la charité eftant fort refroidie. Qu fi me voulez efcouter, ie vous en dira. 
Ix ou trois de leurs rencontres. La miere eft, du prefcheur de ce Caref, lequel voyant qu'on ne luy donnoit n, nous va dire en vn de fes fermons, le diable auec fon foudre eftoit tomen l'Eglife où il eftoit, \& que ce diable fçachant où fe mettre $\&$ ranger, tant aufe de l'eau benifte, des autels, que s croix \& bannieres, qui eftoient en te Eglife, s'eftoit fourté en fa bourfe, urce que là il n'y auoit croix ne banere, tout eftant allé en procelfion. Les diteurs fcachans bien ce qualil vouit dire, luy remplirent fa bourfe de oix, à fin que le diable auee fon foue n'y tombalt plus. La feconde renontre des prefcheurs, adioulta celuy ui auoit faict la premiere, c'eft d'vn redicateur lequel voyát que fes fermós 'eftoient gueres frequentez, \& par conequent qu'il ne gaignoit pas beaucoup, a dire vn iour à fes auditeurs, quele liable auoit la nuict paffee parlé à luy, $x$ quie fil le lendemain on vouloit fe trouaer à fon fermon, il leur diroit des choes efmerueillables \& efpounantables, \&. leur conteroit tout ce que le dia.

$$
\text { R } 7
$$


TRE N TE-TROISIESM E

ble luy auoit dit, \& leur en donneroit. fi bonnes enfeignes que perfonne $n$ ' douteroit. Cela diuulgué par toute ville, vous ne fçauriez croire le peup qui fe trouua le lendemain à fa predic tion, mefmes de ceux qui n'auoier bougé de la chambre \& du lict il y auoi vn 2n, $s^{\prime} y$ firent porter. Ce prefchcur vo yant ii grand nombre de peuple là affem blé,leurva dire, Meflieurs c'elt grád cas quand ie vous ay parlé tous ces jour de Dieu, \& de ce qu'il a faict pour nous vous n'en auez tenu conte, \& mainte nant vous voulez bien fçauoir ce que le diable m'a dict \& reuelé, aimans mieux ouyr parler du diable que de Dieu. Ainfi tout le peuple s'en retourna de ce fermon tout confus, \& fans fçauoir rien du diable autre chofe, ne du prefcheur. Mais les auditeurs iugeans en eux-mefmes que ce predicateur deuoit eftre quelque homme d'efprit \& accord, il s'en trouua vn entre les autres, qui luy enuoya vn bulletin en fa chaire, vn jour qu'il prefchoit, par lequel breuet il prioit ce prefcheur de l'affeurer en fa confcience d'vn doute qu'il auoit, 
it, fi les efcargots eftoient chair ou fron, \& s'il en pounoit manger en refme fans offéfer Dieu.Ce prefcheurfant en luy-mefine que ceftuy-cy deit eftre quelque bon compagnon, qui loit eftre alfeuré de fa confcience, int leu ce breuet a fes auditeurs tout at, va dire: Quiconque foit qui m'ait royé ce billet, \& doute fi les efcargots t chair ou poifsó,\& en veut auoir mó uis, qu'il s'affeure que c'eft du poifson, que ce n'eft point de la chair, \& qu'il peutr máger en Carefme săs fcrupule, en liberté de cơfcience, mais ie luy cólle qu'il fe dóne garde descornes. Ceux la Seree voulans rire de ce conte, furét apefchez par celuy qui l'auoit fait, cóauant à conter que ce frere prefcheur it puny de cefte raillerie, ainfi que ie uus conteray. Vous fçauez, commençaà dire, que les troubles ont efté caufe ue plufieurs parroiffes font demeurees ins pafteur \& fans doctrine, \& queles arroiffiens, pour la plus part, vitroient ans religion. Parquoy la guerre eftant n peu affoupie, il fut aduifé par l'Euefux \& Diocefain, qu'on enuoyeroit aux lieux 
TR EN TE八TR OISIESM E lieux les plus reculez quelques Ecclef ftiques \& gens fçauás, pour les remett en leur premiere deuotion \& creáce. E tre autres fut delegué vn predicateur $q$ leur difoit qu'onfe dónalt garde des co nes en mágeant des efcargots, \& en all. de lieu en lieu fit cóuoquer en vne Egl fe, commife à fa vifite, tous les parroiffi d'icelle, aufquels en cathechifant il $\mathrm{fa}_{\mathrm{a}}$ foit dire leur creance, leur Paternofter, e Aue Maria, \& fur la fin leuv faifoit dir \& apprenoit leur Cófiteor. Or ces parroil fiés en difant, Mea culpa Deus, ne frappá point leurs poictrines, cóme c'eft la cou ítume, il les aduertit de ce qu'ils deuoié faire, \&en battát luy-mefmes fa poictri ne leur difoit, quád vous direz, Mea cul pa,Deus, fràppez tous là, cómevous voye que ie fay. Ce qu'ils firent, car difan tous enfemble leur Confiteor, quand fyt à dire, Mea chilpa, Deus, qu'on dit par trois fois, ils vont aufi par trois fois frap. per fur l'eltomach de leur cathechifeur I'vn apres l'autre', felon qu'il leur auoi commandé de frapper tous là où il frap. poit, fans confiderer que c'eltoit leur poictrine qu'ils deinoyent battre, laguelIn? 
uoit fait le mal, \& nou pas la fienne, ils eftoient deuenus groffiers par difrinuation de ne dire leur Conjuteor. Il aifoit tard, \& fi chacun craignoit de dalizer les Ecclefialtiques, parquoy e voulant retirer, il fut arrelté par vn

a Seree, lequel a propos de ce frere cheur, nous va conter qu'ilfe troula maifon d'vne fienne parente, en uelle icelle eftant fort malade, ilfe uua vn lacobin \& vn Medecin, l'vn lát medeciner l'ame, l'autre le corps. eft-il, que cefte malade ne pouunnt res bien parler, ne pounoit auffi eftre nentendue de fon confelfeur, qui va au Médecin, Monfieur, ne fçauriezis la faire parler vn peu mieux, $\&$ plus inatement, à fin qu'elle puiffe faire endie fa volonté, \& ce qu'elle a fur fa fcience ? Le Medecin, fans penfer en 1 , ne confiderer que fon confelfeur là lent eftoit Iacobin, luy va dire, Monir noftre maiftre, il eit bien difficile de poutuoir faire parler autrement, car a dans la gorge des gros Iacobins qui npefchent de pouuoir parler. Ayant Medecin, qui eftoit de la pretendue Religion, 
TRENTE-QV ATR IESME Religion, acheué de dire cela, il co mence à s'excufer enuers ce frere pr cheur, en luy difant qu'il ne print po cela en mauuaife part, \& qu'il ne l'au pas dit pour loffenfer \& fafcher. Le cobin luy refpond, qu'il n'y auoit qui meritaft excufe, \& que quant à e ils appelloient ces flegmes qu'on crac des gros cordeliers. De peur d'entrer ces comptes plus auát, il fut deliberé $q$ chacun fe retireroit en fa maifon, peur d'eftre prins pour ceux que nous fommes pas.

TRENTE-QVATRIESME (2) th W Desfols, plaifans, ydiots, badins.

(6) $N$ fçait affez que durant les emı 1. nerfs \& ligamens de l'humaine \& con mune focieté, vne des principales chof que faifoient les habitans des villes, $c^{\prime}$ ftoir de fe donner garde qu'on ne les fus print Et pour ce faire, vri chacun denc Are ville alloit aux gardes des portes, qu

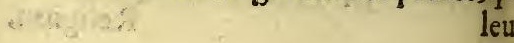


arriboient par fort. Et eftaus là, c’ede s'enquerir quelles noumelles roient, pour fcauoir qu'on poumoit dre de ces troubles. Et encores qu'on uft point de garde ce iour là, tout le nde eftant de loifir, on ne laiffoit de rouuer, pour le plus foutéty apprendesmenteries, d'autant que les paf. s'accommodoient felon l'humeur de $x$ à qui il falloit refpondre, ayans en mmendation de ne dire iamais cho. jui defpleuft aux gardes, ne voulans paffer chemin, fans qu' on fceuft quel y ils tenoient. Que fi quelques vns; auoient efté ce iour là à la garde, fe auojent en vne de nos Seree, d'aboril falloit fçauoir ce qu'ils y auoient ris. Le tout eftant mis fur le bureau, cun felon fon humeur, fe formoit fa ne ou mautuaife fortune, la penfant itable, tant plus elle luy plaifoit. Que François, eftant en paix, eft fort.cuux de nouuelles, que fera-il dua it les guerres ciuiles, où chacun a ineft? Le François, ny en paix, ny en erre, ne gardant nullement la loy des heniens, par laquelle il eftoit defendù à 
TRE NTE-QVATRIESME duà toute perfonne d'ofer enquerir cun eftranger de nouneau venu en ciré, dont il venoit, quel il eltoit, ny c'eit qu'il demandoit, fur peine d'e banny. Et faifoient cela, pour defen aux hommes le vice decuriofité, leq eft toufiours prompt de vouloir efpier affaires d'autruy, ne regardant point a fiennes. Cefar remarque des lors en ftre nation ce vice, qui y ent encore, $d$ ' refter les paffans que nous rencontro en chemin, \&z les forcer de nous dire 0 jls font, \& $x$ de prendre à iniure \& occa de querelle, s'ils refufent de nous ri pondre. Or en cefte Serec fe trouma meffere Panthaleon, lequel auoit elté iour intendant à vne porte, \& fuperi tendant la nuict en vne tour \& portaj qui nous va faire le cópte du plaifr qi leur auoit donné vn plaifant Sybilot, $l_{1}$ quel s'eftoit prefentéce jour là à la por। pour y entrer. Ce qui refiouiit la Sere de telle forte qu'il n'y fut rien dit quin fentift fa folie, loing ou pres. Et à la ve rité, vous diriez que nature a enuied s'elbatre, quand elle fe metà faire d relles pieces d'hommes qu'il s'en trouve

\& qque 
u'elle nous veut bailler du paffetéps; ous faire rire. Noftre Panthaleon unença ainfi: A celte aprés difnee, il prefenté à noftre porte vn vray frácipe, pour y entrer, ie luy demande me il s'appelloit, en riant il me va qu'il ne s'appelloit point, mais bien on le nommoit Gredendan : Puis ie demande dont il venoit, il me refpód, lvenoit de Paris, quel bruit il y auoit, 'a dit, qu'il n'y auoit nulbruit, en ot bougé fr matin qu'il n'y anoit perne leué, \& puis recita ces deux vers, depuis i’ay veu en Lipfius: Defierant latrare canes, vrbéfque filebant. mnia noctis erät placida compofia quiete. uns oyans cefte refponfe, difoit noPanthaleon, ne furent pas d'aduis de ilfer entrer, l'accufant d'eltre vn éf, puis qu'il fçauoit parler Latin, les es ne s'en faifoient que rire, \& le erent là,comme eltant alfez trauaillé a propre folie,difans qu'on peut auffi eftre fol en Latin qu'en François. zany icy voiát quón le faifoit la trop ndre,nous va dire, que veritablemét enoit de Paris, mais qu'il ne leur en pounoit 
IREN I E-QV A T R IES ME pouuoit pas dire grande chole n'ay peu voir la ville à caufe des maifons aufi qu'ils s'y mouroient fi fort, qu cent boutiques fermees on n'en trout pas vne otuuerte. Les gardes lors eur grand' enuie de luy bailler du rou billy, dont les lardons font de bois , 8 faire crocheteur. Mais ce zany ay autrefois efté en cefte ville, de bonne tune aduifa fon holte, qui eltoit deg de auec nous, auquel il va dire Hé!M fieur de ceás, ie vo 9 prie me laiffer ent $\&$ ie vous diray des nouuellès, c'eft y a force Reiftres leuez, \& qu'ils font dix mil cheuaux bien montez. Son hof que ce fibilot appeloit toufiours $M$ fieur de ceans, encores qu'il fult hors ville, luy va demander s'il n'eftoit poi Hugenot, il luy refpond, ie voy bien à c Ite heure que vous vo moquez de mo fçauez vous pas bien qu'il n'en eft pas temps? Si ie vous ay dit, qu'il y a des $R$ Atresleuez, penfez-vous qu'ils foyen cefte heure icy encores aulint; Lors fut deliberé qu'aucuns de la garde le duiroient en vne holtellerie, \& feroie. commandement à fon holte d'auoir e 
fur luy. Que sil euft efté à Tollette; it noftre Panthaleon, qui nous condes nouuelles de la porte, on l'euft oyé au lieu public \& Hofpital, où sớt zles infenfez, ettant ce plaifant did'eftre receu à la fefte $2 x$ confrairie fols, qu'on appelloit guirinalia. Si les font comprins aucc les infenfez, rejua quelqu'vn de laSeree, \& il y en zutát en Épagne cornme en ce paîs, il bien que ceft Hofpital foir bien réour les nourrir, \& bien grad, pour les :r. Illuy fut refpondu, qu'il y anoit 1 plus de fols \& d'infenfez en Efpagne non pas en ce paîs, fi nous voulons ire Monfieur Bodin, lequel dit en fa thode, que les Meridionaux deuient pluftoft fols \& furieux que les Septrionaux, à cefte caufe (dit-il) volis unerrez toute l'Afrique garnie de fons dotees pour receuoir les fols \& Cez, \& mefmes en Italie vers la PouilCalabre \& Naples, où l'air eft chaud, il roune des Monafteres, où les Moniais \& fols qu'ils nomment Mati ducafont referrez \& enfermez, là où en la ' Allemagne, il n'y en a quafi point, \& s'il y 
IRE N TE-QVA TR I E S ME sily en a, leur folie ne procede pas cholere, mais du fang, \&z ceux-cy ioyeux, ne faifant que fauter $\&$ dan que s'ils entendent des inftruments, les incitent à danfer, ils danferont ques à ce qu'ils foient contrainets d repofer, \& ie gueriffent ainfi, \& app lęnt les Allemans celte folic \&z fureu mal de fainct Vitus. Si eft-ce ( replic vn autre ) qu'on a bafty à Paris vne $m$ fon pour ces pauures gens, car il y a ef au deffus de la porte, Pour les pauu de fens. Mais ie ne fçay fi tous y pour loger, d'autant quón dit en Latin, \& bien vray en François, Stultorum nume. eft infinitus, fi qu'aucuns on dit, que fi to les fols portoiét marotte, quion ne ç $_{\text {. }}$ pas de quel bois on fe chaufferoit, ce qu'ily a au monde beaucoup de fo qui ne le penfent pas eftre, la folie diuerfifiant felon quel'humeur eft chal ou froid. Que tout le monde foit fol, a ioultoit il, Ariftote dit, que nul fáge menteur, l'efcriture dit, tout homme menteur, donc nul homme elt fage. Di gene dit que celuy eft fol qui ne fe co. tente, tout le monde elt donc fol, par 
nul n'eft content de fa fortune. Le rerbe dit-il pas, que qui ne fait les s en ieunefle, les faict en vieilleffe? donc neceffaire, que nous foyons fols, au en vn temps, ou en l'autre. ut dire que le monde eft fans homfages, lefquels font morts petit a , les fols ne font iamais morts, ils oufiours vefcu \& croiffent tous les s. Il feroit donc bon, adioulta il, qu'il y a tant de fols, \& fi grande firé de folie, d'auoir des medecins difcerner l'humeur qui peche à fin corriger, comme il y en auoit vn lan, qui n'eltoit medecin que des \& voicy comme il les guerifloit. mettoit dans vn lac tous nuds, 8 tachans à vn poteau, les laifloit là rer \& l'eau \& la faim, felon qu'il oyoit hors du fens, \& iufques à ce 1) recogineult quelque amendemét: alleurant qu'il auoit grand' prelle, yant gueres perfonne qui n'ait que humeur. Qu'ily ait beaucoup Is, adioultoit-il, cela le demonitre quion dit qu'il y a vne folie ene du Ciel, laquelle infpire les SyLiu iij.

S 
STRENTEMQVA TRIES M billes, les deuins \& vaticinateurs, \& Poëtes. Socrate appelle cefte folie

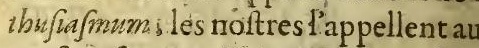
nesfois faueur diuine, aucunesfois lies, de là vient qu'on appelle les Po fols, \& les Sybilles foles, comme troulue en Virgile, 2. of o ?"? ? In fanam vatem appiciessqué rupe fub - Fatacanit:

Combien de fois, nous demaindoi eftant tous feuls en vos chambies, au vòus marché au beàu milieu des reàux, craignans de mettie le pièd leurs: Vousaffeurant que ceux quif eftimez fages, font le plus fouvent le folies en fecret, \& ceux qui font cogneus pourrifols, la manifeftent, eft vine gitande fageffe à vn homme(ence quil foit fol ) de contrefaire le fage pourvouns móltrer, adiouftoitril,qửl apasbeaucoup de fages, qui foier fag commétles: Perfesiappellent leurs $\mathrm{A}$ ges, les:Grecsileurs Philiofophes, les diens leurs Gythinofophiftes arceeftà ae 2 les fages, nuds, conxsdel Caleci lenrs Buachmaties oles Egyptiens te Pieftes, les Cabidiftes lequir Dropher 


$$
S \text { E R E . }
$$

aulois leurs Douydes, les Turcs leurs alloyers, c'eft à dire gens de bien, faez. Efcoutez ce que dit monfieur Bon, qu'en toute la Grece on ne peut iaais tromaer que fept fages, encores il doute s'ils l'eftoient:-car comme il , s'ils eftoient fages à leur iugement, nel'eftoiét pas, \& n'y a hóme qui foit outéfage, parce qu'ilfe nomme luyíme fage, \& dit qu'ill'elt, le premier it de folie eftát de s'eftimer fage.Que ous dictes que ces fept fages eftoient res au iugement du peuple, encores ins,dit Bodin, d'autát qu'il faut que fage iuge foit fi vn autre l'eftor tout euple n'eftoit pas fage, car il n'y en jit que fept en toute la Grece. Que fi ourd'huy tout le monde eft fage, \& on ne trouuegueres de fols \& ignos, c'eftparce que tous font les fages Philofophes. Si.cela of vray (replivne Felfe tonduë) qu'il faut qu'vn e foit iuge fi vn autre l'eit, il fera bien. icile de trouuer vn medecin pout guerit, d'autant qu'il faut cognoifte aladie denant quon puiffebien redier, or pourla recognoiftre il fau- 
T RE N TE-QVATR I ESME droit trouuer des medecins fages, po fçauoir ceux qui font malades de fol Et ie croy, difoit-il, que c'elt vne d principales caufes pourquoy les fols trouuent point de guerifon: $\&$ auffi $q$ les medecins ne veulent toucher à ce maladie, de peur qu'on leur die, Med cura teipfurn. Et de faict, vous ne voy point quion guerifte les fols auec ius mauues, comme les anciens Romai - faifoient, en le prenant tiede, ou au l'helebore blanc, comme les Grecs, quel purge par deffus, nageant par fubftance au ventricule, encores qu foit beaucoup plus molefte \&r dang reux que le noir, dont $v$ foyent les $\mathrm{At}$ bes, qui purge par le bas. Que fil'he bore gueriffoit auiourd'huy les fols, malfure, adiouftoit-il, qu' il feroit bi cher: eftant la maladie fi commune, fi enracinee en nos cerueaux, quil faudroit prendre vne bonne doze, $q$ voudroit guerir. Et parce que ce mer camét eft tenu pourl'vn des plus for \&r qui fubuertit pluts l'eftomach \& ve tricule, ie voudrois, en payant, quel medecins en fiffent l'efpreuue, aula 


\section{$S E R E$.}

de remettre en fon premier vfage, poffible qu'il feroit double profit. Il faut donc pas s'efmerueiller (repli1a vn de la Seree) fi la cure de folie eft ce téps difficile, puis qu'on n'vfe plus 1 vray remede, qui eft l'helebore, la elancholie ne fe pouuant tirer du rps qu'autec difficulté : dont le plus unent procedent les paffions d'efprit, i ne font aifees a appaifer.Et d'autant diou?toit-il ) que le melancholic, qui nommé en Latin imaginofus, c'eft à re fantafque, eft plus fage que le fanin, ou autre, s'il deuient furieux \& fenfé, fa furie \& folie fera fort fâieufe à guerir, la melancholie ne fe aniant pas facilement. Mais repliqua elqu'vn, qui vous a dict que le mencholic foit le plus fagé de toutes les tres cóplexions, eftát froid \& fec, veu 1e Cardan dit que l'homme eft l'anialle plus fage de tous, parce qu'il eft aud $\&$ humide, tout au contraire? Il y fut refpondu, que l'Elephant, qu'on t auoir le fang froid \& melancholic, toit le plus fage de toutes les autres ites, la feckereffe \& la froideur call- 
TREN T E- QV A R IE S M E fans le bon efprit: ce qui fe prouue,pa ce que le melancholic, qui eft froid fec, elt le plus fpirituel de toutes autres complexions:dont il aduient $\mathrm{c}$ les hommes font volontiers plus fag que les femmes, \& les gens vieux q les enfans., \& 2 des enfans, ceux qui for fecs de nature, ont plus d'efprit qure l mollets, mais auffi ces grands efpri ne font de duree pour viure lónguemé parce qu'en tels corps n'y a grande ht midité, qui caufe la longue vie : le actions principales de l'efprit remuan $\&$ fort vif, deffechant le corps , \& 1 corps deffeché aiguifant l'efprit, ma ce n'elt pour durer long temps : car tan plus que noftre corps deffeche, tan plus nous fommes prefts de noltre fin comme l'enfant tant plus il naift fec pluftoit il eft vieux. Et outre, adiouta il, que ces grands efprits \& bonnes me moires ne viuent gueres, auec cela, il ont le plus foument le iugement, la rai fon $\&$ le difcours plus court que cens qui ne font pas fi fpirituels, \& voicy raifon. Vous fçauez que pour conıren drebien, il faut de la mollefle au cer 
II, mais poutule retenic la ferineté $y$ reguife ; qui fe fajat par fecherefle. les excellentes memoires \& prom: $s$ conceptions, ce font intemperaes du cerueau, l'vne trop molle, l'atit. trop feiche, qui ne font pas tant ables :carl'efprit fera bon:s s'il eft 17: temperé, eftant la prudehce la nejpale action de lihomme temperés omme teinperé ay ant toutes îs fitez moderees, \& nulle exceffuce; ir int plus de iugement \&o de raifon, cnes qu'il ait lefprit vn peir groffiers eceluy qui a beacucoup d'efprit,aycant nemoire \& la conception bonne. Ie fcay, ova dite vn autre, ou ien fuls, 'entens pas celà, ie ne puis mordre ie ne mets tes dentis, ne fçachans i ie dois eftimer fage $\&$ de bon efprit, le feparer du lourdaut, du groflet du fol : \& eft vne chore bien difficile n iuger. Ce qua monfté celny qui aice la langue Italianifee, quand il Cait où mettre Brufquet le traulát fir fage que ceux qui le prenoient urvo bouffor, qui faict dire a laueur de celiure, que Brafquet n' eftoit. a1,

$$
\text { S } 4
$$


IRENTE-QVATRIESME pas fi fol qu'on le faifoic. Et laiffant plein de bons tours quil à faicts, p eltre trop communs, ie vous en di vn qui vous fera poffible rire. C'eft d Confeiller dut Paflement de Paris, quel ayant difné aux faux-bourgs, Brufquet tenoit fa polte, $s^{\prime}$ addreff luy, le priant de luy prefter vn de

- cheuaux auec une houffe, pourle ce duire feulemér iufques au Palais,à c: fe qu'il fe plaignoitbien fort. Brufgi ayant perdu vin procés en la Cour, 1 baille le meilleur de fes cheuaux de fte : Le Confeiller eftant monté deffi ayant fa grande robe, Brufquet, fi fortir fon poltillon, lequel comine ca à corner \& à pofter, \& le cheual Confeiller aprés, fi bien quil fut ir poffible à ce Monfieur d'arrefter ff cheual qu'il ne furt à la prochaine $p$ fte : \& i ievous laiffe à penfer fi Brufqu rioit à fon retour, quand il le veid $\mathrm{r}$. tourner toutà pied, \& tout fangeu. Vne autrefois, fut-il adioufté, Bru quet fçachant'qu'vne grande Dame di uoit venir pour veoir $f a$ belle femm il luy fir à croire que celte Dame efto foulds 
rde, \& à la Dame que fa femme it fort dur. Et Dieu fçait le plaifir il prenoit de les veoir crier fi haut a d uy l'vne de l'autre. A l'autre fois, Iqu'vn fe plaignoit à Brufquet qu'il oit mal monté, luy ayant baillé vn ual, qui en courant la pofte s'eftoit npule col : \& que Brufquet s'en efrueillant, luy auoit dit que c'eftoit des bons cheuaux qui fut dans $\mathrm{Pa}$ , \& s'efbahiffoit de cela, n'ayant nais faict ce tour là en toute fa vie. is on adioufta, que ce qui faifoit uuer Brufquet plaifant, fans eftre nuyeux, c'eftoit qu'il ne repetoit iais vne mefme chofe, \& quion fe che bien toft d'vn bouffon, quand il. fçait qu'vne chanfon. Il eft vray, dit-on, que fi vous euffi ez veu Brufet , \& ouy parler, vous l'euffiez prins ur vn bouffon, mais en fes actions affaires, vous. l'euffiez prins pour homme bierraduifé : \& fur dit, qu' il falloit pas iuger de l'efprit d'vn hom- par quelques rencontres \& ioyeufe$z$, carvous trouuerez des perfonnes "om eitime folles, \& d'autres qu'on. S. 5 
TREN T E QIV A.TR IES M E eltime fages, que fi on prent garde qu'ils font $\&$ difent, on fe trouu bien loing de fon conte. Efcoutez dire vin de la Seree, ce que refpon un feruiteur à vne Dame qui le v loit accueillir : car cefte femme ayant demandé s'il eftoit fage ou \&- luy ayant dict que s'il eltoit rage feruiroirmieux : s'il eftoit fol, que $p$ le moins il luy donneroit du pa remps. Ce feruiteur luy va dire, dame, ie fuis fage quand il me pla \& fol quand ie veux, Et.Dieu- çai cefte fernme l'accueililit; \& fi elle ne. donna pas toutce qu'il demandoit $p$ fon falaire. Ce cyue pourrez cogn Itre, va dire vn de la Seree, par ce que vous conteray prefentement. Vn D de Milan, commença-il à dire, au à fa fuitte vn quon eftimoit bouff \& plaifant, parce qu'il mettoit en cript, \& faifoit regigtre de toutes ch fes qui fe faifoient en la Cour de $f$ Seigneur \& maifte, qu'il penfoit gnes d'eftre enregittrees en fon diat \& papier iournal. Arriua vin iourq le Duc allant vifiter ce papier, comn 
SIR E f. I if $\quad 204$

aifoit foument, fe troumabien auarit regiftré, \& en groffe lettre, daris ces moires, parce gú il alıoit baillé tren: mille du€ats à vn!More, qu'il ne gnoiffoit que de huict iours: , pour aller achepter des chenaux en Barrie Ce Duc, tont en cholere de man? afon bouffor, i pourquay il l'auois uché ez enreginaté fon papier ioury 1. Pourquay luy refpond fon bouff , pourautant cue tu as baillétrente llo ducats à vn Negre, que tui ne co oiffois point il n'y a tas long temps: ais, repliqua le Duc s'ilmiameine s cheuaux pour mon argent, quelle licauny-iefaicte, qui merite d'etre fe eniton liure? Il n'y airra rien de Até, luy refpond ce bouffon : car sjil uient, \& tameine des cheuaux pour n argent, loss ieffaceray ton nom monpapier, \& Y metray le fien. pus ceux de la Serec tronuerent cétemcontrefi a propos, quils ne pout jent juger quel humeir maifrifoit. contreroqlletir. Vn autre prenant la role, vadire quil auoit vir contéa ire de la refponfe d vin lourdaut s ati. S. 6 . 
TRE N T E-QV A TR I ES M E ilfera encores plus difficile de dif ner l'humeur, quile faifoit refpon à ce qu'on luy propofa. Ie mé trou vn iour, difoit-il, à la tabléd'vin gra Seigneur, où nours eftions bien emp chez, a rendie la raifon, pourquoy Efpagne on faifoit tes pains plus grat qứ en France ou Italie. Les vns difoi que c'eltoit à caufe que le grand pa fe tient plus frais que le petit, \& qu ne fe defleiche pas fi toft, eltant li pagne fort chaude. Les autres fouf noient que les. Elpagnol's auoient let fours plus grands que les autres pe ples, parce qu'ils difent que le pain meilleur cuit en vn grand four qu' vn petit le pain cuit en vm petit for ne cuifant pas efgallement, comine vn grand, \& les fours d'Elpagne efta grands, ce $n$ elt pas de merueilles $s^{\prime}$ font les pains grands, \& auff qu'a l'e forner on faict les pains. cornus. I tiers difoit, que tant plus le pain elto grand, tant plus, on le troutuoit fauó reux \& meilleur, ayant plus de vertu faculté affemblee, comme le vin eff plt fort \& meilleur en vne pippe qu'en v 
frard. Que le grand pain , adioultoitfoit meilleur que le petit, cela fe peut ouver de ce qu'il y auoit des féltes: ii fenommoient Magalartia, à caufe la grandeur des pains, dont le pain oit eftimé fur tous les autres, \& auffi in que celuy de la ville d'Erefus, fi as croyons au Poëte Archeltrate: ur lequel pain Mercure prenoit bien peine de defcendre du ciel, \& en vefaire prouifion pour les Difeux. Et ffi quand le pain eft perit, il fe brufle r la croufte, \& demeure mal cuit au dans, par liobltacle de la croufte hae : \& fila pafte croift \& leue mieux and il en y a beaucoup, que quand n'en y a gueres, comme on dit, que la ite fe leue mieux durant la pleine une quen autre temps. Lors vin loutlut qui feruoit à la table, nous voyant If grand debat, fe va mocquer de ous, de ce qu'eltions empefchez en fi eur de chofe, $\&$ nous va dire, que les. fpagnols faifoient leurs pains plus tands quailleurs, parce qu'ils y metyyent plus de pafte : Or deuinez, va ire celuy qui nous faifoit ce conte

$$
\text { Si } 7
$$


I R E N T E-Q.V A.T R I E S M E comme ce fotart l'à peu deuirer: $C e ̣$ rencontre en mit vin autre en mermo re a yn de la Seree, qu'il commenc ainfl. Yous fcauez, difoit-it, que di rant lestroubles plufieurs ont ved 1 ines, qui n'efperoient point de iama! la voir, \&r fi s'en fuffent bien paffez car celuy qui, fe met fur la mer, ou eft fol, ou il eft pautre, ou il a enúie d mourir: Et quand on leur demandoi parauants $s^{\prime} i l$ atroient veu la mer, jl fe coritentoient de dire que non, mai refpondoient quils auoient bien ver vn homme, qui difoitauoir yeu vn au tre homme, qui difoit laugir veuc Ceux-cy, dequoyie vous veux parles ayans veu lamer à leurs defpens,eltan de retour, entyerent vnjous en difpu te, pour fcauoir pourquoy les marinjers \&c ceux qui hantent la mer, portgien à leurs ceinctures des gaines de bois. Le vns difoiét que c'eftoit parceque le cui fe pourrit \& moifit fur leau, aufi bię que le fer fe charge de roiille, à caure de l'humidité excafrue \&nirreufe. Les autres affeuroient que le bois empef choit qu'équelque effort le couteaun 


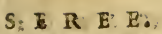

Ifaft celuy qui le portoit, ce que le ir ne poumoit faire. Ne fe poutuans acrder,ils s'aduifent d'en demáder l'adsà vn quils eftimoient rude \& grof-i r luy demandant, vien-ça, toy gui as. inté la mer auffi bien que nous, pour -; 10y eft-ce que les mariniers portent, s gaines de bois, ou de corne, gares de blomb? C'eft habile homme; ns y trouuer aucune difficulté, leurva fpondre, qu'ils portoient des gaines bois; poury mettre leurs couteaux. is, le voyant de fibon efprit, on luy manda comme il auoit peu trouuer mer. Il va refpondre en fon lourdois, outesfois parvn axiome general \& vetable) que ceux qui ne fçauent pas le nemin de $l_{2}$ mer, \& y veulentaller, 'ót qu’à fuicure la riuiere; \& qu'il auoit it ainfi. Eftans entrez ces gens de met i v ne autre queftion, de ce que les $\mathrm{ma}^{2}$ niers, \& ceux qui nauigent, deuenoiét untoft gris; que ceux qui dementét fur terre, il fut dit que la principale caueftoit l'humidicé de la mer, comme humidité faict que la femme ales cheerax plus grands quel'homme. Mais de cefte: 
TREN T E-QV A T R IES M E cefte queftion, on entra en vne autre pl difficile, à fçauoir pourquoy les cheue blanchiffoient le plus fouuent, auant barbe, Les vns attribuans cela à l'hum dité du cerueau, les autres aux vapeu: qui y montent, les aucuns à la quali des cheueux \& de la barbe, qui eft diue fe, le poil de la barbe eftant plus fort, plus roide que celuy des cheueux, dor il refifte mieux a la grifonneure. $\mathrm{Ne}$ pouuans refoudre, ils s'adreffent ence res à leur oracle, luy demandant, pout quoy les cheueux deuenoient plufto blancs que la barbe. Qui leur va refpor dre, c'eft à caufe que les cheueux for plus vieux de dix ou douze ans que barbe. Nous auions de couftume en no Serees, apres auoir ris, de difcourir d quelque chofe pour apprendre, \& ou y euft du profit \& de l'vtilité, eftant faire à vn fol de toufiours rire; auffi qqu' en y a qui font morts de trop rire : com me fit Philemon, qui fe print fi fort rire, voyant vn afne qui mangeoit de figues fur vne table, que la fin de fon ri fur accompagné à ceile de fa vie. Voyó donc quand c'elt que l'on peut eftre af 
uré de la mort, fi en riant les hommes eurent : Parquoy vn de la Seree comença à difcourir comment fe pounoit re, quel'vn foir fans iugement, qui laiffera à auoir le fens \& l'imaginain bonne, l'homme poutunt eftre fage vne chofe, qui fera fol en l'autre,vne cultéanimale pouuant eftre offenfee, mme le iugement, \& l'autre ne la fepas, comme la memoire, ne s'enfuint pas pourtant que ces vertus aniales ayent leurs places diftinctes au rueau, la memoire n'eftant point fur derriere de la telte, le fens commun $r$ le deuant, \& la ratiocination fur le ilieu, comme c'eft l'opinion des Ara$s$, toutes ces facultez refidans au cerau en mefme lieu. Que fi nousvons, adiouftoit-il, quelques vns qui cellenté vne faculté, ayát l'autre vie, cela procede de l'imbecillité d'vne s faculitez, car il fe peut faire que la emoire ferableffee, \& $z$ le iugment ne fera pas, vne faculté eltant plus foieque l'autre. Ne faut donc trouuer trange, difoit-il, fila memoire quife outiera foible, fera offenfee par quel-

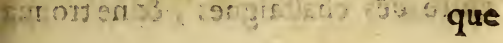


IRENTE-QVATR ES M E que maladie oul accident, le iugeme Gemeurant vigoureux, $8 x$ en fon entis

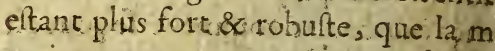
moire encores que toutes ces facult animales foient logees en mefme lie

Vne felle-tondue n'entendant rien ce difcours, va prier la compagnie luy dire quelle faculté eftoit offent en vnde fes voifins, lequel n'euf $i$. mais permis quion euft trempé le pot ge à fes ouuriers, lefquels trauailloiet fousterre, qu'ils ne fulfent montez haut, ouy bien à ceux qui eftoient $f_{t}$ fa maifon, car, difoit-il, on ne fçait-quá ceux quil foffoiet en terre doiuent mor ter mais quant à çeux qui trauaillen fur les maifons, ils tae peutuent faillir defcendre.Puis cefte felfe,tondue va ac ioufter que ce voifing eftoit bien mesle eftant aufit fol que fage, \& qu'il auo böne enuie de nous conter deux ou troi petites defes, faceties. La premiere eff que ce voi finatoit vin de fes voifins plu riche \& plus chiche que luy , lequel lus empruntoit tous les iours vne poêle per cee, pour faire cuire fes chaftaignes Vn iour ce maunais riche ayantàfait cuire des chaftaignes, \& ne troutuan 
TRENTEQVATR IESM I feurer s'il y auoit en lui de la folie or la mefchanceté. Puis va demander c humeur trauailloit vn chiquaneur difoit, apres qu'on luy auoit baille coup de bait on, i’auray centefcus d coup là, frappez encor pour voir quand on l'euft refrappé, bien, difoi ce font deux cens. Celuy qui luy bail. les baftonnades, le voulant encorect ger de bois, va dite à ce chiquaneur, $t$ voyla pour autre cent efcus, \& ce fe trois cens efcus que tu auras, ce qu' il vouluft endurer, \& luy vadire, $q u{ }^{\prime} j$ uoit peur qu'il ne funt pas affez ri pour payer le tout, \& qu'il n'é feroit fans cautiō.ll eft aifé à deuiner, replic quelqu'vn, quel humeur auoit faifi luy qui fe laifloit batre à credit. Mais vous prie me dire quel deffaut d'efp auoit celuy, a qui vn grand Seigne dit, apres qu'il euf faict vne grande uerence à deux eftages, mettez le bc net, mon amy, car eftant contrainct mettre fon bonnet, \& n'ayant qu' chapeau en fa main, illuy fouvient d uoir vin bonnet de nuict en fa poch qu'il tire, \& mettant for chapeau fur 
, prenant fon bonnet, le met fur $\mathrm{fa}$ \&z ainfi mit le bonnet, comme ce fieur luy auoit commandé, ce qu'il ouuoit faire auec fon chapeau, com1 luy ferrbloit. Mais, va dire vin de ree, qui fit dire au Sauoyart, vn de Roys allant en Italie, que fice fot de France, eut bien fceu conduire rtune, il eftoit homme pour deuenaittre d'hoftel de fon Duc? Eftoit-ce fon imagination ne conceuoit altplus efleuee grandeur, que celle de maiftre, ou fi cela procedoit pour oir iamais bougé de fon pays, ou in oit faute de iugement \& d'efprit? outez vn pareil conte des François fe trouuerent en vne ville liguee \& tinee, où il fut traicté lequel gottnement eftoit meilleur ou le Royal, tu peuple. Vn petit homme en fon g va loiier fur tous les gounernemés, y qui auoit le nom de Rebublique, fibien, que tout le peuple tout haut tire,nous voulons que ce petit homqui afi bien dit, foit la Republique: des plus endormis de la Seree, va nander quelle faculté éftoit bleffee à 
TRE N T E-Q-VATR I ESME on Chreftien, qui auoit vn peul'ef rroublé, lequel rédit vn fouflet à vn qu'il auoit emprunté, à bon conte luifluy difant, fi jet'ay baillé vin Het, ce n'elt pas felon ton Euangil mele rendre; non pas, luy repliqui fol felon le texte, mais c'eft bien felo: glofe. A ce qu'il auoit faict \& dit,va pliquer vn autre,ie ne le trouue fol c de bonne forte, mais fçachant qu'il \& confiderant fa petite tefte, \& $c 0 \mathrm{~cm}$ elle eft poinctue, il elt aifé à inger q n'a pas grande ceruelle, eftant de la uree de ceux qui nont pas. le cerue bien faict: Aginete \& Galien afferma quela petite tefte de l'homme, denc faute de iugement, $\& 5$ peu de ceriea \& mal fait,â cairfe, difent-ils, que quar les ventricules du cerueau font preffe les efprits ne peuuét faire leurs œuure \& actions, ne trouuans pas les condui libres \& ouverts, encores que Hipp crate fafle mention d'vne maniere d'h mes, lefquels pour fe rendre differens sulgaire, vouloyent anoir potir marqu de leur noblefle, \& de leur efprit, la te Ac poinctue, les matrones, quand l'er ri? 
t naiffoit, luy ferrans la telte auec taines bandes. Ie ne penfe pas, fut-il liqué, qu'on cognoiffeles fols par la e, encorés quon die, il a la tefte 1 faicte, mais pluftoft on les fepare fages,s'sils viennent à eftre en autho. : car tant plus le finge monte haut, l'auantage il monftre fon cul, \& tel a en reputation'd’eftre fage, eftát perine priuee, qui s'eft faict declarer fol, unt deuenu perfonne publique, comon ne cognoift pas ile vice d'vn vaifuquand il eft vuyde; mais ouy bien and on y verfe quelque liqueur, alors Is verrez par où il s'en va. La plus nde fageffe qui foit, adiourtoit-il, th de fe cognoiftre foy-mefonescar qui ot quil y ait tant de fols; , finon que it le monde penfeeitrefage, \& comdit monfieur Pybrac? Maint un pourroit par têps denenir fage,

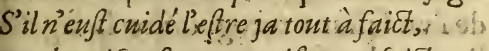
Quel artifan fut onc maiftre pranf aich wis" Du premier ionr de for apprentiffage? àce propos, difoit il s pres de cefte le il y a vn homme, leque! penfe eftre is fage quil n'elt, parce quid lett fou-

uent 
T RE N TE-QVATRIES ME uent appelle des gens de village pour appoincter. Vniour ayant fi grád' pre qu'il n'y pouuoit fournir,va dire, fe uant de rable, à ceux qui l'attendoie pleuft à Dieu n'arcoir iamais efté qu' fot \& vnafne,ie ferois en repos. Et quelqu'vn d'entr'eux luy va refpödre y a long-temps que vous auez ce que mandez, monfieur. Mais à voltre adu demanda vin autre, fi les fages font $p$ tenus aux fols, que les fols aux fages? penfe refpond vn de la Seree, que les ges apprennent plus des fols, que les fu des fages:les fages voyans la fauted fols, s'engardans d'y tomber, là ou fols ne s'eftudient point à imiter les 1 ges. Etrauff, difoit-il, qu'on n'appres des fages que les moyens pour deuen meilleur, mais on apprend des fols 1 raifons d’eftre plusaduifé: Que fi les fc feruent aux fages, adiouftoit $-i 1$, la fol de l'vn faifant recognoiftre la fageffer l'autre, les fagesne manqueront po: de fujet: \& ne feruiroit pas beaucoi queles fages feruiflent aux fols ; parr qu'on h'en peutgueres twouuer pour 1 , imiter \& apprendre d'eux. Qu'il n'y a 
grand nombre de fes fáges, on le rra apprédre de Plaute, en fon Guron, où il y a, facis quod pauci faciunt, les interpretes interpretent pauci, 7, fapientes. Que feruent les fols aux s, difoit-il encores, ou bien ceux les contrefont, ef coutez que feruit on à tout fon paìs; lequel s'en vint tuur où ceux de Tarante faifoient s Concions \& harágues publiques, illé comme vin fol, \& faifant l'iné, car autrement on ne l'euft pas efIl auoit fur fa teite vne couronvn réchant de terre, \& en fa main lanterne. La commune, qui s'amuuftoit à des badineries qu'à de bonchofes, luy faict la plus grande chemonde, vn fol en faifant cent, ant aprés luy comme aprés vn fol, fçauoir qu'il vouloit dire, \& quelameur l'auoit prins. Quand il vit da peuple à l'entour de luy, qui ernoit auec fa lanterne, \& qui luy oient des oreilles de veau fur fa , \& la corne au cul, il leur va dire, eu de fe fafcher, \& les tanfer:le ois qu'il n'y eut en toute celte ville Liu. iij. 
I R E N T E-QVA TR IES M E que moy quifut fol, mais ie voy en y a bien d'autres. Vous faictes b leur difoit-il, de vous joüer, gaudi rire, \& de permettre qu'on s'efba \& quion fe recree, durant qu'il v eft permis : fi vous eltes fages, ioui de voltre liberté, car fi vous faictes rrement, il faudre viure non à vo plaifir, mais au vouloir des autres comme il leur plaira. Les fages de rente, fes concitoyens, apprindrent lors de ce fol, qu'il falloit garder fo berté, n'eftant pas fi fol qu'il en por l'habit. Quelqu'vn prenant la pari va dire quili auoit veu en vne hifto vn autre bouffon; qui feruoit auf fon maifte de meneftrandier, lequel liura fon Seigneur d'vn fi grand pe queie ne fçay fi vn plus fage que euft peu faire ce qu'il fit. C'eft que chard Roy d'Angleterre ayant eu q relle outre mer contre le Duc d'Auf che, n'ofant paffer par l'Allemagne eftat cogneu, \& encores moins pa: France, pour le doubre qu'il auoit Philippes Augutte, fe defguifa. Mai Duc d'A uftriche, qui fçauoit fa ven 
$t$ arrelter \& enfermer dans vn chau, où il demeuta prifonnier, fans l'on fceut de long temps où il eftoit. ce Roy ayant nourry vn bouffon, luy feruoit auffi de meneftrel (car Roy auoit toufiours vne belle merandrie ) il penfa que ne voyant t fon feigneur, illuy en eftoit pis, ffi qu'il aimoit le Roy fon maiSçachant donc ce bouffon de meandier, que fon Roy eftoit party tre mer, mais nul ne fçachant en païs il eftoit arriué, il s'en va d'Anerre, \& cercha maintes contrees, fçauoir s'il en pourroit ouyr nous. Si aduint, aprés plufieurs iours $z$, qu'il arriua d'auenture en vne alfez prés du chaftel où fon maie Roy Richard eftoit, \& demáda à lofte à qui eftoit ce chaftel, \& l'holte lit qu'il eftoit au Duc d'Aufriche. demanda s'ily auoit là dedans des nniers : car toufours s'en enqueecrettement où qu'il allät. Et fon luy dit, qu'il y auoit vn prifon, mais qu'il ne fçauoit qui il eltoit, $t$ bien vna qu quon l'auoit mis la 
TRENTE-QVATR I ESM dedans. Quand ce menefrandier en dit cecy, il fit rant qu'il s'accointa cuns de ceux du chaltel (comme m frandiers s'accointent facilement) il ne peut voir le Roy, ne fçuoir f ftoit-il Lors il fe va aduifer d'vne fequ'vn plus aduifé que luy n’euf mais fceu inuenter. C'eft qu'il vin iour à l'endroit d'vne feneftre où e le Roy Richard prifonnier, \& comn ça à chanter vne chanfon en Franç que le Roy Richard \& luy auoient fois faicte enfemble. Quand le. d'Angleterre entendit la chanfon 'cogneut que c'eltoit fon menef qui auoit nom Blondel. Et quan boufion de meneftrandicr eut di moitié de la chanfon, le Roy Rich fe prità dire l'autre moitié, \&z l'ach Er ainfi Blondel fceut que ceftoi Roy fon maiftre. Si s'en retourn Anglecerre, \& aux Barons du païs ta lauencure. Ie votis prie, difoit liny qui anoit faict ce conte, fi le plus ge homme du monde eut fceu plus f: pour fon maittre, \& fi ce bouffon meneitrier ne profita pas plus au F 
chard fon maifre, que les plus fages fa Cour ? Poffible, replicjua quelvn, qu'on eftimoit ceftuy meneftrel iffon, \& l'eftoit pour auoit trop d'ef$t$ : car nous difons, il a tant d'eforit il en eft tout fol, les plus grands etts eftans plus fubiects à denenir fols, les lourdaux, groffiers, \& rudes: a fe que tant d'efprits concurrans enable, \& à la foule, \& l'vin voulant tir auant l'autre, s'empeichent les les autres:comme quand vne grofle upe veut fortir d'vne porte à la hafte, vns eimpefchent les auties de fortir, fe trouuent les perfonnes en celte frefi agitees, qu'elles ne penuent le er, comme ces iours paffez ie vy vn rdaut qui me fit rire, encores que ie neifle pas grand' enuie, eltant aufi flé que luy, lequel difoit tout haut fortant, l'ay bien deu de l'argent, nme chacun fcait, fi ne fus-ie iamais reffé que ie fuis. Et de faict, celuy peut auoitbon efprit, de quile corps Pefprit font agitez deçà \& $\&$ delà : car at plus vn homme elt fage, d'autant a de mouuement de le lprit \& du 
TRENTE-QVATRIESME corps tranquile \& arrelté: \& d'aut qu'il fera fol, tant plus il fera en cor nuelle agitation. De là vient (adi ftoit-il) qu'on affeure que les lieux regions agitees du vent, \& des ea font plus luietes à produire des $f$ que le pays qui eft coy \& tranquille fans grande perturbation d'air, d'ea $\&$ de vent : auffi quand on veut $d$ qu'vn homme n'eft gueres fage, \&z ? $c^{3}$ eft vn efuenté, on dit, il feroit bo joiier de la cheurie, car il a bien vent. Et auffi que ceux qui ont for vent en la tefte, l'ont legere : $\&$ ditque ceux-cy, ils deuoient mettre plomb en leur telte, mais il falloit ftoft dire deffus: parce que nous tro uons en Hyppocrate vn fol, qui difo n'auoir point de telte, auquel pour mede on appliqua du blomb fur la teft à fin qu'il fentit en auoir vne. Ma demanda vn autre, ne fçauroy ie c gnoiftre par les actions d'vn fol, s'il fol de trop d'efprit, ou de peu, comm font les lourdaux, les idiots, \& gro fiers, ayans les ef prits hebetez, moull \& rebouchez. On luy refpond 2 qu 
$x$ qui font fols de trop d'e fprit, font alus ioyeux, plus faceticux que les: ormis \& fongeards, qui le font par te d'efprit. Or à fin qu'on en co ult la verité, on va conter des fo, \& des renconties, $\&$ des vins \&z autres. La premiere fut d'vu ba- lequel fans eitre fariné fit celte ftion a fon maiftre qui eltoirgrand gneur , Vien-ça, Monfieur, à vne tu dy, c'elt la verité, à l'autre fois $y, c$ elt la raifon : apprens moy quelifferéce il y a entre verité \& raifon. maifre luy refpond, que c'eftoit t-vn, de dire cela eft raifonnable, ou eft veritable, \& qu'il n'y auoir nul ifference. Lors ce fol va repliquer à maiftre, fi vous aujez voltre nez à in cul,encore que ce fuit la verité, fe-ce doncla raifon:Si c'eft la verité \& ifon, demanda-il encores à fon mai, \& qu' euffiez voltre nez à mon cul, aimeriez vo' mieux, ou que mon cul couppé,ou voftre nez ? Ce Seigneur I voulant depefcher, luy va dire, ${ }^{\prime}$ a ${ }^{2}$ rois mieux cét fois que ce fut ton cul fut couppé. Par-Dien, va lors dire T 4 
$T R E N T E-Q V A T R I E S M E$ cebadin âfon maifre, fi auriez-v de belles lunettes. La fecond folie, on mit en auant, parloit d'vn fol : quel troumant deux ou trois vieilla en vn cimitiere, qui le vouloient refter pour rire, \& luy en faire cont le retenants par force, leur va di qu'ils luy faifoient tort, le prenant leur aduantage, eftans prés de le maifons, \& furleurs fumiers, \& qu deuoient pluftof demander des nc aelles de l'autre monde, que de s' mayer de celles de ce temps. Le troif me compte, fut d'vn bedeau de nof Vniuerfité, lequel ayant leu l'Edict paix, ou il eftoit dit, que tous eftra gers, tant d'vne part que d'autre, fero licentiez, il s'en vint aux Dosteurs, le difant, Meffieurs, regardez de faire bo ne compofition des licences, nous ga gnerons ce que nous voudrons, car Roy veut que tous eftrangers, tant d' ne religion que d'autre, foient licétie Ce bedeau apprefta à rire aux Docteu \& aux Efcolliers, à qui on en fit vne çon. Ces contes acheuez, il fut dit qu c'eltoient des rencontres de ccux qu 
at fols pour auoir trop d'efprit. Paroy on fe met 'à compter des folies \& uffonneries des ruitiques \& rurawx, on eftime lourdaux accomparez à $\mathrm{ax}$ des villes, n'eftant pas eftrange e ceux des champs foient plus idiots e ceux des villes : parce quijls ne yent pas tant qu'eux, qui pour celte fon fontappellez aftuti des Latins, id , vibani, fuiuant le Grec, comme i'ay uué par efrrit. Toutesfois qu'il fe uue bien des gens de village qui font fif fins que ceux des villes, voire qui affinent, comme on raconta d'vn tard des champs, qui s'en alla chez vn ganifte, \& voyant que ce ioüeur d'ores auoit vne grande foutane, luy va re, ie voy bien que vous auez efté male, \& que lon vous à baillé l'on ction, fi voy bien que vous eftes organifte, voftre cafaquin elt faict à tuyaux orgues, ayant les foufflers bien prés. vous aideray, \& feray à l'Eglife ce le ie pourray aux orgues, ie luis de ftat. Celt organifte penfant qu'il fult meltier, luy faict bonne chere deux trois iours. Orvn jour qu'il y auoit $T$ s 
I R E N T E-QVA TRIES ME fefte à bafton, le maiftre organifte prefente leclauier: Ce fotard luy va: re, qu’à la veritéil eftoit bien de l'eft. mais que c'eltoit à fouffler. L'organi fe voyant affiné, luy prefente fon fot flet, \& fon gros tuyau, luy difant for flez-là, puis qu’eftes du meftier, \&z cer dant ie ioiieray des doigts. Quelqu' de la Seree, en fe riant va dire: faut auff eftre deux aux orgues, quand l'c ganifte à foufflé, ne fcauroit-il al joüer des doigts? Il me femble(difoitque tout iroit mieux. Car iay veu bon organifte, lequel eftant reprins Chanoines pour ne fonner rien qui va le,difoit que le fouffleur qu'on luy auc baillé en eftoit caufe : car, leur difoitquand ie cuide fonner \& dire $\mathrm{Ky}$ eleyfon, le fouffleur fouffle $S$ anctus par derriere:donnez-moy done vn bon for fleur. Il fut aufi en cefte Seree ame en ieu vn villageois, qu'on ausit pri pour trauailler aux ardins, \& fut con que ce iournalier enragé de rien fair eftoit toufiours trouné par le maiftre l'auoit loiie, où il fe repofoit, lequel fe peat tenir de luy dire, quilil ne tr: uaillo 
illoit point, \& qu'il ne faifoit rien? rs ce iournalier luy va refpódre (fans bouger d'où il eftoit couché de fon ig) Qui a affaire à gés de bien il fe ree.Le lendemain on le trouua en dorint, \& fon maiftre luy dit, \& bien vous tmez? eft-ce ainfi que ma befongue fe ct: Pardonnez moy, luy refpond ce Irnalier, ie ne puis iamais eftre oiffi, fant que ie face toufiours quelque ofe. Le Seigneur pourtant ne laiffoit rendre ce iournalier à fa befongne; ce qu'il luy appreftoit à rire, comme it encores cefte fois : \& voicy comnt. Il faut entendre qu'sl n'y a pas p long temps qu'on ne mangeoit int de beurre le Carefme : mais la erté des huiles occafiohna l'Eglife de inettre d'en manger,en baillant cinq niers pour les pauures, \& autres œu. es pitoyables. Or ce Monficur , aat ce chaud oururier à fa befongne, 8 ayant faict bailler du betmre vn ar de Carefme, il void qu'il n'en ange point, \& qua'il faict confcien d'en vfer, il huy va dire, mon amy, il faut que bailler vo petit tlanc \&े T 6 
T R E T E-QV A TR I ES M E l'Eglife, \& puis vous pourrez man dubeurre fans pecher, \& fans fcrupo tout le long du Carefme, tant que vo voudrez. Ce iournalier bien aife va mander à fon maiftre, Monfieur fo niront-ils pas de beurre auff? Si maiftre fe print à tire vous n'en dou point : puis que vous en riez, pourt toir feulement ouy dire. Ce maif qui eftoit de nos Serees, nous con qu'vn iour il demáda à vn fien meftay comme il fe portoit depuis deux trois iours que fa femme eftoit mor lequelluy refpondit, quard ie reuins l'enterretnen de ma fernme, mieffuy les yeux , \& trauaillant à plorer, ch. cun me difoit, compere, ne te foucie fçay bien ton faict, ie te donneray bi vne autre femme. Helas! me difo il, on ne me difoit point ainfi, qua i'eu perdu l'vne de mes vafches. Ce m itayer, acheua de dire celuy qui auoit commencé le conte, trouna bi pluftolt vne femme que non pas vne che : encores qu'il ne vouluft iama payer l'enterrement de fa femme: quád le Cuté \& le Marguiller luy dem doie 
ient de l'argent pour fa fepulture, il ur difoit. Et comment voulez-vous: oir le corps \& les biens? Et quand le uréluy difoit, Vous auiez vne tant . mme de bien, vous la deuez enfepulirer honorablement:ie n'en crois rien, fpondit il, vne femme de bien ne laifiamais fon mary. Par là vous poutuez ger quil eftoit auare ; fi bien que and on le vouluft marier, le pere de fille qu'on luy vouloit bailler en maage, ayant grand' enuie de s'en defai$\therefore$, n'eftant beurre net, prefche tant ce tard; qu'il luy faict accroire que fa He, auec qui il le vouloit marier,auoit us mefine couverture \& l'vne bien. rés de l'autre, deux bons moutlins, l'vn l'eau, \& l'autre à vent : ce que le maié trouua veritable dés la premiere uict des nopces. Ce marié ay ant vn viin nom, \& le voulant changer pour l'anour de fa femme

Neprens point un nom eftranger, Pren Iean, c'eft un nom de baptefme, Dit Ja fermme, \& fans danger Le te baptiferay moy-mefme.

I 7 


\section{TRE N T E-QV ATRIES M E}

On adioufta à ces contes celuy $d^{\prime} i$ potier, à qui fon confelfeur deman quel peché il auoit faict, auquel le p rier auoit refpondu, que le plus gras peché qu'il eult iamais faict, eltoit cinq chopines. Le Curé qui penfo que celtuy-cy fe moqualt, luy don en penitence de porter iufques à $\mathrm{Pa}$ que vingt \& cinq febues à chacun fes fouliers. En ce temps là reuenat fe confeffer, fon Curé luy demand s'il auoit accomply fa penitence, \& refpond veritablement qu'ouy. Le cor feffeur en riant luy va dire: tu donc bien enduré. Le penitent luy re pond, non-ay pas beaucoup, car ielc auois faict cuire. On conta qu'vn pla deur auoit vn grand $\&$ gros procés, qu'on luy enfeigna vn ieune Aduocal pour deffendre fa caule, duquel il $n$ voulut point, encores qu'on luy eur dit qu'il auoit le plus grand bruit del ville, le marché \& les cloches:difan que fon procés efioit plus vieux qu ce ieune Aduocat \& qu'il n'en fçauroi rien fçauoir, celt A'duocat n'eftant pa aé quand fon procés fut commencé 
rquoy il fallut luy bailler vin Aduocat ffi vieux que fon proces:penfant qu'eins tous deux d'vn mefme temps, fon faire s'en porteroit mieux, \& n'en voutiamais faire autre chole, quelques monftrances que lon luy en fift, ce aideur ayant plus de befoin de hellere pour purger fon cerueau, que de ifons \& paroles. On n'a fait des con$s$, va dire un de la Seree, que des petits ipanons ie vous en feray vn d'vn Seieur, qui n'auoit pas plus d'efprit qu'il y en falloit:lequel eftát en vil coche, qu'on ferroir les cheuaux, il difoit,alns, allons. Et quand fes gensluy diient, fi faut-il, Monfieur, que les cheaux foyent ferrez : Et point, point, refondit-il, allons toufiours deuant, les neuaux viendront apres. Celtuy Moneur, ayant.vn feruiteur qui s'aidoit ien des dents, mais non pas des iambes, a dire ces quatre vers:

$V$ alet qui vas $f i$ viffernent

Dela dent, alors que tu masche,

Et qui es du pied par trop la che. Mafshe du pied, va de la dent. uelque autre prenant la parole com: mença 


\section{T R E N T E- Q Ý A T R I ES M E}

mença à nous conter la rencontre d' bouffon. Nous fçauns tous, difoit que le Marquis de Galt eftoit de là Monts, Lieutenát de l'Empereur Cha les cinquiefme, en fon armee de Ser zole. Or ce Marquis en la bataille Serizole, penfant auoir la victoire François, aufquels commandoit $f_{t}$ Monfieur d'Anguyan, dépefcha vin fie bouffon, luy baillant armes \& cheua \& outre luy promettát deux cens $\mathrm{e} f \mathrm{cu}$ sil portoit la premiere nouuelle de victoire, qu'il penfoit auoir gaignee, Madame la Marquife fa femme ?apri queles Imperiaux eurent crié, victo re, victoire. Mais arriuant tout le cor traire, il arrine auffi que ce bouffo fut prins auant qu'eftre gueres loin Celuy qui l'auoit faict on prifonnie le voyant fi bien armé \& monté, per foit eftre riche: \& voulant tirer de lu quelque bonne rançon, fe troulua bie loing de fon conte :car l'ayant vn lon temps traicté, en fin il cognut que c'e Atoit vn zani de Iean Corneto, leque fuiuoit quelque Prince du camp Im perial. Parquoy il lefic armer \& mon 
I tout ainfi comme il eftoit quand il uoit prins, \& puis le prefenta en it equipage à Monfieur d'Anguyan, y demandant s'il vouloit acheter fon ifonnier. Mófieur le Prince, le voyant bien en conche, \& fi eft, luy demanqui il eftoit, d'où, \& de quelle mai$\mathrm{n}$, \& là où il alloit quand on le fit ifonnier. Ce braue caualier luy va nter, que le Marquis fon maiftre, uoit ainfi monté \& accoufté, \& oue luy auoit promis deux cens efcus 1 portoit à fa femme les premieres suuelles de fa victoire. Mais qu'e?t menu le Marquis, luy demanda Moneur le Prince : Ie croy, luy refpond ce uffon, que le Marquis a voululuyefme gaigner fon argent, \& qu'ily it alléle premier \& $x$ auant moy. Il ny ut feigneur au cainp des François, aiăt ii cefte refponfe, qui n'euft voulu auoir zany, à la condition de payer fa ranon, s'il fe trouuoit par les Loix militaiis quelle rançon doiuent páier les fols tans prins en guerre? car il s'y en troue auffi bien quailleurs. Ce n'eft pas de herueille, va repliquer vn autie de la Seree, 
TRENTE-QVATR IESME Seree, files gráds feigneurs ont des fo $\&$ bouffons auec eux guiles accomp gnent, car, difoit-il, nous troumons qu les Romains, quiont efté eltimez d plus fages, en auoient mefmes en le plus grand tromphe:eltant leur couft me d'auoir vn fol ou vn plaifant en le char de triomphe, le iour deleur en tree, tant pour amufer le peuple, qu pour empefcher que celuy qui trion phoit ne s'enorguillit par trop, luy bai lant pour compagnon de fon triomph vn fol, ou vn efflaue. Et Pline a uff di que ce badin feruoit de deffédre le cha! rot de triomphe, difant au peuple qu' fe contentaft de le regarder, \&z que ce la gardoit les gens de parler, quand or voyoit au' doz de celuy qui eftoit en grád honneur, vn efclaue, ou vn faquin ou vn fol, \& fi contentoit fortune, vray bourrelle, \& ennemie d'honneur \& $\mathrm{d}_{1}$ gloire. Quelqu'vn reprenant ce qu'or auoit dit cy deffus, qu'ils s'eftoient trou. uéaucuns qui vouloiét payer la rançor de ce zany, va dire, encores fçay ie bon gréà ces feigneurs, qui ne veulent auoir du paffe-temps qu'il ne leur cou. 3,2

fte 
au contraire de plulicurs, qui riront nt que vous voudrez, pourueu que ce foit a leurs defpés. Et vrayement,adufa-il, les Romains n'en faifoient pas fi, car nous troumons qu'ils bailloient us les ans à Rofcius trente mille efcus l'efpargne, pour faire feulement dix is l'an le badin à Rome. Auffe eftoit-il excellent par deffus tous les autres uëurs de Comedies, que fi fur le theafe difoit quelque chofe froide, tout peuple crioit:zon agit Rofcius: eftás ces efferes zanins \& Panthaleós en fi grăd edit enuers le peuple Romain, qu'il franchiffoit ceux qui auoyent bien diné. Et ces badineries qu'on failoit $x$ Comedies, ont fait quele Tragic a point eu tant de credit quele Coic : combien que i'eftime plus de cas faire pleurer, que de faire rire, veu ie le rire eft le propre del'homme. Si ouuons nous, repliqua vn autre, quiven uppius Tragic, monftra bien parfon itaphe, quil auoit efté auffi bien reu du peuple que ceux qui faifoyent re. Voicy fon Epitaphe: Flebunt amici, er bene noti,morte mea: 


\section{TRE I I-QV A T R IE S M E}

Nam populus ornis me vino lachrymat eft.

Puis il fut adioulté, comme les ancier auoyent eu en grande recommend tion les ieux comiques, les farces, \& badineries, \& folies: pour lefquels ieu ils auoiêt bafty plufieurs fuperbes The tres, \& ingenieufes caues: de telle for qu'on ne leur pouuoit bailler plus grá contétement, que de leur exhiber que ques ieux fur les theatres. Et y en auo de fi grád appareil, qu'ils ne fe cele broient que de cent ans en cent ans, pour cela s'appelloyent ieux feculaire qui eft le temps d'vn fiecle. A cefte cau fe, Herodote dit, que les heraux qui le publioyent, difoient, venez veoir de ieux non iamais veuz, \& que iamais neverra plus, n'eftans pás de l'opinio de Platon, qui iúgea lesplaifans, com ques \& tragiques deuoir eftre deiette de fa Republique, comme maniere di gent inutile \& pernicieufe. Croirie: vousbien, va dire va de la Seree, qu ces comedies \&ztragedies ont efté ioiiee. de telle ardeur $\&$ affection, que Séne que ditqu'vn Vibius Gallus deuint, paı 


\section{$S$ E R E E :}

aniere de dire, fol \& infenfé de gayeté e cour , \& de fon confentement. Car nitant par trop les fols, \& les contreifant à fon poffible, cefte imitation changea en nature, \& fut fol à bon cient, auffi bien qu'il s'eft trouué des iieurs de tragedies, lefquels pour loir ioiiévne perfonne furieufe, come vn Hercule, vn Orefte, ou Aiax, ont 1 telle affection à les bien reprefenter, a'eux melmes au milieu du ieu deuejient veritablemér enragez \& furieux, faifoient actes de tranfportez \& d'engez, tels que furent ceux qu'ils reprentoyent. Ce qui eft confirmé, fi on en ubte, par Lucian. Ie voudrois metțre, dire vn autre, fur ces $T$ heatres, où le us foument comparoiffent les fols \& rrieux, les amoureux auff, l'amour tant vne efpece de folie, qui fe guetpar la diete, que fi l'amoureux pour adurer la faim, ne fe guerit point, le mps le pourra guerir, pour le moins il loucira fa folie, que fil'vn ne l'autre luy profite, qu'il fe pende, car il fera é amoureux s'il n'en guerit. Quelque effer Panthaleon voulant mettre fur 
T R E N T E-QVA T R I E-S M E ce Theatre les persónes qui penlent $\mathrm{p}$ fois veoir deuant leur yeux leur prop femblance, ou quelque autre tigure, réuoyé,parce qu'on luy dit que c'elto pluttolt maladie que folie, qui vient la veüe, qu'ils ont fi debile qu'elle peut penetrer guetes loing, fibien qt les rais des yeux eltans repouffez \& re uoyez par le plus prochain aïr, fót, veo cesimages:\& refemblances, encore q Mercuriali die, cela venir plutoof du v ce de l'imagination qui eft corrópue, quelle fait qu'à aucuns apparoiffent de humeurs deuant les yeux, qui les fai imaginer veoir quelque idole ou ftatu deuant les yeux, comme il aduient à gé yures, aux petis enfans, aux malades, \& ceux qui en furfaut s'efueillent. Mai d'où vient, demanda vn de la Seree qu'on a veu des fols \& y diots, eft ans e: fanté, de peu d'efprit, tombez malades parler fagement, doctement, \& elegam ment: Si bien que l'Anactife dit anoi veu vn lourdaut, \& groffier, feruiteu d'vn grăd Seigneur, deutenu moniaque difcourant fi bien de la forme de yotruerner vn Royaume, on Republique. 


$$
S \text { E R E E. }
$$

ue chacun le venoit veoir \&z ouir, \& in mailtre melmes ne partoit gueres auprés deluy, fouhaitant qu'il fult ufiours malade, ne voulant payer le ledecin, qui de fage \& fçauant qu'il toit, l'auoit fait deueuir vn fot, \& lourùt comme au parauaut?ayant efté mis confeil de la ville, s'il n'eftoit pas eilleur pour toute la cótree de le lâifren cefte maladie, que de l'en ofter. fut refpondu par l'Anacrife mefme, te cela, pouuoit venir du temperamét cerueau, qui eft changé par la mala:l'homme prudét \&z fçauant demeunt fans efprit, perdant \& oubliant ce il çauoit:le lourdaut \& ignorant,acerant plus de fçauoir \& entendemét il n'aucit eu parauant, car les vns en té ne pouuans parler, eftans mala$s$, viennent eloquens, à caufe de cer$n$ point de chaleur où ils font parues,à raifon de leur maladie, qui à mué temperament de leur cerueau, parant froid, dont procedent chofes cóires.Les autres, retpondoyent-its, par e naturelle intemperature, eftans fretiques, difent chofes merueilleufes,

tant 
IRENTEQVATRIESM E tant pallees qu'à venir. Les autres $p$ vne chaleur extreme $\&$ démefuree cerueau, cognoillent les chofes à veni ou par vne inegalité de la chaleur nat relle, ou par fon temperament, ce qt Hippocrate attribue a la diuinité, app lant les chofes merueilleufes, diunite confelianty auoit en ces maladies qu que chofe diuine, puis qu'il n'en po moit rendre raifon. Mais quelle raifo repliqua quelqu'vn, euft-il peu donn qu'vn frenetic peuf parler Latin, far l'auoir apprins, quelques raifons qu'e amene l'Anacrife de la confonance qu y a de la langue Latine auecl'ame ra fonnable; Meffieurs Bodin \& Fren auffi, adioufta-il, euffent dit que ce fri netique, lequel parloit Latin, fans $l^{\text {: }}$ uoir ia mais apprins, eftoit enforcel ou poffedé du diable \& malin ef prit, ci me fit vne fois ce Frenel, lequel voyar vn ieune garçon ignorant, qui, nean moins parloir Grec, il ingea que l'e fpr: malin le faifoit parler celangage, fan s'amufer aux raifons de l'Efpagnol, plu fieurs tenans qu'l y a des demons q parlent par le ventre, comme le diabl 
a Raillerie, entrăs dans le corps, que Grecs ont appellez Pythows, engajtries; on Euriclees, ce dit Plutarque. Et roy, difoit-il, que quand l'Anacrife t rédre raifon, comme il fe peut faiqu'vn frentique parle Latin fans oir apprins, qu'il le dit expreffémét, 'qu'ón luy prefte l'oreille auec plus tention:car fi quelqu'vn veut prouque le Soleil eft clair \& luyfant , \& il nous efchauffe, il oftera incontite defir de l'efcouter, ne difant rien louueau : mais s'il entre en lice pour ntenir que c’elt Aftre eft obfcur \& d,Dieu fçait comme il refueillera \& rera à fơy les efprits, \& les rendrá attifs à l'ouir. Mais doù vient cela; deda quelqu'vn, que les fols preuoiét ux les chofes a venir que les plus faSi nous voulons croire à Ariftote, fut-il refpondu, c'elt par ce que leur noire \& leur efprit n'elt gueres océdes chofes prefentes. Vne Feffeduë voyant qu'on s'endormoit en difcours, va dire à ceux de la Seree, ous veux faire vin conte d'vn feruide gentil-homme, qui de fagen'eLiu.iij. 
T REN T EOQVA T R IES M E Itoit point deuenu fol, ny dé fçaua ignorant, mais Dieul'ayant creé, \& $\mathrm{n}$ au monde, l'auoit lailfé là. Or il arri vn iour que fon maitre fe fachár à lu l'appella Roy des Sybilots, \& des fo ce feruiteur và refpödre à fon maiftre, luy va dire, pleuft à Dieu que ie le fuft car i'efpererois commander à tel qu plus de puiffance que moy: mais ie vo bien, difoit ce feruiteur, que ie ne fer. iamais grand Seigneur, les places fo: prinfes. Son maiftre fe prenant à rir luy commanda d'aller achepter destr pes chez vn boucher nommé: Daui puis quill le vint retrouner au fermó, où il alloit. Ce qu'il fit : \& fur le poi quece badin de feruiteur entroit où difoit le fermon, pour trouner fon ma ftre, le prefcheur va dire: qu'eft-ce qu dit Dauid? Ce feruiteur va refpondr que les tripes font vendues. Cepred cateur s'en fcandalizant, va dire que poiffon commençoit toufioursà fent par la tefte:voulant dire, que la fauted feruiteur redondoit fur le maiftre. $\mathrm{Ma}$ le peuple congnoiffant le maiftre \& feruiteur, ne s'en fit que rire : aprés qu 


$$
\text { S E R E E. }
$$

maifte leur eut conté ce qui auoit ct dire cela à fon homme. Il y a bien is, adiouftoit-il, car bealucoup de ceux i eftoiét à cefte predicatiŏ affeurerét e ce feruiteur eftoit d'vne famille \& ne race, dont tous efto ient honeftent fols \& ioyeux : \& outre, que touts ix qui naifoient en la maifon, où feruiteur eftoit né, encores quail ne fent de la lignee, venoient au monfols, \& fi l'eftoient toute leur vie: ement que les grands Seigneurs fe urniffoient de fols en celte maifon, par ce moy en elle eitoit de grand reau à fon maiftre. Ie vous diray vn autour, ad oufta-il encores, que fit ce fme feruiteur à fon maiftre : lequel ant a la table d'vn grand Seigneur, figne à fon valet de luy apporter à re : ce qu'il executa, mettant defbs fon manteau le verre \& le vin, \& baillant à boire à cachettes. Tous fe nás a rire, le maittre fe fafcha:le fereur lors lay ya dire, vous mauez dendé a boire par figne, ie penfois que voutuffiez point quautre que vous ift, \& parce vous ay-ie porté du vin.

$$
\text { V } 2
$$




\section{TRENTE- QV A T R IES ME}

fecrettement. Vn autre prenant la $p$ role va dire à ceux de la Seree, penf vous que les fols foient fi miferabl qu'on les eftime? I'ay vn homme, foit-il, qui a efté fol honnertemer comme ceux de cefte maifon, qui $m$ affeuré auoir efté plus ioyeux durant remps de fa folie, que quandil a e? guery : voulant auoir action cont ceux qui auoient retourné fon ce ueau en fes gonds, luy ayans ofté ioye que luy apportoit fa folie : au bien que Trafibule, lequel ayant ef non feulement infenfé, mais furieu eftant reuenu à luy, difoit qu'il n'auo iamais vefcu plusayfe, plus conten ne plus ioyeux, que durant fa foli Ie croirois bien pluftoft cela, repliqu quelqu'vn, que de croire qu've ma fon peuft rendre ceux qui y naiffer fols : combien que Laërce ayt êfcri qu'il y auoit vne maifon à Athene en laquelle tous ceux qui y naiffoier eftoient fols : à caufe dequoy le Senat fit abatre, n'aimant pas plus les fols qu , Seneque, qui efcrit à Lucilius: $T$ „ fçais bien, que Harpąte, fole de $m$ femme 
femme, eft demeuree en ma maifon, comme vne charge hereditaire : car quant à moy, dit Seneque, ie fuis ennemy mortel de tels monftres, que fi ie veux prendre mon paffe-temps de quelque fol, i ne le vay prédre gueres loing, ie me mocque \& me ris de moy iefme. Sur la fin de celte Seree, n'ayant int faute de fujet, il fut mis en auant, l'inconftance \& legereté procedoient vne trop grande chaleur, comme auins affeurent, difant que la chaleur hemente lefleure les figures qui font a cerueau, \& les faict boiiillir, à raifon equoy fe prefentent à l'ame plufieurs nages des chofes qui l'appellét, \& l'initent à lá contemplation d'icelles: \& ame pour iouiir de toutes, laire les nes, \& prend les autres : aduenant auement de la froideur, laquelle rend homme ferme \& ftable en vne opinion, arce qu'elle retient les figures refferees, de maniere que la froideur ne perset de les efleuer, \& par ainfinefe retefentent à l'homme autres images uil'appellent. Puis aprés fut demandé ourquoy les hommes petits de corps 
TRENTE QVATRIESME eftoient volontiers plus fages $8 \mathrm{~m}$ mie aduifez que les grands : le prouuant Homere, qui faict Vliffe tres-pruder $\&$ petit de tacure, \& au contrai Aiax fol, \& temeraire, \& de grand' ture. Les yns, fuiuant les Philofoph naturels, difoient que l'ame raifonn ble amaffee en vn, \&ren brief, a plus force pour ounrer, allegans ce dit fo celebre, $V_{i r}{ }^{9}$ vnita fortior eft feif $\int a$ dipper là où au contraire, l'ame eftant en corps large \& f pacieux, elle n'a for fufficante pour le mouuoir. Mais la pl grand' part de la Seree, fe contenta fo de la raifon qu'en donne l'Efpagnol fon Anacrife, quand il dit, que cela viet de ce yue les grands hommes \& larg outbeaucoup d'humidité, laquelle d late grandement leur chair, qui et caufe de leur grádeur,aduenant au cor traire aux petits,car par la grande ficc té, ils n'ont peu fe dilater, ni engreffe par la chaleur naturelle, à raifon dequo ils demeurent petits. Or eft-il, dit l'Ana crife,qu'il n'y a pas vne qualité qui nui fe tát aux ouures de l'ame \& de l'elpri que fait la gräde humidité, \& qui rend 


\section{S E R E E.}

entendement fi vigoureux que faict la ecité. A la verité, va dire vn Drolle, ie oy quill foit ainfi : mais nous y auons al pourueu pour ce foir, car nous nous mmes largement bumectez du bon nde noftre holte:mais au ant que cefte umidité nous ofte du tout l'efprit, ie us d'aduis de nous en aller en nos maions tout droict, fi nous poutuons.

T RENTE-CINQVIES ME S E R E E.

Dela diuerfaté des langues, of du langage.

We. Vrant vne annce des troubles ( ie ne fçay laquelle, tant il y en a eu) ous auions vn prefcheur, lequel vint in iour à parler de la langue Syriaque, ù pourtant il n'entendoit gueres, \& refchoit qu'en icelle auoit efté efcrit le gouneau Teftament premieremét:d'aucant difoit-il, que les enfans d'Ifraèl, et ans captifs en Babylonne, oublierent leur langue naturelle Hebraique, \& ap- 
TRENTE-C INQY IES ME prindrent la Syriaque, qui eftoit la turelle de Babylonne, \& de faicten res aniourd'huy il fe trouue des No ueaux Teltamens imprimez en langa Syrien. La plus part de la Seree aya eltéà ce Sermon, fe mit à difcourir rant le foupper, \& aprés, fursles la gues, \& fur leur diuerfité. Entre autr chofes, il fut dict que la Religion plus foument eftoit traictee en vne la gue, de laquelle le commun n'vfo point, ni ne l'entendoit : comme l' glife Chreftienne Occidentale fe fert Latin, les Chreftiens Orientaux du $S_{1}$ rien, les Abyrius \& Ethyopiens d Chaldaique: \& 2 la langue du vulgai de tous ceux-là; eft autre. Les Iuifs n veulent que lévieil Teftament en $\mathrm{He}$ brieu, les Mahumetiftes ne permetten leur Alcoran eftre leu ou entendu qu'e langue Arabique, en laquelle il a ef premierement efcript, la langue Arabi que reflemblantà l'Hebraique, Chal daique, \& Syriaque, ayant cours er leur Religion, \& és difciplines, \& entre les Doctes de Turquie : combien que le langage Sclauonien leur foit plus com 
un, \& parmy les Turcs, \& en la Cour grand Seigneur, \& en tout le pais ill tient en l'Europe. Puis il fur dict, te la langue Tartarefque eftoit entenë par les Septentrionaux , \& par ceux l'Orient : la Morifque parl'Affrique, Brafilienne és terres neufues: mais ion ne fçauoit fi leur religion eftoit tictee en vne lágure, \& quu'ils en parlarat vne autre. Quelqu'vn de la Seree enant lors la parole, va dire: Ie ne efbahis pas tant de ce que la religion traictee en vne langue, \& le peuple parle vin' autre, gue ie fay qu'en vn efme Royaume, en vne mefme Pronce, foubs vn mefme Seigneur, il y $t$ trois ou quatre fortes de langage du ut differens : mefmes en noftre Fran, il le troune vn langage, qui eft le eton n'eitant nullement entendu des ançois, ne de pas vn de leurs voifins, n'en approche aucunement, \& fion eçaurort dire dont il eft venu : \& enres en vne mefme langue $f$ trouluetrois \& quatre fortes de langage: les ens d'eltat en ayans vin, \& le vulgaire a autre. A propos de cefte langue Bre- 
T RE NTE-CINQVIESME tonne, va dire vn de la Seree, le gra Roy François s'efmerueıllant de ce gage, demanda vn jour à quelques v d'où poumoit eftre venuë celte lang \& s'ily awoit point quelque autre ple quil l'entendift,ou qui en approch puis demanda fi celte langue Bret nante eftoit copieufe, douce \&z be \& s illy auoit point quelques hitoit où autres liures efcrits en langage $B$ ron. Il fe trouua la auprés du Koy Gentil. homme Breton bretonnant, quel exalta fa langue, iufques à dire Roy, que Iefus-Chrift eftant en la cro auoit parlé Breton, \& que $\mathrm{Hely}, \mathrm{H}$ Jamafabathany eftoit langage Bretc Le Roy voyantl'affection que ce $S$ gneur Breton portoit aे fa langue \& fon päs, luy accorda, luy difant, vraj ment, mon Gentil-honme, je vous croy, \& péfe à la verité que lefus-Chr eftant en la croix parla Breton:par gu'eftans entre deux larrons, il vouk eftre entendu d'eux. le ne fçay, va di celuy qui faifoitle conte, file Breto entendit bien la rencontre, mais to ceux qui auoient tant foit peu de ne 
prindrent fi fort à rire, qu'il leur fut npoffible d'en dire leur opinion au loy, combien que luy-mefmes en iant les en preffoit. Quant-à nioy, va epliquer vn autre de la Seree, ie penfe ue la langue Bretonne foit vn langage al plaifant \& rude, \& n'en déplaife ux Bretons. Er qui me le fair croire, dioit-1l, c'elt que quand nous voulons ire qu'vn hóme parle mal, nous l'apelons Barragoiiin, qui eft autant à dire omme fi nous difions, il parle Breton, ar barra en Bretó, c'eft à dire du pain, $x$ goiiin du vin : tellement que ceux ui parlent ain $f 1$, appellans du pain arra, \& goiiin du vin, nous difons. u'ils font Barragoiiins, c'elt à dire, u'ils parlent fort ma!. Ce propos acheié, il fut difputé fi c'eftoitivne fcience que fçauoir, \& auoir apprins les lanzues, l'vn difant que nó, \& que fçauoir es langues, n'eftoit qu'vne entree pour apprédre les fciences: l'autre fouftenoit contraire, parce qu'on ne trouve gueres perfonne fçauate és langues, qui ne foit docte, \& İçache les fciences qui ont enté traictees en ce langage, \& 
3. TRENTE-CINQVIESME quon ne fçauroit apprendre l'vn fa l'autre: eftant plus difficile à apprenc $\& z$ entendre les langues, que dappre dre les fciences : confurnant la moil de noftre aage à entendre feuleme vne langue tellement quellement, pour fçauoir v́ne fcience, foit la I rifprudence, foit la Medecine, no n'y employerons que trois ou quat ans. Et qu'il foit ainfi, adiouftoitqu'en apprenant vine langue, on appre quant \& quant la foience qu'elle tra cte, ne voyouss-nous' pas le Seiginei Scaliger ( pour le iourd'huy \& du coll feutement de tous, vin des plus fçaua de nottre Europe ) auec les langues qu a fi bien apprinfes quili eft mal-aife d'e approcher s entendre, \& fçauoir tor tes les foiences qui ont efté traicter aux langues qu'il a apprinfes ? Encor que ce foit vn grand labeur, repliqu quelqu'vn, d’apprendre vn autre lan gage que le naturel, quand il eft du tou different, fi eft-ce qu'il eft bien neceffal - re à ceux qui veulent voyager d'entent? dre \& parler plufieuts.langages, le plu foument arriuant de grafids inconuenie 
ar deffaut de s'entendre l'vn l'autre, caufe des diuers idiomes, \& pronunations differentes, qui fe trouuent a vi mefme langage, ou pour n'enindre pas vn mot equiuoque, ayant eux fignifications. Les Romains, diit-il, eltans fort perfecutez dela pee, confulterentleurs dieux dont cela ouuoir prouenir. L'Oracle refpond, uis Dy defpiciuntur. Alors on inftitua orce proceffions, victimes, facrifices, feftes à leurs dieux. Mais la contafon ne celfant pour toue cela, ils fuint confulter vin de leurs Prophetes, uileur va dire la vraye fignification de e mot Latin defpicire, commel'oracle entendoit: \& que les mots de l'orale, quia Dy despiciuntur, eftoit à dire, arce que les dieux eftoient regardéz u haut en bas $A$ cefte caufe les Roaains firent counrir toutes les ruës où eurs dieux deuoient eftre portez en eurs proceffions, à fin que perfonne ne es peut regarder, \&tivoir du haut en as, Encores auiourd huy, adiouftoit-il, uand le Turc parfe par les rues, on ' ne ofètort tenirés feneltres hautes, \&leV 7 
T R E N T E-C I N QVIES M E regarder du haut en bas : \& celt, cer femble, que ceux qui font les plus hau femblent mefprifer ce qui eft plus 'b qu'eux. Et pour vous monftrer, difoj il encores, le mal qui peut arriuer, $\mathrm{nr}$ feulement de n'entendre point vn mc mais auffi de ne s'entendre point li l'autre, efcoutez, ie vous prie, vin pla fant conte aduenu entre vn François, des eftrangers, qni n'entendojent làngue Françoife. Nous eftions, con mença-il à dire, trois ou quatre compagnie qui allions à Paris : puffa à Blois, où eftoit le Roy, il arriua qu's des noftres, eftant boiteux de natur qui eftoit tout le derrier, tomba à ter: par la cheute de fon cheual, quoy qi foit furle paué, ie ne veux en rien més tir. La garde des Suyffes, qui eftoit lk gee en ce quartier, le releue de deffoul fon cheual: luy baillant fon cheual $p$ : - la bride. Celuy qui eftoit tombé, far remonter, tenant fon cheual par la br de, ccommence d nous fuiure, venar pas à pas aprés nous. Les Suiffes, com me ils font fecourables \& humains , - voyans ainfi aller, \& quid clochoit,pen 
ans qu'il fe fut rompu ou difloqué vne ambe en tombant, le fuiuent, \& l'emoignent qui çà qui là:les vns le tenans, is autres luy tirans les iambes à leur orce, penfans luy rabiller la fracture \& iflocation. Ce pauure boyteux ne fenat que le mal que ces beaux hab:lleurs e Suyfles luy faifoient ne pounant l enurer,crioir à pleine tefte:Hé! meffieurs as Suyffes, pour Dieu laiffez moy, ie ne ne fuis faict aucun mal, Dieu mercy, ie ay point la iambe rompue, ie fuis boieux de nature, \& n'ay iamais cheminé utrement:ce n'eft point la cheute, mefieurs les Sauciffes, qui me faict cloper infi que vous penfez. Mais eux n'entéans point le langage de noftre compa, non, n'on plus qu' il n'entendoit point eleur, penfoiét bien, l'oyant ainfi crier, qu'il fut rompu, \& que la douleur de la racture le faifoit ainfi crier \& plainIre. Que voulez vous ? pour ne s'entenIre point l'vn l'autre, ces Suyffes le ra:outrerent fi bien, en luy allongeans les ambes, puis les replians \& remertans en eur naturel mouuement, ce leár femloit, que n'eftant boiteux que d'vne iambe, 
TRE N TE-CINQVIESME iambe, ils le rendirent qu'il clocho des deux, \& là où il alloit affez bien boiteufant, ils le rendirent fans fe po uoir bouger d'vn lieu : tellemét qu'et mefmes furent contrains de l'apport apres nous. fur leurs hallebardes, ne pouuant en aucune maniere tenir $f$ fon cheual. Le voyant apporter en Ate forte, nous fufmes bien efmerueille \& ne fçauions que dire ne penfer, lo que les Suyffes, fans nous dire aut chole, que $G$ ot de noc,nous affeurerét qu noftre comp gnon de voyage eltoit bie habillé : ce qu'ils nous firent dire par v truchement quils auoient, qui efto Breton, lequel nous affeura qu'il n auoit os qui ne fut en fón lieu, \& en naturelle place, \&z qu'ils l'auoient fai vifiter par leurs Medecins \& Chirurgi ens, lefquels leur auoiét dit que quan. il geloit comme il faifoit alors, qu’à 1 moindre cheute on fe pouuoit caffer iambe tout a net: $d$ 'autant que la froi deur, auflibien que la chaleur, engen droit vne fechereffe, qui faifoit roidi - l'os, dont il eftoit : rendu plus fragil, oú en temps de pluye, il deuient mol selain? 
S E R E. : , 231 oyable \& obeiffant, \& par ainfi malaiàfe rompre \& froiffer. Noftre comgnon de boiteux, que nous laiffares à l'hoóttellerie allicté, ne s'en pouint venir auec nous, tant il eftoit eftroé, $s^{\prime}$ en voulut plaindre au Roy: mais le oy ay ăt fceu ce qui en eftoit, ne s'é fit ie rire, apres auoir demandé s'il auoit oyen de feiourner là, \& fceu que les yffes l'alloient tous les iours veoir, enans auec eux leurs Chirurgiens \& oubeurs, fe feparans à la fin bons ais, luy difant qu'ils l'auoient fi en adoubé que iamais il ne feroit iteux , \& qu'il iroit auffi droit que autres. Il fut auffi dit que la vatédes langues eftoit caufe de la miredes hommes, les peuples fe declans ennemis des vns \& des autres ur la diuerfité de la langue : que fi vfoit tous d'vne mefme langue, pouns l'vn a l'autre dire en propres teres ce qu'on veut, il y auroit plus granamitié entre les hommes. Ce conte heué, voicy quelqu'vn qui va dire iil ne trouuoit point fi eftrange detoy diuers peuples parloient diuers langa 
TIE T T E-CINQV I E S E langages, fans s'entendre l'vn l'aut quil failoit comme les hommes d' puis parlant rudement, ceuxd'vne a tre contree doucement, les vus dugi fier, les autres du dedans de l'eltom yeu que lis paroles fe faifoient \& $f$ moyent en tous hommes du monde ne mef me forte, $\&$ de mefmes organ \& par mefmes membres qui feruent prolarion. Vn des pius habiles de Serees: \& à qui on fe raportoit des fes plus d fficiles, voyant qu'on le reg do $t$, va rendre la raifon donc cela $p$ cedoit ? difant, que tant plus le peu efto: Septentrional, tant plus il parl du dedans de l'eitomac, \& du cour, de voix pleines de confonantes, voyeles, rudement prononcees, \& $z$ au beaucoup d'alpirations : a caufe de force \& vertu des efprits, dont ils o grande affluence, \& de l'impetuofité leur gránde chaleur. Mais ceux qui bitent les parties Auftrales, difoit-il, le Midy, qui ont leur chaleur tempere $\$$ les efprits debiles, prononcent do cement, \& les femmes encores plus $n$ gnardement, parce qu'elles ont les 
its \& la chaleur plus debiles que les mmes. Mefmes la langue prendenres quelque nature des eaux, qui angent la voix \& les langues, \& faid ce ceux qui demeurent pres des inie, font begues le plus fouuent, \& ont langue gralle, $8 \tau$ fi parlent autrement tes autres. Car nous voyons les Seentrionaux, qui habitent pres de la er, auoir la voix plus groffe, \& de la ennent les bonnes Baffecontres, \& Meridionaux, qui n'ont pas tant aux, auoir la voix plus grefls. Ce qui peut veoir manifertement, difoir-1l, prenant deux vaifleaux de terre, qui ent pareil fon, fi vous en mettez l'vn leau affez long temps, \& puis que le iez tout vuide, il aura le fon plus aue \& bas quel'autre, lequel n'aura int efté en l'eau. Ie croy, repliqua vn tre, que les voix grefles \& groffes des uples fe font comme à vne harpe : où corde la plus courte \& plus prochaide l'angle, rend le fon plus clair \& btil, \& les autres qui def́cendent par dre, fonnent plus gros: ainfi les naons qui font plus pres de l'effieu Meridjonal, 
TRE N T E-C I NQVIES ME ridional, à caufe de la briefue $\&$ cou hauteur du Ciel, parlent \& chant clair \& grefle: puis defcendant par dre iufques aux extremes parties Sep trionales, qui font les plus enloigne elles forment leur voix naturellem. plus graues, groffes \& baffes. Mais 9 direz vous, demanda vn de la Seree ce que vous verrez en vne mefme $P$ uince, en vne mefme ville, n'y auoir vne mefme prolation \& prononciatic lesgens d'eftat ayans vne prolation accent pour eux, \& le vulgaire vn au à part : toutesfois eftans participans mefmes eaux, de mefmechaleur, \& mefme vertu en leurs efprits. Celuy $q$ auoit mis cefte propofition en auanc, fouftenát va dire, que ce n'eltoit pou tant qu'vn langage, \& qu'vne prono ciation que parle l'homme d'eftat, \& racaille du peuple, s'entendins bi l'vn l'autre, mais que c'eftoit que le vi gaire e?toit corrompu: comme à Ron n'y auoit qu'vne lágue, qui eftoit la $L$ tine, en Grece, vne autre, qui eftoit Grecque, mais celle de la popula eftoit corrompue, 82 moins elegant 
qu'on peut veoir, difoit-il, au Latin Virruue, architecte, \& maiftre ingeur, \& de Ciceron confulaire : que fi commun peuple corrompt bien les ts, auffi font bien les gens d'eftat te vne fentence. Mais, ie vous prie, veut dire toute la France, quand dit, il ne faut point faire à Dieu barde feurre, en lieu qu'il deuoit dire, il faut point faire à Dieu gerbe de feurou de foarre? Et vous diray bien d'atage, difoit il, c'elt que mefmes les is d'eftat, \& les plus grands n'entent pas des mots qui font faict Fran$s$, que d'autres entendent, $\&$ dont vent, comme vous entendrez tout intenant. Le grand Roy François, e des lettres, \& appuy des lettres, unt vn iour à table, feu Bouin luy preta des Epigrammes, \& encores que Roy difnaft, il ne laiffa en mangeant lire ces Epigrammes, \& toutes les squ'il mangeoit vn morceau, il di. t toufiours, voicy de bons Epigrams, Vn cheualier de l'ordre, grand Seieur, $\&$ des principaux de fa Cour, voat le Roy lequel en foupant difoit tou 
TRENTE-CINQVIESME toufrours voicy de bons Epigramm penfa que ce deuoit eftre quelque bon viande qu'il mangeoit, qui auoit no Epigramme, difant à tous les morcea qu'il prenoit au plat, ô lès bós Epigra) mes! regardant fur la cable s'il pourr poincrem irquer qu'elle viande c'elt que des Epigrammes. Ce Se gneur eft -de retour à fon logis, il va dire à fo cuylinier, tu ne mi fais point mang d'Epigrammes, ie viens du difner Roy,iln'a mangé aucre chore à fon di ner, \& les a trouuez fi bons qu'il ne poumoit tenir de dire, mon Dieu, 1 bons Epigrammes: tu ne fçais rié en to eltat, \& cela eft fi commun chezle Ro Le cuyfinier fafché refpond à fon ma Atre, Monfieur, comment voulez-vor que ie vous accoufre \& que ie vol ferue celte viande d'Epigrammes, que Roy troule fi bonne, puis que ie fçay que c'elt, ny à quelle lauce elle mange: que fi $i$ en auois veu, ie de piterois tous les cuiliniers du Roy faire mieux, Ce Seigneur des le lende main enuoye vn de fes gens au maitr d'hoftel de chez le Roy, le priant de lu. 
doyer de la cuyfine du Roy des Epiimmes; que le Roy le iour par auant oit trouué fi bós à fon difner Ce maid'hoftel, qui auoit affifté au difner Roy, fe doubéant bien de ce qui en oit, eftant vn petit plus fçauant que rcompagnon d'armes, va refpóndre d gentil-homme, mon amy, allez dire aे ofieur qu'i! n'aura point d'Epigramss; \& que c'et vne viande Royalle, \& il n'en y a que pourle Roy, \& que ie n oferois bailler. Le maiitre d'holtel resauoir faict ce refus, vint trouuer Roy, \& luy conte comme vn telluy oit enuoyé demander des Epigrams, qu'il auoit le iour-d'hier trouucz ons a fon difner : dont ill'auoit refuout à plat. Puis va dire au Roy, vous verrez bien bouffer contre moy : car n'affeure qu'il s'en plaindra d vous. Ie us laiffe à penfer fi le Roy ne trouua bonne cefte rencontre, \& s sil en fut. e. Ce friand d'Epigrammes ne faillits enir trouver le Roy, \& l'ay ant falué, ne difoit mot. Le Roy fe doubtant? en de ce qui en eltoit, luy demande, ! qu'as tu, inon pere? Tefte-Dieu, 
TRENTE-CINQVIES ME ainfiuroit-il) va il refpondre au $R o$ c'eft voltre Capitaine Borguet eftoient if familiers qu'il l'appello toufiours ainfi) qui $m^{3}$ a refufé de $n$ bailler de voftre cuifine des Epigran mes, que trouuiez fi bonshier à voft difner, \& ne voulois en auoir que pou en taiter, \& f çauoir fi celte viande elto fi bonne que vous difiez: $\&$ aufit po en monftrer à mon cuifinier, à fin c m'en accoufter, \& $\&$ faire manger, pu qu'ils font fi bons. Le Roy plus affeu de la rencontre que iamais, feprint fort à rire, qu'il fut contrainct déd clarer à ce Seigneur, qu'il aimoit bies tout ce qui en eftoit; à fin auff qu'il $r$ trouuant mauuais dequoy fon maift d'hoftel luy auoit refufé des Epigran mes, \& qu'il luy en vouluft mal. Ce Epigrammes defpefchez, on fe mit apre vn autre mets: qui eft, comme il eftoi pofrible.d'introduire en vn pais vn nou ueau langage, \& quion laiffe le premie qui eftoit naturel à tous ceux de ceft Prouince : èftant alfeuré cela eftre ad uenu en noftre France, \& qu'auiour d'huy ayans des liures efcripts en vieur 
nçois, on ne les pourroit plus entennon plus que Polybe en fon hire Romaine, interpretant le prerraicté faict entre les Romains \& Chartaginois, foubs les premiers nfuls Brutus \& Valerius, ne fçait où n elt : \& pour fon excule il dit,qu'en is cents cinquante ans, fi grande muon eftoit aduenuë en la langue Roin, que plufieurs paroles dudict icté \& accord ne pounoient eftre enduës, par les plus curieux \& diliis rechercheurs de l'antiquité , qu'agrande difficulté. Ce changement langage fe faict, felon Bodin, fut-il pondu, quand plufieurs nations font mblees, ou qu'elles fe frequentent e l'autre:car lors ils s'engendrent mots nourueaux, par la naiffance quels, comme des hommes, les pre.. ers prennent fin. Il y a bien plus, va

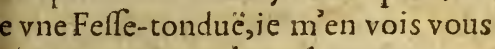
re vn conte, par lequel vous enten$z$ que ceux d'vn mefme païs ne s'endent point l'vn l'autre, encores que mots, \& le langage n'ayent aucunent changé:les gens d'eftat n'entenLiu. iij. 
I IRENTE-CINQVIESME dans point le vulgaire. En vn de $n$ troubles (ie ne fçaurois plus conter) $v$ compagnie d'hommies d'armes, pa fans par la Xainctonge, \& s'en allans frege d'vne ville, rencontra vne ban de charretiers du pains de Poictou, q alloit au fel : lefquels bien armez. pampre \& d'efguillons pour picqu leurs boufs, fortoient auec vn grat bruit d'vne tauerne. Ces gens de gue re les voy ăs ainfir accouftrez \& efchau fez, leur de mandent: Où allez-vous $\mathrm{m}$. amis?llls leur refpōdent, nous allons à faur. Ces gens-d'armes qui fe haftoier pour s'y trouuer, penfans que ces cha: retiers fe voulufient mocquer d'ew: commencerent à les charger d’appoir ctement \& prenans leurs armes, qu eftoient leurs efguillons, les firent cro cheteurs, leur difant, Mort-Dieu vous eftes branes gens pour aller a l'al fault, vous raillez-vous des gens d guerre? Tant y a, qu'ils furent fi bie battus, qu' il ne falloit point dire, plock Domme, car ils fçauoient bién pour qu c'efioit, mais ils ne f̧̧auoient pas pour quaoy on les auoit ainfi chargez: ce 
intils-hommes n'entendans point la pulace de Poictou, qui appelle du I de la fat. Vous m'auez faict fouue$r$, va dire vn autre, d'vn gentil-home de Poictou, qui alloit bien à la fau Poicteuin, mais non pas à l'affault bon François : car le camp eftant deant Broiiage, il alla \& reuint de la fau us de vingt fois, mais celtoit à che$1, \&$ en des charrettes : \& quand les mmes luy demandoient, Monlieur, i allez vous? il leur refpondoit, à l'afult, \& lors elles le prioient de leur 1 apporter, \& qu'elles l'achepteroient. : non fenlement, adiouftoit-il, la diuerté desidiomes \&z de la prononciation porte diuers fens, mais aufin les mots de nous prenós des autres langues, que ous excorions, cóme faifoit le Ly moun de Pétagruel. Comme il arriua n'y a is long têps à vne féme"s̀ qui on difoit ue fon fils eltoit fidefrage, pour nevouir efpoufer vne fille à laquelle on diit qu'il auoit promis. La merci-Dieu, a dire la mere, mon fils n'eft point fideage, mais de mon mary, gui eft fon re. Acheueso que furent ces rencon$\mathrm{X} \hat{i}^{2}$ 
T R N T E-CIN QVIES M E tres, vn marchant de la Seree voyar quauec les chofes ferieufes de la di uerfité des langues, chacun ne laifloit y entrelaffer quelque plaifant conte commença à parler en cefte forte. n'y a perfonne icy qui ne f̧cache qu'a uant nos guerres ciuiles $\&$ inteftines il y auoit de belles foires Royales Poictou : où lon trouuoit grande abon dance de toutes marchandifes, $\&$ de marchands de diuers pais, \& de diuer fe langue. Or à vne des foires de Fon tenay, il fe trouua là des marchand Allemans, qui ne fçauoient pas vn mo de François, \& î auoient affaire à de François qui n'entendoient leur lan. gage: parquoy il fallut trouuer in truchement, qui entendift ces deux langues pour trafficquer. De Iatin, difoit noftre marchand qui faifoit le conte, nous n'en portons gueres aux foires, \& 2 'en faifons pas grand traffic, \& qui n'auroit aux foires autre chofe à debiter, à grand' peine fçauroit-on rauner les defpens, \& en faict-on main tenant li peu de conte, que qui n'auroit autre marchandife que du Latin, on mourroit 
nourroit de faim auprés, \& n'en retireoit-on pas la moitié de ce qu'il coufte: encores queles marchands qui ont de zans affortimens, \& de bonne marchandife, difent ${ }_{2} c^{2}$ eft marchandife Latine. Pour trouver donc vn truchement a ces François \& Allemans marchands, il leur fut enfeigné vn ieune homme de la ville de Fontenay, lequel auoit bien voyagé,' \& que polfible il pourroit auoir efté en Allemagne, \& apprins celte langue. On s'en va en la maifon de ce ieune homme de Fontenay où ils ne trouuent que fa mere, à qui ils demandient fi fon fils ne fçauoit point parler Allemand : elle leur refpond qu'elle n'en fçauoit rien:mais il eft bien vray, leur dit-elle, quil en a vne flute, \& qu'il en ioiie aucunesfois. Ceux qui entendirent celte refponfe, ne fe peurent tenir de rire, de ce que celte femme penfoit, que cefte flufte d'Allemand (en Latin fiftula obliqua) peuft refpondre \& parler Allemand, puis que fon fils en fçauoit ioiier, \&, qu'elle ne pouuoit rien dire qui ne fut Allemand, eftant de ce païs-là. Aprés que ceux de la Seree $\mathrm{X} 3$ 
TRENTE-CINQVIESME

eurent autant ris que ceux qui auoier parlé à celte femme, un fianc-a-trip n'ayant ouy parler que des langues ei route cefte Seree, nous va dire quion a uoit oublié la principale langure, la plu commune, \& la meilleure, \& celle qu'i aimoit le mieux : c'ett dit-il, la langu de bouf, quand elle eft bien falee, ac coufree, \& parfumee, comme font cel les du Mans. Or quand celtuy s'apperceut qu'on ne riout point de fon conte il nous iura qu'il le fçanoit auant que le François Italianifé fut au monde:mais pourcela guion n'en verroit point de procés. Et à fin de monîrer à toute la compagnie qu'il fçauoit autre chofe que de inanger des langues de bouf, il nous va dire, qu'en ce temps il fe trouuoit des perfonnes qui entendoient, \& parloiét autant delangtres que $M y$ thridate, Roy de Pont, qui fçauoit parler vingt \& deux langues diuerfes,aufquelles il commandoit : difant auff qu'il n'y auoit pas long temps que l'Empereur Federic vnziefme regnoit, lequel parloit Grec, Latin, Hebrieu, Arabe, Morefque, Allemand, François \& Italien:

\& que 


$$
S E R E \bar{E} \text {. }
$$

que de noftre remps il s'eltoit veu truchement de Sultan Solyman, atif de Corfou, qui parloit parfaicteent (ce dit Bodin) le Grec vulgaire Literal, Turc, Arabe, More, Tartare, erfien,Hebrieu, Armenien, Molconi,Hongre, Efclauon, Italien, Efpanol, Allemand, Latin \& François. II alloit, va repliquer quelqu'vn, que ce. uy-cy eut apprins ces langues eftant eune:car, comme dit l'Anacrife, l'aage uquel regne plus la memoire, qui eft n l'enfance, eft plus propre pour aprendre les langues, que n'elt pas l'aare auquel nous auons plus d'entendement, de iugement, \& de raifon, eitans nommes parfaicts, fa memoire feruant plus à apprendre les langues, que ne faict nil'efprit, ni le jugement, ni l'imagination. Les enfans auffi retiennent mieux ce quils apprennent que les autres, pource que nous retenons mieux ce que nous admirons, \& fain 8 Thomas dit que les enfans admirent toutes chofes, comme leurs eftant nouuelles \& non accouftumees. Et de la l'Anacrife infere qu'auec grande diffi- 
TRENTE-CINQVIES ME culté s'alfemble la langue Latine au la Theologie fcholaftique, \& qu'or nairement on ne void gueres aduer qu'vn homme foit enfemble bon $L$ tin, \& profond icholaftique :à cau dit-il, que ceux qui font bons Latin ont confequemment vie bonne $\mathrm{m}$ moire, autrement ils ne pourroie deuenir fi excellens en vne langue $q$ n'elt à eux propre: : \& ceux qui font fç uans en Theologie fcholaltique, or par confequence l'elprit \& le iugemen bon: Or eft-il, qu'il eft bien difficil de trouuer le tout en vn mefme hom me : car comme dit l'Anacrife, fi quel qu'vn à vne excellente memoire, $i$ $n$ aura pas grand entendement \& iuge ment, \& au contraire, s'il a le iugement boil \& l'entendement, il n'aura pas grande memoire : d'autant que l'entendement \& la memoire font puiffances contraires, l'vne combatant auec l'autre, l'vne demandant beaucoup d'humidité \& molleffe au cerueau, qui elt la memoire, \& l'entendement beaucoup de ficcité, qui font chofes contraires en vn melme fujet. Qui ne fe con- 
ntera de celte raifon, dit l'Anacrife, fe fainct. Thomas, l'Ef cot, Durand, \& ajetan, qui font les premiers \& prinpaux de cefte faculté, \& il fe troutede grandes fubtilitez en leurs cures, dictes \& efcriptes en gros \& comun Latin. Dequoy n'y a autre raifon, lon l'Anacrife, finon que ces graues. atheurs ont eu dés leur enfance fort auure memoire, pour eftre excellens n la langue Latine: mais eftans venus. la. Dialectique, Metaphyfique; \& heologie fcholattique, ils ont obteu la cognoiflance telle que nous voons, parce qu'ils auoient vn grand ntendement. Vn de la Seree ayant ien notéce difcours, va faire la comlainete que font les gens doctes du ourd'huy, comme de Pontus de Tyard, ierre de la Ramee, de ce que nous mployons la moitié de noftre aage, $x$ la meilleure, à apprendre deux ou rois langues, \& employons plus de empsà entendre \& 2 parler ces iargons, quanciennement ne faifoient les anciens à paffer par toutes les fonces $\&$ diffiplines liberales. Parquoy on fe de 
T RENTE-CINQV IES M E woit, difoit-il, foigneufement empl yer d"embellir \& enrichir fa langue, $d^{2} y$ efcrire, \& $y$ metre tous les ars lib raux \& fiences, puis qu'il eft plus dif cile d'apprendre vne langue eftrang re, oùles fciences font traictees \& crites, que non pas la fcience melme, aufi qu'il eft mal-aifé que l'art foit naif que la nature, l'art ne poumant galler la nature, eftant impoffible, matiere de langage, que nous puiffor iamais arriuer a la perfection des nat rels: tefmoing le Lefbien Theophr te, lequel narchandant du Poiffo àvne poifonnerie d'Athenes, tout a premier mot quill deflacha, elle s'af perceut foudain qu'il n'eftoit pas na wrel du païs, \& luy dit, eftranger mo amy, vous n'en rabbatrez rien : \& auoit plus de vingt-ans qu'il demeuroi à Athenes, \& eltimé vn des mieux par: lans. Mais, demanda quelqu'vn, fi ot n'apprendroit point plufton \& plu facilement la langue Latine en lap prenant comme nous faifons l'Italien ou l'Efpagnol, \& l'Allemand, en de gasurans, \& conuerfans auec eux, quia- 
e des reigles \& la Grammaire? Quant moy, difoit-il,ie penfe que les anciens pprindrent le Grec \& le Latin auec noins de difficulté qu'auiourd'huy, arce qu'ils nourriffoient à cefte fin es Efclaues parlans Latin, \& Grec: omme nous trouuons en vn autheur, ui dit auoir apprinsle Grec, collognio irsiorum afjuefactus famuloruin : qui eft à ire, maccouftumant parler auec ef laues Grecs. Le Seigneur de la Monagne dit quil apprint ainfila langue atine, fon pere ayant efté curieux de e le faire parler ny hanter, pendant $f_{a}$ euneffe, finon auec perfonnes qui ne arloient auec luy autre langage que le atin. Et me femble, adiouftoir-il, gu'il eroit facile d'apprendre ainfi les langues, s'il fe trounoit des peres qui geuffent auoir à leurs gages des Allemans ou eftrangers, qui ne parlaffent à leurs enfans que Grec, Latin, ou vne autre langue qu'on vouluf apprendre. Er pourquoy non, repliqua in Drolle, puis que $i$ 'ay veu en Grece, Turquie, 8 Italse des enfans qui n'auoient que quatre ou ciñg ans, qui parloient Gree, 3. 6 
IRENTE-CINQVIESME Turc, \& Italien tout courant. Et po confirmer la difficulté qu'il y a à a prendre les langues eftrangeres, $c$ ftuy-cy, qui regrettoit tant le tem qu'on employe à entendre $\&$ declin des noms \& des verbes, non fans eft tous les iours foüetté, nous va fpecific quatre langues, qui font eltimees plus difficiles, felondu Bartas: foit qu nous regardions les characteres eftrar ges de la langue Turquefque, les figu res. Hieroglyph ques des Egyptien les poincts qui feruent de voyele aux Hebrieux, \&r les accents qui peni blement fe remarquent en chacune di .ction Grecque. Mais, repliqua quelqu autre, auec la difficulté de ces quatr langues, ne trouuez-vous point eftran ge, que les characteres propres \& peculiers à vne langue, feruentneantmoins a dautres? Comme nous, voyons que les chracteres Hebraiques feruent à la langue Chaldee: les Arabefques à la Turque, \& a autres peuples, tantien Afie quen Afrique, qui font tous differens en langage: \& quafi toute la Chreftienté vfe-elle pas de l'efcripture 


\section{S E R E E.}

\& des characteres Latins, combien que les parlers \& langages foient differens? Toutesfois ie penfe, difoit-il, ces characteres Latins, dont vfent \& fe feruent tant de diuerfes langures, eftre venus des Grecs, fuiuant Tacite, qui dit que les lettres Latines ont la forme des plus anciennes Grecques, ce quia faict doubter à plufieurs, cedit Vigenere, fi les rooles que Cefar dit auoir elté trouuez au camp des Suyffes, la depefche que fit Cefar à Cicerö, \& les papiers 82 les actes des. Druydes, eftaient efcripts en langage \& characteres Grecs,ou feulemét en characteres Grecs, \& en autre langage. Car comme dit Vigenere, celay qui n'entendra point. la langue Latine, ne la Françoife, mais feulement cognoiftra les characteres Latins, s'il void ces characteres, dont vfe le Francois, l'Allemand, \& les autres nations, il penfera que ce fort Latin:pource que ce font les propres \& naturels characterés du Latin : ainfi Cefar voyant ces chiaracteres Grecs en des memoires des Suylfes ; à peu penfer le langage eftre. Grec: du moins Cefar dit literis Gracis.

X 7 
TRE N T. E-C INQV I ES M E Ie croy, va dire vn de la Seree, que s'i fe trouue vn peuple qui ne fçache du tout rien., n'ayant characteres ni elcripture, voyant efcrire, \& regardant de l'efcripture, il fera fort efmerueillé, que s'il veut elcrire, il faudra emprunter des nations les plus voifines $\&$ ciui lifees, leurs characteres, pour y metre fon langage : comme ont faict la plus grand' part de toutes les contrees, lefquelles ont emprúté les characteres $\mathrm{La}_{2}$ tins, pour exprimer ce qu'ils vouloient dire $\&$ declarer à ceux qui demeuroient en lointain païs. A ce propos, difoit-il, ceux qui ont efcript des Tartares, \& des Indiens Occidentaux; difent qu'il n'y a pas cinquante ans que ceux de ces païslà, voyans les Efpagnols efcrire, à faute de papier, auec vn poinçon fur certaines fueilles efpoiffes, \& que par là ils faifoient entendre à cent lieuës aux antres ce qu'ils vouloient, ils fe mirent en fantafie qu'il y anot quelque diuiwité cachee en les fueilies, \& ne les pouuoit-on garler do les adorer, iufques à ce que qua lques vns de leurs enfarss. ay ans apprinis liviage des letures,

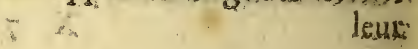




\section{S E R E E:}

eur firét comprendre comme ce miltete paffoit. Et à la verité, ce dit Vige-

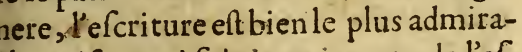
ble artifice qui foit iamais party de l'efprit de l'homme, de voir que certains petits pieds de mouche faicts à noltre fantafie, puiffent reueler, à quelque longue diftance que ce foit, les conceptiōs de noltre efprit. Vn autre repliqua, qu'ily auoit bien caufe de s'efbahir de la diuerfité des langues, auffi bien que de l'efcriture ? qui confiderera commét vn peuple parle vne langue, \& s'entendent les vins les autres: \& vn autre peuple parle ivn autre langage, fans qu'ily ayt yn feul mot pareil. Pierre Meffie, difoit-il, apres Herodote, faict vne queftion, demandant quel langage parleroyét deux petits enfans nourris en $l_{i}$ eu. où perfonne ne parlalt. Les vins difent qu'ils parleroient Hebrieu, pource que fainct Augutin tiér que c'êt la premiere langue que parloient tous les hommes au parauát la confufion $8 x$ diuifion d'icelles. Herodote dit, que l'experience en fut faicte entre les Egyptien, \& Erigiens, qui eftoiest an debatlaquclle des; 
TRE N T E-C I N Q I E S M E des deux eftoit la premiere de ces deu langues, \& queces enfans direnţ be qui fignifie pain en langue Frigienn Meflie dit que ces enfans feroyent na turellement, \& deux-mefmes, vn lan gagenouueau. Quantà moy, difoit-il ie ferois de l'opinion de ceux qui main tiennent qu'ils ne parleroient ne $\mathrm{He}$ brieu,ne Chaldee, ne Egyptien, ou Fri gien, ny autre nouueau langage qu'il fe pourroyent forger, mais qu'ils ne parleroyent point du tout, \& feroyen muets, comme font les fourds qui n'en. tendent rien, \& $n^{2}$ entendans rien, n'ont garde de parler. Apres que ce doubte eut êté debatu aflez lóguement de beaucoup de raifons, quelqu'vn va demander qui eftoit caufe que la langue Grecque \& Latine eftoient demeurees viues és efcritures, \&z eftimees \& honorees des fudieux, côme elles furent és aages, efquels elles onc efté propres \& familieres: de telle forte qu'vn homme ne fera point eftimé eftre fçauăt s'il ne les fçait. Et pourquoy eft-ce difoit-il, que noftre langue vulgaire Françoife ne pourra deuenir telle que ces deux langues, ont faict: 
aict, veu qu'efcriuains ne defaillent, efquels fe trauaillent pour l'oiner \& ccroiftre? Et encores qu'aucuns fe peruadent la dignité, \& eftiment qu'on fait ncores auiourd'huy de la langue Grecue \& Latine, proceder de certaine eleance \& facondité naturelle, qui êt en es deux langues: ie ne voy point touesfois qu'elles ayent autre force $\&$ veru, que celle laquelle leur fut dónee par vage de parler \& defcrire, non plus que la langue Françoife \& Italienne: \& ine voy qu'ó ne fe puiffe declarer auffi ien,\& aufli propremét, \& copieufe mét 11 François \& Italien, qu'en Grec \& Lain, encore que Paul Paruta aye dit, que es compofitions de ces deux langues rançoife \& Italienne (qui ne feruent eulement, dit-il, quà delecter) ne fufifent pour donner reputation à vne lanue, \& la dilater en plufieurs Prouin:es, fi qu'elles foient apprinfes \& ho1orees de diuers peuples. Mais la raifon de tout cela eft, à mon aduis, de ce que es François n'ont tenu compte de leur angue, $\&$ ont mieux aimé la Grecque \& Latine, \& y efcrire, qu'en leurlangage 


\section{RE N T E-C I NQY IES ME}

gage maternel, dont Otfrid moine Vviffembourg fe plaint de fon temp qui elt enuiron l'an huict cens foixan $\&$ dix, parlant aux François, leur difar Et combien que les François fe garde de faillir és aurres langues, ils n'o point honte de voir la leur filaide mal polie:ils admirent les autres, Oifrid, \& craignêt d'y faillir d'vne fe le petice letric, chopans prefque à ch que mot de leur langue Françoife. Ch fe efmerueillable, dit $i l$, encores que fi grinds perfonnages, tant pruden aduifez; fubrils, fages, \& renommez faincteté, facent tant d'honneur à vn langue eftrangere, fans vouloir mettr en vfage la fienne propre. Er qui eit aul. caufe que noftre langue Françoife $n$ s'eft pas tant eftenduè que la Grecqu \& Latine? C'elt que le François voulan profiter à tous, a mieux ai méé efrire es Latin qu'en fa langue, parçe que plo fieurs entendans le Latin, n'eaflèn entendu le François:\& auffi que les Pro uinces efquelles celangage fe parle, c'ef à Ççauoir le Françoiss, ne command point aux eftrangers; q qui eft vn granc

moyer 
oyen pour eftédre l'v fage des langues: aurant qu'vn chacun s'efforce de faire tédre fes doleances à ccluy lous le cóandement duquel il eft, \& de la proteion duquel il a befoing. Et lors pour ir celte Seree, par vn bon prefage pour ofre Prince, ie fouhaite que dans u de temps toutes les natiós du moneuffent befoing d'apprendre à parler oftre langage François: les langues fe ultiplians \& renforçansà mefure que s Princes qui en vfent s'aggrandiffent.

TRENTE-SIXIES M E $S E R E E$.

Des Ladres of des Mezeaux.

Vrant les troubles \& guerres ciui1. les \& inteftines, qui ont efté bien andes, $f$ rous confiderons, que durant Monarchie Romaine, qui a efté $f_{1}$ a me, \& a tant duré , il n'y a eu que huict uerres ciuiles : \& en noftre France en ou de temps, il en y a eu d'auntage ien grandes auff, fi nous regardons sux qui font morts en ces guerres : \& 
TRE N T E-S I X IES M E que nous en faifions iugemét parce Appian en a efcrit des Romains, qui que Cefar nombra le peuple deRom prés les guerres ciuiles, \& $x$ qu'il ne tr ua que cent cinquante mille homm combien qu'au parauant il en fut co trois cens vingt mille, prenans du ment du public, Or dóc durant nos gu res ciuiles tant de fois prinfes \& repr fes, vous fçauez que chacun eftoit co trainct, à fon rang, d'aller à la garde portes : \& puis eftant de retour, on portoit au bureau, durant le fouper, en la Seree, tout ce qu'on auoit faict apprins là de nou ueau, parce qu'en lant on chaffe les ennuis. D'entree, qu qu'vn va conter $d^{\prime} v n$ bourgeois \& dat de fon efquadre, lequel fentant matin vn peu de froid aux iambes, eft en garde, auoit dit,ie fuis marty que $n$ 'ay prins à ce matin mes lazarines, qui on auoit,refpondu : \& celles qu vous auez chaulfees font elles pas à vo Ce fut affez, car chacun entendit bien qui celte fourde atteinte s'addreffo Parquoy laiffant le particulier, on fe mettre fur le general, mettant en auar 
ais où il y auoit le plus de ladres. Et :rouvé que nof re Poitou n'en eftoit eres taché:à caufe de la region qui elt aperee : que s'il y en auoit, que c'eient ladres blancs, appellez cachots, juots, capots, \& gabots qui ont la fabelle ? ques'sils font ladres, ils le font dansle corps, le commencement de rerie eftant long temps au parauant dedans auant que paroiftre : à raifon e la lepre fe fait toufrours pluftolt x parties interieures qu'aux exterieu.Er pour móftrer qu'il n'y a pas beauup de ladres en ce pays, il me founiét $n$ bon foldat, lequel ayant prins du in benift de la Transfiguration, \& renant de la garde, demanda à vne nine, qui amafloit pour les ladres, amie, amaffez vous plus pour nous? quelle luy refpódit, que non, \& qu'on vouloit rien bailler : parce qu'ils diient qu'il n'y auoit perfonne à la malerie? \& puis luy dit. \& que n'y venez us? Tous ceux de l'efrouiade fe prenát ire, luy dirent qu'il y denoit aller oute aduanture? \& que pour le moins 'exempteroit de beaucoup de charges \& 


\section{TRE IN I E-S I XIESME}

\& exactions, à quoy on eftoit fuject d rant ces guerres inteltines, \& partia tez. Lors le foldat va repliquer, qu'il feroit pas le premier, qui durant temps fi miferable, fe feroit rangé és preferies pour euiter l'air de ce remp plus dangereux que la ladrerie, \& en pefté de mille \& mille ennuis:les vns s rendans pour viure, aucuns pour n'eft emprifonnez \& rançonnez, la plus pa des habitans des villes ayans efté cor traincts d'y mourir de pefte, pour n' muer d'air, \& aller aux champs, à caul des gens-d'armes \& voleurs, quil les pr noient, emprifonmoient, rançonnoier \& tuoient:tellement que plufieurs pou fauter leurvie fe mefoient anec les la dres, fibien qu'on fut contrainct, pout la multitude de ceux qui fedifoient la dres, de faire langoyer ceux qu'on you loit receuoir,n'eltant pas permis d'eltr ladre, à celuy qui le vouloit eftre : eftan defendu à toute perfonne de fe direla dre, s'il ne l'etroit à vingt \& quatre ca. rats, à poix de marc, \& à l'ef preutue de la copelle, reiettans de, maladeries ceux gui n'en aloient que deux ou trois 
S E R E-E.T 246 ains. Comme en ce mefme temps il $t$ defendu à beaucoup de pauures gens faire de la poudre àcanon, de peur ills ne milfent le feu en la ville: à afe qu'il fe trouua vn poudrier à qui maifon brufla, \&x tout ce qu'il auoit, feu s'eftant prins à fa poudre, \& $x$ tout qu'il perdit ne valant pas cent fols, ás à loüinge, il amalfa d'aumofnes, plus cinq cens liures. Lies autres en voulás re autant furent empefchez:car il fut ffendu aux pauures gens de faire plus poudre: \& qui n'y etift remedié, ils fsét bruflé les maisós qui n’eftoiét pas ux, voire toute la ville, pour fe faire hes d'aumofnes. Auff, difoit-il, qui uft retranché les ladres, ce n'eulfent éen tout le pays de Poicton que laeries \& lepreferies : car en plufieurs ux on ne troutoit maifon qui ne fut rnie d'vne croix \&x d'vne cloche, \& uant la poite d'vntronc, auećles arjiries des ladres, la cliquerte $\&$ la bar: penfans par la eftre exempts de toupilleries. Ce qui fe tronáa fi comin en Poictou, où Dieu mercy ce mal rare, que les gens-d armes ne lailferét dentrer 


\section{T RE N T E-SIXIESM E}

d'entrer \& loger pas tous, fans anoir ef gard à l'efpounentail qu'on mettoit : l'entree des maifons, \& difoient qu'il: efteient riches coinme ladres. Que c'euft eftéés regiős Meriodionales, qu'or euft troulué tant de maladeries, on ne s'en fut efbahy, eftans ceux du Midy fort fuiets à la lepre: à caufe d'vn humeur melăcholique engendré par gran de chaleur. Sibien queLeon l'A friquair. \& Aluarez difent, cefte maladie eltref commune aux Meridionaux, quon ne trouue par les champs en l'vne \& l'autre Mauritanie, que maifons \& hofpitaus pour les ladres : ce qui a donné occafion aux Anciens d'appeller ce mal, Morbus Punicuse morbus Arabü.Par melme raifon, les Ethyopiens, ayant le iang froid \& melancholic comme eux font fort fu. jets auffi à ce mal, \& l'ont appellé Elephantiafis: pource que les Elephans ont le fang froid \& melancholic commeles ladres : ou bien de ce que cefte maladie prend és iambes, \&r les rend fi enflees, qu'elles deuiennent auffi groffes que celles des Elephans. Et non feulement, adiouftoit-il, le pays chaud abonde en ladres, 
ires, mais aufi les regions par trop ides: à caufe que le lary par le froid uenaitt efpoix, tardif, \& congelé, ct \& rend les gens ladres : comme Allemagne y en a beaucoup de tels. Vn de la Seree fa va elmerueilles ce qu'auant Pompee le grand, on moit iamais ouy parler de lepreux toute Italie, finon apres qu'il eut aquis la Paleftine \& Iudee : comn gue ce mal fur fort peculier en ite l'Ethyopie, \&z quà celte caufe yfe en auroit faict force Loix, ce e n'ont faict ny les Grẹcs ny les Roins. le croy, repliqua quelqu'vn, e cefte maladie eft plus contagieufe veneneufe en vin pais qu'en vn au: car nous trouuons que Domini- Catalufie, Prince de Lefoos, fa ume eftant deuenciè ladreffe, ne la ua pour cela ne de fa table, ny de lict. Il luy fut refponda, que c'et is lamitié que porioit le mary à la gme, qui luy faifoit oublier tout le ger qui en pouunit venir, \& non quil penfant le mal eftre moindre là; en l'Egypte \& Ethyopie. Quefiles Liu.iij. 
T R E N T E-S I X I E S M E

Egyptiens, Ethyopiens, \& Arabes fo plus perfecutez de ladrerie que tous a tres, difoit-il, ie conclurray qu'ils efto. plus riches, que les Grecs \&r que I Romains, fi ce qu'on dit commur ment eft vray, il eft riche comme vn dre. Ce prouerbe, va repliquer vn Fer tondue, eft caufe que beatucoup ne ve lent rien donner par aumofne à pauures ladres : \& me fouutent qu fut dict, n'y a pas long temps, $a u$ briqueur de noftre parroiffe, qui am foit pour eux : Monfieur mon amy ne veux rien bailler pour les ladre car on dit que les plus riches de la vil le font. Vous ne fçauez pas poffible, dire vn de la Seree, pourquoy les 1 dres font plus riches que les autre c'eft, difoit-il, pource qu'ils n'enge, drent gueres d'enfans, à caufe qu' font atri-bilaires, \& par confeques froids \& fecs, toute generation fe fa fant par humidité \& chaleur: \& tas moins qu'on a d'enfans la fucceffic en eft meilleure, $\mathrm{Ou}$ bien, adiouftoit-1 les ladres font riches, pource que pe fonne ne fe veut mettre en leurligne 
tant moins il $y$ a de perfonnes en ae heredité, elle en elt plus ample. II ur prend bien auffi, repliqua vn autre, eftre riches: lor feruant beaucoup ax lepreux \& à leur maladie, pour le oins l'adouciflant \& mitigant, fi on ivfe auec des confumez, \& fiofte la ranteur de la bouche, fi on $y$ tient de r. On dit auffi que Paracelfe, MedeA Allemand, a guery vn grand nome deladres par le moyen de l'or poble, combien qu'il foit facheux à croi, que l'or foit medicamenteux ou alienteux, puis qu'il ne peut dompter ftre nature, ou eftre dompté par icel. : \& les Medecins \& Apothicaires ont mis que par brauade vaine en urs medecines \& reftaurans de l'or \& sperles. Si elt-ce, va dire vn Drolle, le le prouerbe François. Il eft riche mme vn ladre, n'elt pas toufiours veriole:car i'ay veu vn ladre en noftre pariffe, qui eltoit des plus pautes, $\&$ fi laiffoit d'aller tout le premier à l'ofte, encores que ce ne fut a fon rang, fant cela, pource qu'il vouloit mal on Curé, salieurant que pour vin de- 
T R N T E-S I X I E S E nier qu'illuy bailloit, de luy en fair perdre vn cent, \& toute fon offert d'autant que tous les autres parroifler n'alloient iamais à l'offerte baifer 1 paix aprés luy:encores que les Legitt tiennent que c'elt vn grand figne d's mitié, de parenté, \& de conionctior de baifer la paix apres vn autre. Voil pas, adioutoit-il, vne grande rufe $\varepsilon$ malice en ce ladre?lequel eftant fi griel nement perfecuté, deuoit pluftoft per fer à appaifer l'ire de Dieu, qu'à fe yar ger: combien que i'ay ouy dire autres fois que les ladres, les femmes, \& le gens vieux, eftoient fort vindicatif \& grands trompeurs: parce que fe de fians deux mefmes; \& fçachansleur de faillir l'efprit, la force, le moyen, \& l'ac dreffe pour paruenir à quelque chof tafchét à y paruenir par malice \& fine fe:poffible eftant vne-des raifon pour quelle les lepreux deuiennent riches Mais pourtant, difoit-il, ie ne voudroi pas pour toutes les richeffes en auoir vi perit grain : non pas feulement pou moy, niais pour mes enfans, \& les enfan demes enfans, d'aut ant que quand 
nal eft hereditaire \& quion l'apporte lu vétre de la mere, il ne fe peut iamais uerir. Toutesfois pour corriger ce mal que toute la lignee ne foit entachee le ce venin, il fera bon de marier les enans defcendus de gros fang; auec des émes \& des filles bien faines; \& de bonne lignee : car la mere peut amortirpar a bonnefemence, $\&$ ion bon fang, le enin du pere, n'eftant pas la femme fi fuiete à la lepre que l'homme : à caufe de fes moys qui la purgent. Pour cela, c'eft vne chofe fort maunaife pourles enfans, d'eitie entez de franc en franc, \& là où la reigle, nube pari, ne doit auoir lieu: car fur tout il faut, s'il eft poffible, marier celuy de quiles paréts font doutéux \& fufpects, auec vne femme de bonne race, \& bien faine, à fin que le venind pere, qui eft caché pour vn temps, puiffe eftre corrigé par le bon téperament de la mere:parce que la mere, qui apporte plus à la generation que le pere, fera que les enfans ne fentiront rien de la difpofition naturelle du pere. Et non feulement pour celte maladie if elt bon de fe marier en race bien faine, 


\section{T R E N TE-S I X IE S ME}

mais auffi en toutes maladies heredi taires, principalement en la goutre: l, goutteux ne fe deuant approcher de $f:$ femme pendát qu'il eft aux abbois de f: maladie, s'il ne veut que fes enfans s'er fentent, la femence contagieufe s'ef. coulant \& s'amortiffant petit à petit. Et encores pour aider à tout cela, il fera bon de bailler à ces enfans doub. teux vne bonne nourrice, \& 2 bien faine, \& d'vne bonne temperature : car la bonne nourriture leur profitera beaucoup: comme auff les maladies natu. relles, aufquelles font fujets les petits enfans, les purgent bien fort, le venin des parents eftant tant plus mis hors $\&$ amorty, d'autantplus qu'ils auront eu la verolle, la rougeolle, la teigne, la galle, \& femblables maladies. Et combien que nonobltant toutes ces chofes, linclination demeure, qui peut monfrer la difpofition qui n'elt encores apparuë, $\mathfrak{f}$ on $\times\left\{\mathcal{L}_{\mathrm{e}}\right.$ de maunais regime: fi eft-ce auffi que celte difpofition naturelle, \& ce venin, fe peuuent diminuer auec le temps de ligne en ligne; iufques aे fe perdre, fi 


$$
S \text { E R E E }
$$

$s$ enfans rencontrent ou le pere ou mere fains, \& tout le refte que i'ay ct. Et ne voit-on pas bien, difoit-il, s plantes tranfportees \& tranfplanes perdre leur venin \& propre naurel? Mais s'il eft vray, demandavn atre de la Seree, que ceux qui ont les eux bien ronds foient fujets à la lere, \& qu'elle fe cognoiffe fi les cenres de plomb brufé nagent fur leur rine? cela denotant les humeurs eftre art graffes \& groffes, \& la melanchoe eftre corrompuë \& efpanduë par out le corps. S'il ent vray auffi, deandoit-il encores, que cefte malaie fe puiffe guerir, nonobitant qu'elfoit du tout formee \& enracinee. Ce qui me le faict demander, difoit-il, eft que Theuet dit en $\mathrm{fa}_{\mathrm{C}}$ Cofmograhie, qu'en Affrique, où il y a abonlance de ladres, on vend le fang des ortuës, \& la chair aufli, qu'on faict oire \& manger à ces malades, quiles ruerit fi bien qu'ils n'y retombent ianais. Dont ie in'elbahis, fi cela eft vray, que les tortuës de ce pais ne font plus cheres, \& qu'on n'en vfe, \& fiel-

$$
\text { Y } 4
$$




\section{T RENTE-S I XI ES ME}

lesn'ont point la vertu de celles d'A frique, quion nien faict apporter de, pais là, aufr bien que de la momi ou de leur fang, dont elles ont bea coup :eftans les torrués de par delà grolies \& grandes, qu'vne a fuffit difner de quatre vingts hommes, teft ayant trois pieds de large: fi bie qu'vn paffant s'ertant endormy delli vine tortue, penfant que ce fuit vn pierre, fe trouna porté fl loing hol de fon chemin, qu'il ne fçauoit où eftoit, ne qui l'auoit mis là. Tousceu de la Seree fe prenans à rire, celuy qu parloit de ces porte-maifons, va dire fivous ne le croyez, vous aurez plu ftoft faict de vous en prendre à The uet, que de l'aller veoir: \& ne l'euff pas creunon plus que vous, n'eult elt que l'hiftoire de l'Amerique le confirme, difant qúaux inles de la mer rou ge, \& au cofte des Indes, il fe trouue des tortuës fi grandęs, que d'vne có quille on en pourroit couturir vne mait fon logeable, ou en faire vir vaiflea nauigable. Nous irounons dans Spartiatus, qu'il fut donné à Albinus"vié

totruë, 
ortuë, pour baigner fes petits enfans: zque les enfans des Cefars auoient ce riuilege de fé lauer dans le cauitez des ortuës. Pline auff ditqu'il y a vn peule, quion appelle mange-tortuës, pare que les habitans de ceite contree e mangent que des tortuës de mex ju'ils peichent, \& n'ont auffi autre ouuerture de maifon. Mais, demaria quelqu'vn, lefquelles tortuës font eilleures pour la guerifon des ladres, u celles de la mer, ou celles de tere? Car ie fçay bien, que la plus finguere, \& qui a plus de faueur \& reque$e$, eft celle que lon nomme Nemorale, z qui faid fon terrier dans les bois: icheffe du paîs de Prouence \& Lanuedoc, \& delice des grands Seigneurs. Luelqu'vn prenant la parole, en lieu e refpondre à cefte demande, nous a apprendre à les prendre : difant que our amorfer tortuës, qu'il falloit rendre fel armoniac, vne once, oinon, lé poids d'vn efcu, greffe de eau, le poids de fix elcus : puis faie pillules, \& les bailler aux tortués, \& enantsà l'odeur, elles fe prendront. 


\section{T R N T E-SIX IES ME}

Cefte tortuë nous ayans mis hors $d$ chemin, comme elle auoit faict le pal fant de Theuet qui seftoit couch deffus vne: nous fufmes remis à noftr premier fentier par vn de la compa gnie, qui va dire : ie croy que la raifo par laquelle les tortués gueriffent. 1 lepre anec leur fang, vient de ce qu'e: les mangent les viperes, lefquelle foulagent auffi les ladres. Et ceux l: difo $t$ - il, n'entendent pas bien la prc prietédestortues, \& à quoy elles fes ment, lefquels, auant que les manges les font nourrir en quelque iardir. pour les purger de leurs humiditez, pl fans que les tortues les feroient mou rir, à cauf e de leur nourriture:car la tor tue eftant remplie de la chair de vipere troutue fa guerifon \& fon remede es l'herbe appellee thigan, par la contra rieté de cefte herbe au venin. Il el wray, adioufta-il, quaucuns affeuren que les chancres en Latir.cancri, \& tou tes fortes de huiltres, \& de poiffon gu a des coquilles, mitigent la chaleur:di fang, \& l'aduftion de la melancholie audibien que les tortues, tellemét qu 
es ladres, lefquels font prés de la mer, qui mangent ordinairement de ces oiffons qui font efcaillez, peuuent uerir de la lepre : les lepreux trouuans uerifon en mangeans de ces poiffons ncoquillez, auffibien qués grenouiles, qui fontés lieux marefcageux, \& ansles eftangs, fi on en mange ordiairement : pourueu que ce foyent de elles qui fautent, car celles qui fe traient tont trop venimeafes : les greoiiilles moderans la chaleur du fang, mitigans laduftion de la melancho: mefme on dit que le pourceau, ruet à ladrerie, fe guerit s'il mange des renoiiilles \& des ef creuices. Quelque utre va dire, qque fans enuoyer filloing $n$ Afrique pour auoir des tortues, $\&$ eleur fang, \& fans fe mettre en frais our recouurer des poiffons a efrails, \& des huiftres, il ne falloit à ces ma ades qu'vifer de la recepte de Cardan, wi affeure par experience, que le bain u premier fils né, où font les reliques u fang mentrual, guerit les lepreux.Sa aifon eft, que le fang le plus corrom. u, qui eft dans le corps. des mezeaux, 


\section{T R E N T E-S I X I E S M E}

attire à foy celuy qui eft moins corron pur, qui elt le refte des mentrues: fibie! que ce fang qui elt ef pardu apres lien fantement, eftant de telle wature quel noftre, toutesfois plus vitié ; \& plu chanld par la force de l'enfant', entran par les vaines $\&$ arteres dulepreux, con traint,purge, \& efteint l'autre fang cor rompui \& gafté, comme les rayón's dt Soleil font efteindre la flimme da féu \& comme le plus grand feit confumi le moindre, à caufe qu'il confune $k$ nourrifement da perit: le feu icy bas $f_{1}$ paiffant d'humidiré. le croy que c'ef cela, va dire vi de la conpagnie, qui a faict dire à beancoup de perfonizes queles lardre tuoient les petits enfáss pourenatioirle fing : \& que les fuper. ftitieux Inifs., qui lont fort fujets à lepre, en ont xuff tonfours effé accu. fez : ce qui feru t poffible de coưuertur pour ch ffer les Templiers hors de France, \& defe fainu de leurs biens. Er n'elt pas chofe noubelle, adiouttoit-il de dire que le fang des petits enfans gnerit de la lepre car nous trounens en Nicephorus \& Cedrenas, que Conitan- 


$$
\text { S E R E E. }
$$

in le grand, eftant furprins de lepre, fut confeillé par des-Medecins Grecs, de faire vn lac dufarig de petits enfans, là oulil fe baigneroit \& que d'alleurancé Hgueriroit: Pline ayant efoript que cela entoit familier aux Rois d'Egypte que de fe baigner aux fang des perits enfans, pour guerir de la lepre, parce que leur fang, eftant chauld \& hutride, elt contraite a celuy des lepreux, qui eft froid \& fec. Mais cebon Empereur ne peut endurer les larmes $\&$ cris de's meres de ces petits enfans, qu'ón leur auoit prins pour les tuer, tellement quils leurs furent rendus : \& fut guery Conftantin par la bonté de Dieu, s'eftant lané en la pifcine que le Pape Sylueltre luy enfeigna. Lebon Empereur difant,

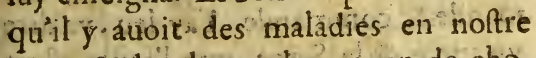
corps, \& des abus en beaucoup de chofes, quilne font point tant de thal enles endurant, quils feroient en les oftant. Si eft-ce, répliạta quelqu vin, quón dit que les laifs du fourd huy, lefquels ont lebriit de tuex tes petits enfaris, ae s'en feruenì pas pour bâgner lés ladres, car ils n'én defrubente qu vri jencores nele क्भवृ. 


\section{TRENTE-SI XIIES ME}

peuueut-ils faire qu'on ne le fçache comme lion a veu de noftre temps. Trente, où les Iuifs attirerent a eux vn petit garçon, lequel ils efgorgerent, l'é poinçonnants par tout le corps, dequoy l'autel que les Chreftiens vont veoir tous les ans là, porte fuffifant tefmoignage. Combien qu'aucuns difent que les Iuifs à la verité s'aident bien de fang humain, \& le facrifient, mais qu'ils l'acheptent des Chirurgiens \& maiftes d'eftures, \& quilis le mettent en vne phiole de verre, pour leur feruir à faire venir le diable, approchant cefte phiole du feu, appellant ce mailtre Gounin, iufques à ce que cefang foit bouilly, \& fe foit raffis:comparant lors pour obeir \& refpondre à tout ce qu'on luy demande \& commande. I'ay leu, va dire vn autre de la Seree, que l'huile eftoit fort bon pour baigner les ladres : ce qui elt confirmé par Olaus, qui raconte que les Efpagnols en lauoient leurs ladres, \& pour cela leur trafficque ceff $f_{a}$ ayans accouftumé de vendre leurs huiles à ceux de Septentrion, quand onleur sut dit que les Efpagnols la vendoient 
prés qu'ils s'en eftoyent feruy à lause eurs ladres. Et me fuis fouuent esbahy, lifoit-il,de ce qu'en a efrrit Olaus, veu u'il y a en EIfpagne peu de ladres, \& quafi point, craignans tant cefte maladie qu'ils ne mangent gueres de chair de pourceau eftant chole notoire, que e frequent vfage de manger chair de pourceau engendre la ladrerie : attendu que les pourceaux par le rapport d'Aiftote, font fujets à engendrevien leurs corps vne abondance de grains de mezellerie. Ce mal fe guerit auffi, adioufta quelque autre, fi nous croyons Pline, auec menthe fauuage, fes fueilles mafchees $\&$ appliquees fur la ladrerie, pas l'experience de ce qui aduint fortuitement en vn lapre ? lequel fe voulant déguifer \& mafquer, de peur d'eftre cogneu, le frot:a le vifage de Menthe fauuage: mais la fortune (luy difant mieux qu'il ne penfoit) voulut qu'il fe trouma guery de fa ladrerie, aucuns eftans en cefte opinion, que toutes les proprietez affignees a la menthe faunage, fe doyuent entendre de la Napeta, qui eft le Calamát commun des A poticaires: Les 


\section{TRE N T EOS I XIES M E}

autres difent"qu'vfer foüuent de racines d'A fperges cuites en vin-aigre, elt fort bon pour la fanté des ladres:comme auff la graine de Pauot blanc, \& les oindre de la liqueur de Cedre. Les moderres alfeurent aufl, adioaftoit-il, que la chair de viperes mangee par les ladres, les guerit:le vering du ferpent attirant foy le venin de la lepre: comme d'aunture fut efpiouné ce dit Galien, par des moifionneurs, lefquels troumants vn ferpent mort \& noyé dans leurvin, le baillerent à boire à vn ladre defefperé, quile beut entieremét, ne fçachant rien de la vipere morte dans ce vin : dont-il euita la force de la maladie. Et ne faut pas s'efmerueiller de cela,difoit-il, veu que deux poifons en l'hommé fe peutét deffaire \& tuerl'vn l'autre, luy demeurant fain:cela fe faifant, de ce que nature irritee par le venin du ferpent, reiette \& repouffe tant qu'illuy eft poffible, levenin du ferpent, \& la matiere veneneufe de la lepre, laquelle faict le mal. Oubien ćef qué la chaleur du ferpent, en ouurant les pores, dechaffe celt humeur ajelancholiquie des ladres au deज\%.

hors, 
ors, \& à la peau : car en vfant foument e viperes, il fort à la peau des grolles ufules fquameufes. Que s'il en ya,dioit-il encores, qui ayent en horreur 'vferde ferpens: que ceux la mangent es poules qui auront efté engrefrees de iperes; car il a efté experimenté cefte iande eftre fouveraine contre la ladreie : auffi qu'il n'y a rién meilleur pour es elephanticz que le ius d'vne ieune oule, encores qu'elle n'ait efté nourrie le viperes. Que fi la chair deviperes, ou e vin beu où elles auront trempé, ou le heriaque de férpens, ou le trocifque le Tyr meflé auec de l'eau $\&$ diu vin lanc, en prenant trois fois la fepmaize : ne gueriffent du tout ces pauures ;ens, pour le inoins cela leur fera venir ne nouuelle peau: le corps s'enflant bie ort en vfant de ces remedes, la chair en iftát mollifiee, qui faict tómber lá peau le deffus, qui eft dure, \& toute croufteenee : \& par deffoubs reuient vie a unre peau molle \& plus douce. Ie croy, epliqua vn autre, que les viperes ne ont pas fi veneneufes à les manger cóne on le penfe', leur fubftance eltant

moyen 


\section{TRENTE-'SIZIES M E}

moyenne entre ceft humeur vitieux, \& le corps: car fi elle approchoit plus pre: du venin, elle tueroit comme faict it venin : aufii fi elle n'en tenoit quelqui chofe, \& qu'elle nourrift feulement,el. le fe conuertiroit en la fubltance du corps, \& ainf ne feruiroit de rien à guerifon de la lepre. Que fi voulez, adiouftoit-il, que la vipere aye encores plus de vertu pour feruir aux ladres, faut, ce difent Diofcoride \& Eginete, faire vne maniere de faupoudré, qui fe faictainf. Il contient prendre vin pot de terre tout neuf, \& $\mathrm{x}$ metre dedans le vipere, apres auoir efté efcorché,en luy oftant la telte \& la queuë:puis y metre du fel,\& des figues pilees, auec du miel? \& le pot eltant bien couuert, metre le tout cuire en vn four; $\&$ apres piler $8 z$ reduire le tout en poudre:que fi aucun en veut manger, le trouuerra fort bon \& fauoureux, en le mangeant auec autres viandes. Et pour vous montrer que les ferpens n'ont pastant de venin comme on dit, ou bien queleur venin foit corrigé en quelques cótrees. nous trouuons que les Ethyopiens Macro- 
es viuent cent \& fix vingts ans, pour anger de la chair de ferpens, \& s'en ourrir, fe gueriffans par ce moyen de nezelerie, par quelque proprieté ferette \& occulte. Aucuns auffi nous afeurent, difait-il encores, que fi vous uez vin lepreux en vn bain qui aura ruy à lauer vn cadauer, \& homme 10rt, il guerira de la lepre. Et à fin que é penfiez que ce foit de la forcellerie - Bodin, cela fe faict à raifon quela ratiere de la ladrerie, qui eft iettee iufues à la peau,n'y fera plus pouffee par nature, à caufe de l'antipathie \& conarieté qu'a ce corps mort auec la lete: d'autant que tout animal fuit l'oeur d'vn autre animal de fon mefine enre: dont aduient que cefte matiere ui faict la lepre, fuiant la fenteur du. idauer, s'amaffe toute en vn, $\& s^{\prime}$ eftant ndue forte par la quátité, eft mife deors, ou par bas, ou parfueur,ou par aue voye. Ie ne veux oublier auffi à vous re, adiouftoit-il, que l'herbe veronine, tout fon ius exprimé de fes fureil$s$, que l'eau qui en eft diftilee, par fon equent vfage, apporte guerifon aux ladres: 
TRE N I E-S I X I ES M E ladres : \& qu'à celte caufe on l'appe l'herbe aux ladres. Que s'il leur fort boutons \& taches de ladrerie au vil ge, le jus ouvin de fraifes eft foumera pour les ofter : moyenant que cefte ait elté mife dans vn vaiffeau de verr lequel ait eftélong-temps en vn fumie Aufi qu'aucuńs afferment que l'Em raude puluerifee, prinfe par les lepreu leur elt grandemét profitable: auff bic que les eftuues chaudes de boix de lar $\&$ fon eau : eftát fort bon auffi contre venin vfer d'eau de la mer, \& s'en l'aue \& fe baigner en l'éau de mer, laquel les Egyptiens oht creu guerif toutes $m$ ladies: eftant auff foutuerain pour 1nal, natiger fur la mer, a caufe qu'e le prouoquele vomir:ce qu'elle faict, par la naujgation, poúr n'eltre vn mo uenèt felón noltre naturel, \& inaccou fumé, toutes chofes non accouftumee troublans les perfonnes, ou bien quel fenteur \& odeur de la marine prouoqu le vomir: auec lequel les humeurs, qu caufent la maladie, fortent dehors : le ladres ayans en leur eltomac, \& $z$ es pat ties quility fertènt, grande aftluence d $=30-1$ 
eft humeur corrompl : ce qui faict u'ils parlent ranche, eftans toufiours aroiiez, à caufe de la corruption de la oix , \& de fés organes. Parquoy fi vounzefprouuer fi quelques gueux ne contefont point les ladres, faut regarder ils fe font point liez la gorge, auec vn 1 , a fin de parler ranche. Quelque auede le Seree ayant peur qu'on le foup. onnaft d'en anoir quelque grain, n'en ifant rien, va dire, que fi la lepre ne faiit guerres que faifir v homme, qu'il y auoit plus affeuré remede que de le aire chaftrer, comme il fe tiouue tit. de uppare vitiagtis, 20. lib Decret. cap. 5. Exeis pudendorum multium prodeft, d'autant, ifoit-il, que la complexion du ladre, haude \&r feche, fera changee \& alteree $n$ vne froide \& humide: celte frigidité huumidité garantiffant non feulemét e la lepre, mais auffide toutes ma ladies ui viennent de chaleur \& ficcité : \& fi elaiffera ce chaftré, pour eftre leger de exux grains, d'eftre bon Capitaine hon, re:comme la Turquie nous en rend on tefmoignage Et confeillerois toulours a ces paures gens, (1a maladie confirmee 
TRE NTE-SIXIESME confirmee ou non) de fe mettre a l'exá men de la copelle: tant pour la palier, prolonger leur vie, que de peur $\mathrm{d}^{\prime} \mathrm{y}$ ton ber:\& auffi qu'on les y devoit contrair dre, à fin que la progeniture en fult plu ftolt perdue : car fi les ladres n'engen droyent point, il y a long temps que race en fuft perdue. Mais, repliqua que qu'vn, Vlpian defend de chatrer les claues pour mieux les vendre, $\&$ dit qu ceux qui les font chaltrer pour leur plai fir, font dignes de mort, \& punis pa la Loy Cornelia, ou bien par la Loy d talion, \& de la pareille: \& que mefme ceux qui fe font chaltrer, encores que ce foit par deuotion, doyuent eftre chatiez par les Loix \& par les Princes: fi ce n'elt par necelficé, ou pour euiter pis, comme en ces pauures gens icy : le $\mathrm{Ca}$ non permettant aux ladres de fe faire chaftrer, difant quion ne peut ofter de la Preftrife celuy qui pour la lepre aura defgarny labourfe de monnoye. Que fi quelquivn fe faifoit chapponer pour fon vilité \& profit, \& non pour fanté, pour auoir la voix grelle, \& pour chanter le deffius, ie le penferois puniffable, 
S E R E E.

es femmes eftans de mon opinion: \& tuffile Canon les priue des fainctes ortres, \& Galien dit que les tefticules ont parties plus excellentes que le :eur: d'autane que le cour eft prin cipe le la vie feulement, mais les tefticules ont la vie meilleure: eftant vne choe plus digne de bien viure, que de riure fimplement. Ce fera des tefticues, va dire vn autre, ce que vous oudrez: mais fi mes parents eftoient oubçonnez de lepre, ie ferois bien vuyler cefte belle marchandife de mabouique, pour euiter cefte leproferie : les ommes pounans eftre priuez de leurs arties genitales, fans encourir la mort: :omme on veoic des garde-couches du "rád Seigneur, à qui on couppe les trois arties de la generation. Et commeles iommes, fans danger, peuuent eftre pritez de leurs parties genitales, tout de ne?me eft des femmes, qui peuuét eftre riuees de leurs parties feminines geniales; \& demeurer en vie: la matrice de a femme, ny les parties viriles des hönes, n'eftans point neceffaires àla vie, y à la fanté. Nous troulions efcrit, adiouftoit- 
IRE N T E-S IX I E S M E iouftoit il,dans Thalcondile Athenie que Tamburlans, qui print Baiazet, $\mathrm{Se}$ gneur des Turcs, eitoir fi ennemy mo tel lesladres, quaautant qu'il en rel controit deuant Juy, ils fe poutoye bien affeurer de farre le faulc:difant $n^{3}$ fre raifonnable de laifier pluslongu ment regner vne telle pefte: les ladr ne feruans, difoit-il, que d'infecter autres, \& procreer leurs femblables, auec cela viuans en tant d'angoiffe? de martyre, qu'on leur faifisit vn gran bien de les ofter de ce monde. Il deuo regarder, repliqua vn de la Seree, fil maladie eftoit confirmee, ou non: ca ie penfe que par antidotes, celle qui e. du pręmier degré fe puiffe curer, cell du fecond fe pouuant feulement ca chier: du tiers, cefera beaucoup fi pa receptes elle fe peut mitiger : carla le pre qui fe faict par vne aduftion $\&$ cha leur d'humeurs, principalement melá choliques, eftant incontinent en $\mathrm{fa}$ for ce \& vigueur, fe rend fort cortofue, \& corifinge, nonobithnt tous ces reme des.Dont aduient, difoit-il, queles per fonnes fortes \& robuites's chaúdes pal thor wot

nature, 
ar nature, comme font les ieunes, e viuent gueres en leur maladie : là ù au contraire, fil la maladie de lepre ient de caufe froide, \& d'humeurs qui 'efpoiffiffent \& s'oppilent, tellement ue la chaleur n'y puiffe entrer, ils iennent à fe congeler, lors cefte lepre emeure long temps, fans fe confirter ny empirer, en vn mefme eftar, fi ien que ceux qui font lepreux de ce tosfang, \& de cefte humeur froide, emeurent long temps en leur ladrerie: omme font les enfans, les gens vicux, : les femmes. Que s'il s'en trouue de tux-cy qui nee vinent gueres, cela adient à caufe qu'il y a toufiours en nous lus de chaleur bruflante que de froieur gelante. A cefte caufe, adiouftoit, les Medecins defendent à cefte madie les viandes trop chaudes, pource u'elles bruflent le fang, \& le difpoint à la lepre: \& trouuent aufí mauais de manger du poiffon fraifchemét rins, parce qu'il augméte le mal,comien que la marine foit bonne \& faine ax ladres. Et fur tout deffendent de anger des lentilles, que les Iatins Liu.iij. 
TRENTESIXIES ME nomment lens ou lenticula, car ceux $q$ en vfét font fort fujets à deuenir ladre Mais, luy repliqua quelqu'vn, pou: quoy donc eft-ce que la lepre fe mu tiplie plus és païs froids qu'és regior chaudes, ficelle qui fe faict par ch: leur eft plus afpre, que celle qui 1 faict par le froid? Et parce, luy futrefpondu, que ceux qui demeurente pais froid, ont plus de chaleur intern que ceux qui habitent és regions chat des. Il fut aufí dit, que la lepre fe mu tiplioit plus és regions feches qu'és hu mides, à caufe des humeurs qui fe for plus groffes \& efpoiffes par la ficcit Dont aduenoit que les lepreux n'e ftoient gueres malades de fieures, 1 ficcité, qui eft en eux, empefchant 1 putrefaction, de laquelle prouenoi Ia fieure : ainfi ceux qui font gras di nature difficilement deuiennent ladres à caufe de l'humidité qui refifte à la fif cité, la ficcité rendant le fang gros efpoix. Quxe s'il aduient que les perfon. nes graffes deuiennent lepreufes, on le peut aif'ement cacher, d'autant que ce qui engraifle gueritla lepre. Quelquivn 


\section{- SERE E.}

u'vn prenant la parole, nous va conr d'auoir ven vn Medecin quỉ proettoit de guerir les ladres, les gouux, les hectiques, paralytiques, \& líes maladies, deplorees de tous les edecins. Celuy qui fe vouloit mete entre fes mains, qui eftoit honneement ladre, luy enuoye demander l'argent à emprunter : ce Medecin npirique luy mande qu'il eftoit paue compagnon. Lors le malade ne ulut fe mettre entre fes mains, luy ant, que ce n'eltoit qu'vn affronteur, que s'il fçauoit guerir les maladies nt il fe ventoit, qu'il deuoit eftre is riche que les Foucres. Ce difcours y, vn autre de la Seree va conter vne toire pitoyable \& veritable, d'vn ieuhomme nouuellement marié, lequel r la jaloufie de fa femme fut rédu la: car cefte femme pour fe vãger de mary, \& de celle quil entretenoit, expreffement la cópagnie d'vn là, dont puis apres, elle, fon mary, \& 1 amoureufe deuindrent ladres. Et fi touftoit que ce n'eftoit rien de nouau, veu qu'on trounoit efcript, que 
TRE.NTE S I XIE S M E

les femmes des anciens Romains e failoient bien quafi autant, toutesfoi fans qu'elles fe miffent en danger: $\mathrm{ca}$ ces Dames eftans ialouzes, \& $\int_{e}$ you lansvanger de celles fur qui elles àuoie opinion de leurs maris, eftouffoient $d s$ ftellions ou lezards dans les fards dor elles eftoiêt affeurees que leurs comp? gnonnes d'amours fe fardoient le vif ge, pour les rendre lentilleufes, de faictes, \& le vifage tout ladie \& bot tonné. Que aifément la ladrerie 1 donne, diloit-il, nous trouuons efcrif que par faute d'auoir bien nettoyé yn lancette de laquelle on auoit frai chement faigné vn ladre, \& puise auoir faigné vn autre, il s'enfuiu: vne telle corruption en la maffe fan guinaire, par limpreffion confequu riue à l'ouuerture faicte par ladite lan cette, que non long temps apres parw rent quelques fignes de ladrerie. Auf on a veu par experience, que la peft prend à celuy qui aura efté faigné d'y ne lancette non nettoyee \& emundee qui aura percé la bolle d'vin peftifcré Et fine fçay, adiouftoit-il, fi ie doj 


$$
S \text { E R E E. }
$$

croire que pour auoir fubitement 1 endu l'vrine apres vn ladre, au mefme lieu, que la contagion s'en enfuiue, aufi bien quon prend la caquefangue allant apres vn autre à la moime garderobe. Vn fecond Panurge, qui efioit en cefte Seree, voyant quon ce piffionnoit de ce iaune homme qui citcit deuenuladre par la ialoufie de fa femme, pour nous refiouir, va commencer à dire le bien \& le plaifr quauoient les ladres, aficurànt qu'ils n'eftoient pas fi

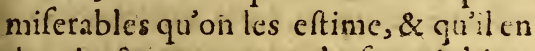
deuoit eftre creu pour le fçauoir bien. Premierement, dilivit i!, lis lides ne fout point courmentiz dz fisutes, 1. ficcite eftant contraire à la putr,f. ction qui engendre la ficure. Ils ne font point auffi fujets aux poux, morpions, puces, punaifes, \& autre vermine venant de corruprion, ne à la maladie qui s'appelle Morbus pedicularis, \& phtiriajis, la ficcite empefchant toute pourriture: ny à la pefte, vn venin repoufiant l'autre:parquoy il me femble, difoir-il, qu'il feroit fort bon de faire cftudier telles gens en la Medecine \& Chirur-

$$
\mathrm{Z} 3
$$


- TRENTESIXIES ME gie, pour fecourir les pauures pefter d'autant que ne prenans point la pefte on ne feroit fans fecours, comme ilar riue bien fouuent par la mort des $\mathrm{Me}$. decins \& Chirurgiens, qui font fujet à la pefte commeles autres. Les ladre. auffi, difoit-il encores, n'ont nulle peu d'eftre coquus, perfonne ne s'appro. chant de leurs femmes, de peur de de. uenir ladres, comme le ieune homme s'ils s'accoftoient de la ferrme d'va la dre, mefmes les Diables de Bodin n'er oferoient approcher : qui feroit vn f grand bien pour les maris ialoux, que ie m'affeure qu'il en y a qui voudroient eftre ladres pour cela. Outre ces commoditez, les ladres ont plus de plaifir aux femmes que les autres, \& font quafi toufiours deffus', à raifó dela chaleur eftrange qui les brufle par le dedans: \& aufli que leurs vafes fpermatiques font remplis de groffes humeurs crues, vifqueufes \& flateufes, qui font enfler \& dreffer le trinquet : à cefte caufe plufieurs femmes ayans eu affaire à des ladres, ont fouhaitté que leurs maris le fuffent. Par la mefme chaleur 
les ladres font inextinguiblement alterez, beuuans fempiternellement, \& vous fçauez le plaifir que c'eft de boire de bon vin : ce qui fait quion ne troule gueres les ladres fans barril, \& fans leur lettre de couronne, auec le petit cntonnoir:combien que Paré die quon leur haille le barril \& les cliquettes, à fin de les cognoiftre. Et me founient qu'il n'y a pas long temps que des Reifres trouuans des ladres à cheual, auec leurs barrils, que les Mattois appellent le roiiillard, leur fircnt bonne chere, \& apresauoir beu au roüillard, cependant qu'ils leur bailloient vne note auec leur boys-crolant, vont dire bonne ladre, bonne ladre, boiuent à cheual, \& nous à pied. Vne autre commodité qu'ont les ladres, c'eft qu'ils vont toufiours à cheual, dont $i^{2}$ en ay veu protefter diniure atroce quand ondifoit, ie ne vay point demander les Eftreines \& l'Aguillauneuf àcheual. Les autres aduantages des ladres font qu'ils couchent feuls, \& ont leur chambre à part: ils ont du plaifir à fe grater, à caufe que la peau leur cuit 
TRENTESIXIES ME toufiours, ie mien rapporte à ceux qi ont efté galeux s'il y a du plaifir à grater:ils ont toufiours de l'argent frai c.u pour en auoir il elt aiféà leuer leu boutique, il ne faut qu'vn petit mou choir, \& le barril deflus, \& en vnè de muins vn ayguillier de Croutelles, 8 voilà leur eftat dreffe:à cefte caufe or dit, il eft riche comme vn ladre: \& vou fçauez que pour eftre riche on $n$ craint point toutes les plus grande mefchancetez \& vilennies du monde pour y paruenir. Vous direz, repliqu vn autie, toutes les commoditez \& plaifrs que peument auoir les ladres, ne men feraz-vous pas enuie, com bien que ie fçache qu'il y a des perfonnes qui le font, qui nole penfent pas eftre: car on tient que le Cancer $\&$ les Loups, font yne efpece de ladrerie, qui eft particuliere, \& qui n'eft qu'en vn lieu,\& la lepre eft vn Cancer vniuerfel, lequel occupe tout le corps: \& combien que la lepre, le Cácer, \& les Loups vienuent d'vne mefme caufe, la lepre toutesfois qui ne faict que commencer,fe guerira pluftoft que le Cancer \& 
les Loups: d'autant que la matiere qui caufe cefte lepre particuliere de ces deux, eft dedans les veines, qui eft caufe quion ne les fçauroit guerir fans mutilation du membre oú elles font attachees, en oftant les veines dans lefquelles eft la racine du mal : \& la matiere qui faict la lepre vniuerfelle, eft efpanduë par tout lecorps, \& parce plus ayfee à chaffer. Il vaudroit donc mieux, va dire vin Franc-a tripe, efre honneftement ladre, que d'aunir vn Cancer ou des Loups : Le Cancer toutesfois ayant de plus griefs fymptomes \&z accidens que les Loups, à caufe du lieu où il s'attache, qui eft le plus fouuent és mammelles des femmes, qui font molles, ayans vne grande caparité , quii les fait plus fujetes au Cancer que les hommes, quii font plus molefez des Loups aulf que les femmes:les hommes en ceft endroict eftans de meilleure condition que les femmes, parce qu'il vaudroit micux nourrir dix Loups qu'vn Cancer.Ie fçay ; fut-il repliqué, pourquoy on appelle vne efpece de lepre particuliere, Cancer: mais 
T RE N IES I X IE S M E ie voudrois bien qu'on meuft appris pourquoy on nomme l'autre elpece d lepre particuliere, lupus. Illuy fut rel pondu, que c'eftoità caufe que ceft maladie des Loups, qui s'attache com munement és iambes, mange toufiow Ia partic oì elle eftencharnee, comm les Loups, beftes voraces, mangen beaucoup de chair, \& en mangent es figrande quantité, qu'elle demeure pourrie en leur eftomac l'efpace di huict iours, \& eftant puante, ils iettem parmy l'air des fumees groffes $\&$ indi. geftes, par lefquelles l'air prochain of infecté : lequel alternatiuement dépra. ue \& corrompt l'air circonuoifin, er forte que de l'vn à l'autre il paruient aे l'homme qui aura veu le Loup: fi bien que ceft air corrompu faifira tellement les poulmons, ferrant l'artere vocale, quauec grande difficulté on pourra parler, parquoy on dit, il a veu le Loup: ou bienle Loup enroiie vne perfonne de fon regard par la frigidité de fon cerwean, laquelle feiuge par fa groffe tefte: la vertu donc vifible s'addreffant au Loup pour.le regarder, attirè 
S E R E

264

foy de fa froideur, laquelle renuoyec à leftomac, où font les organes de la roix, faict qu'ils font reftraincts \& $\mathrm{re}$ errez. Et parce que monfieur Scaliger, difoit-il encores, fe moque de ce commun prouerbe, il a veu le Loup, ie le confirmeray pat Theocrite, quj dit, :omme on m'a fait à croire, As tu veus e Loup, que tu ne parles point? \& par Vergile. Lupi Moerin videre priores. Mais foit vray ou non, fi eft-ce que :eux qui ont les loups aux iambes font arouez, auffi bien que les ladres, \& ont la voix caffe \& baffe: que finous Lounions garder nos iambes des loups, uffi bien qu'on en garde les brebis, n'auroit pas fi grand peur d'eux : cas on dit que le Loup ne fera aucun tort ux brebis fi vous liez au col de celle ui va la premiere va ail fauuage. Puis jue nous terons le Loup aux oreilles; a dire vne Feffe tonduè, ef coutez en leux ou trois petits contes. Le pregier fera d'vn homme riche, que tous ognoiffez, lequel a achepté vne majon, où maintenant il demeure:tous dient qu'il a bon marché, que la maifon 
TRE N TES IXIES ME eft belle, bien baftie, bien ayree, bien faine,fort fpatieufe: tout le mal qu'ils y troument, c'eft qu'il a de mauuais voifins, d'autant qu'ils le laiffent mange aux Loups. Lc fecond conte fera que ce mal auoyfiné vin iour voulant vendre fon cheial à vn de fes voifins; l'ache. preur s'efmaye fi le chenal n'eftoil point vitieux, craignant qu'il fut paoïreux \& vmbrageux, on l'affeura quic non : carluv difoient fes voifins, comment feroit ce cheual ombrageux: quand les Loups montent tous le: iours defítus, \& les porte fans en auoir aucune peur? Noustroutuons, adiou. ftoit-il, d'vn qui fe vantoit que le peuple le porta fut fes efpaules, le ious quu'il prenoit pofléfion d'vn office : luy eftant repl qué qu'on le croyoit bien,à caufe que les Loups l'empefchoient d'aller, les Loups des iambes eftans bien differens de ceux des champs: cat ceux dés iambes empefchent d'aller, \& les autres font caure de legereté, d'autant qu'on affeure quéles cheuaux qui ont elté tirez \& refcous des Loups, quion appelle licopfades, font plus le- 
S E R E E.

265

gers que les autres: mais auffi ils s'accordent en vne autre chofe, c'eft que les Loups desiambes rendent la partie où ils s'attachent fi tendre, que fans les ligamens elle tomberoit à pieces \& à topins: \& les Loups animaux ayant mordu vn mouton, ou quel que autre animal, rendent auff leur chair fort tendre, à caufe de leur haleine, laquelle eft fichiude \& ardente qu'elle fond \& digere les os mefmes en leur eftomac: ce qui fait que la chair de la befte mordue du Loup fe cotrompt ayfément, \& auffi deuient plus tendre, fe difent ceux qui ont mangé des animaux arrachez d'entre les dents des Loups: le foye du Loup ayant outre vne proprieté \& vertu fecrete, qu'en le mangeant il guerit ceux qui y ont mal. Sur la fin de la Seree, laiflans la lepre particuliere, ils fe mirent à difputer fi les capots de Gafcogne eftoient vrayement ladres: mais nen eftant rien conclud, ie ne mis rien en ma memoire, finon qu'il fut dit que l'efpreunela pl' certaine pour fçauoir fi vn homme eft ladre, eftoit de luy mettre vn poinçon bien auant dans 
TRE N TES IXIES ME|

la fole des pieds, car on affeure qu'il ferabien ladre sil ne le fent: \& de là eft venu qu'on dit d'vn homme qui laiffe gouuerner fa femme ou fes parentes à quelques-vns, c'eft homme eft bien ladre, il ne fent point quand on luy pique fa chair. Et auffi fut dit par vn de la Seree, que fi cefte efpreuue eftoit vraye, que les Diables rendoient donc ladres ceux qui fe donnoient à eux, tous les Sorciers eftans ladres aे vingt \& quatre carats: parce, difoit-il, que Bodin affeure que les Diables marquent les leurs, à fun qu'ils les obligent à eux par ce moyen, comme par vn Sacrement': \& qu'en cefte marque on pourroit fourrer toute vne grande ayguille, ou quelque autre fer poinctu, fans qu'ils en fentent rien, eftant vn moyen aux magiftrats de conuaincre les Sorciers auffi bien que les ladres. Il me fouvient aufi qu'vn marchand, qui eftoit en cefte Seree, ayant bien royagé, nous centa qu'il auoit efté en m certain pays où les fourrures de hermine n'elteient point cheres, parce difoit-il, que l'attouchement 
ment de ces peaux rendoit les hommes ladres. Ie ne fçay s'il vouloit dire, que telles fourrures eftans bien cheres en ce pays, rendoient ladres ceux qui les portoient. Et puis ce marchand icy, non hors de propos, nous conta vne belle rime que luy $\&$ vn autre marchand firent en allant à vne foire de Poictou, ayans trouué en la valee de fainct Mayxant vn barril : car l'ayant amaffé, l'vn fe met à rimer, \& puis attache fa rime auec de la cire, à l'vn des coftez du barril trouué : \& pource que c'eft de la rime de marchand ie la veux dire : il y auoit ainfi:

\section{Ce barril fut reconuert}

Enla valee fainct Mayxant,

Lequel on trouna tout ounerts

Et delaiffé pour vn paffant.

L'autre marchand, auffi bon rimess. que fon compagnon, prenant ce barril, le va pendre àvn arbre, apres auoir mis de l'autre cofté ce quatrain:

Q us'aucun de vous ne fe hazarde De prendre ce unide barril, 
TRENTES IXIES M E Sice n'eft quelque affeuréladre De pere en fils, so de droict fil.

Ce marchand, apres auoir recité ees belles rithmes, nous affeura quau retour de la foire ils retrouuerent encores leur barril pendu où ils l'auoient laiffé , bien fort augmenté d'autres rithmes \& billets : car les paffans qui fçauoient lire, njauoient garde de prendre ce barril, \& le defpendre, encores que le cartel efcript deffus le permift à aucuns : ceux qui ne pouuoient lire, encores moins, ayans peur que ce fuffent quelques Magiciens ou Sorciers qui l'euffent mis là, pour faire tomber quelque malheur à ceux qui enleueroient ce barril: les paffans mefmes n'en of ans approcher non plus que d'vne chofe fee \& enchătee. Alors quelqu'vn, en s'en allant, va dire, ie fuis d'aduis que nous laiffions le barril où il eft, auffi bien n'auons nous point befoing de boire pour meshuy, niefmement en tel vaiffeau, principalement fi le barril eft de bois d'If, parce que Pline dit, qu'ayans efté faicts en France des barrils du bois 
$\begin{array}{cc}\text { SE E RE E. } & 267 \\ \text { d'If d'Efpagne, pour mettre \& porter } & \end{array}$ du vin, que ceux qui en goufterent ne deuindrent pas feulement 12 dres, mais aucuns en moururent.

Fin du troijlefme Liure.

ET NVGA SERIA DVCVNT.

Cefte premiere imprefjoon, faicte fur la co. pie augmentee to corrigee parl' Autbeur, esté achenee le troifrefme iour de Nonerinbre mil fix cons fept: 


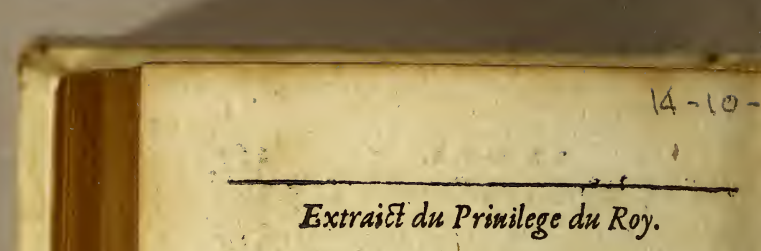

Ar grace \& Privilege du Roy, il eft permis à le3. remie Perier, marchand Libraire en l'Vniuerfité de Paris, d'imprimer ou faure imprimer Les Serees de feu Guillawme Bouchet, diuifees en trois volumes, nouuellement augmentees, reveuës \& corrigees par luy melme. Et deffences font faidtes à tous autres $L$ ibraires 2x Imprimeuts de ce Royaume, de les imprimer ou faise imprimer, vendre ny diftribuer, foit enfemblément ou feparees, ny en extraire aucune chofe fans le congé $8 x$ confentement dudit Perier, pendant le temps \& terme de fix ans entiers \& accomplis, à compter du tour 24 datte que la premiere impreffion en fera faicte, fur peine de mille liures d'amende, applicables le tiers au Roy, l'autre audit Perier, \& l'autre aux pauures, \& de zous defpens, dommages \& interefts, comme plus anplement eft contenu \& declaré és lettres dudit Privilege. En outre, veut fadite Majefté qu'en mettant vn exsraitt dudit Priuilege au commencement ou à la fin de chafcun defdits liures, il foit tenu pour bien \& deuëmér fignifić à vn chafcun. Donné à Paris le feptiefine iotx d'Aouft, 1607 .

Par le Rog en fon Confoils.

$$
\text { DE VERNESON. }
$$

Et feclleas en fimple quexë du grand fear de cire iaulne.

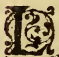

Edit Perier a confenty \& confent que Thibaud Ancelin, Imprimeur ordinaire du Roy à Lyon, iouilfe dudit Priuilege, ainfí qu'il a efté accordé entr'eux és Eftudes des Notaires foubsfignez, à Paris le $2 \varsigma_{0}$ ious d'Aouft, 1607 .

BELOT.

FARDEAV。 


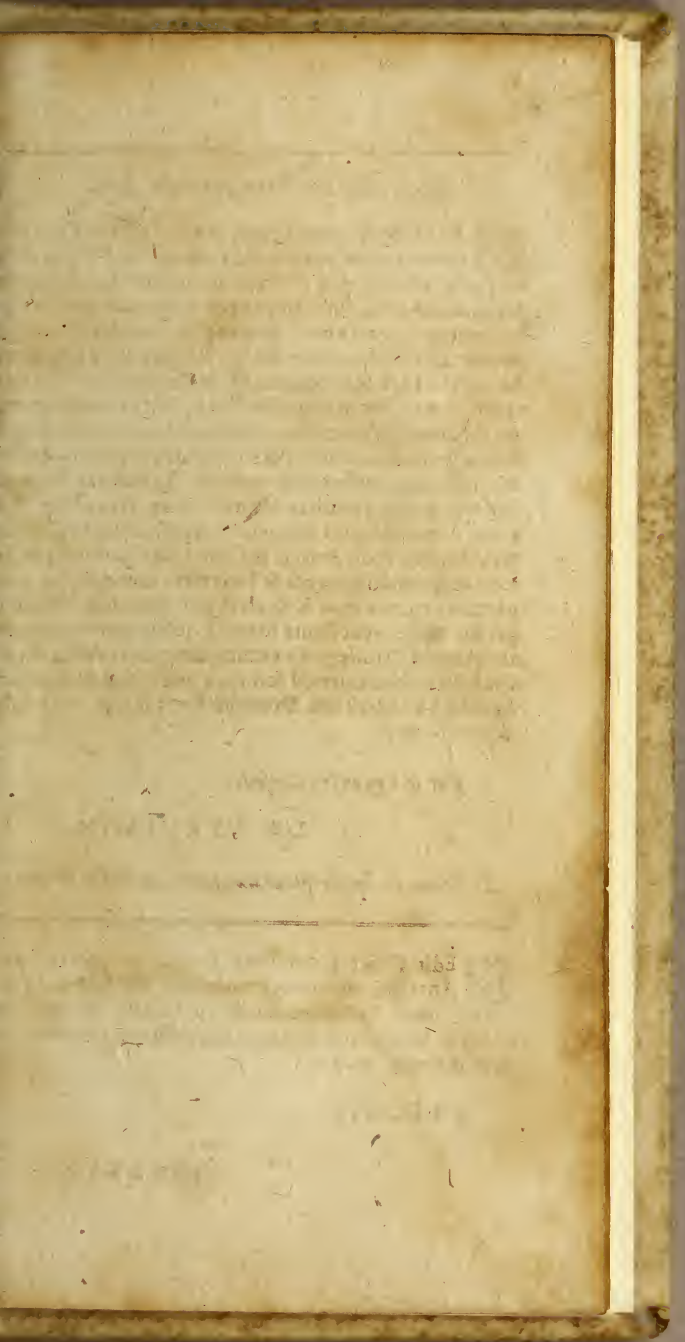




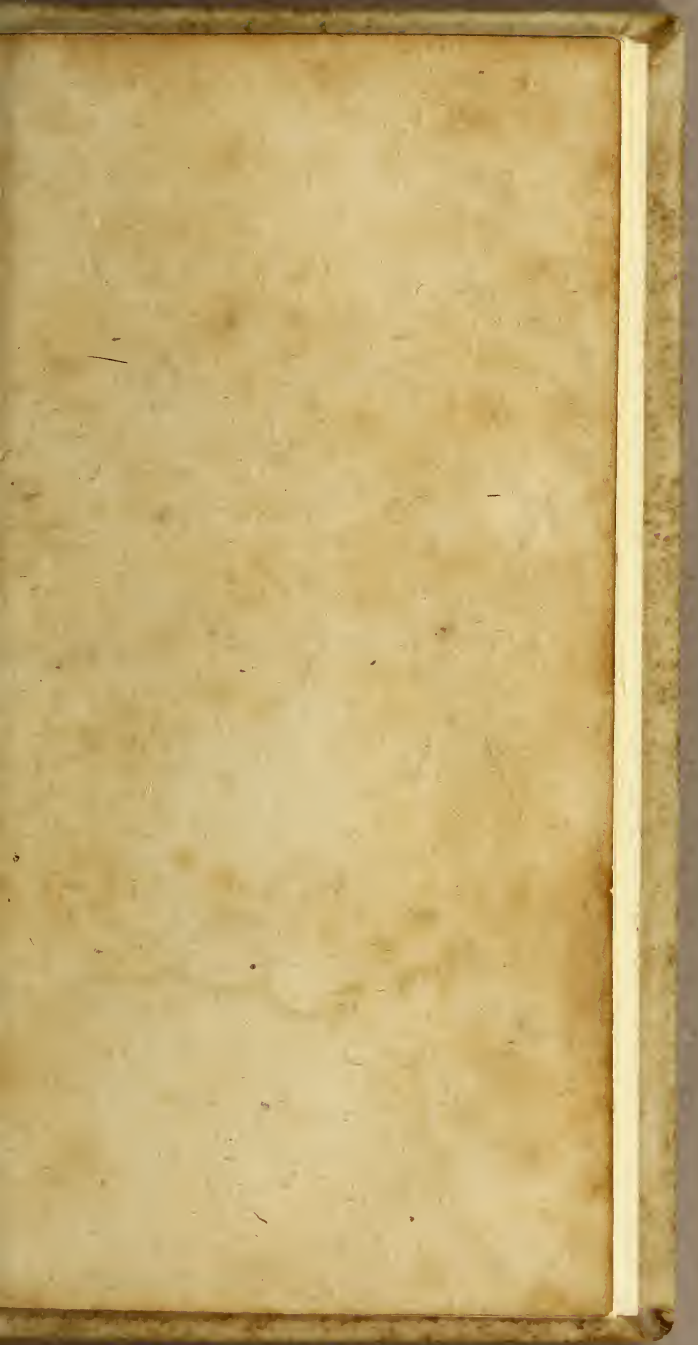




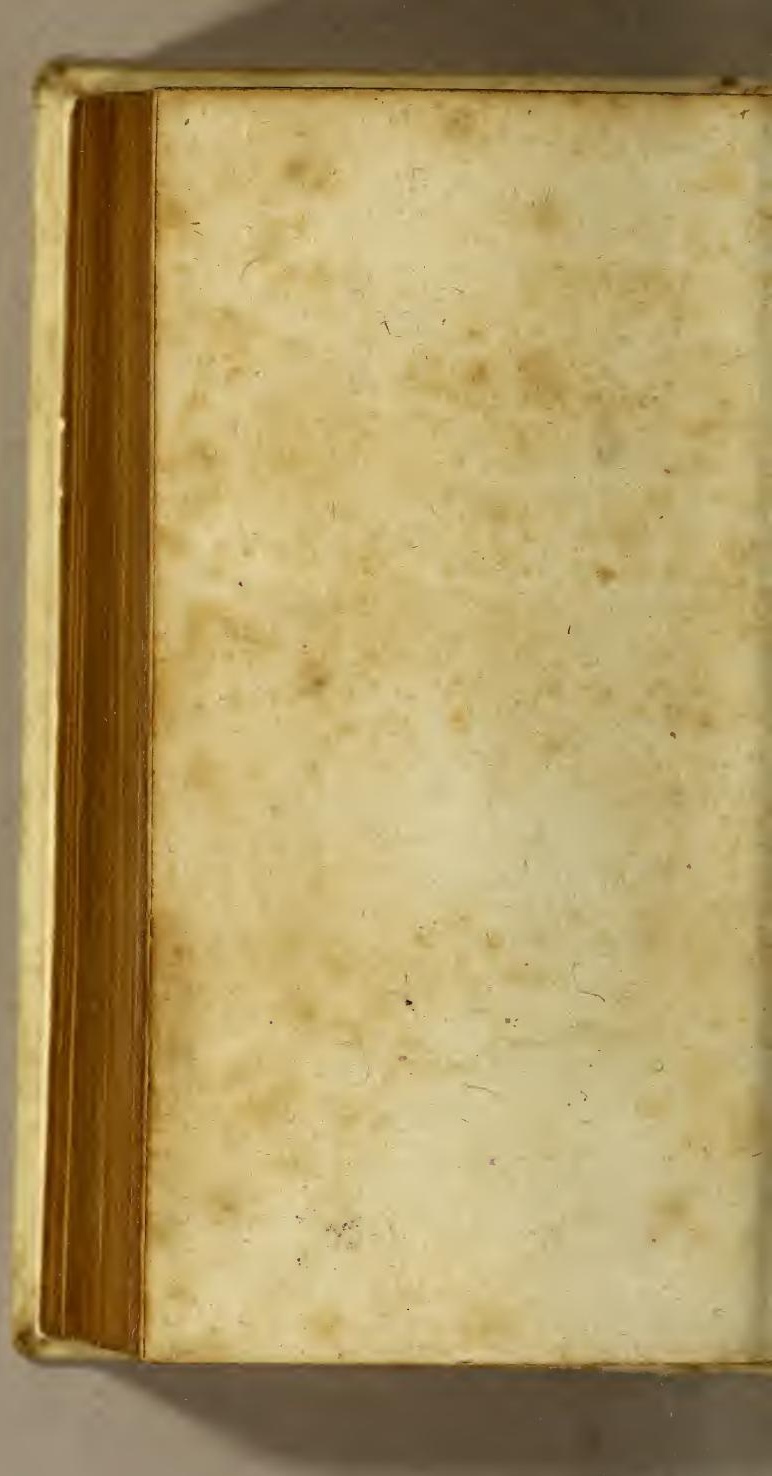


E608

B753t

$14 Y 13(3 / 3)$ 


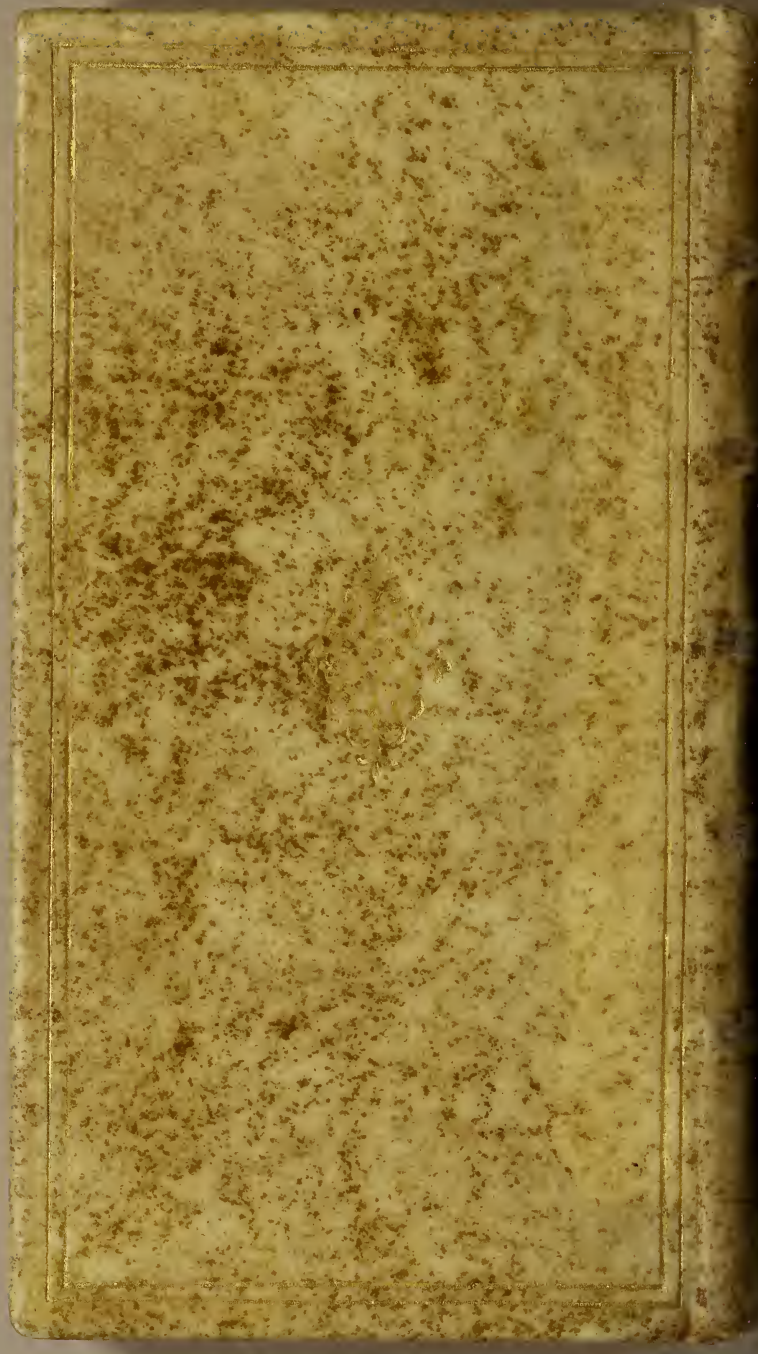

